Portland State University

PDXScholar

$1-1-1987$

\title{
Selected Functions of Nurse Practitioners in Oregon and Some Implications for Nurse Preparation
}

Mary Jean Schindler

Portland State University

Follow this and additional works at: https://pdxscholar.library.pdx.edu/open_access_etds

Let us know how access to this document benefits you.

\section{Recommended Citation}

Schindler, Mary Jean, "Selected Functions of Nurse Practitioners in Oregon and Some Implications for Nurse Preparation" (1987). Dissertations and Theses. Paper 56.

https://doi.org/10.15760/etd.56

This Dissertation is brought to you for free and open access. It has been accepted for inclusion in Dissertations and Theses by an authorized administrator of PDXScholar. Please contact us if we can make this document more accessible: pdxscholar@pdx.edu. 
SELECTED FUNCTIONS OF NURSE PRACTITIONERS IN OREGON AND SOME IMPLICATIONS FOR NURSE PREPARATION

\title{
by
}

MARY JEAN SCHINDLER

A dissertation submitted in partial fulfillment of the requirements for the degree of

\author{
DOCTOR OF EDUCATION \\ in \\ COMMUNITY COLLEGE EDUCATION
}

\author{
Portland State University \\ Oregon State University \\ University of Oregon \\ C) 1987 Mary Jean Schindler
}


TO THE OFFICE OF GRADUATE STUDIES AND RESEARCH:

The members of the Committee approve the dissertation of

Mary Jean Schindler presented February 25, 1987.

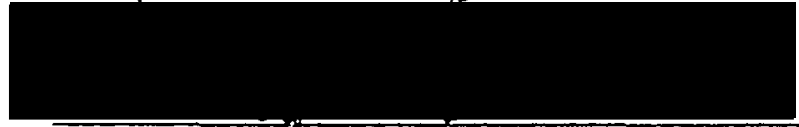

David E. WiTtis, Chairperson - PSU

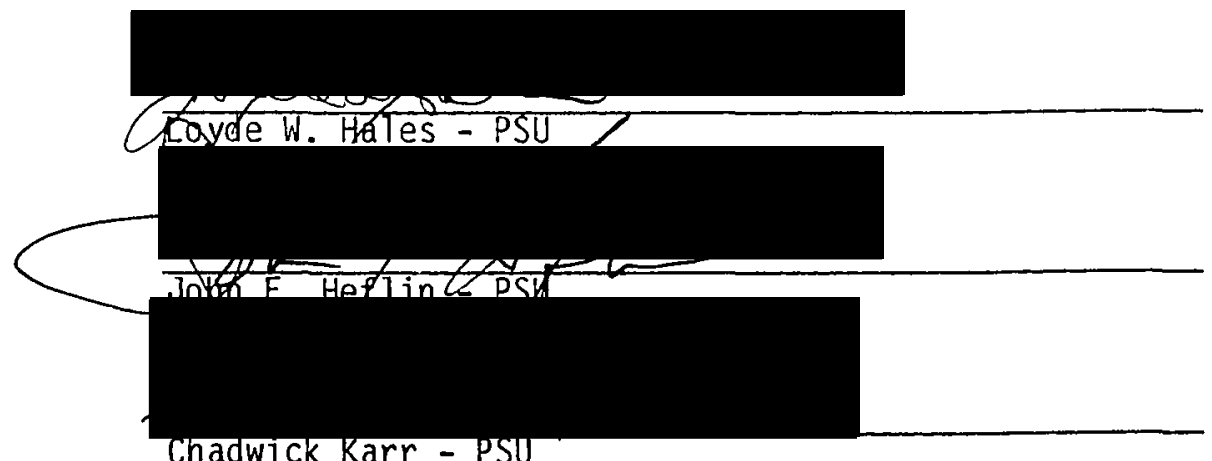

Chadwick Karr - PSU

APPROVED:


Richard A. Schmuck, Tri-University Program Coordinator

(University of Oregon)
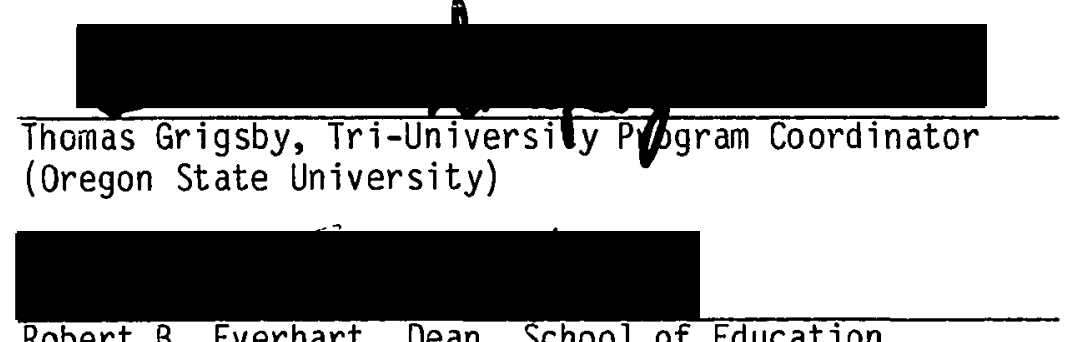

Robert B. Everhart, Dean, School of Education

(Portland State University)

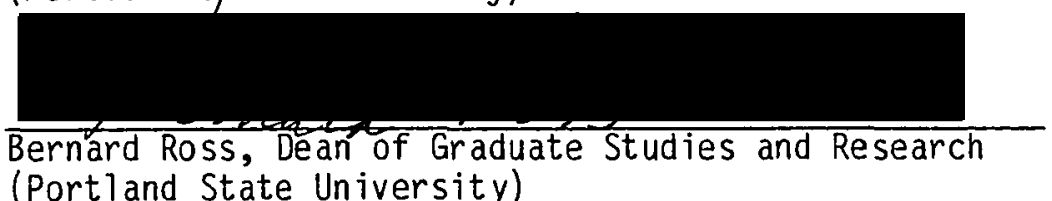

(Portland State University) 
Dedicated to

Sandra Schindler Lawrence

John Alfred Schindler

Carol Jean Schindler

Kurt Andrew Schindler 


\section{ACKNOWLEDGEMENTS}

The completion of a doctoral program represents the support and commitment of many people. I am profoundly grateful to all the members of my family--those related to me by birth and those related to me by marriage. Their support expressed in so many ways for so many years has been a constant source of strength.

I wish to express my gratitude to the members of my dissertation committee for their counsel, guidance, encouragement, time, patience, and expertise.

I gratefully acknowledge the dissertation materials made available by A. D. Drice, M. J. M. Ward, and A. M. F. Warren from their studies of nurse practitioners in the 1970s.

To the nurse practitioners in Oregon who participated in this study, I am most indebted.

To many other friends, colleagues, and former teachers, I am deeply appreciative. Without their encouragement and cooperation, this study would never have been undertaken. 
TABLE OF CONTENTS

PAGE

DEDICATION ............................. i

ACKNOWLEDGEMENTS .................. . . iv

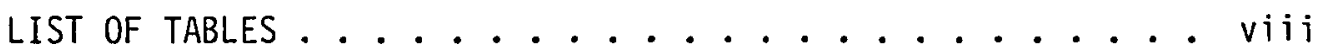

CHAPTER



Primary Care............. . 2

The Function of Various Types of Nurse Practitioners (NPS)

Preparatory Programs

Statement of the Problem. . . . . . . 12

Significance of the Study ........ 12

Legislators

Health Care Consumers

Nurse Practitioners

Educators

Students

Professional Policy-makers

Hospital Administrators or Physicians

The Purpose of the Study

II REVIEW OF THE LITERATURE . . . . . . . . . 17

Origin and Development of the Nurse

Practitioner........... 17

Definitions and Descriptions

Government Regulations

Relations with Consumers and Colleagues . . . 30

Collaboration with Physicians

Perceptions of Others about Nurse

Practitioner Functions 
Preparation for the Function of Nurse Practitioner Levels of Preparation

Definition of Terms .......... 46

I I I METHODOLOGY. . . . . . . . . . . 54

Design. . . . . . . . . . . 54

Subjects.............. 55

Instrumentation .......... 55

General Information

Practice Setting

Functions

Administrative and Public Relations

Functions

Procedures.............. 58

Statistical Methods........... 60

IV ANALYSIS AND DISCUSSION. ........... 63

Sampling Characteristics. . . . . . . 64

Total Sample

Specialty Areas

Classification and Analysis of Data

Description of the Responding Sample..... 66

Age of NPs in Oregon

NP Background: Academic and Experiential

NP Preparation

NP Practice

Selected Functions of Nurse Practitioners . .

Chi-square Testing of NP Specialty Areas

Health Promotion and Maintenance

Management of Health Care

Treatment in Collaboration

Prevention of Illness and Disability

Guidance and Counseling 
Policy-making Functions .......... 163

Health Care Policy-makers

Administrative Policy-makers

Public Relations Functions. . . . . . . 169

To Patients

To Other Disciplines

To the Community

To Legislators

V SUMMARY, CONCLUSIONS, RECOMMENDATIONS. ...... 173

Summary ............. 173

Purpose of the Study

Populations Studied

Selected Characteristics and Attitudes

Nurse Fractitioner Functions



Findings and Implications for Education and the Field

Limitations

Recommendations .......... 196

REFERENCES .................... 199

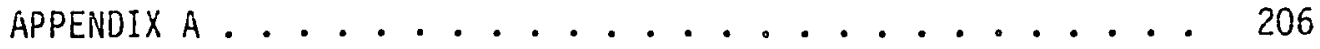

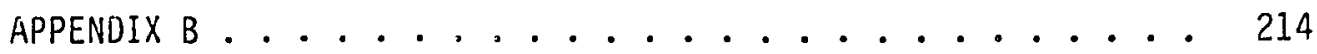

APfENUIX C . . . . . . . . . . . 22? 


\section{LIST OF TABLES}

TABLE

PAGE

I The Number and Percent of Completed Questionnaires

Retured in Response to Each of Three Mailings . . . 59

II Age of NP's Reported in Frequency and Percentages . . 67

III NP Background: Academic and Experiential Reported

in Frequency and Percentages........ 68

IV NP Preparation Reported in Frequencies and

Percentages.............. 73

$V$ NP Practice: Setting, Socio-economic, and

Attitudinal Responses. . . . . . . . 76

VI Percentage of Responses by Health Promotion and

Maintenance Functions . . . . . . . . 84

VII Percentage of Responses by Specialty Areas to

Health Promotion and Maintenance Functions. . . . 89

VIII Results of Chi-square Tests on Responses to

Health Promotion and Maintenance Functions. . . . 96

IX Percentage of Responses by Management of Health

Care Functions. . . . . . . . . . 105

$x$ Percentage of Responses by Specialty Areas to

Management of Health Care Functions ....... 111 
XI Results of Chi-square Tests on Responses to Management of Health Care Functions . . . . . . 119

XII Percentage of Responses by Treatment in Collaboration Functions .......... 131

XIII Percentage of Responses by Specialty Areas to

Treatment in Collaboration Functions. . . . . . 134

XIV Results of Chi-square Testing on Responses to

Treatment in Collaboration Functions . . . . 137

XV Percentage of Responses by Prevention of

Illness and Disability Functions. . . . . . . 142

XVI Percentage of Responses by Specialty Areas to

Prevention of Illness Functions. . . . . . . 145

XVII Results of Chi-square Tests on Responses \pm 0

Prevention of Illness and Disability Functions. . 148

XVIII Percentage of Responses by Guiciance and

Counseling Functions. .......... 153

XIX Percentage of Responses by Specialty Areas to

Guidance and Counseling Functions . . . . . . 156

XX Results of Chi-square Tests on Responses to

Guidance and Counseling Functions ....... 159

XXI Frequencies and Percentage of Responses: Health

Care Policy-makers in the Practice Setting. . . . 164

XXII Frequencies and Percentage of Responses:

Administrative Policy-makers in the Practice

Setting . . . . . . . . . . . . 
XXIII Rank Order by Specialty Responses to Health Promotion and Maintenance Functions ...... 178

XXIV Rank Order by Specialty Responses to Management of Health Care Functions. . . . . . . . 180

XXV Rank Order by Specialty for Treatment in Collaboration Functions .......... 183

XXVI Rank Order by Specialty for Prevention of Illness and Disability Functions . . . . . . 185

XXVII Rank Order by Specialty for Guidance and Counseling Functions. .......... 187

XXVIII Classifications of Responses to Question 3 a:

"How Do You Interpret Your Function to Patients?" .

XXIX Classifications of Responses to Question $3 \mathrm{~b}$ :

"How Do You Interpret Your Function to Other Disciplines?" ............... 225

$X X X \quad$ Classifications of Responses to Question $3 \mathrm{c}$ : "How Do You Interpret Your Function in the Community?" .................

XXXI Classifications of Responses to Question $3 \mathrm{~d}$ : "How Do You Interpret Your Function to Legislators?" . . 229 XXXII Analysis of Sample of "Same as Above" Responses to Question 3: "How Do You Interpret Your Function to Patients, Other Disciplines, the Community, and Legislators?" . . . . . . . . . . . . 
AN ABSTRACT OF THE DISSERTATION OF Mary Jean Schindler for the Doctor of Education in Community College Education presented February 25, 1987.

Title: Selected Functions of Nurse Practitioners in Oregon and Some Implications for Nurse Preparation

APPROVED BY MEMBERS OF THE DISSERTATION COMMITTEE:
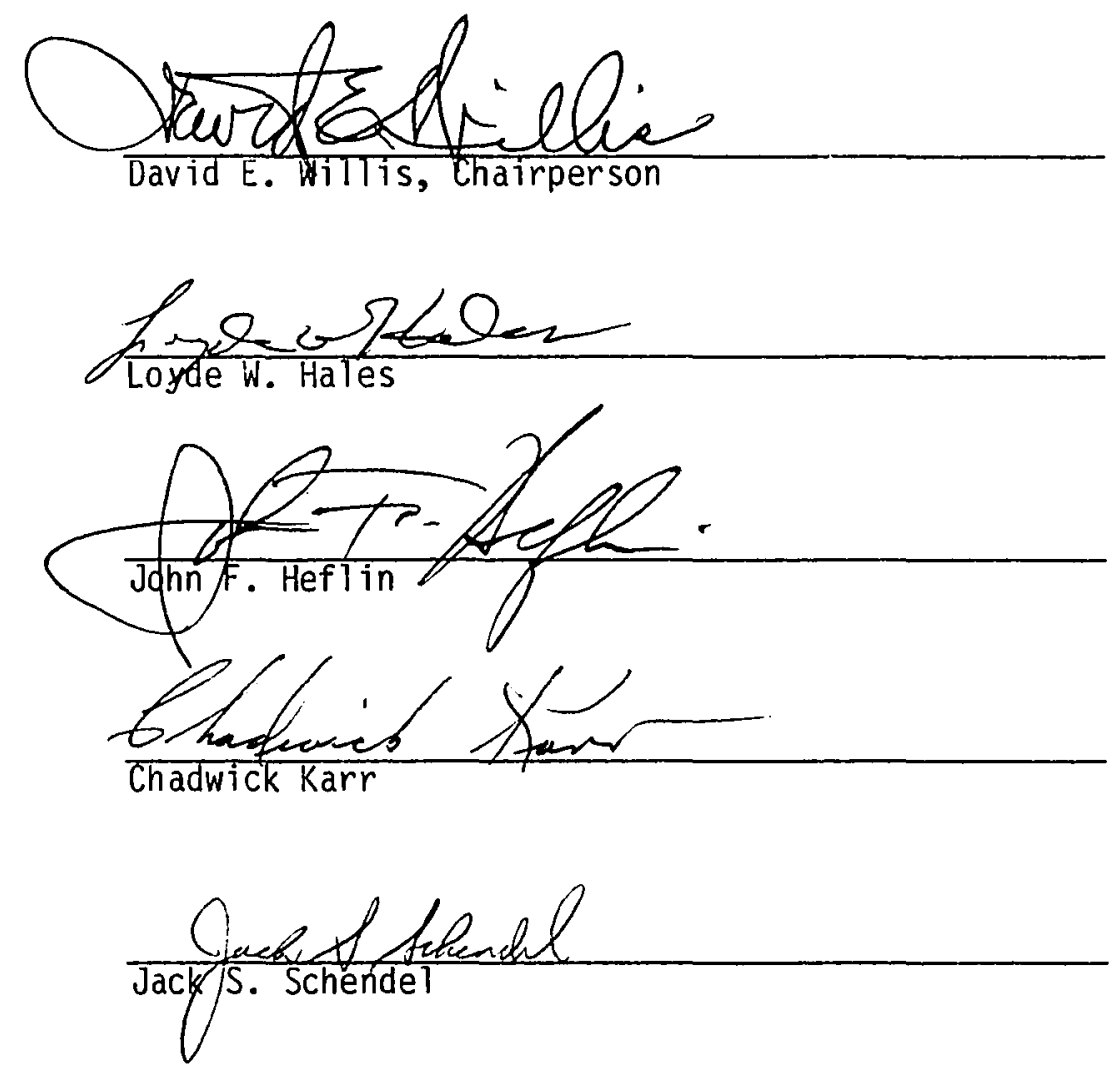

\section{Purpose}

This study was designed to determine the perceptions of the Oregon-certified nurse practitioners (NPS) with respect to their 
usage, competency, and preparation for selected functions. Clarification of what NP's perceive themselves doing and with what degree of competence could give structure and direction to their preparation. In Oregon, NPs provide specialized primary care in collaboration with physicians and other health care professions and agencies. The performance of an NP may vary according to the specialty, setting, and needs of the consuimer. If some functions of the NP could be brought into clearer focus, then not only could benefits come to the health care consumer, but also heaith care professionals could work together more efficiently and productively. Furthermore, educators could build programs with a clearer sense of purpose and structure.

\section{Procedure}

The data were obtained through a survey of 574 NPS certified in Oregon. A four-part questionnaire was adapted from instruments developed by researchers of NPs in North Carolina, Arkansas, and Colorado. The analysis of service diaries provided by Oregon nurse practitioners, additions by the Oregon State Board of Nursing, and pretesting in the field resulted in statements about selected characteristics and attitudes, practice settings, and clinical and community functions of Oregon nurse practitioners. Questionnaires were mailed, and 386 were analyzed.

\section{Sumnary of Findings and Conclusions}

Three research hypotheses were formed and tested by chi-square. The following findings and conclusions were identified: (a) Some relationships did exist between NP functions and specialty groups with 
respect to competency, frequency of performance, and preferred preparation. (b) Most nurse practitioners serve a large number of consumers in low or very low economic circumstances through community or home heaith agencies. (c) Some functions of high competency and usage are needed in the preparation of all nurse practitioners at the baccalaureate and master's level. (d) Higher education is preferred for preparation of nurse practitioners in a sequence of baccalaureate in nursing followed by a master's degree which qualifies for certification in a nursing specialty. (e) For the functions of lower competency and usage, reduced emphasis or deletion from nurse practitioner preparation is desirable. (f) Some functions are suitable for major emphasis in continuing education programs with the standards of higher education. 


\title{
CHAPTER 1
}

\section{INTRODUCTION}

\begin{abstract}
American medicine leads the world in research and development of specialized diagnostic and therapeutic techniques, but lags behind in actually delivering health care, particularly primary care to those who need it most, the elderly, minorities, the poor, and geographic locations which have no physicians. (Bliss \& Cohen, 1977, p. 375)
\end{abstract}

The inequality of health care is being exacerbated by forces such as out-of-control health costs, government and business restrictions to curb expenses, and expanding corporate control of health care which are leading to "'a very sterile, Orwellian interaction that will be technicaly correct" (Kotulak, 1985, p. A2). These widespread changes in the health care delivery system have contributed to the development of the expanded function of the nurse who has been educated to provide primary care in a specialty. The nurse practitioner is a person who has been educated and certified to provide specialized primary care to assist in meeting the challenge of unequal distribution and expenses of existing methods of providing for the maintenance of health and the care of illness in America. 
PRIMARY CARE

As delineated in the Oregon Administrative Rules (OAR) of the Board of Nursing (1980), primary care includes a broad range of personal health services. Some of those services include: (a) promotion and maintenance of health, (b) prevention of illness and disability, (c) management of health care during acute and chronic phases of illness, (d) guidance and counseling of individuals and families, and (e) referral to physicians and other health care providers and community resources when appropriate.

During the provision of primary care, the physical, emotional, social, and economic status, as well as the cultural and environmental backgrounds of individuals, families, and communities (where relevant) are considered. The client is provided access to the health care system, and, a single provider or team of providers, along with the client, take responsibility for the continuing coordination and mangement of all aspects of basic health services needed for individual and family care (Oregon State Board of Nursing (OSBN) 1980, 851-30-001).

In Oregon the nurse who is certified to implement the expanded function of providing primary care is recognized by law as a nurse practitioner (NP). Since 1979, the NP may obtain limited authorization to write prescriptions. Nurse practitioner has been defined in the Oregon Revised Statute as a licensed registered nurse who has been certified by the Board of Nursing as having satisfied requirements for special competencies and fulfilling all relevant rules and 
regulations, established by the Board of Nursing for, among other things, the maintenance of "certification, including continuing education" (Oregon Revised Statute [ORS], 1977, 678.375). A "normative nurse" (Weiss, 1983, p. 139) with a long tradition of "bedside care for the individual patient," (Katz, 1969, p. 54) may acquire specialized education to qualify for legal certification to function as a specialist in the provision of primary health care to consumers.

Wheeler and Gilham Counties in Eastern Oregon comprise 2,835 remote and mountainous square miles, where two nurse practitioners provided services in 1975 that saved residents having to drive 45 or 60 miles to the nearest physicians. Due to complications in Oregon Law, the State Board of Pharmacy on May 26, 1977, ordered the pharmacists in Condon, Oregon, to stop honoring the "prescriptions written by the two nurse practitioners who practiced in Gilnam and Wheeler Counties" (Sullivan, 1977). A committee of Eastern Oregon$i$ ans from Wheeler, Gilham, and Morrow Counties met with representatives of the Board of Pharmacy, the Board of Nursing, the Oregon Medical Association, the Oregon Nurses Association, the State Health Division, and four legislators from Eastern Oregon. The large committee--not without disagreement-recommended that counties with fewer than 5,001 persons, or where a physician licensed in Oregon does not maintain an office within 30 miles of a nurse practitioner's clinic, make use of nurse practitioners and allow them to write prescriptions with the approval of the physician (Sullivan, 
1977). With some changes, the reconmendations of the committee were enacted into Oregon law.

The Function of the Various Types of Nurse Practitioners (NPS)

In an expanded specialty role, such as Psychiatric-Mental Health, the function of the nurse practitioner (NP) has been defined as "clinical practice based on specialized education which prepares a registered nurse to provide primary health care" (OSBN, 1980, 851$30-001)$.

The law recognizes the capability of the NP to take responsibilty for the provision of various kinds of health care in a specialty area, "the scope of which shall be based upon educational preparation, continued experience and the accepted scope of professional practice" (OSBN, 1980, 851-30-003). Certified NPs in Oregon integrate "health maintenance, disease prevention, physical diagnosis and treatment of common episodic and chronic problems... in primary health care" (OSBN, 1980, 851-30-003) in specialties which include the following categories:

1. The family nurse practitioner (FNP) has special knowledge and skills in responses to common problems in primary care with families;

2. The prediatrics nurse practitioner (PNP) has special knowledge and skills to provide care for common problems in primary care with children;

3. The adult nurse practitioner (ANP) implements the advanced nursing function in common problems in the provision of primary care with adults; 
4. The geriatric nurse practitioner (GNP) provides advanced nursing functions with the elderiy;

5. The psychiatric-mental health nurse practitioner (PMHNP) is authorized to accomplish primary health care with persons who have common mental or emotional problems;

6. The nurse midwife (NM) has authorization to provide primary maternal health care;

7. The women's heaith care nurse practitioner (WHCNP) has specialized in the provision of primary health care with women;

8. The school health nurse practitioner (SHNP) specializes in the provision of primary health care with school children; and,

9. The college health nurse practitioner (CHNP) specializes in the provision of primary health care with college students.

Nurse practitioners provide "primary health care in collaboration with the physician and other health care professions and agencies" (OSBN, 1980, 851-30-003). Ward's (1975) nation-wide study provided some details about the activities of NPs who have specialized in the care of families. Within the specialty, the NP may make

initial and/or continuing assessments of the health status of a person of any age group independently or in collaboration with others...take health histories, perform physical examinations, diagnose, treat, and manage common health problems, recognize health needs and problems and [where appropriate] to provide care alone or jointly with other health care workers or to initiate referrals for health care needs and problems that are beyond [the] scope of practice... in order to provide the best possible care for patients. (pp. 14-15) 
The law has empowered the NP to move beyond traditional nursing to provide expanded nursing functions wherever the need exists.

The assurance of finding help, close by, wherever one happens to be... is a human need (for reduction of anxiety) first, and only secondarily a matter of economics, politics, professional perogatives or semantic debate. The urgency of the need is accentuated by the public's realization that it is not likely to be met by any of the traditional health care professions, their patterns of practice or modes of education." (Pellegrino in Bliss \& Cohen, 1977, p. Xv)

The provision of care wherever it is needed led many of the practitioners of the expanded function in nursing to separate themselves from dependence upon physicians, because "nearly 85 percent of physicians still practice in urban-suburban rather than rural settings" (B1iss \& Cohen, 1977, p. 375). Few nurses in the expanded function are found in hospitals (B1 iss \& Cohen, 1977, p. 376).

One NP described her function as falling "in the middle of the old territory occupied by physicians and registered nurses, one white-shoed foot in each world" (Cargi11, 1985, p. MW7).

A pediatric NP has acquired expertise and skills needed to perform functions once restricted to physicians. When the NP educates mothers about infant care, feeding, toileting, and the values of breast milk, a physician is left free to handle the more complicated cases. The NP was reported to give more time than a physician to do an examination and to view consumer education as the largest part of her function in an out-patient clinic (Cargill, 1985, p. MW7). Monitoring patients for ordinary illnesses, such as infectious conditions of the ears, lungs, or bowels, and educating the 
mother to provide health care takes up most of the day. Educating the mother about normai growtin and development helps her to observe and contribute to the child's progress. The writing of prescriptions includes those for birth control pills and antibiotics but prohibits special intensified medicines, such as the chemotherapies. The sharing of in-depth knowledge of child idiosyncrasies has helped mothers manage problems related to the health care of their children.

Another NP may operate an independent clinic. For example, one pediatric nurse practitioner operates the North Portland Community Health $\mathrm{Clinic}$. Situated as it is in an urban area comprised of many families at a low or very low economic level, the clinic serves a type of population which attracts very few independent health care providers other than NPs. Many of the federal policies that support NPS were directed toward such medically underserved populations. As an accommodation to the needy, services are provided on a sliding scale of fees based upon the economic resources of the client.

In the case of the North Portland Community Health $\mathrm{Clinic}$, a network of community participation makes low-cost health care possible. A retired accountant donates bookkeeping services on a regular basis. Persons are assigned by the courts to provide services. Boxes and racks of donated clothing have been made available in the reception area for anyone to take without charge. Social sensitivity is another aspect of the networking that has contributed to the success of low-cost community health 
services. When a deatn occurred in the family of her business neighbor across the street, the PNP from North Portiand Community Health Clinic attended the funeral "not," as she said, "because I have to, since I don't know the family, but if I don't go, my absence would be noticed and talked about" (M.A. Taylor, August 26, 1985, Personal Communication).

The provision of low-cost health care in a needy neighborhood may be susceptible to criminal activity. The office of the North Portland Community Health $\mathrm{Clinic}$ had been robbed of thousands of dollars worth of tennis shoes which had been donated by a famous manufacturer for free distribution. During the day a garden hose had been taken from the front yard. The office of the attorney next door had been robbed of its equipment and furniture. A driver was warned to park in front, rather than on the side street out of sight of the office. The risks have not stopped a courageous and dedicated NP from the provision of primary health care in North Portland.

At the North Portland Community Health $\mathrm{Clinic}$, referrals comprise a significant part of the services. Clients make numerous inquiries on the telephone or in person about the location, cost, and availability of low-cost services such as inoculations for school. A pile of hand-outs about inoculations had been prepared and placed on a counter as a free service by the NP.

\section{Preparatory Programs}

During the years of their professional growth, NPs have been products of a variety of preparatory programs. Another definition 
of the NP emphasizes the preparatory aspect of the function as "the nurse whose education extends beyond the basic requirements for licensure as a registered nurse [and] is formally planned to prepare students for expanded functions in diagnostic and treatment needs of patients" (United States Department of Health Education and Welfare [USDHEW], 1980, p. 2). This longitudinal study by USDHEW (1980) provided information about the oreparation and function of NPs in most of the states. Few NPS in (1regon participated in that study. Initial Certification. For initial certification as an NP, a candidate must present to the Oregon Board of Nursing the following:

1. Current Oregon licensure as a registered nurse, and, 2. Evidence of successful completion "of a certificate or degree program appropriate to the specialty area and approved by the Oregon Board of Nursing." (OSBN, 1980, 85120-300)

Additional educational credit and evidence of current clinical competence may be required under certain conditions of elapsed time. The NP must have demonstrated competence in the skills and knowledge expected of the registered nurse and must have had specialized preparation in order to demonstrate the competence, skills, and knowledge of expanded nursing practice.

The preparation of the NP and the continuing education required to maintain certification have increased in rigor in Oregon and in othe states. On January 1, 1981, a nurse who wanted to be an NP in Oregon needed at least "a baccalaureate degree with a major in nursing plus satisfactory completion of an educational program in 
the specialty area. By January 1, 1986, a nurse who applies for initiai certification shall have a master's degree in nursing with preparation in the specialty area in which expected to practice" (OSBN, 1980, 851-20-300). The NP preparation may occur within a master's degree program or in a conbination of a master's degree program and an NP program.

Standards for Accreditation. Educational programs in nursing which prepare candidates for certification as an NP must meet staridards which have been established by the Oregon Board of Nursing. A four-year college or university may offer a program which leads to a master's degree in nursing. Adult learning and problemoriented teaching of patient management are emphasized.

Minimal competencies in behavioral terms shall be required of each course and for the total one-year program. Specialized in-depth education shall consist of theory and practice in one or more specialty areas. Content shall include:

A. Patient assessment, including 1 ab[oratory] and other diagnostic procedures appropriate to the clinical specialty areas;

B. Analysis of data and problem identification:

C. Development of management plans including further diagnostic studies, therapy, patient education and identification of parameters for follow-up;

D. Modification of management $\mathrm{plan}$ based on new patient data and/or new information regarding appropriate management of identified problems. (OSBN, 1980, $851-30-248$. 3. 6. A-D)

Initial preparation shall include 480 hours during six months with a physician or with an NP in the specialty area iii which the student is a candidate for certification. 
Continuing Education Requirements for Oregon Nurse Practi-

tioners. The Board of Nursing established the requirements for continung education. During the two years prior to the date for renewal of certification, the NP must document at least 100 contact hours of continuing education relevant to the specialty area. The Oregon Board of Nursing accepts continuing education according to the following criteria:

1. Independent learning activities [ 1 imited to 50 hours in the two years];

2. Reading professional journals, books, and other printed materials;

3. Reviewing audio-visual materials;

4. Hospital, nursing home, or clinic staff meetings, rounds;

5. Informal professional meetings such as journal clubs;

6. Provision of consultant/preceptor services to other nurse practitioners or to physicians;

7. Receiving consultant/preceptor assistance from other nurse practitioners or from physicians;

8. Participation in professional performance review (as reviewer or reviewee);

9. Attendance at courses, seminars, work-shops, conferences or institutes related to the specialty area offered by a college or university or by a local/state/ regional/national professional organization or private/ public health care organizations; and,

10. Presentation and/or publication of a professional paper for lay or professional persons ( 1 imited to 20 hours in the two years). (OSBN, 1980, 851-20-310)

Every two years in addition to the continuing education requirements for recertification, the applicant must show current Oregon 
licensure as a registered nurse and must demonstrate in peer review competence in NP clinical skills selected by the Board of Nursing and appropriate to the specialty of the applicant.

The scope of practice of the nurse practitioner in Oregon is based upon educational preparation, continued experience, and the accepted scope of professional practice of the particular specialty area. Such management is to be provided through integration of health maintenance, disease prevention, physical diagnosis, and treatment of common episodic and chronic problems, includng pregnancy, in primary health care in collaboration with physicians and other health care professions and agencies. (OSBN, 1980, 851-30003)

\section{STATEMENT OF THE PROBLEM}

Clarificaiton of what NPs perceive themselyes doing and with what degree of competence could give structure and direction to their preparation. In Oreogn, NPs provide specialized primary care in collaboration with physicians and other health care professions and agencies. The performance of an NP may vary according to the specialty, setting, and needs of the consumer. If some functions of the NP could be brought into clearer focus, then not only could benefits come to the health care consumer, but al so health care professionals could work together more efficiently and productively. Furthermore, educators could build programs with a clearer sense of purpose and structure.

\section{SIGNIFICANCE OF THE STUDY}

Current knowledge of the functions of the NPs in Oregon could benefit legislators, health care consumers, NPs, educators, 
students, and policy-makers for health care professionals and hospital administrators or physicians.

Lt ijslators

During the legislative session, many bills regarding NFs may be presented to lawmakers who must make important decisions which affect health care consumers. Facts about preparation and performance could facilitate informed decision-making by members of legislative committees. Current information about the function of NPs has been requested to update packets of information for the use of members of the legislature. (Nurse Practitioner Special Interest Group [NPSIG], 1984, November).

\section{Health Care Consumers}

A lack information about what NPs do in Oregon has been observed: "A marketing consultant who surveyed the Eugene-Springfield area found only one out of 50 people knew who a nurse practitioner was" (NPSIG, 1984, September, p. 4). When consumers have had knowledge of NPs (in some states with adversarial situations), the consumers have successfully supported NPs. Increased and widely disseminated information about the function of NPs could contribute to cost-containment of health care in Oregon. Whether or not a person lives in an area which contains a limited array of health care providers, a person is entitled to the highest level of available skill. 


\section{Nurse Practitioners}

Information about the function of other NPS and health care providers disseminated to patients could assist the patient to make informed decisions about the choice of health care provider. Current information about their functions could help NPs provide effective testimony at various levels of the legislative process which affect the NP and the provision of health care at modest cost with maximum benefit to a wide range of consumers.

\section{Educators}

Those who plan NP preparatory programs may benefit from knowledge of what NPs perceive they are doing and with what degree of confidence. As an aid to decisions about when and how to emphasize preparation to perform certain functions, up-to-date information could give direction to NP preparation and continuing education. Knowledge about their competencies in certain functions could assist NPs in making requests of educators to design programs in response to a perceived deficit in knowledge or competence. The demands of actual practice need to be addressed in the programs which prepare NPS.

\section{Students}

In the earliest years of their education, students could be made aware of the function of the NP as a possible goal for career development. If $\mathrm{planning}$ is to occur to make the function of the NP more meaningful in the schools, then current data about the preparation and performance of NPS is needed. 


\section{Professional Policy-makers}

Current data about the preparation and function of NPs in Oregon may facilitate timely and effective suggestions. Local organizations of NPS have participated in the development of a statement about their scope of practice. "The revised statement will direct the Task Force of the Council of the American Nurses Association to develop practice standards. These practice standards can then be adopted by each of the states for use in quality assurance programs" (NPSIG, 1984, November, p. 5). If policy-makers at the local, state, and national level could be influenced by NPS who are better informed during discussions, debates, goal-setting, and the development of action plans, then "a National Action Plan for NPs" (NPSIG, 1984, November, p. 5) could represent current knowledge about Oregon.

Hospital Administrators or Physicians

The expanded skills of the NP may benefit hospital administrators who seek to provide advanced nursing knowledge to the professional staff and to the health care consumer. Direct and/or indirect services could enrich collaborative health care at many levels and settings within the facility. For example, by screening patients, the NP may free the physician to attend to the health care problems which are beyond the scope of NP practice. 
THE PURfOSE OF THE STUdY

The purpose of this study is twofold:

1. To determine the perceptions of the Oregon-certified NPs, in general and by specialty, with respect to the:

a. Frequency of performance of selected functions;

b. Competence in performance of each function; and, c. Preparation for each function.

2. To compare the perceptions of NPs in various specialties with respect to each of the above. 
CHAPTER II

REVIEW OF THE LITERATURE

After the second World War, a new dimension appeared in the provision of health care. In response to an ever-increasing need, the nurse practitioner (NP) emerged within the nursing profession. Many investigators have written about the activities, expectations, attitudes, decisions, and characteristics of nurses in advanced or extended practice in various specialties. This chapter contains summaries of literature which relate to the function of the NP as follows: (a) origin and development of the NP, (b) relations with consumers and other health care professionals, and, (c) the preparation of the NP. The first section includes definitions and descriptions together with government regulations. The second section contains some collaborative functions and some perceptions by colleagues and consumers about NP functions. The third section consists of levels of preparation of the NP.

\section{ORIGIN AND DEVELOPMENT OF THE NURSE PRACTITIONER}

This section defines and describes some key concepts and processes together with government regulations which may be associated with the function of the NP in Oregon. 
Definitions and Descriptions

The NP is a currently licensed registered nurse who qualifies for delivery of care in an expanded specialty role within the practice of nursing (Oregon Revised Statute (ORS), 1983, 678.010, 375, 390). The NP provides primary care in at least one specialty.

Primary Care. Health care may be initiated by the client or the provider in various settings and may include a broad range of personal health services: (a) promotion and maintenance of health, (b) prevention of illness and disability, (c) management of health care during acute and chronic phases of iliness, (d) guidance and counseling of individuals and families, and (e) referral to physicians and other health care providers when appropriate.

During the provision of primary care, the physical, emotional, social, and economic status, as well as the cultural and environmental backgrounds of individuals, families, and communities (where applicable) are considered; the client is provided access to the health care system, and, a single provider or team of providers, alung with the client, is responsible for the continuing coordination and management of all aspects of basic health services needed for individual and family care (OSBN, 1980, 851-30-001).

Categories of Specialties. A previous listing of the NP specialties is enlarged below to include recent descriptors from the Oregon Nurses Association (ONA).

1. Family Nurse Practitioner (FNP) provides primary care to persons encompassing the age continuum. 
2. Women's Health Care Nurse Practitioner (WHCNP) provides primary health care to women.

3. Geriatric Nurse Practitioner (GNP) provides primary health care to older aduits.

4. Adult Nurse Practitioner (ANP) provides primary health care to adolescents and adults.

5. College Health Nurse Practitioner (CHNP) provides primary care to college age individuals.

6. Certified Nurse Midwife (CNM) provides primary health care to essentially healthy women and newborns and the related childbearing processes.

7. Psychiatric/Mental Health Nurse Practitioner (PMHNP) evaluates and treats mental and emotional disorders across the age continuum.

8. Pediatric Nurse Practitioner (PNP) provides primary health care to persons newborn through young adults and promote the psychosocial, physical, and developmentai well-being of the child, and have the ability to independently make and act on decisions related to health status.

9. School Health Nurse Practitioner (SHNP) provides primary care to children of preschool, primary and secondary educational age groups. (1986, pp. 5-7)

Scope of Practice of the Nurse Practitioner. In addition to

the services provided by the registered nurse, the NP is authorized

to provide

management of mental and physical health care in the applicable specialty area, the scope of which shall be based upon educational preparation, continued experience and the accepted scope of professional practice of the particular specialty area; such management is to be provided through integration of health maintenance, disease prevention, physical diagnosis, and treatment of common episodic and chronic problems, including pregnancy, in primary health care in collaboration with physicians and other health care professions and agencies. (OSBN, 1980, 851-30-003) 
Outline of Case lianagement. As an example of the way an NP provides health care within a specialty, the conceptual framework of a case is provided. Most NPs at the national level provide care in Health Maintenance Organizations (HMO), public health agencies, and private practices (Bliss \& Cohen, 1977, p. 376). Home visits are common. In Oregon most NPS are presumed to follow the national patterns. The competencies that are performed in the practice settings generally reflect the following objectives of case management: taking a history, making physical and psychosocial evaluations, formulating an assessment and individual treatment plan, counseling, teaching, and systematically recording what was done.

The history contains a systematic and sequential history of the chicf complaint, the major symptoms are fully identified. Pertinent information other $+:$ an for the presenting problem(s) is obtained for other major divisions of the history. A social history is obtained which includes identification of support persons and resources available to the patient and to his family in the pursuance of optimum health.

The physicil and psychosocial evaluations made by the NP require the exercise of judgment as to the significance of the various parts of the examination. The patient's personality, mental, and developmental status are evaluated. A systematic and thorough approach is utilized.

Based upon the history and evaluations, the NP formulates assessment of the patient's problems. The patient and/or family are 
included in planning the management of care. A treatment plan is developed which inciudes: medications, treatments, diagnostic studies, consultation, referrals, and follow-up. The development of treatment planning is flexible to adapt to a wide variety of social and cultural backgrounds.

As opportunities arise during the exam, the NP provides health teaching. Counselng, anticipatory guidance, and preventive health teaching are provided to the patient and family. Teaching techniques are adjusted to individual patient needs.

The NP keeps legible, accurate, and thorough records. The records are organized to permit easy identification of problems and their current status.

\section{Government Regulations}

The growth of the NP movement occurred in a context of federal and state legislation. At the federal level, Anderson (1974) wrote "health care issues are increasingly decided upon in the political arena in competition with other demands related to defense, transportation, commerce" (p. 107). The participation of the health professional in political activities is "an essential extension of his professional life if he hopes to see his values operationalized through the formation of public policies" (p. 112). The political impact continued after passage of legislation as "both public and private interest is centered on the agency charged with the authority to develop operational policies to carry out the intent of the $1 a w^{\prime \prime}$ (p. 114). 
As a national agency responsible for implementation of 1 aw, the Department of Health Education and weifare was charged with the development of policy based on the following results of the federal legislative process:

1. The National Health PI anning and Resource Development Act of 1974, citing as one of the ten national health priorities "the training and increased utilization of...especially nurse clinicians" (P.L. 93-641, 93d Congress, January 4, 1975)

2. The Nurse Training Act of 1975 (P.L. 94-63) authorizing funds for institutions to $\mathrm{plan}$, develop, expand or maintain existing nurse practitioner training programs; and

3. The Healtin Professions Educational Assistance Act of 1976 (P.L. 94-484). (Cited in Bliss \& Cohen, 1977, p. 378)

While federal legislation gave impetus to the development of the NP, the preparation and implementation of the role are controlled by State legislation known as nurse practice arts. State legislators have passed laws to legalize the practice of nursing and expanded specialties in nursing. Adminisirative rules are developed and enforced by the board of nursing to assure that the public receives the highest possible quality of nursing care. Recently nurse practice acts in many states have been revised. Definitions have been changed, prohibitions have been deleted, and new listings have been made of acts which are permitted to be performed ty nurses.

As each state examined its policies and statutes, a variety of concerns were expressed. Keller (1975) noted a request by local physicians that the "State Board of Medical Examiners investigate" 
(p. 43) to see whether nurses were practicing medicine. "Concurrently, an officer of the local medical society wrote to the State Board of Nurse Examiners registering concern that we might not be practicing nursing according to the law" (p. 43). In 1982 the Oregon Medical Examiners were asked to "seek an Attorney General's opinion on whether the NP scope of practice is legal" in Oregon (NPSIG, 1982, p. 2).

In some instances, nurses and physicians have cooperated to develop regulations to their mutual advantage. Physicians have given public support to nurse practitioners. In Washington in 1980, "the state board of medical examiners was quite supportive during the writing of regulations" (New State Board Regulations, p. 2136). In other cases, the iegislators worked out compromises between divergent groups.

I. Nebraska, legislation known as the Practice of Nursing in Expanded Roles Act legalized the 50-year practice of Nebraska's nurse anesthetists. The NP was defined by the Act in terms similar to the language of the USDHEW Longitudinal Study of Nurse Practitioners. The Act assigned the Nebraska State Board of Nursing with the responsibility of regulation of NPS (Nebraska Legislature, 1981).

In response to the concerns of many persons about discrepancies between actual practice and the strict interpretation of existing laws, many states have revised and continue to revise the statutes. A new expanded nurse practice act was passed in Colorado (New Practice Act, 1980). The Colorado Nurses Association was 
charged with the responsibilty of regulation of the practice of nurses who "by reason of postgraduate education and additional nursing preparation have knowledge, judgment, and skill" (p. 1261).

As the states have modified Nurse Practice Acts to accommodate the conditions and requirements of the delivery of advanced nursing care, perhaps the sections of the Acts which relate to prescriptive privileges have been the most controversial. Different states have addressed the matter in a variety of ways. Almost a dozen state laws enable nurses to write prescriptions, but implementation of the laws has been sporadic. Tennessee passed legislation in 1980 which mandates the state "board of nursing to determine qualifications necessary for nurses to prescribe drugs" (New State Board, 1980, p. 2152). Typical of the qualifications with which a state board might respond to a mandate similar to that given to the Tennessee board of nursing are the qualifications specified by the Washington State Board of Nursing.

Nurses can obtain prescriptive authority without specific protocols or a collaborative relationship with a physician.... Requirements for prescriptive authority include a year of clinical practice as a CRN [Certified Registered Nurse] and completion of at least 30 contact hours of continuing education in pharmac iogy and clinical management of drug therapy related to the area of specialty practice. (New State Board Regulations, 1980, p. 2125)

The State of Washington has authorized its qualified "CRN" autonomous prescription privileges for medications related to the area of specialized function.

Many other states permit prescriptions to be written by nurses in collaboration with or under the supervision of physicians. In 
New Mexico, the board of nursing reguiates and approves authority of nurses to write prescriptions as collaborator of a physician, or under the supervision of one. California, Nevada, Utah, and Vermont have statutes which specify that nurses who write prescriptions must do so under the supervision of physicians (Utah Nurse, 1981; New State Board, 1980; New Practice Act, 1980; California State Board, 1980).

Arkansas provided an example of active resistance to giving NPS prescriptive authority. Since 1979, opposition has been described as "a solid wall" of organizations of physicians, "Pharmacists, podiatrists, and chiropractors" (Arkansas MDs Charged, 1981, p. 934).

Oregon has a more cooperative professional community than does Arkansas. Oregon's nurse practice act gives prescriptive privileges for medications within the specialty of the qualified NP under his/ her own license and without a "working relationship with physicians" (NP Prescribing, p. 653). The 1979 law granted direct payment to NPS in addition to prescriptive privileges if criteria are met and application made to the Nurse Practitioner Advisory Council. Qualifications for prescriptive privileges include certification as an NP by the Oregon Board of Nursing, and the completion of 30 hours of pharmacology specific to the specialty area within 12 months of application to the council. Maintenance of prescriptive privileges requires an additional 25 hours of pharmacological training every two years. As of April 1981, 78 NPs in Oregon were approved to write prescriptions (excepting experimental and narcotic drugs) from a formulary of approximately 280 medications. 
Government Regulations: Nurse Practitioner Preparation.

Government subsidization of the cost of health care broughi

increased federal regulation of preparatory programs. In many

states the NPS have diverse entry levels and credentialling

systems. The American Nurses Association has accredited non-degree

programs as continuing education; the National League for Nursing

has accredited the degree-granting programs which meet its

criteria. The Department of Health Education and Welfare has

suggested that the "programs continue to be allowed to vary rather

than be standardized" (B1iss \& Cohen, 1977, p. 379), despite a

recommendation from a 1974 study by the General Accounting Office

that the state and federal governments should cooperate in the

development of mutually agreeable criteria for preparatory and

experiential standards.

Observers since 1975 (McCormack, 1975; National Technical

Information Service, 1976) have expected the acceleration of central

control of Health care delivery. In a discussion of the Health

Maintenance Organization (HMO) Act of 1973, McCormack wrote,

The PSRO [professional standards review organization] law and the quality assurance provision of the HMO bill will shape the environment into which national action will shortly introduce some form of universal health insurance. Any such insurance plan will be accompanied by requirements for relatively stringent resources accounting procedures and for centralized management of presently independent health care institutions and practitioners. (1975, p. 57)

In 1976, the writers of the Nurse Practitioner and Physician Assistant Training and Deployment Study urged the government to encourage improvement of laws, certification, accreditation, and student sup- 
port: by both the public and private sectors for the purpose of increasing productivity.

Critics raised questions about the role of federal policy in influencing the devleopment and revision of curricula, faculty education, and the preparation of students for identified specialties. Jessie Scott, assistant Surgeon General and director of the Division of Nursing questioned whether the preparation of nurse practitioners "should continue to be [federally] funded if reimbursement under Medicare and the Social Security Act are denied" (Sultz, 1979, p. 216). The suggestions was made that educational institutions cooperate to resolve discrepancies between previous preparatory activities and practices following graduation. Educational institutions were urged to determine the content and duration of preparatory programs for NPS which would assure the protection of the best interests of the health care consumer.

Standards for Licensure/Certification. Most states tend toward professional certification as the way to authorize the performance of extended functions in nursing (Leitch \& Sullivan, 1977). In order to obtain professional certification, the registered nurse in most states must document preparation in courses which are often part of a university school of nursing in cooperation with a school of medicine. The preparation for primary care differs from the preparation for office or clinical assistance. The NP preparation emphasizes independent decision-making regarding the health care needs of persons, direct accountability, and responsibility to the recipient for the quality of the care provided. 
Higher Standards for Requirements. The Oregon board of nursing has steadily increased the educational requirements to qualify as an NP. Since 1980, an applicant for initial certification has needed at least a baccalaureate degree majoring in nursing and to have completed satisfactorily a program of education appropriate to the area of specializaton. Since 1985, the program of education required for the initial NP certification is a Master of Science in nursing (OSBN, 1983).

National Certification of Nurse Practitioners. Administered by the American Nurses' Association through the division of advanced specialized practice, national certification of NPs is required in some states and strongly encouraged in Oregon. The divisions are advised by the councils who "assist the certification board in designing and establishing guidelines for specialist certification" (Division on Psychiatric and Mental Health Nursing, 1976, p. 1).

More and more states are using national certification. As an example of the requirements for application, those for national certification in psychiatric-mental health nursing are listed below:

1. At least four hours weekly of direct clinical nursing practice,

2. A master's or higher degree in nursing with a specialization in psychiatric-mental health nursing or some equivalent combinations of educational programming may be acceptable if provided by nationally recognized accredited institutions of higher learning,

3. Two years of full-time post-psychiatric-mental health nursing practice.

4. Accessible clinical supervision or consultation,

5. Experience in at least two different treatment modalities, and,

6. At least 100 hours of post-masters supervision/consultation by a certified member of the core mental health disciplines (clinical specialist in psychiatric-mental health nursing, psychiatrist, psychologist, psychiatric 
social worker). (American Nurses' Association, 1982, p. 12)

The requirements for national certification in other specialties are similar to those above. The requirements of the American Nurses' Association are designed to assure the provision of the best possible health care to the consumer.

An increasing number of states require national certification as a prerequisite for their certification. In Washington until July, 1984, if one could pass the examination in the area of specialization, the applicant could submit any formal educational program and clinical practice acceptable to the board of nursing. Certification was available with two years of current clinical practice in the specialty. Although the national certification exanination continues to be required, the program of study must equal at least one academic year following the successful completion of credentialling to become a registered nurse. Current practice in the area of specialization will no longer substitute for the formal program of study (Washington, 1982). In the Administrative Rules accompanying its 1982 Nurse Practice Act, "certification is à voluntary form of credentialling, under sponsorship of a national certifying body that recognizes specialized and advanced nursing practice" (Washington, 1982, p. 15).

Other states have required increasingly stringent preparation of nurses who perform expanded functions. Until 1982, Colorado required completion of at least a baccalaureate or continuing education program with both clinical and didactic components acceptable to the board of nursing (Rules and Regulations, 1982). However, in 
1982, the Colorado Nurse Practice Act specified the completion of a "nationally accredited educational program for preparation as an advanced practicioner of nursing or who has passed a national certification examination of a nationally recognized accrediting agency accepted by the boand" (p. 2).

To prepare a registered nurse to provide primary care in one or more specialties, the Oregon board of nursing has statutory authority to develop and administer relevant standards for education and performance. For initial certification, the student must receive "specialized in-depth education in one or more of the specialty areas designated in these rules [including] content in the following areas:

1. patient assessment, including 1 ab and other diagnostic procedures appropriate to the clinical specialty areas;

2. analysis of data and problem identification;

3. development of management $\mathrm{plans}$, including further diagnostic studies, therapy, patient education and identification of parameters for follow-up;

4. modification of management $\mathrm{pl}$ an based on new patient data and/or new information regarding appropriate management of identified problems. (OSBN, 1980, ch. 851, Div. 30)

The requirements for NP certification have increased in Oregon and in several states. Candidates are required to have a master's degree and eligibility to apply for certification by the board of nursing in Oregon.

\section{RELATIONS WITH CONSUMERS AND COLLEAGUES}

With the emergence of federal support for the education of NPS came increased interest in their practice. A position paper was published by the National Joint Practice Commission (1975), which 
had been established to facilitate the basing of "current and anticipated medical and nursing practice on a sound legal foundation"

(Hall 1975, p. 1). The statement on medical and nurse practice acts approved by all of the sixteen Cornmissioners says in part,

The accumulation of knowledge and the expansion of techniques and skills able to be utilized in the care of individuals and in the prevention, treatment and cure of disease has necessitated or resulted in a realignment and readjustment of nurse and physician roles.

Practice acts which now serve as conditions for licensure and continuing licensure in each profession must be examined to ensure the legality of these realignments and readjustments for the protection of both the public and the professionals involved. (Hall, 1977, p. 1)

Collaboration with Physicians

Two NPs in Washington shared a thriving collaborative practice with a psychiatrist and recommended the experience.

We propose a model of providing primary psychiatric service for adults with severe emotional problems, utilizing collaborative approach between professional disciplines. The approach is an extension and expansion of the traditional office practice of psychiatry and conventional role definitions of traditional health professons. (Thomas, 1982, p. 193)

The author described the scope and management of a practice which is directed at a population characterized by frequent episodes of illness and hospitalizations that are devastating to patient and family alike.

In 1982, Chen, Barkauskus, Ohlson, \& Chen noted, "the similarities in caseload composition between nurse and physician practitioner may create either a high degree of interprofessional collaboration or conflict" (p. 169). Investigators studied NPs and 
physicians "in many ambulatory care roles. The clinics in the study were those in which NPS functioned in patient management, which was not generally true for non participating clincs" (p. 167). The physicians attended to many more kinds of health care needs than did the NPS, except in the area of obstetrics and gynecology where the physicians and NPS attended to an approximately equal number of needs. Caseloads for both physicians and NPs showed a 1 arge number of "frequently reported health problems" (p. 168), indicating the potential for increased utilization of NPS. The maintenance of wellness was characteristic of NP health care management in the community. In the provision of care in the specialty of adult medicine, a significant difference was found between the physicians and the NPS in their focus on wellness. In hospitals, the patient management of both physicians and NPs centered on illness. Patients reported their perceptions in a formal study.

National television has focused attention on some aspects of the relationships between the NP and the physician. In an interview with Dr. Loretta Ford, a prominent advocate of NPs, she noted the improvement in the "quality of care" (WNET, Sept. 21, 1983) when physicians and NPS "collaborate." On the other hand, physician Gehringer stressed the need for NPs to avoid problems by staying within their scope of practice by "not [practicing] medicine without the education and experience to do so" (WNET, Sept. 21, 1983).

A Missouri NP used standing orders for routine procedures and referred anything out of the ordinary for advanced care; she 
preferred the practice of nursing (not medicine) and wanted to provide good health care together with the physician (WNET, Sept. 21, 1983). A different perspective was given by an attorney who said there was an economic motive in the resistance to NPS (WNET, Sept. 21, 1983).

Perceptions of Others about Nurse Practitioner Functions

A review of eight studies of practice settings which included NPS showed mixed attitudes by physicians and other nurses toward the function of the NP (Flynn, 1975; Patterson \& Skinner, 1971; Record \& Green1ick, 1975; Reed \& Rogelmann, 1971; Slome, Daly, Meglen, Thiede, \& Wetherbee, 1976; Theiss, 1976; Wright, 1975; Wright, 1976). Some physicians and nurses accepted the concept of the NP but disagreed about acceptable NP functions; other nurses felt threatened by the NP. However, a group of 237 Texas nurses viewed the NP positively, with potential for greater professionalization of nursing practice and better health care for the public. Problems were identified for a specific group of nurse graduates who may be uncomfortable with the notion of an independent function in nursing (Wright, 1976).

A review of nine studies of practice settings which included physicians and NPs showed acceptance of the function of the NP by physicians, other nurses, and the consumers of health care functions (Hanson, 1973; Holmes, Livingston, \& Mills, 1976; Kahn \& Wirth, 1975; Lewis, 1978; Lewis \& Cheyovich, 1976; Linn, 1976; Merenstein, Harvey, \& Barker, 1974; Thurman \& Snowe, 1976; Whittington, 1970). 
Among the specific benefits identified were an increased volume of practice (12 per cent in the Holmes, Livingston, \& Mills, 1976, study), increased patient satisiaction (Merenstein, Harvey, \& Barker, 1974), better utilization of physician time and skills (Kahn \& Wirth, 1975), and enhanced quality of care available to psychiatric and developmentally disabled patients (Whittington, 1970).

Not all employers and evaluators of NPS have been physicians. Nurse administrators (including supervisors), nonclinical administrators, nurses (including public health nurses and other nurse practitioners), other nursing personnel, clerical staff, pharmacists, patients, people in the community, and others (includes social worker, personnel manager in industry, and various types of adminsitrative personnel) have provided favorable evaluations of the function of the NP. Reports on the performance of the NP affect the future development of the function.

Perceptions of Consumers and Colleagues about Nurse Practitioners. The NP functions in a clinical setting. A one-year demonstration study of NPs compared the reactions of the consumers and co-workers in a county hospital, an out-patient clinic, a neighborhood health center, and in private group practice. All participating patients who had contact with the NPs reported satisfaction with the care which they provided. About half the professionals (44 physicians, and 21 nurses) who participated in the study indicated their belief that NPS would have difficulties obtaining recognition for their capabilties (Flynn, 1975). 
This task of gaining recognition has been addressed by Weiss, who wrote in 1983, "steps should be taken to provide nurses with the skills to identify and articulate their practice domain so that they can effectively influence others" (p. 139). A study which included consumers, nurses, and physicians found in general that respondents saw the provision of most health services to be the joint responsibility of nurses and physicians. Areas of practice found to be of particular interest to nursing "were concentrated in health promotion and maintenance, self-care and integrating family and cultural considerations into care" (p. 139). As a nurse, the NP has acquired and expanded a set of skills with which to shape a new professional identity.

The acceptance of NPs continues to be reported. A 1980 longitudinal study of NPs by the United States Department of Health Education and Welfare (USDHEW) found "the overwhelming majority of employers (93 percent) reported that the benefit did outweigh the costs" (p. 32). Employers rated themselves as satisfied with 100.0 percent of the master's level NPS, as compared with 95.9 percent of the certificate level NPs (p. 153). When employers were asked to indicate the most significant effects of employing the NP, the certificate level NP was identified most often for improving the quality of care in general; the master's level NP was noted most frequently for extending services to more persons in general.

Not all employers were satisfied with NP performance. Of the few employers reporting dissatisfaction with NPS, the most 
frequently given reason was "time of NP not filled to maximum productivity" (USDHEW, 1980, p. 141).

The amount of acceptance indicated by the employers was compared with that indicated by the NPs. In most cases, the employers saw the NPS as less accepted than the NPS saw themselves. The acceptance by patients was rated almost the same by employers and NPs from all prugrams. For the NPS from master's programe, 100.0 percent agreement between NPs and employers was indicated regarding NP acceptability in all categories, except one -- that employer category of "nurse administrators (including supervisors)" (USDHEW, 1980, p. 146). Apparentiy the master's prepared NP was most likely to be seen by employers (and to be self-perceived) as well accepted by various groups in the practice setting. Perceptions of Nurse Practitioner Functions in Oregon. A1though the United States Department of Health and Welfare (1980) study showed at the national level a 93 percent rate of acceptance of the functions of NPs by 198 employers, including 102 physicians, Schleining (1980) showed a different pattern of reactions to NPs in Oregon. Generally the sampled physicians had a positive attitude toward NPS, who were credited with contributions toward better patient care and of being capable of providing expanded nursing care. However, the Oregon physicians indicated that clients prefer to obtain information on medical topics from physicians rather than from nurses. Almost half the physicians showed a belief in the notion that clients talk more freely about personal matters to physicians than to nurses. Except for the performance of physical 
examinations, the Oregon physicians did show a "willingness to

delegate some traditional physician functions requiring judgment and decision-making to the nurse practitioner" (Schleining 1980, p. 45).

Preparation for the Function of Nurse Practitioner

During the 1950's and 1960's when Duke University launched pro grams to prepare NPs in Durham, North Carolina, the efforts were not successful. The early programs were launched under circumstances wh did not include governmental support. By the middle 1960s, social a economic conditions had changed. National legislation led to the delivery of health care to an ever-widening portion of the populatio Advances in technology challenged health care providers to develop expertise consistent with the increasing needs and expectations of $t$ health care consumer.

The knowledge-base in the nursing profession expanded at a rat consistent with that of other health care professions. Specializati enabled nursing to maintain its high standards of care in response $t$ diverse and expanded clinical needs. A nurse who acquired advanced education in a nursing specialty could qualify as an NP.

Between 1967, when the first NP was graduated, unti1 1977, B1 $i$ and Cohen (1977) reported a total of 7,000 NPs had been prepared at rate of 1500 yearly from more than 85 certificate and 50 master's degree programs (p. 376). Studies to evaluate the effects of the federal legislation have recommended the continuation of support for the education of NPs. 
Levels of Preparation

Differences of opinion have surrounded the preparation of NPS. One group maintained that the teaching of "physician tasks," the utilization of "physician tools," and encouragement of joint "practice with physicians do not prepare nurses, but are preparing physicians' assistants" (B1iss, 1977, p. 210). Other academicians who are also practitioners of nursing emphasized the need for "strong clinical skills, collaboration with physicians, and open admission to NP programs to a variety of nurses." Nurse leaders have noted two more practical concerns of significance to the NP movement: (a) present certificate programs are useful, but, as specialists, all NPs should be prepared at the master's level to assure that the graduate has acquired high-level skills in making decisions and to gain more impact for NPS, and, (b) the reimbursement of NPS should be in proportion to their preparatory experiences instead of just receiving wages (Sultz, 1979).

Another perspective came from Sullivan, Kitzman, and Dachelet (1979)

Nurses prepared at less than the baccalaureate level focused to a larger extent on the illness of the sick individuals. It appeared that nurses prepared at this level usually lacked both the interest and experience in dealing with patient needs at the health end of the spectrum. (p. 166)

The conclusion may be made that different levels of preparation have emphasized different functions in the provision of nursing care in the practice setting.

Self Care. A different perspective was presented by Loretta Ford, one of the pioneer advocates for NPS. She believed the 
highest level of care is self-care and that's a more difficult challenge for health professionals than providing the care ourselves..... It is becoming increasingly obvious that preventive and psychosocial solutions to health care problems cannot be taught in the modern Flexnarian university hospital which is the locus of medical education.... If primary care is taught at all, it must be taught in ambulatory health care settings [which] permit the training of several disciplines in close proximity, sharing educational and service experiences [in] primary health care teams... which interact with consumers. (Sultz, 1979, pp. 216-218)

Loretta Ford stressed the importance of patient counseling and primary care team interaction. The provision of health care should focus on self-care, and the preparation of health-care professionals should occur jointly in ambulatory health care settings.

Speaking from the observation of public health in Oregon David Lawrence, M.D., Associate Health Officer, noted "conflict" which has resulted when academia in the fields of medicine and nursing have tended to implement programs insufficiently coordinated with the needs of health care consumers. He emphasized the importance of developing preparatory programs which are responsive to the needs of the consumer and the requirements of the health care marketplace to assure the retention of the interaction "between education and service" (Sultz, 1979, pp. 215-216).

Characteristics of Nurse Practitioner Preparation. As a steadily increasing phenomenon, the NP is a product of a variety of preparatory programs. In the Longitudinal Study of Nurse Practitioners (USDHEW, 1980), the definitive education

of a nurse practitioner is formally planned to prepare students for expanded functions in diagnostic and treatment needs of patients. Educational programs were accepted (when) they met the following criteria: They must offer a formal curriculum as opposed to inservice training for 
their own employees; they must provide preparation in extended nursing roles; i.e., primary care skills, such as history-taking, physical examination, ordering laboratory tests, and assuming responsibility for medical management of selected cases with emphasis on primary care. They must require that students be registered nurses in order to enroll. (p. 2)

The NP has been educated and is licensed to practice nursing. Additional education has prepared the nurse to perform extended nursing functions.

Most programs prepared graduates for extended nursing practice in a specialty, such as pediatrics, emergency, maternity, or psychiatric care. About one-third of the programs studied in the USDHEW (1980) report were locaced in the West and Midwest. The largest number of programs in a single region were located in the South (34 percent), which al so reported the most new programs between 1974 and 1977. Of the various specialties, family care was the most represented; 62 percent of the total number of programs focused on family and child care, and the other five (pediatric, midwifery, maternity, adult, and psychiatric) specialties comprised the remaining 38 percent of the programs.

Programs were typed according to whether the graduate was awarded a certificate or a master's degree. Of the 178 programs, 117 awarded a certificate and 61 awarded a master's degree. Credits were identified as either academic or continuing education (USDHEW, 1980).

The length in months of preparation ranged from the shortest (4) in some certificate programs to the longest (24) in some 
master's programs. Averages were 9.8 months for the certificate and 15.4 months for the master's prograns.

An assessment was made of the average number of montis each program devoted to "didactic" and "preceptor" components. The supervised clinical practice in patient assessment and management is known as a "preceptorship"; it follows the formal, theoretical portion of the program. Certificate programs averaged 5.5 months (compared with 14.7 months average for the master's programs) in the classroom and clinical segments of the didactic component. The "preceptorship" was the other component of both certificate and master's programs. The time given to preceptorship averaged 9.8 months in the certificate and 15.4 months in the master's programs. The time given to both components was considerably longer in the master's programs (USDHEW, 1980).

In terms of time and subject matter, an overview has shown the relative emphases for the certificate and master's programs. Most of the time in certificate programs focused on teaching students how to take histories, do physical examinations, assess wellness, and manage illness. In comparison, the students in master's programs were given more and longer opportunities to learn these skills. Quality assurance was an area of more extended concerns in the master's than in the certificate programs. Both types of programs addressed the areas of professional development, legal aspects, research competencies and electives (USDHEW, 1980, p. 16).

A detailed listing of the first nine specific skills developed in master's programs for nurse practitioners included: 
1. Develop a health maintenance program including prevention and education for each patient.

2. Take a medical history.

3. Perform a physical examination.

4. Assess clinical information.

5. Determine what clinical information is to be obtained on each patient seen.

6. Counsel patients on psychosocial problems.

7. Determine the management of diagnosed illness.

8. Counsel patients on medication.

9. Perform laboratory tests. (National Technical Information Service, 1976, p. 12).

Master's programs for NPs were said to place heavy emphasis on

research, as well as on the acquisition of such skills as historytaking.

Most NP programs were found to emphasize an independent role for the NP, with patient counseling as a primary focus. The counseling function may utilize a high level of skill in teaching. As Redman (1980) wrote,

excellence in the teaching-supportive aspects of care is central to expanded nursing roles. Moreover, we need to provide nurses wishing to improve their teaching skills with the same conditions that patients need: that is, an open, warm relationship with someone whose behavior they can use as a model and who can help them to analyze their own [behavior]. This might be done by assigning a nurse to a teaching team or to a mentor who would aid in developing increasingly complex teaching skills. (p. 259)

While consumer education has been mentioned frequently as a significant component of the function of the NPS, courses in education were not identified either in the preparation defined for the certificate or for the master's programs in the programs reviewed in the 1980 study by the United States Department of Health, Education, and Welfare. 
Objectives for NP Students. Since the independence of the NP is different in many ways from the more familiar nursing iunction, the instructors of NPS have been expected to assist NP students to accomplish the following sample of objectives: (a) ability to evaluate critically the health history of a patient, (b) perform basic physical and psychosocial assessment, (c) decide when to refer to the physician for evaluation or supervision, (d) recognize and manage specific minor common conditions, (e) formulate and implement a plan of care, (f) refer to community health resources, (g) visit homes, and, (h) assist entrance into the health-care system (Popiel, 1973). Must of the courses are organized into specialties. Varying lengths of time are needed to complete the course, depending upon the specialty, the provider, and the relevant governmental regulations.

Length of Preparation. In 1973, a typical course was 10 to 16 weeks of formal instruction combined with clinical practice (Popiel, 1973). Most courses have lengthened, both in their formal and in their clinical components. A study in 1980 (United States Department of Health, Education, and Welfare) showed a steady increase in numbers of both certificate and master's programs between 1970 and 1977. "The average length of certificate programs was 10 months and of master's programs, 15 months" (p. 13). Through a certificate program, the associate degree nurse may obtain qualification to be an NP. The criteria for certification as an NP are identified by the individual state board of nursing. 
States, such as Utah, have accepted the two-year associate degree preparation as adequate for the basic nursing preparation of the NP. Other states, besides Oregon and Washington, have required additional education or training before awarding NP certification (Hal1, 1977). Oregon has preferred the applicant to have a master's degree in the designated specialty, but, before 1981, an applicant needed only to show the board of nursing "evidence of having completed a certificate or degree program appropriate to the specialty area and approved by the Oregon Board of Nursing" (OSBN 1980, Ch. 851, Div. 20).

Professional Adjustments. Writing in 1974, Cohen and observed the following functions to be typical of nursing care as

those functions which are thought to comprise the nursing role. Typical elements of the nursing role are observations, care, counseling, maintenance of health, and administration of medications or treatments. Usually prohibited from the nurse's function are acts of diagnosis and prescription. (p. C -5$)$

Traditional nursing as described above may be changed -- extended or expanded -- into the NP function. Cohen (1974) observed the following discrepancies between the function identified in the statutes and the function performed with the health care consumer.

A7though statutorily barred from participating in areas of diagnosis, perception, and most treatments, nurses are not only allowed to perform these functions when necessary, but may even be liable in negligence if they do not respond adequately to patient needs. A hospital nurse who discovers a patient in a crisis of worsening condition is expected to evaluate that condition, diagnose its cause, and take immediate steps to alleviate or correct the cond $i$ tion until a physician arrives. A measure of this expectation is that nurses are far more frequently sued for neglect of duty, i.e. "ommission, than for over extension 
of their role (Anderson)"... if non physician personnel are capable of caring for patients in moments of life-endangering crisis, then they could certainly be relied upon for diagnosis and treatment when, lacking an emergency, there is more time. ( $p p . C-6,7)$

Upon receipt of the certification from the board of nursing, the NP may encounter a range of reactions from others consistent with the implementation of any change in function. As Banton (1965) wrote,

for an individual to move from one role to another is not always an easy matter. It requires that he know the rights and obligations of the role to which he is moving and that he change his behaviour accordingly. It al so requires that other people recognize his change of role and modify their behaviour towards him in a corresponding fashion. Rolechanging therefore creates problems for social relations (a) the greater the change for the individual, (b) the more people there are who meet him in both his old and his new roles and therefore have to modify their behaviour. ( $\mathrm{pp}$. 93-94)

Having been prepared to implement the basic nursing function, each NP must "change...behaviour" (Banton, 1965, p. 94). The registered nurse who becomes an NP has earned certification and the right of recognition by health care consumers, the community of health care providers, and the general public for the acquisition of specialized knowledge and skills.

Not only has the integration of different functions required adjustment by the individual NP, but the different functions have required adjustment by the members of the community who interact with the NP. Perhaps the members of the medical community interact frequently with the NP and may be expected to experience frequently 
the need to adjust or to "modify their behaviour" as Banton (1965) put it (p. 94).

The medical community and the community at large may increasingly use the specialized knowledge and skills of NPS. The competencies demonstrated by each NP are expressions of an advanced or expanded nursing function for the benefit of the health care consumer. Education has been instrumental in the establishment and continuation of the expanded role within nursing practice. One way to assess whether their education has prepared them to meet the needs of the health care consumer is to survey the NPS in Oregon.

DEFINITION OF TERMS

\section{Advanced Nursing Care:}

Synonymous with practice in an expanded specialty role or area; clinical practice based on specialized education which prepares a registered nurse to provide primary health care. Council of the American Nurses' Association:

Contributes to the advancement of professionalism through the enhancement of professional expertise, shaping of policies, and maintaining standards in an important area of nursing. Council of Primary Health Care Nurse Practitioners:

Has a goal to improve the quality and delivery of primary health care through organized efforts of nurse practitioners as primary care providers; members must belong to state and American nurses' association and one or more of the following categories: graduate of a formal organized program that pre- 
pares nurses to function as primary health care NPS, students enrol?ed in such a program, nurse educators teaching in such a program, and NPS who have met the criteria for certification in a primary health care specialty.

Certified Registered Nurses:

Certified registered nurse (CRN) is used in Washington to refer to a registered nurse who has fulfilled the requirements of the board of nursing for advanced and specialized nursing practice.

Diagnosing:

In the context of the practice of nursing means identification of and discrimination between physical and psychosocial signs and symptoms essential to effective execution and management of the nursing care (Oregon Revised Statute 678.010).

Didactic:

Includes a classroom and a clinical component; the classroom component includes such activities as lectures and selfinstruction; the clinical component includes relevant clinical observations and experiences and operates concurrently with the classroom component (USOHEW, 1980, p. 57).

$\underline{\operatorname{Drug}(s)}:$

Medicines and preparations for internal or external use of human beings which are recognized in the formulatory authorized by the Advisory Council on NPs' privileges of writing prescriptions (ORS, 1983, 678.375). 
Expanded/Extended Specialty:

Practice in an expanded specialty role or area means clinical practice based on specialized education which prepares a registered nurse to provide primary care; categories of specialties may include: (a) family, (b) pediatric, (c) adult, (d) geriatric, (e) psychiatric/mental health, (f) midwife, (g) women's health care, (h) school health, and (i) college health (OSBN, 1980, 851-30-001).

Flexnarian:

Flexner was an early and highly respected physician educator whose influence in medical education persists to the present, when physicians are educated in didactic, academic settings which seldom include students from other disciplines as peers and where the health care consumer usually is viewed as a relatively passive recipient of services.

Formulary:

A listing of the medications approved by the Advisory Council that may be prescribed by an NP authorized to prescribe drugs within the scope of specialized practice (ORS, 1983, 678-385).

Function:

Any condition or state of affairs that results from behavior (Biddle, 1979, p. 51).

Human Response:

Those signs, symptaris and processes which denote the person's interaction with an actual or potential health problem (ORS, 1983, 678.010). 
National Joint Practice Commission:

Sixteen nurse and physician commissioners are prepared to advise State joint practice committees and others who are reviewing options within existing medical and nurse practice acts for possible routes and models for the formulation of new acts to achieve the necessary freedom to provide the consumers with needed care in their respective states (Ha)1, 1977, p.

1).

Normative Nurse:

A registered nurse with a long tradition of "bedside care for the individual patient" (Katz, 1969, p. 4).

Orwellian:

Advanced mechanical button-pushing computerized business oriented type of health care where "people will be stockpiled, rationed and treated very badly" (Kotulak, 1985, p. A2).

Physician (MD):

Any person who holds a degree of Doctor of Medicine or Doctor of Osteopathy (ORS, 1983, 677.010).

Physician's Assistant (PA):

A person qualified by education, training, experience, and personal character to provide medical services under the direction and supervision of an Oregon licensed physician in active practice and in good standing with the Board of Medical Examiners; the purpose of the physician's assistant program is to enable physicians licensed under the law to extend high 
quality medical care to more people throughout the state (OSEN, 1980, 847-50-005).

Practice of Medicine:

A person is practicing medicine if he does one or more of the following: (a) advertise, hold out to the public or represent in any manner that he is authorized to practice medicine in this state, (b) for compensation directly or indirectly received or to be received, offer or undertake to prescribe, give, or administer any drug or medicine for the use of any other person, (c) offer or undertake to perform any surgical operation upon any person, (d) offer or undertake to diagnose, cure or treat in any manner, or by any means, methods, or devices or instrumentalities, any disease, illness, pain, wound, fracture, infirmity, deformity, defect or abnormal physical or mental condition of any person, or (e) act as the representative or agent of any person in doing any of the things mentioned; the language of sections 1-5 does not appy to registered nurses nor to the regulation of the healing arts other than medicine or podiatry. (ORS, 1983, 677.085, $677.060,677.070)$

\section{Practice of Nursing:}

The registered nurse bears primary responsibility and accountability for the nursing care patients receive; functions of practice include: assessment and diagnosis (a licensee shall assess the patient's needs based upon nursing history and observation of the patient's signs and symptoms from which to 
determine a nursing diagnosis), planning (a licensee shall establish goals and develop patient care based upon the diagnosis), delegating (the licensee shall implement the plan of care and/or delegate such nursing functions as deemed safe for other licensed nursing personnel to perform), supervision (the licensee shall provide minimal and direct supervision of personnel to whom he/she delegated nursing care that he/she will evaluate), teaching (the licensee shall be responsible for such health care teaching as will help other staff personnel, improve patient care and contribute to patients' and families' health maintenance and well-being), observing, recording, and reporting (a licensee shall observe the cond $i$ tions, signs, and symptoms of the patient, record them, and report significant changes to the appropriate person, making accurate legible, and intelligible entries in records required by law or custom in the pracice of nursing). (OSBN, 1980, $851-30-170)$.

\section{Preceptorship:}

The internship or preceptorship portion is a specified period of supervised clinical practice in patient assessmerit and management and is a requirement for completion of some programs; this is distinct from and follows the clinical experience offered concurrently with the didactic portion (USDHEW, 1980, p. 57). 
Prescribe:

Direct, order or designate the preparation, use of a or manner of using by spoken or written words (ORS, 1983, 678.375).

Prescriptive Privileges:

Authorization by the Advisory Council to prescribe medication from a limited listing appropriate to the specialty of the nurse practitioner.

Protocol:

A predetermined set of orders for the delivery of health care. PSRO:

Professional standards review organization checks the records of health care delivery to assure the provision of maximum efficacy and efficiency in the utilization of resources. Registered Nurse (RN):

A person who has met the requirements of the board of nursing to practice nursing, the extent of which is continually changing, is dependent upon generic education and demonstrated competence in those special skills acquired through inservice, continuing education, or graduate studies which may be safely added to current practice and are within the realm of such practice (OSBN, 1980, 851-30-160).

Role:

Those behaviors characteristic of one or more persons in a context (Biddle, 1979, p. 58). 
Scope of Practice of Nurse Practitioner (NP):

In addition to the services provided by the registered nurse, the NP is autnorized to provide management of mental and physical health care in the applicable specialty area, the scope of which shall be based upon educational preparation, continued experience and the accepted scope of professional practice of the particular specialty area; such management is to be provided through integration of health maintenance, disease prevention, physical diagnosis, and treatment of common episodic and chronic problems, including pregnancy, in primary health care in collaboration with physicians and other health care professions and agencies (OSBN, 1980, 851-30-003).

Standing Orders:

Predetermined directions for the piovision of health care which have been written to be implemented at a later time if needed for specified circumstances.

Sunset Review:

The study by legislators of a nurse practice act which is scheduled to expire, unless legislators are convinced of continuing need for the act.

\section{Task Force of the Council:}

Sub-committee of the Council of the American Nurses' Association assigned to develop national standards of practice of NPS. 
CHAPTER III

METHODOLOGY

Included in this chapter are a description of the design of the study, the subjects, the instrumentation, the procedures of data collection, and the statistical methods which were used to analyze the data.

DESIGN

Because the data came from nurse practitioners (NPs) in all parts of Oregon and in many of the continental United States, onsite interviews or evaluations of NP functions were impossible for an individual researcher. An exploratory survey design which utilized the mailed questionnaire was chosen as the most appropriate for this descriptive ex post facto study. The two research purposes were:

1. To determine the perceptions of the Oregon-certified NPS, in general and by specialty, with respect to their (a) frequency of performance, (b) competence in performance of each function, and (c) preparation for each function; and

2. To compare the perceptions of NPs in various specialties with respect to each of the above. 


\section{SUBJECTS}

Five-hundred and seventy-nine nurse practitioners (NPS) were certified in Oregon in January of 1986. Five of these were not included among the subjects of the study because they either lived outside the continental United States or participated in the pretesting of the questionnaire. Each of the remaining 574 was solicited to provide responses to selected functions of a nurse practitioner. Three separate mailings were made during the winter of 1986 from a list of the Oregon-certified NPs compiled by the Oregon Board of Nursing (see Appendix A). Three-hundred eighty-eight (68\%) of the NPs provided the responses used in this study.

\section{INSTRUMENTATION}

Four instruments were constructed to obtain data in the following areas: (a) general information, (b) practice setting, (c) functions, and (d) administrative public relations functions. (See Appendix B.) The final form of the questionnaire resulted from modifications made in response to pretesting of Oregon NPs.

\section{General Information}

The first instrument was designed to describe the respondents in terms of: age, background, and NP preparation.

\section{Practice Setting}

In the second instrument, the respondents were asked about the major setting, its characteristics, and those of the clients. NPs 
were requested to assess their attitudes toward some of the conditions of the practice.

\section{Functions}

The third instrument was compiled from instruments developed for studies of NPs in other regions. Warren's (1979) study analyzed the "extent to which NPs are functioning in the role for which their educational programs prepared them" (p. 124). Of the 46 statements which addressed "specific role activities," 16 were incorporated into the list of functions mailed to Oregon NPS.

Another 24 functions were derived from a 1978 study by Drice of NPS in California. Drice used a scale of "non-traditional (extended) functions...customarily performed by licensed physicians" (p. 42) to assess the distribution of the functions of nurse practitioners with respect to level of preparation and health care experience. The functions in the Drice (1978) study originated from a 1977 study directed by R. S. Lawrence in conjunction with physicians in North Carolina who rated their willingness to delegate task responsibility to NPS. "The length of training proved to be the most common reason given for wanting to delegate additional tasks" (p. 302). Furthermore, "It is evident that the vast majority of respondents to this survey trust that the training programs will teach appropriate tasks to nurse practitioners" (p. 306). Although the scale developed by Lawrence, Defriese, Putnam, Pickard, Cyr, \& Whiteside, in 1977 and used by Drice in 1979 contained a list of traditional nursing tasks, only the 24 tasks classified as 
"extended" nursing tasks were among those submitted to the Oregon NPS.

The compilation of 40 functions was arranged into three Likert-type scales designed to assess the respondents' thoughts with respect to their competence, frequency of use, and preference for place in NP preparation. Each function was followed by a:

1. Four-part scale to indicate level of competence,

2. Five-part scale to show frequency of use, and

3. Four-part scale to assign place in NP preparation for major emphasis.

The scales were modified from Ward's (1975) study of family NPS throughout the nation.

As a way of probing the relevancy of the 40 functions to those performed by the Oregon NPS, four NPs in active practice recorded their daily activities for two weeks. The recordings were contentanalyzed and compared with the functions from the other regions.

The 40 functions were categorized under the scope of practice developed by the Oregon Board of Nursing in 1980 as follows:

1. Eleven were included in health promotion and maintenance;

2. Fifteen were under management of health care;

3. Four were categorized as treatment in collaboration;

4. Five were designated as prevention of illness and disability; and,

5. Five were classified as guidance and counseling. 
Administrative and Public Relations Functions

The fourth instrument consisted of two parts and was intended to obtain information about the interpersonal network in which the clinical functions were implemented both with in the practice setting and the wider community. The structured items originated with Warren's (1979) study of the role practice activities of the NPs in Arkanasas. The items had been developed during a series of pretests by three groups of NPS who evaluated content, clarity, and relevance.

The final questionnaire resulted from modifications made in response to pretesting of Oregon NPS and to recommendations by the Oregon State Board of Nursing.

\section{PROCEDURES}

The four instruments were combined into a single questionnaire. A letter of introduction, a letter of explanation, a letter of informed consent, and two self-addressed return envelopes together with the questionnaire were mailed in January of 1986 to 574 NPs who were certified in Oregon. See copies of these materials in Appendix $A$ and $B$. One questionnaire was returned by the post office as undeliverable with an expired forwarding address.

Three hundred and eighty-eight of the 574 subjects returned completed questionnaires. Using a systematic follow-up method, a response rate of $67.5 \%$ was obtained. The NPs returned 186 completed questionnaires within three weeks of the first mailing. When a follow-up letter was sent to non-respondents, the NPs returned 77 
more completed questionnaires. Five weeks after the initial mailing of the quastionnaire, another follow-up letter was sent and the NPS completed and returned eight additional questionnaires. Following the mailing of a third follow-up letter, which contained a copy of the original questionnaire marked "Duplicate," another 115 NPS returned completed questionnaires. Two more questionnaires were returned too late for analysis. (See Table I.)

TABLE I

THE NUMBER AND PERCENT OF COMPLETED QUESTIONNAIRES RETURNED IN RESPONSE TO EACH OF THREE MAILINGS

\begin{tabular}{lccc}
\hline Mailing & Date & $n$ & Percent \\
\hline Initial Mailing & January 9, 1986 & 88 & 22.8 \\
First Follow-up & January 28, 1986 & 175 & 45.3 \\
Second Follow-up & February 14, 1986 & 8 & 02.1 \\
Third Follow-up & February 21, 1986 & 115 & 29.8 \\
\hline Total & & 386 & \\
\hline
\end{tabular}

Since the questionnaire was mailed to all the NPs certified by the Oregon Board of Nursing, the recipients included 358 NPS who were in active practice on January 9, 1986, and 28 NPS who were not in active practice at the time. Both groups of NPs submitted questionnaires which were completed in compliance with instructions to accommodate the differences in circumstances. A total of 386 questionnaires were analyzed. 


\section{STATISTICAL METHODS}

Data were computer scored and analyzed by statistical programs found in the SPSS: Statistical Package for the Social Sciences (Nie, Hul1, Jenkins, Steinbrenner, \& Bent, 1975); and, SPSS Update 7-9 (Hull \& Nie, 1981). Statistics computed included frequency distributions, medians, and percentages.

Where the method would give useful information, descriptive statistics were applied to all data. Responses to the first sixteen items, which described characteristics of the sample, were summarized in frequency distributions and percentages for the total sample and for six specialty groups.

The 40 functions were grouped into five headings: Health Promotion and Maintenance (11), Management of Health Care (15), Treatment in Collaboration (4), Prevention of Illness (5), and Guidance and Counseling (5). Classification of functions was based upon the scope of NP practice presented in the Oregon Administrative Rules (1980). For each of the 40 functions, a tabulation of the levels of the function was performed separately for "Level of Competency," "Frequency of Use," and "Place in NP Preparation." Summary statistics were used to present percentages of responses by all participants (NPS in general) to each of the levels of each of the functions.

For each function, a cross-tabulation of the levels of the function with the six specialty groups were performed separately for "Level of Competency," "Frequency of Use," and "Place in NP 
Preparation." Summary statistics were used to present percentage of responses by each specialty group to each of the levels of each of the functions. Chi-square was used to test for the independence of specialty area and function. The .05 level of confidence was selected as statistically significant for each test.

With no indication of the magnitude of the relationship, chisquare "is a test of independence of the variables" (Kerlinger, 1964, p. 171). The independence was considered to be statistically significant when the chi-square value was not due to chance at the .05 level of confidence. Hopkins and Glass (1978) wrote that chisquare could be seen as a way "to see if there was a difference in the responses" (p. 320). Each of the responses qualified for only one category, each category was separated from every other category, and each response was entered only once. In this study, chi-square was calculated form frequency of responses in contingency tables. In some instances, the data could not be analyzed because the difference in the responses was not evident. Some functions were used with similar competency and frequency by each of the specialty groups; no discernible differences existed.

Thus, chi-square was used to test the followng statistical hypothesis for each of the 40 functions:

There will be no significant differences between the perceptions of the Oregon-certified NPs in six specialty areas with respect to the:

1. Frequency of performance of selected functions:

2. Competence in performance of each function; and,

3. Preparation for each function. 
Cross-tabulations were compiled using responses by NPs in six specialties to the three categories of the 40 functions. When using the chi-square in a test of independence for two-way tables with degrees of freedom greater than one, nu more than $20 \%$ of the expected cell frequencies should be less than five (and none less than one). In the analyses using NP specialty as one variable and eithe "Level of Competence" or "Frequency of Use" of a function as the other variable, sometimes two or more adjacent categories of the second variable needed to be combined in order to meet this criterion for minimum expected frequency. Because the categories of "Place in NP Preparation" could not be combined logically, selections with low expected frequencies were excluded from the analysis as needed to meet the criterion.

The open-ended questions were analyzed for content by tabulation of the frequency distribution of certain themes, topics, and language of the NPs in genera1. Kerlinger (1973) described content analysis as "an objective and quantitative method for assigning types of verbal...data to categories" (p. 417).

In the verbal data of this study, the single most common response was "Same as above." An analysis of 41 of the "Same as above" responses suggested that most NPs referred to the statement(s) made by the participant to patients. "Same as above" probably meant that the interpretation of the NP function to patients was the same as that made to other disciplines, to the community, and to legislators. 
CHAPTER IV

ANALYSIS AND DISCUSSION

In responding to the questionnaire used in this study, nurse practitioners (NPS) presented their views concerning the performance of certain functions and their recommendations as to the kind of preparation that would most effectively equip them for those tasks. The analysis of the data collected is organized within four sections. The first section describes the participants in this study for the effect of the sampling characteristics on data analysis. The second section describes demographic characteristics of the participants, including their academic and professional experiences, practice settings, and attitudes not only toward what they do as NPS but also toward the adequacy of their preparation for the NP function. The third section describes certain functions in clinical practice. The fourth section contains analyses of the questions pertaining to policy-making and public relations activities. Summary tables show how well respondents thought they were performing each of the selected functions, how often they did it, and where in their preparation they wanted to emphasize that function. 


\section{SAMPLING CHARACTERISTICS}

\section{Total Sample}

of the 574 questionnaires which were mailed to certified Oregon NPS, 388 were returned (a return rate of $67.60 \%$ ). In accordance with the directions for those NPs who were certified in Oregon but were not in active practice in the state during the winter of 1986 , 28 NPs completed only the first page of the questionnaire. Two questionnaires were returned too late to be included in the analysis. Thus, for the analysis of the responses to the questions on page one, the responding sample was 386; for the remainder of the questionnaire, the responding sample for analysis was 358 .

\section{The Specialty Areas}

An NP specialty area is identified according to the consumers of its health care services. For example, the Psychiatric-Mental Health NP provided services to the person with mental or emotional illness. For this study, responses by NPs in the six specialty areas with sample sizes of at least 30 were chosen for analysis. Sixteen NPs from three other specialties (Geriatrics, College Health, and School Health) al so participated in this study. Since the number of respondents in these specialties was too small to be examined separately, and it was unclear how they could be combined with the other specialties represented, these 16 respondents were included in the analysis of the total sample, on the one hand, but excluded in the comparisons between specialties on selected variables, on the other hand. 
The selected specialty areas are presented in order of the number of respondents:

1. Aduit Nurse Practitioner (ANP), 65

2. Women's Health Care Nurse Practitioner (WHCNP), 56

3. Family Nurse Practitioner (FNP), 53

4. Psychiatric-Mental Health Nurse Practitioner (PMHNP), 52

5. Pediatrics (PNP), 50

6. Nurse Midwife (NM), 34.

\section{Classification and Analysis of Data}

As an aid to comparisons among the responses, percentages were calculated based upon the total number of valid responses to a choice associated with a variable. A percentage represents the number of respondents selecting a particular choice divided by the total number of valid responses to the choices associated with that variable times 100, (e.g. 5 divided by 358 times 100, equals 1.3 percent). Where the number of respondents ( $n$ ) differs from 386 (first part of the questionnaire) or 358 (remainder of the questionnaire), the respondent(s) indicated too many responses, "not applicable," and/or no response. Discrepancies between the totals in the rows of the tables may reflect the inclusion of respondents of all specialties in the total sample; other totals in the row refer to the six specialties whose responses were sufficiently numerous for statistical comparisons. 


\section{DESCRIPTION OF THE RESPONDING SAMPLE}

For purposes of discussion, the demographic characteristics of the respondents were organized into four natural groups. The first grouping consists of responses about age. The second is comprised of responses about academic and experiential background. The third grouping contains responses about NP preparation, and the fourth grouping is about the NP's practice setting. Comparisons were made between the responses of the NPs in the six specialty areas and those of the total number of respondents (358, or 386 if not all in active practice). The information obtained from all respondents (including those who completed only Part One) was included in these analyses. Where parentheses appear in the tables, they enclose a number associated with the aligned descriptor.

Age of NPs in Oregon

Table II shows that $45.5 \%$ of the 386 subjects were between 36 and 45 years of age. In the specialty areas, the FNPS and the NMs were the youngest, with nearly half of them under 36 and approximately $90 \%$ under 46 years of age. The oldest NPs were PNPS and WHCNPS, with approximateiy $1 / 4$ aged 46 or older.

NP Background: Academic and Experiential

Table III presents the distributions of the NPs in general and those in six specialties with respect to education, experience as an RN prior to becoming a nurse practitioner, and experience as an NP in Oregon. For analysis and discussion, subheadings follow below. 
TABLE II

ACE OF NP'S REPORTED IN FREQUENCY AND PERCENTACES

\begin{tabular}{|c|c|c|c|c|c|c|c|c|c|c|c|c|c|c|}
\hline \multirow[b]{2}{*}{ ACE } & \multicolumn{2}{|c|}{ TOTAL } & \multicolumn{2}{|c|}{ ANP } & \multicolumn{2}{|c|}{ HHCNP } & \multicolumn{2}{|c|}{ FNP } & \multicolumn{2}{|c|}{ PMHNP } & \multicolumn{2}{|c|}{ PNP } & \multicolumn{2}{|c|}{ NM } \\
\hline & $n$ & $\bar{\phi}$ & $n$ & $\%$ & $n$ & $\%$ & $n$ & $\%$ & $n$ & $\%$ & $n$ & $\%$ & $n$ & 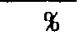 \\
\hline $26-35$ & 130 & 33.8 & 20 & 30.8 & 20 & 35.7 & 26 & 49.1 & 15 & 29.8 & 15 & 30.0 & 16 & 47.1 \\
\hline $36-45$ & 175 & 45.5 & 34 & 52.3 & 21 & 37.5 & 22 & 41.5 & 26 & 50.0 & 22 & 44.0 & 14 & 41.2 \\
\hline $46-55$ & 52 & 13.5 & 8 & 12.3 & 12 & 21.4 & 3 & 5.7 & 9 & 17.3 & $B$ & 16.0 & 2 & 5.9 \\
\hline $56-65$ & 28 & 7.3 & 3 & 4.6 & 3 & 5.4 & 2 & 3.8 & 2 & 3.8 & 5 & 10.0 & 2 & 5.9 \\
\hline TOTAL & 385 & & 64 & & 56 & & 53 & & 52 & & 50 & & 34 & \\
\hline
\end{tabular}


TABLE III

NP BACKGROUND: ACADEMIC AND EXPERIENTIAL REPORTED IN FREQUENCY AND PERCENTACES

Variable $\frac{\text { TOTAL }}{n} \frac{\text { ANP }}{n} \frac{\text { WHCNP }}{n} \frac{\text { FNP }}{n} \frac{\text { PUHNP }}{n} \frac{\text { PNP }}{n} \frac{\text { NM }}{n} \frac{\pi}{n}$

Level of Basic Nursing Education

$\begin{array}{lcccccccccccccc}\text { Diploma } & 79 & 20.5 & 13 & 20.0 & 15 & 26.8 & 9 & 17.0 & 9 & 17.3 & 8 & 16.0 & 7 & 20.6 \\ \text { Assoct ate } & 51 & 13.2 & 12 & 18.5 & 9 & 16.1 & 7 & 13.2 & 3 & 5.8 & 1 & 2.0 & 5 & 14.7 \\ \text { Baccalaureate } & 232 & 60.1 & 37 & 56.9 & 31 & 55.4 & 29 & 54.7 & 36 & 69.2 & 39 & 79.0 & 21 & 61.9 \\ \text { Master's } & 20 & 5.2 & 3 & 4.6 & 0 & 0.0 & 8 & 15.1 & 3 & 5.8 & 1 & 2.0 & 0 & 0.0 \\ \text { Other } & 4 & 1.0 & 0 & 0.0 & 1 & 1.8 & 0 & 0.0 & 1 & 1.9 & 1 & 2.0 & 1 & 2.9\end{array}$

Highest Level of Formal Education

\begin{tabular}{|c|c|c|c|c|c|c|c|c|c|c|c|c|c|c|}
\hline Diploma & 33 & 8.5 & 4 & 6.2 & 13 & 23.2 & 2 & 3.8 & 1 & 1.9 & 4 & 8.3 & 4 & 11.8 \\
\hline Associate & 16 & 4.1 & 1 & 1.5 & 5 & 9.0 & 2 & 3.8 & 0 & 0.0 & 2 & 4.2 & 1 & 2.9 \\
\hline Baccalureate & 104 & 26.6 & 15 & 23.1 & 26 & 46.4 & 14 & 26.4 & 3 & 5.8 & 20 & 41.7 & 10 & 29.4 \\
\hline Master's & 219 & 56.7 & 44 & 67.7 & 11 & 19.6 & 35 & 66.0 & 43 & 82.7 & 19 & 39.6 & 17 & 51.5 \\
\hline Doctorate & 14 & 3.6 & 1 & 1.5 & 1 & 1.8 & 0 & 0.0 & 5 & 9.6 & 3 & 6.0 & 2 & 5.9 \\
\hline TOTAL & 386 & & 65 & & 56 & & 53 & & 52 & & 48 & & 34 & \\
\hline
\end{tabular}


TABLE III (CONTINUED)

\begin{tabular}{|c|c|c|c|c|c|c|c|c|c|c|c|c|c|c|}
\hline \multirow[b]{2}{*}{ Varlable } & \multicolumn{2}{|c|}{ TOTAL } & \multicolumn{2}{|r|}{ ANP } & \multicolumn{2}{|r|}{ WHCNP } & \multicolumn{2}{|r|}{ FNP } & \multicolumn{2}{|c|}{ PMHNP } & \multicolumn{2}{|r|}{ PNP } & \multicolumn{2}{|c|}{ NM } \\
\hline & $n$ & 8 & $n$ & 8 & $n$ & 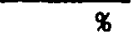 & $n$ & $\%$ & $n$ & $x$ & $\pi$ & $\%$ & $n$ & $\%$ \\
\hline \multicolumn{15}{|c|}{$\begin{array}{l}\text { Highest Level of Formal Education } \\
\text { by Nursing Major }\end{array}$} \\
\hline Diploma & 33 & 8.5 & 4 & 6.2 & 13 & 23.2 & 2 & 3.8 & 1 & 1.9 & 4 & 8.3 & 4 & 11.8 \\
\hline Nursing & (33) & $(100.0)$ & (4) & $(100.0)$ & (13) & $(100.0)$ & (2) & $(100.0)$ & (1) & $(100.0)$ & (4) & $(100.0)$ & (4) & $(100.0)$ \\
\hline Assoclate & 16 & 4.1 & 1 & 1.5 & 5 & 9.0 & 2 & 3.8 & 0 & 0.0 & 2 & 4.2 & 1 & 2.9 \\
\hline NursIng & (15) & $(93.8)$ & (1) & $(100.0)$ & (5) & $(100.0)$ & (2) & $(100.0)$ & $(0)$ & $(0.0)$ & (2) & $(100.0)$ & (1) & $(100.0)$ \\
\hline Baccalaureate & 104 & 26.9 & 15 & 23.1 & 26 & 46.4 & 14 & 26.4 & 3 & 5.9 & 20 & 41.71 & 10 & 29.4 \\
\hline Nursing & (93) & $(59.4)$ & (11) & $(73.3)$ & (24) & $(92.3)$ & $(14)$ & $(100.0)$ & (3) & $(100.0)$ & $(20)$ & $(100.0)$ & (9) & $(90.0)$ \\
\hline Master's & 219 & 56.7 & 44 & 67.7 & 11 & 19.6 & 35 & 66.0 & 43 & 82.7 & 19 & 39.6 & 17 & 50.0 \\
\hline Nursing & (197) & $(90.0)$ & (39) & $(89.6)$ & (8) & $(72.7)$ & (32) & $(91.4)$ & (43) & $(100.0)$ & $(18)$ & $(94.7)(1$ & 15) & $(89.2)$ \\
\hline Doctorate & 14 & 3.6 & 1 & 1.5 & 1 & 1.8 & 0 & 0.0 & 5 & 9.6 & 3 & 6.3 & 2 & 5.8 \\
\hline Nursing & (4) & $(29.6)$ & $(0)$ & $(0.0)$ & (1) & $(100.0)$ & (0) & $(0.0)$ & (2) & $(40.0)$ & (0) & $(0.0)($ & (2) & $(100.0)$ \\
\hline
\end{tabular}

Note: Parentheses enclose number of NPs and assoclated percentage with nursing major in the highest level of formal education.

Total includes NPs from other specialties in addition to those tabulated. 
TABLE III (CONTINUED)

\begin{tabular}{|c|c|c|c|c|c|c|c|c|c|c|c|c|c|c|c|}
\hline \multirow[b]{2}{*}{ Variable } & \multicolumn{2}{|c|}{ TOTAL } & \multicolumn{2}{|c|}{ ANP } & \multicolumn{2}{|c|}{ WHCNP } & \multicolumn{2}{|c|}{ FNP } & \multicolumn{2}{|c|}{ PMHNP } & \multicolumn{2}{|c|}{ PNP } & & \multicolumn{2}{|c|}{$N M$} \\
\hline & $n$ & $x$ & $n$ & $\%$ & $n$ & $\phi$ & $n$ & $\Phi$ & $n$ & 8 & $n$ & & & $n$ & $\%$ \\
\hline
\end{tabular}

Years of Practice as RN before Becoming NP

$\begin{array}{lcccccccccccccc}0 \text { through 9 } & 228 & 59.7 & 36 & 55.3 & 37 & 67.2 & 42 & 50.7 & 25 & 49.1 & 29 & 59.2 & 23 & 67.6 \\ 10 \text { through } 19 & 111 & 29.1 & 22 & 33.9 & 13 & 23.5 & 8 & 15.3 & 21 & 41.3 & 15 & 30.5 & 8 & 23.4 \\ 20 \text { through } 29 & 33 & 9.7 & 4 & 6.1 & 4 & 7.2 & 2 & 3.8 & 5 & 9.8 & 4 & 8.1 & 3 & 8.8 \\ 30 \text { through } 39 & 8 & 2.2 & 2 & 3.1 & 1 & 1.8 & 0 & 0.0 & 0 & 0.0 & 1 & 2.0 & 0 & 0.0 \\ 50 & 1 & 0.3 & 1 & 1.5 & 0 & 0.0 & 0 & 0.0 & 0 & 0.0 & 0 & 0.0 & 0 & 0.0\end{array}$

Years of Practice as Oregon NP

\begin{tabular}{|c|c|c|c|c|c|c|c|c|c|c|c|c|c|c|}
\hline 0 through 4 & 148 & 38.5 & 26 & 40.0 & 12 & 21.5 & 21 & 39.6 & 20 & 39.2 & 12 & 24.0 & 16 & 47.0 \\
\hline 5 through 9 & 165 & 43.1 & 27 & 41.6 & 27 & 48.2 & 22 & 41.5 & 27 & 53.0 & 20 & 40.0 & 15 & 44.1 \\
\hline 10 through 14 & 69 & 18.0 & 11 & 16.9 & 17 & 30.3 & 10 & 19.8 & 4 & 7.9 & 17 & 34.0 & 3 & 8.8 \\
\hline 15 through 19 & 2 & 0.6 & 1 & 1.5 & 0 & 0.0 & 0 & 0.0 & 0 & 0.0 & 1 & 2.0 & 0 & 0. \\
\hline
\end{tabular}


Level of Basic Nursing Education. Most of the NPs received their basic nursing education in baccalaureate nursing programs. The largest percentage (78\%) was found among the PNPS, with PMHNP $(69 \%)$ and NMs (62\%) next. Basic nursing education was acquired in a baccal aureate program by more than $60 \%$ of the NPS in general. Highest Level of Formal Education. Table III indicates that the highest level of education achieved by most (219) NPs was the master's degree (57\%). The largest number (102) were obtained between 1981 and 1986. With approximately 83\% having a master's degree and 10\% having a doctorate, the PMHNPS had the highest level of educational preparation, followed by ANPs $(68 \%$ master's and $2 \%$ doctorate) and FNPs (66\% master's). The WHCNPs ( $46 \%$ baccalaureate degree) and PNPS (42\% baccalaureate) had the lowest level of formal academic preparation. The doctorate degree had been awarded to 14 NPs overall, four of whom had majored in Nursing.

Years of Practice as an RN before Becoming NP. The majority of NPs had practiced as an RN for nine (or fewer) years before becoming an NP (60\%). For each of the six specialty groups, more respondents fell into the "0-9 years" category of practice as a registered nurse before becoming an NP than in any other experience category. In order from the least to the most years of prior experience, the specialties were: FNPS, NMS and WHCNPS, PNPS, ANPS, and PMHNPS.

Years of Practice as Oregon NP. As can be seen in Table III, $43 \%$ of the total sample had 5-9 years of Oregon practice; an 
additional $39 \%$ had less than five years of practice. With the exception of NMS, more respondents in each specialty group fell in the 5-9 years of practice as a NP in Oregon category than in any other experience category. The NMs had more respondents in the 0-4 years category. The NMS had the smallest number of years of practice as NPs in Oregon, followed by the PMHNPS. The most experienced NPS were the PNPS and WHCNPS, respectively.

\section{NP Preparation}

Table IV shows the preferences of the NPs for the order of educational development, their distribution by specialty areas, the type of NP program which prepared them for NP candidacy, and their continung NP education.

Preferred Sequence for NP Preparation. Over $80 \%$ preferred a baccalaureate degree, followed by a master's degree which qualifies for NP certification in a specialty area. This pattern was the choice of each specialty group, although about $21 \%$ of the ANPs preferred that the NP preparation follow a master's degree.

NP Specialty. All nine of the NP specialty areas were represented in the study. The ANPs, with 65 respondents were the most numerous, and the SHNPS, with 2 respondents, were the least numerous. The six most numerous specialty areas were selected for comparison with respect to selected functions.

Type of NP Program. Most NPs were products of master's degree NP programs (52\%); however, $42 \%$ were certificate prepared. The type of NP program varied across the specialties, with over $96 \%$ of the 
TABLE IV

NP PREPARATION REPORTED IN FREQUENCIES AND PERCENTAGES

Variable $\frac{\text { TOTAL }}{n} \frac{\text { ANP }}{n} \frac{\text { WHCNP }}{n} \frac{\text { FNP }}{n} \frac{\text { PMHNP }}{n} \frac{\text { PNP }}{n} \frac{\text { NM }}{n} \frac{\pi}{n}$

Preferred Sequence for NP Preparation

ADN, followed by NP,

followed by BS

$17 \quad 4.3 \quad 1 \quad 1.7$

10.4

BS, followed by MS,

followed by NP

53

$15.0 \quad 12 \quad 20.7$

BS, followed by MS which

includes NP

283

other

$30.2 \quad 45 \quad 77$.

2

NP Specialty

$\begin{array}{lllll}65 & 19.9 & 56 & 17.2 & 53\end{array}$

10.20

$\begin{array}{llll}0.0 & 1 & 2.1 & 2\end{array}$

6.3
Separated
Gerlatric (GNP)
(n) (x)
Coalth (CNHP) 6; $1.8 \%$
School Health (SHNP) 2; $0.6 \%$

Type of N Program

\begin{tabular}{lrrrrrrrrrrrrrr} 
Certificate & 162 & 42.0 & 22 & 33.5 & 45 & 30.4 & 16 & 30.2 & 0 & 0.0 & 30 & 60.0 & 14 & 41.2 \\
Baccalaureate & 9 & 2.3 & 0 & 0.0 & 0 & 0.0 & 4 & 7.5 & 1 & 1.9 & 3 & 6.0 & 0 & 0.0 \\
Master's & 200 & 51.8 & 39 & 60.0 & 8 & 14.3 & 32 & 60.4 & 50 & 96.2 & 17 & 34.0 & 17 & 50.0 \\
\hline
\end{tabular}


TABLE IV (CONTINUED)

\begin{tabular}{|c|c|c|c|c|c|c|c|c|c|c|c|c|c|c|}
\hline \multirow[b]{2}{*}{ Variable } & \multicolumn{2}{|c|}{ TOTAL } & \multicolumn{2}{|c|}{ ANP } & \multicolumn{2}{|c|}{ HHCNP } & \multicolumn{2}{|c|}{ FNP } & \multicolumn{2}{|c|}{ PMHNP } & \multicolumn{2}{|c|}{ PNP } & \multicolumn{2}{|c|}{ NM } \\
\hline & $\bar{n}$ & 8 & $n$ & $\%$ & $n$ & $\bar{x}$ & $n$ & $x$ & $n$ & 9 & $\bar{n}$ & $\%$ & $\bar{n}$ & $x$ \\
\hline
\end{tabular}

Yearly Particlpation in Continuing Education

$\begin{array}{lcccccccccccccc}\text { None } & 1 & 0.3 & 0 & 0.0 & 0 & 0.0 & 0 & 0.0 & 0 & 0.0 & 0 & 0.0 & 0 & 0.0 \\ \text { Once } & 5 & 1.3 & 1 & 1.5 & 0 & 0.0 & 2 & 3.8 & 1 & 1.9 & 0 & 0.0 & 0 & 0.0 \\ \text { Twice } & 35 & 9.1 & 5 & 7.7 & 5 & 8.9 & 5 & 9.4 & 7 & 13.5 & 3 & 6.0 & 1 & 2.9 \\ \text { Three times } & 60 & 15.5 & 6 & 9.2 & 10 & 17.9 & 9 & 17.0 & 13 & 25.0 & 7 & 14.0 & 3 & 23.5 \\ \text { Four or more times } & 285 & 73.8 & 53 & 51.5 & 41 & 73.2 & 37 & 69.8 & 31 & 59.6 & 40 & 80.0 & 25 & 73.5\end{array}$


PMHNPS, $60 \%$ of the FNPS and ANPS, and $50 \%$ of the NMS receiving their NP training in master's degree programs. Most of the WHCNPS and the PNPS received their formal NP training in certificate programs $180 \%$ and $60 \%$ respectively). About $94 \%$ of al1 NP programs were either certificate or master's degree.

Yearly Participation in Continuing Education. Continuing education relevant to the specialty area was acquired by most NPS at four or more events each year (74\%). In the specialties, ANPs and PNPS reported the most events attended and PMHNPs the fewest in continuing education.

\section{NP Practice}

Table $V$ includes the physical environment, population and location, estimated income of clients, and attitudes of the respondents toward their NP preparation and their satisfaction as an NP.

Major Setting. Table $V$ shows most NPs in Oregon practice in ambulatory (49\%) and non-hospital community (31\%) settings. Of the 265 responses from NPs in six specialty areas, 221 (83\%) reported major professional activity to be in the two types of settings. Most $(46 \%)$ of the settings were in a large city, with an additional $24 \%$ located in medium-sized cities. A majority of the ANPS (60\%) of the PMHNPs (59\%), and PNPs (52\%) practiced in large cities. Approximately $50 \%$ of the FNPs and $35 \%$ of the NMs practiced in small cities, towns or rural areas. Although the most frequently reported income level of the consumers was in the intermediate range $(30 \%)$, nearly half (49\%) of the NPs served persons whose incomes 
TABLE $V$

NP PRACTICE: SETtING SOCIO-ECONOMIC, AND ATTITUDINAL RESPONSES

\begin{tabular}{|c|c|c|c|c|c|c|c|c|c|c|c|c|c|c|}
\hline \multirow[b]{2}{*}{ Varlable } & \multicolumn{2}{|c|}{ TOTAL } & \multicolumn{2}{|c|}{ ANP } & \multicolumn{2}{|c|}{ WHCNP } & \multicolumn{2}{|c|}{ FNP } & \multicolumn{2}{|c|}{ PMHNP } & \multicolumn{2}{|c|}{ PNP } & \multicolumn{2}{|c|}{ NM } \\
\hline & $n$ & 8 & $n$ & $\bar{x}$ & $n$ & $\%$ & $n$ & $\bar{x}$ & $\bar{n}$ & 8 & $\bar{n}$ & $\%$ & $\bar{n}$ & $\%$ \\
\hline \multicolumn{15}{|l|}{ Major Setting } \\
\hline \multicolumn{15}{|l|}{ In Hospital Practice } \\
\hline Patlent unit & 11 & 3.4 & 2 & 3.3 & 0 & 0.0 & 0 & 0.0 & 3 & 5.8 & 1 & 2.2 & 3 & 11.5 \\
\hline Emergency unlt & 6 & 1.8 & 4 & 6.7 & 0 & 0.0 & 1 & 2.0 & 1 & 1.9 & 0 & 0.0 & 0 & 0.0 \\
\hline Other & 2 & 0.6 & 0 & 0.0 & 0 & 0.0 & 0 & 0.0 & 2 & 3.8 & 0 & 0.0 & 0 & 0.0 \\
\hline \multicolumn{15}{|l|}{ Ambulatory } \\
\hline Private & 77 & 23.7 & 10 & 16.7 & 13 & 25.5 & 15 & 30.0 & 12 & 23.1 & 10 & 22.2 & 8 & 30.8 \\
\hline Prepaid & 23 & 7.1 & 9 & 15.0 & 2 & 3.9 & 4 & 8.0 & 4 & 7.1 & 1 & 2.2 & 0 & 0.0 \\
\hline Hospltal & 44 & 13.5 & 15 & 25.0 & 7 & 13.7 & 4 & 8.0 & 4 & 7.7 & 6 & 13.3 & 2 & 7.7 \\
\hline Other & 14 & 4.3 & 3 & 5.0 & 0 & 0.0 & 6 & 12.0 & 1 & 1.9 & 2 & 4.4 & 1 & 3.9 \\
\hline \multicolumn{15}{|l|}{ Non-Hospital Institutional } \\
\hline $\begin{array}{l}\text { School for mentally or } \\
\text { physically handicapped }\end{array}$ & 2 & 0.6 & 0 & 0.0 & 0 & 0.0 & 0 & 0.0 & 0 & 0.0 & 1 & 2.2 & 0 & 0.0 \\
\hline Grades $1-12$ school system & 1 & 0.3 & 0 & 0.0 & 0 & 0.0 & 0 & 0.0 & 0 & 0.0 & 0 & 0.0 & 0 & 0.0 \\
\hline College & 15 & 4.6 & 4 & 6.7 & 6 & 11.8 & 0 & 0.0 & 0 & 0.0 & 1 & 2.2 & 0 & 0.0 \\
\hline Other & 5 & 1.5 & 3 & 5.0 & 0 & 0.0 & 1 & 2.0 & 1 & 1.9 & 0 & 0.0 & 0 & 0.0 \\
\hline
\end{tabular}


TABLE $V$ (CONTINUED)

Variable $\frac{\text { TOTAL }}{n} \frac{\text { ANP }}{n} \frac{\text { WHCNP }}{n} \frac{\text { FNP }}{n} \frac{\text { PMHNP }}{n} \frac{\text { PNP }}{n} \frac{\text { NM }}{n} \frac{\pi}{n}$

Non-Hospital Community

Health department or home health agency

63

School services or agency 11

$63 \quad 19.4$

other

27

19.40

0.0

$\begin{array}{llll}3.4 & 1 & 1.7 & 0\end{array}$

39.2

16.

$\begin{array}{rrrrrrr}.0 & 6 & 11.5 & 17 & 37.8 & 8 & 30.8 \\ .0 & 0 & 0.0 & 5 & 11.1 & 0 & 0.0 \\ .0 & 14 & 26.9 & 0 & 0.0 & 1 & 3.8\end{array}$

School of Nursing

\begin{tabular}{|c|c|c|c|c|c|c|c|c|c|c|c|c|c|c|}
\hline Hospltal & 1 & 0.3 & 0 & 0.0 & 0 & 0.0 & $\mathbf{0}$ & 0.0 & 0 & 0.0 & 0 & 0.0 & 0 & 0.0 \\
\hline Associate Degree & 2 & 0.6 & 0 & 0.0 & 0 & 0.0 & 0 & 0.0 & 0 & 0.0 & 0 & 0.0 & 0 & 0.0 \\
\hline Baccalaureate degree & 5 & 1.5 & 0 & 0.0 & 0 & 0.0 & 1 & 2.0 & 0 & 0.0 & 0 & 0.0 & 0 & 0.0 \\
\hline Master's degree & 3 & 0.9 & 0 & 0.0 & 0 & 0.0 & 0 & 0.0 & 0 & 0.0 & 1 & 2.2 & 1 & 3.8 \\
\hline Vocation & 2 & 0.6 & 0 & 0.0 & 0 & 0.0 & 0 & 0.0 & 0 & 0.0 & 0 & 0.0 & 0 & .0 \\
\hline
\end{tabular}

Extended Care Facility

Nursing

HMO

other
1

\begin{tabular}{rrrrrrrrrrrrr}
3.4 & 0 & 0.0 & 0 & 0.0 & 2 & 4.0 & 1 & 1.9 & 0 & 0.0 & 0 & 0.0 \\
& 1 & 1.7 & 1 & 2.0 & 0 & 0.0 & 0 & 0.0 & 0 & 0.0 & 0 & 0.0 \\
& 1 & 1.7 & 0 & 0.0 & 0 & 0.0 & 1 & 1.9 & 0 & 0.0 & 0 & 0.0 \\
\hline
\end{tabular}


TABLE $\vee$ (CONTINUED)

\begin{tabular}{|c|c|c|c|c|c|c|c|c|c|c|c|c|c|c|}
\hline \multirow[b]{2}{*}{ Variable } & \multicolumn{2}{|c|}{ TOTAL } & \multicolumn{2}{|c|}{ ANP } & \multicolumn{2}{|c|}{ WHCNP } & \multicolumn{2}{|c|}{ FNP } & \multicolumn{2}{|c|}{ PMHNP } & \multicolumn{2}{|c|}{ PNP } & \multicolumn{2}{|c|}{ NM } \\
\hline & $n$ & $\%$ & $\mathbf{n}$ & $\mathscr{x}$ & $\mathbf{n}$ & $x$ & $n$ & $x$ & $n$ & $\boldsymbol{x}$ & $n$ & $\not$ & $\bar{n}$ & $\%$ \\
\hline
\end{tabular}

Population and Location of Practice Setting

\begin{tabular}{|c|c|c|c|c|c|c|c|c|c|c|c|c|c|c|}
\hline Rural $(2,500$ or less $)$ & 19 & 5.5 & 3 & 4.6 & 1 & 1.9 & 3 & 15.4 & 2 & 3.9 & 2 & 4.0 & 0 & 0.0 \\
\hline $\begin{array}{l}\text { Medium-sized city } \\
(25,001 \quad 100,000)\end{array}$ & B2 & 23.6 & 10 & 15.4 & 20 & 37.0 & 9 & 17.3 & 10 & 19.6 & 13 & 26.0 & 9 & 26.5 \\
\hline Large clty (over 100,000 ) & 161 & 46.4 & 39 & 60.0 & 18 & 35.3 & 18 & 34.6 & 30 & 58.8 & 26 & 52.0 & 13 & 38.2 \\
\hline
\end{tabular}

Economlc Level of Majorlty of Patients

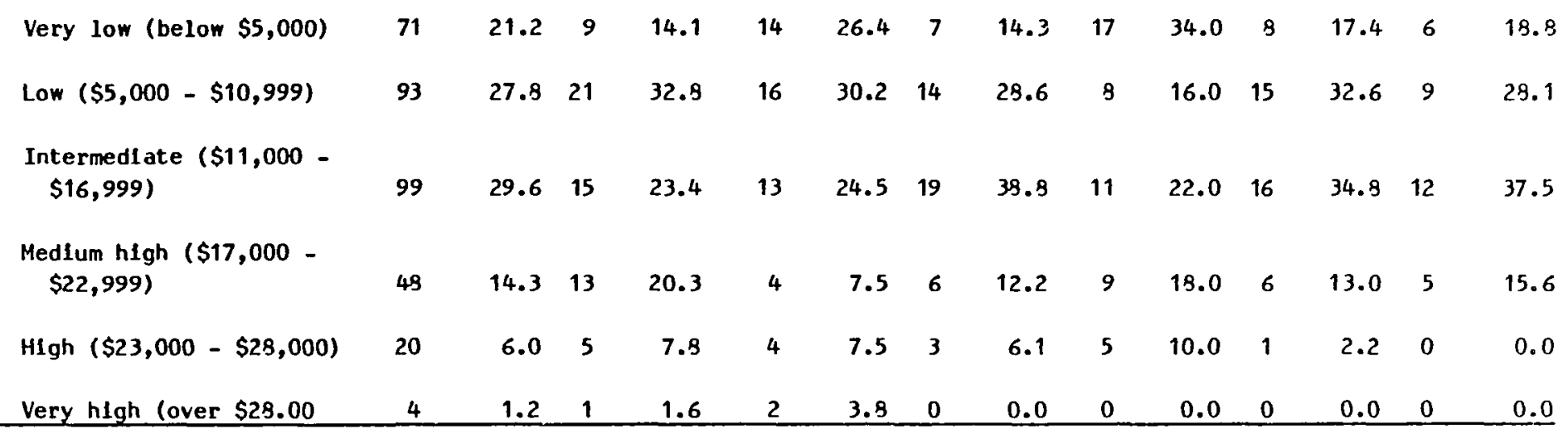


TABLE $V$ (CONTINUED)

Variable $\frac{\text { TOTAL }}{n} \frac{\text { ANP }}{n} \frac{\text { WHCNP }}{n} \frac{\text { FNP }}{n} \frac{\text { PMHNP }}{n} \frac{\text { PNP }}{n} \frac{\text { NM }}{n} \frac{x}{n}$

Attitudes

Adequacy of NP Preparation

\begin{tabular}{|c|c|c|c|c|c|c|c|c|c|c|c|c|c|c|}
\hline Very Inadequate & 11 & 2.5 & 3 & 4.6 & 1 & 1.8 & 1 & 1.9 & 2 & 3.8 & 1 & 2.0 & 1 & 2.9 \\
\hline Inadequate & 22 & 5.7 & 9 & 13.8 & 0 & 0.0 & 2 & 3.9 & 5 & 9.6 & 1 & 2.0 & 0 & 0.0 \\
\hline Somewhat adequate & 98 & 25.4 & 23 & 35.4 & 10 & 17.9 & 13 & 24.5 & 14 & 26.9 & 14 & 29.0 & 5 & 14.7 \\
\hline Adequate & 151 & 39.1 & 20 & 30.8 & 24 & 42.9 & 25 & 47.2 & 20 & 39.5 & 22 & 44.0 & 11 & 32.4 \\
\hline Very adequate & 104 & 26.9 & 10 & 15.4 & 21 & 37.5 & 12 & 22.6 & 11 & 21.2 & 12 & 24.0 & 17 & 50.0 \\
\hline
\end{tabular}

Amount of NP Preparation Used in Practice Setting

\begin{tabular}{lrrrrrrrrrrrrrrrrr} 
None & 2 & 0.5 & 1 & 1.5 & 0 & 0.0 & 0 & 0.0 & 0 & 0.0 & 0 & 0.0 & 0 & 0.0 \\
Few & 9 & 2.4 & 3 & 4.6 & 0 & 0.0 & 0 & 0.0 & 3 & 5.9 & 0 & 0.0 & 0 & 0.0 \\
Some & 67 & 17.6 & 15 & 23.1 & 4 & 7.1 & 9 & 17.6 & 19 & 35.3 & 8 & 16.3 & 2 & 5.9 \\
Most & 197 & 51.8 & 34 & 52.3 & 26 & 46.4 & 31 & 60.8 & 20 & 39.2 & 31 & 63.3 & 19 & 55.9 \\
Al1 & 105 & 27.6 & 12 & 19.5 & 26 & 46.4 & 11 & 21.6 & 10 & 19.6 & 10 & 20.4 & 13 & 39.2 \\
\hline
\end{tabular}


TABLE $\vee$ (CONTINUED)

Varlable $\frac{\text { TOTAL }}{n} \frac{\text { ANP }}{n} \frac{\text { WHCNP }}{n} \frac{\text { FNP }}{n} \frac{\text { PMHNP }}{n} \frac{\text { PNP }}{n} \frac{\text { NM }}{n} \frac{\phi}{\phi}$

Sat isfaction with Responsibilities

\begin{tabular}{|c|c|c|c|c|c|c|c|c|c|c|c|c|c|c|}
\hline Very dissatisfled & 9 & 2.4 & 2 & 3.1 & 2 & 3.6 & $\mathbf{0}$ & 0.0 & 1 & 2.0 & 3 & 6.0 & 0 & 0.0 \\
\hline Somewhat dissatisfled & 29 & 7.8 & 4 & 6.2 & 3 & 5.4 & 2 & 7.7 & 5 & 10.0 & 2 & 4.0 & 3 & 8.8 \\
\hline Indlfferent & 6 & 1.6 & 0 & 0.0 & 1 & 1.8 & 0 & 0.0 & 2 & 4.0 & 1 & 2.0 & 0 & 0.0 \\
\hline Somewhat satisfied & 132 & 35.4 & 29 & 44.6 & 22 & 39.3 & 4 & 25.0 & 19 & 39.0 & 19 & 39.0 & 9 & 26.5 \\
\hline Very satisfied & 197 & 52.8 & 30 & 46.2 & 28 & 50.0 & 5 & 67.3 & 23 & 46.0 & 25 & 50.0 & 22 & 64.7 \\
\hline
\end{tabular}

Satisfaction with Independence and Autonomy

\begin{tabular}{lcccccccccccccc} 
Very dissatisfied & 10 & 2.7 & 3 & 4.6 & 2 & 3.6 & 0 & 0.0 & 2 & 3.8 & 2 & 4.1 & 0 & 0.0 \\
Somewhat dissatisfied & 24 & 6.4 & 3 & 4.6 & 3 & 5.4 & 1 & 1.9 & 4 & 7.7 & 3 & 6.1 & 3 & 3.8 \\
Indifferent & 9 & 2.4 & 0 & 0.0 & 1 & 1.5 & 0 & 0.0 & 3 & 5.8 & 2 & 4.1 & 0 & 0.0 \\
Somewhat satisfied & 103 & 23.9 & 19 & 29.2 & 14 & 25.0 & 15 & 23.9 & 12 & 23.1 & 14 & 29.6 & 9 & 26.5 \\
Very satisfied & 223 & 59.6 & 40 & 61.5 & 36 & 64.3 & 36 & 69.2 & 31 & 59.6 & 28 & 57.1 & 22 & 64.7 \\
\hline
\end{tabular}


were estimated to be low or very low. More than a third $(34 \%)$ of the PMHNPS reported the consumers of their services to have a very low income level.

Attitudes. Most of the NPs (66\%) found their preparation to have been adequate or very adequate to meet their responsibilities in the practice setting. The least satisfied were the ANPs, with $18 \%$ expressing inadequate and very inadequate views and an additional 35\% indicating somewhat adequate; the most satisfied were the MMs, with a majority selecting very adequate (50\%). Most (52\%) NPS used most (but not all) of the expertise from their preparatory experience in the practice setting. An additional $28 \%$ used all of their preparatory experience in practice. The PMHNPs indicated the least use of their NP preparation (with $35 \%$ selecting "some"), while the WHCNPS and NMS indicated the greatest use, with $46 \%$ and $38 \%$ respectively, selecting "al1." The majority of NPS were very satisfied with their responsibilities and independence and autonomy (53\% and $60 \%$, respectively).

\section{SELECTEO FUNCTION OF NURSE PRACTITIONERS}

Five categories from the NP scope of practice (OAR, 1980, 851-30-001) are provided for purposes of analysis and discussion. The 40 functions in Part 3 of the questionnaire (see Appendix B) are categorized as follows:

A. Health promotion and maintenance (functions numbered 24, $33,15,17,27,20,16,32,34,6$, and 5$)$; 
B. Management of health care (functions numbered $7,40,30$, $11,26,28,14,31,35,3,9,13,37,29$, and 25);

C. Treatment in collaboration (functions numbered 4, 2, 8, and 21);

D. Prevention of illness and disability (functions numbered $10,12,19,22$, and 23); and,

E. Guidance and counseling (functions numbered 1, 18, 38, 39, and 36$)$.

The functions were selected from instruments developed by researchers who have investigated NPs outside of Oregon (Drice, 1978; Warren, 1979). The functions were presented in the questionnaire in a sequence similar to the original design. For purposes of discussion, the functions were distributed, analyzed, and compared (by function number and/or description) in terms of the scope of practice of Oregon-certified NPs. The functions are discussed with respect to the NP respondents as whole and to the respondents in six NP specialties. Due to the amount of detail in the tables, attention will be directed only to major points in each table. Some details from the tables are included in the discussion to clarify statistical procedures. In the instances where reference is made to a series of descriptors, the separated values will appear in the same sequence as the series.

\section{Chi-square Testing of NP Specialty Areas}

For each function, a cross-tabulation of the levels of the function with the six specialty groups was performed separately for 
"Level of Competency," "Frequency of Use," and "Place in NP Preparation." Chi-Square was used to test for the independence of specialty area and function. The .05 level was selected to determine statistical significance for each test. Throughout the analysis and discussion, the significance of relationships was found at the $95 \%$ level of confidence in the accuracy of the finding. When using the chi-square in a test of independence for twoway tables with degrees of freedom greater than one, no more than $20 \%$ of the expected rall frequencies should be less than five (and none less than one). In the analyses using NP specialty as one variable and either "Level of Competency" or "Frequency of Use" of a function as the other variable, sometimes two or more adjacent categories of the second variable needed to be combined in order to meet this criterion for minimum expected frequency. Because the categories of "Place in NP Preparation" could not be combined logically, selections with low expected frequencies were excluded from the analysis as needed to meet the criterion.

Health Promotion and Maintenance

The results of the analyses of the Health Promotion and Maintenance functions are presented in this section for the total sample and for the six specialty groups.

Total Sample. Table VI shows that for this category in "Level of Competency," a majority (73\%) of NPs felt "Very Competent" in the "Performance of a general physical examination in the absence of a physician," (function 24). Also most nurse practitioners (54\%) felt 
TABLE VI

PERCENTACE OF RESPONSES BY HEALTH PROMOTION AND MAINTENANCE FUNCTIONS

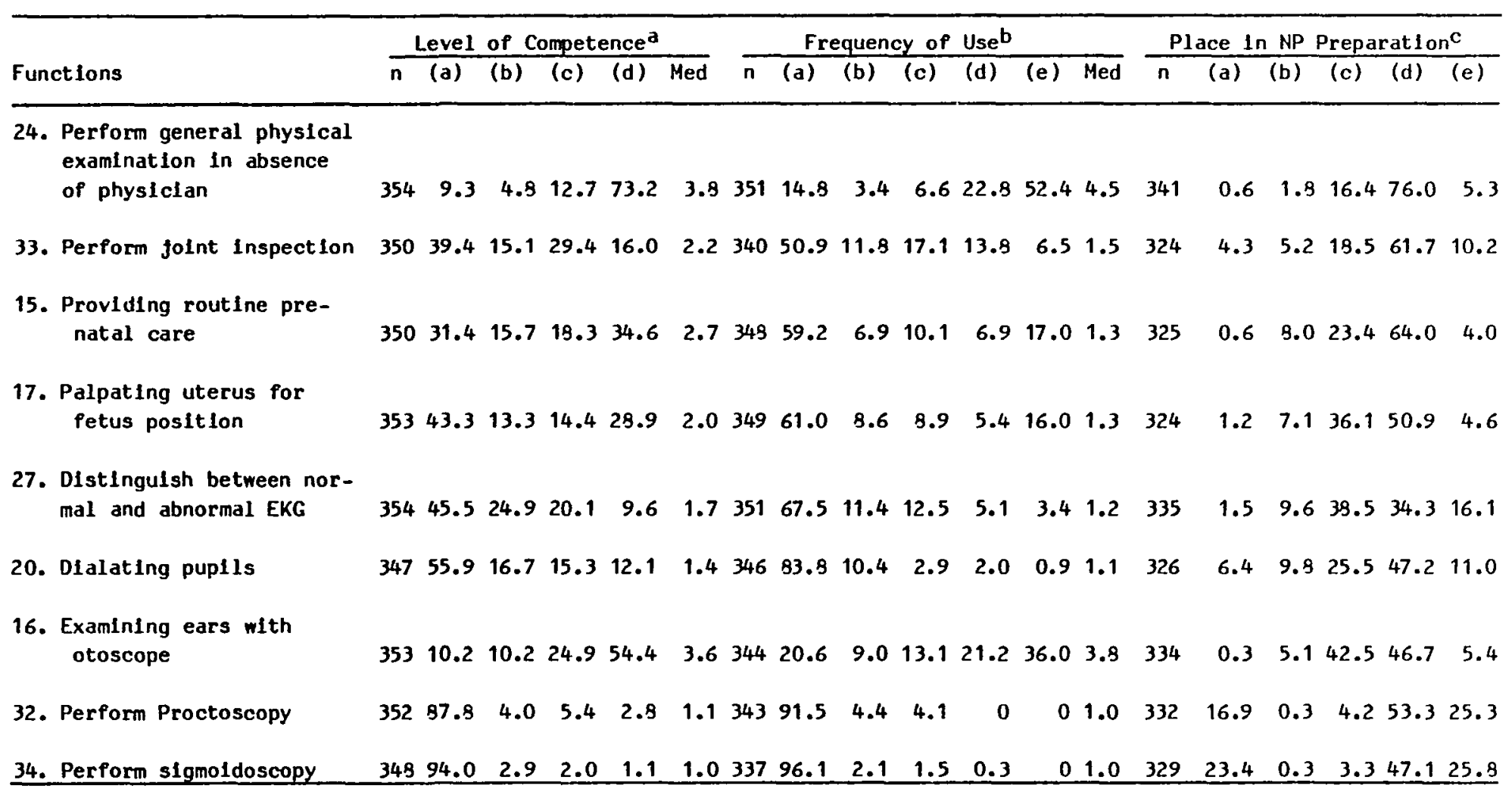


TABLE VI (CONTINUED)

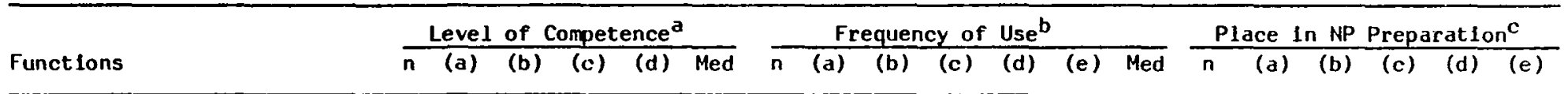

6. Defending what you con-

sider a patlent's rights

when this conflicts with

an Institutional or

agency pollcy

$\begin{array}{lllllllllllllllllll}354 & 2.3 & 9.9 & 44.6 & 43.2 & 3.3 & 353 & 13.0 & 38.0 & 32.0 & 11.9 & 5.1 & 2.5 & 331 & 0.6 & 17.8 & 49.2 & 26.3 & 6.0\end{array}$

5. Serving as a catalyst

for needed health care

changes

Note: Med $=$ Median

aLevel of Competence

(a) Do not feel competent at this time

(b) Feel slightly competent

(c) Feel moderately competent

(d) Feel very competent

$b_{\text {Frequency of Use }}$

(a) Never-l1ttle or no need to use the function

(b) Rarely-monthly

(c) Occasionally-a few times a month

(d) Frequently-several times weekly or every day

(e) All the time-several times every day
Cplace in NP Preparation

(a) Should NOT be included in NP Preparation

(b) Associate programs

(c) Baccalaureate programs

(d) Graduate degree programs

(e) Continuing education Includes courses, seminars, conferences, etc. 
"Very Competent" in "Examining ears with otoscope" (function 15). As a group most of the nurse practitioners judged themselves to be "Very Competent" or "Moderately Competent" in five of the eleven functions in this category: functions $24(86 \%), 16(79 \%), 6(88 \%)$, $5(82 \%)$, and $15(53 \%)$.

They did not feel competent to "Perform sigmoidoscopy" (function $34--94 \%$ ), to "Perform proctoscopy" (function $32--88 \%$ ), and in "Dialating pupils (function 20 -- 56\%). They judged themselves to have slight or little competence on six fuctions: $34(97 \%), 32$ $(92 \%), 20(73 \%), 27(70 \%), 17(57 \%)$, and $33(55 \%)$.

Function 24 ("Perform general physical examination in absence of a physician") was the most frequently used of these functions by the NPS; $52 \%$ reported using it "Several times each day" and an additional 23\% reported using it "Several times each week." The other frequentiy performed function (16, "Examining ears with otoscope") was reported to be used "Several times a day" by $36 \%$ of the respondents to that function in that column; and additional $21 \%$ indicated frequent usage ("Several times a week").

The functions used least often ("Never-little") were: functions 34 ("Perform sigmoidoscopy"), 32 ("Perform protoscopy"), 20 ("Dilating pupils"), 27 ("Distinguish between normal and abnormal EKG"), functions 17 ("Palpating uterus for fetal position"), 15 ("Providing routine prenatal care"), and 33 ("Perform joint inspection") as indicated by $96 \%, 92 \%, 84 \%, 68 \%, 61 \%, 59 \%$, and $51 \%$ of the NP respondents. 
The functions which the NPs considered themselves to be more competent to perform (functions 24 and 16) were those most frequently used. The functions they identified as least competent to use (functions $34,32,20,27,17$, and 33 ) were least frequently used.

In considering the "Place in NP Preparation" in which these functions belong, a majority of the respondents placed five of the functions in graduate degree programs: "Perform general physical examination in absence of physician" (function 24 -- 76\%); "Perform joint inspection" (function 33 -- 62\%); "Providing routine prenatal care" (function 15 -- 64\%); "Perform protoscopy" (function 32 -53\%); and "Palpating uterus for fetal position" (function 17 -51\%). Except for function 32 which was assigned to continuing education by most of the remaining respondents, the second most used category for the above functions was baccalureate programs. Two additional functions were assigned to graduate degree programs more of ten than any other program: "Examining ears with otoscope" (function $16--47 \%$ ) and "Perform sigmoidoscopy" (function $34=47 \%$ ). However, nearly as many (43\%) considered baccalaureate programs the appropriate location for function 16 . The respondents assigned three functions more often to baccalaureate programs: "Defending what you consider a patient's rights when this conflicts with an institutional or agency policy" (function 6 -- 49\%); "Serving as a catalyst for needed health care changes" (function 5 -- 44\%); and, "Distinguish between normal and abnormal EKG" (function 27 -- 39\%). For these three functions, graduate programs were the second most frequently chosen place of major emphasis. 
Thus, all of the 11 functions in the category of Health Promotion and Maintenance were recominended by the NPS to receive major emphasis in the Baccalaureate or Graduate nurse programs. No function was selected for omission from their programs by a majority of the NPs. However, the most recommendations (23\% and $17 \%$, respectively) for omission were received by functions 34 and 32 ("Perform sigmoidoscopy" and "Perform proctoscopy"). The fewest recommendations $(0.3 \%)$ for omission were received by function 5 , "Serving as a catalyst...."

Some NPs chose "Associate degree nurse programs" (ADN) to provide major emphasis in the development of competencies associated with the promotion and maintenance of health. The function 6 ("Defending...patient's rights") was chosen by $18 \%$ of the NPs to receive majort emphasis in ADN programs. Each function in the category was chosen by at least one NP to be emphasized in ADN and continuing education programs.

The functions 32 and 34 were chosen by at least $25 \%$ of the NPS to receive a major emphasis in continuing education programs. Also these functions were noted as rarely used by most (over 90\%) of the NPs. The same functions received "Not competent" indicators from more than $87 \%$ of the NPs.

Percentage of Responses by Specialty Areas to Heaith Promotion and Maintenance Functions. In Table VII the responses by NPs in six specialties to the 11 functions in this category are presented with respect to three dimensions or columns: Level of competency, Frequency of use, and Place in NP preparation. Choices are represented 
TABLE VII

PERCENTACE OF RESPONSES BY SPECIALTY AREAS TO HEALTH PROMOTION AND MAINTENANCE FUNCTIONS

\begin{tabular}{|c|c|c|c|c|c|c|c|c|c|c|c|c|c|c|c|c|c|c|c|}
\hline \multirow{2}{*}{$\begin{array}{l}\text { Specialty } \\
\text { Area }\end{array}$} & \multicolumn{6}{|c|}{ Level of Competence ${ }^{a}$} & \multicolumn{7}{|c|}{ Frequency of Use ${ }^{b}$} & \multicolumn{6}{|c|}{ Place In NP Preparation ${ }^{c}$} \\
\hline & $n$ & (a) & (b) & (c) & (d) & Med & $n$ & (a) & (b) & (c) & (d) & (e) & Med & $n$ & (a) & (b) & (c) & (d) & (e) \\
\hline \multicolumn{20}{|c|}{ Perform } \\
\hline ANP & 64 & 0 & 3.1 & 20.3 & 76.6 & 3.9 & 65 & 7.7 & 3.1 & 7.7 & 33.8 & 47.7 & 4.4 & 63 & 1.6 & 0 & 12.7 & 92.5 & 3.2 \\
\hline WHCNP & 55 & 1.8 & 1.8 & 14.5 & 31.8 & 3.9 & 55 & 1.8 & 1.8 & 10.9 & 18.2 & 67.3 & 4.8 & 51 & $\mathbf{0}$ & 2.0 & 31.4 & 56.9 & 9.8 \\
\hline FNP & 52 & 1.9 & 0 & 7.7 & 90.4 & 3.9 & 52 & 1.9 & 1.9 & 1.9 & 32.7 & 61.5 & 4.7 & 52 & 0 & 1.9 & 11.5 & 82.7 & 3.5 \\
\hline PMHNP & 51 & 58.8 & 23.5 & 13.7 & 3.9 & 1.4 & 50 & 84.0 & 12.0 & 2.0 & 2.0 & 0 & 1.1 & 45 & 2.2 & 0 & 4.4 & 91.1 & 2.2 \\
\hline$P N P$ & 50 & 0 & 0 & 10.0 & 90.0 & 3.9 & 50 & 0 & 0 & 8.0 & 22.0 & 70.0 & 4.8 & 50 & 0 & 2.0 & 28.0 & 66.0 & 4.0 \\
\hline NM & 33 & 0 & 0 & 12.1 & 87.9 & 3.9 & 31 & 0 & 3.2 & 9.7 & 12.9 & 74.2 & 4.8 & 31 & 0 & 3.2 & 22.6 & 74.2 & 0 \\
\hline \multicolumn{20}{|c|}{ Perform folnt inspection (function no. 33) } \\
\hline ANP & 63 & 9.5 & 19.0 & 44.4 & 27.0 & 3.0 & 63 & 20.6 & 23.8 & 22.2 & 17.5 & 15.9 & 2.8 & 60 & 1.7 & 5.0 & 20.0 & 61.7 & 11.7 \\
\hline WHCNP & 55 & 67.3 & 20.0 & 9.1 & 3.6 & 1.2 & 53 & 84.9 & 5.7 & 5.7 & 3.8 & 0 & 1.1 & 47 & 4.3 & 4.3 & 17.0 & 53.2 & 21.3 \\
\hline FNP & 51 & 7.8 & 11.8 & 41.2 & 39.2 & 3.2 & 51 & 13.7 & 13.7 & 29.4 & 27.5 & 15.7 & 3.3 & 50 & 2.0 & 4.0 & 20.0 & 68.0 & 6.0 \\
\hline PMHNP & 51 & $\$ 4.3$ & 9.8 & 5.9 & 0 & 1.1 & 47 & 93.6 & 4.3 & 2.1 & 0 & 0 & 1.0 & 43 & 9.3 & 2.3 & 23.3 & 60.5 & 4.7 \\
\hline PNP & 47 & 25.5 & 14.9 & 51.1 & 8.5 & 2.7 & 46 & 41.3 & 19.6 & 21.7 & 17.4 & 0 & 1.9 & 45 & 6.7 & 6.7 & 12.6 & 62.2 & 9.9 \\
\hline$N$ & 34 & 70.6 & 23.5 & 5.9 & 0 & 1.2 & 32 & 93.8 & 3.1 & 3.1 & 0 & 0 & 1.0 & 33 & 0 & 6.1 & 6.1 & 78.8 & 9.1 \\
\hline
\end{tabular}


TABLE VII (CONTINUED)

\begin{tabular}{|c|c|c|c|c|c|c|c|c|c|c|c|c|c|c|c|c|c|c|c|}
\hline \multicolumn{2}{|c|}{ Specialty } & \multicolumn{5}{|c|}{ Level of Competence ${ }^{\mathrm{a}}$} & \multicolumn{7}{|c|}{ Frequency of Use ${ }^{b}$} & \multicolumn{6}{|c|}{ Place In NP Preparationc } \\
\hline Area & $n$ & (a) & (b) & (c) & (d) & Med & $n$ & (a) & (b) & (c) & (d) & (e) & $\overline{\text { Med }}$ & $\bar{n}$ & (a) & (b) & (c) & (d) & (e) \\
\hline \multicolumn{20}{|c|}{ Providing routine prenatal care (function no. 15) } \\
\hline ANP & 63 & 54.0 & 28.6 & 7.9 & 9.5 & 1.4 & 63 & 31.0 & 9.5 & 4.8 & 3.2 & 1.6 & 1.1 & 59 & 0 & 5.1 & 25.4 & 67.8 & 1.7 \\
\hline HHCNP & 55 & $\mathbf{0}$ & 5.5 & 25.5 & 69.1 & 3.8 & 54 & 31.5 & 9.3 & 14.8 & 11.1 & 33.3 & 3.1 & 48 & 0 & 10.4 & 22.9 & 62.5 & 4.2 \\
\hline FNP & 51 & 3.9 & 9.8 & 41.2 & 45.1 & 3.4 & 51 & 31.4 & 15.7 & 27.5 & 15.7 & 9.8 & 2.6 & 50 & 0 & 2.0 & 12.0 & 80.0 & 6.0 \\
\hline PMHNP & 50 & 68.0 & 26.0 & 6.0 & 0 & 1.2 & 49 & 100.0 & 0 & 0 & 0 & $c$ & 1.0 & 46 & 2.2 & 15.2 & 39.1 & 41.3 & 2.2 \\
\hline PNP & 50 & 56.0 & 18.0 & 20.0 & 6.0 & 1.4 & 50 & 92.0 & 4.0 & 4.0 & 0 & 0 & 1.0 & 47 & 2.1 & 2.1 & 27.7 & 59.6 & 9.5 \\
\hline$N M$ & 33 & 0 & 0 & 3.0 & 97.0 & 4.0 & 34 & 5.9 & 2.9 & 2.9 & 5.8 & 79.4 & 4.9 & 29 & 0 & 6.9 & 6.9 & 86.2 & 0 \\
\hline \multicolumn{20}{|c|}{ Palpating uterus for fetal position (function no. 17) } \\
\hline ANP & 64 & 70.3 & 15.6 & 10.9 & 3.1 & 1.2 & 63 & 37.3 & 4.8 & 6.3 & 1.6 & 0 & 1.1 & 58 & 3.4 & 5.2 & 44.8 & 43.1 & 3.4 \\
\hline HHCNP & 55 & 3.6 & 7.3 & 29.1 & 60.0 & 3.7 & 54 & $3 i .5$ & 7.4 & 19.5 & 9.3 & 33.3 & 3.1 & 45 & 0 & 13.3 & 31.1 & 46.7 & 8.9 \\
\hline FNP & 51 & 9.8 & 27.5 & 37.3 & 25.5 & 2.8 & 51 & 37.3 & 21.6 & 21.6 & 13.7 & 5.9 & 2.1 & 49 & 0 & 3.2 & 32.7 & 53.1 & 6.1 \\
\hline PMHNP & 51 & 92.4 & 11.8 & 5.9 & 0 & 1.1 & 50 & 100.0 & 0 & 0 & 0 & 0 & 1.0 & 49 & 2.1 & 8.3 & 45.8 & 39.6 & 4.2 \\
\hline PNP & 50 & 30.0 & 16.0 & 4.0 & 0 & 1.1 & 50 & 94.0 & 6.0 & 0 & 0 & 0 & 1.0 & 49 & 2.1 & 2.1 & 37.5 & 56.3 & 2.1 \\
\hline MM & 34 & 0 & 0 & 0 & 100.0 & 4.0 & 34 & 2.9 & 9.8 & 11.8 & 0 & 76.5 & 4.8 & 31 & 0 & 3.2 & 32.3 & 64.5 & 0 \\
\hline
\end{tabular}


TABLE VII (CONTINUED)

\begin{tabular}{|c|c|c|c|c|c|c|c|c|c|c|c|c|c|c|c|c|c|c|c|}
\hline \multirow{2}{*}{$\begin{array}{l}\text { Specfalty } \\
\text { Area }\end{array}$} & \multirow{2}{*}{$n$} & \multicolumn{5}{|c|}{ Level of Competence ${ }^{a}$} & \multicolumn{7}{|c|}{ Frequency of Use ${ }^{b}$} & \multicolumn{6}{|c|}{ Place in NP Preparatlon $\mathrm{c}$} \\
\hline & & (a) & (b) & (c) & (d) & Med & $\bar{n}$ & (a) & (b) & (c) & (d) & (e) & Med & $\bar{n}$ & (a) & (b) & (c) & (d) & (e) \\
\hline \multicolumn{20}{|c|}{ Distingulsh between normal and abnormal EKG (function no. 27) } \\
\hline ANP & 65 & 10.8 & 27.7 & 38.5 & 23.1 & 2.8 & 65 & 27.7 & 16.9 & 29.2 & 16.9 & 9.2 & 2.7 & 64 & 0 & 7.8 & 42.2 & 31.3 & 18.8 \\
\hline WHCNP & 56 & 53.6 & 28.6 & 12.5 & 5.4 & 1.4 & 56 & 92.9 & 3.6 & 3.6 & 0 & 0 & 1.0 & 49 & 0 & 19.8 & 39.6 & 25.0 & 16.7 \\
\hline FNP & 52 & 13.5 & 34.6 & 36.5 & 15.4 & 2.6 & 52 & 39.5 & 26.9 & 19.2 & 11.5 & 3.8 & 1.9 & 51 & 2.0 & 3.9 & 33.3 & 39.2 & 21.6 \\
\hline PMHNP & 51 & 70.6 & 17.6 & 7.8 & 3.9 & 1.2 & 50 & 88.0 & 10.0 & 2.0 & 0 & 0 & 1.1 & 46 & 2.2 & 2.2 & 45.7 & 45.7 & 4.3 \\
\hline PNP & 49 & 63.3 & 26.5 & B.2 & 2.0 & 1.3 & 49 & 87.8 & 8.2 & 2.0 & 0 & 2.0 & 1.1 & 49 & 2.1 & 6.3 & 39.6 & 33.3 & 15.8 \\
\hline$N M$ & 34 & 79.4 & 11.8 & 8.8 & 0 & 1.1 & 32 & 100.0 & 0 & 0 & 0 & 0 & 1.0 & 33 & 0 & 15.2 & 27.3 & 45.5 & 12.1 \\
\hline \multicolumn{20}{|c|}{ Dilating Puplls (function no. 20) } \\
\hline ANP & 64 & 42.2 & 15.6 & 28.1 & 14.1 & 2.0 & 64 & 73.4 & 20.3 & 4.7 & 1.6 & 0 & 1.2 & 61 & 4.9 & 8.2 & 18.0 & 55.7 & 13.1 \\
\hline WHCNP & 54 & 72.2 & 11.1 & 7.4 & 9.3 & 1.2 & 54 & 96.3 & 1.9 & 1.9 & 0 & 0 & 1.0 & 44 & 6.8 & 15.9 & 20.5 & 40.9 & 15.9 \\
\hline FNP & 50 & 26.0 & 30.0 & 26.0 & 18.0 & 2.3 & 51 & 74.5 & 19.6 & 3.9 & 2.0 & 0 & 1.2 & 51 & 11.8 & 13.7 & 21.6 & 41.2 & 11.8 \\
\hline PMHNP & 49 & 69.4 & 22.4 & 4.1 & 4.1 & 1.2 & 48 & 95.8 & 4.2 & 0 & 0 & 0 & 1.0 & 45 & 4.4 & 11.1 & 40.0 & 44.4 & 0 \\
\hline PNP & 48 & 60.4 & 14.6 & 20.8 & 4.2 & 1.3 & 49 & 37.5 & 8.3 & 2.1 & 2.1 & 1.1 & 1.1 & 49 & 6.3 & 10.4 & 33.3 & 37.5 & 12.5 \\
\hline NM & 34 & 79.4 & 5.9 & 0 & 14.7 & 1.1 & 34 & 85.3 & 2.9 & 5.9 & 2.9 & 2.9 & 1.1 & 31 & 0 & 3.2 & 35.5 & 54.8 & 6.5 \\
\hline
\end{tabular}


TABLE VII (CONTINUED)

\begin{tabular}{|c|c|c|c|c|c|c|c|c|c|c|c|c|c|c|c|c|c|c|c|}
\hline \multirow{2}{*}{$\begin{array}{l}\text { Specialty } \\
\text { Area }\end{array}$} & \multicolumn{6}{|c|}{ Level of Competence ${ }^{a}$} & \multicolumn{7}{|c|}{ Frequency of Use ${ }^{b}$} & \multicolumn{6}{|c|}{ Place in NP Preparationc } \\
\hline & $\mathbf{n}$ & (a) & (b) & (c) & (d) & Med & $n$ & (a) & (b) & (c) & (d) & (e) & $\overline{\text { Med }}$ & $\bar{n}$ & (a) & (b) & (c) & (d) & (e) \\
\hline \multicolumn{20}{|c|}{ Examining ears with otoscope (function no. 16) } \\
\hline ANP & 65 & 0 & 9.2 & 26.2 & 64.6 & 3.7 & 64 & 9.4 & 6.3 & 17.2 & 31.3 & 35.9 & 4.0 & 63 & 0 & 3.2 & 47.6 & 49.2 & 0 \\
\hline WHCNP & 54 & 9.3 & 14.8 & 46.3 & 29.6 & 3.1 & 53 & 26.4 & 18.9 & 22.6 & 18.9 & 13.2 & 2.7 & 49 & 0 & 4.1 & 53.1 & 30.6 & 12.2 \\
\hline FNP & 51 & 0 & 2.0 & 7.8 & 90.2 & 4.0 & 50 & 4.0 & 0 & 4.0 & 20.0 & 72.0 & 4.8 & 51 & 0 & 3.9 & 37.3 & 51.0 & 7.8 \\
\hline PMHNP & 51 & 54.9 & 31.4 & 11.8 & 2.0 & 1.4 & 47 & 89.4 & B.5 & 2.1 & $\mathbf{0}$ & 0 & 1.1 & 44 & 2.3 & 4.5 & 59.1 & 31.8 & 2.3 \\
\hline $\mathbf{P N P}$ & 49 & 0 & 0 & 8.2 & 91.8 & 4.0 & 49 & 2.0 & 6.1 & 2.0 & 16.3 & 73.5 & 4.9 & 48 & 0 & 4.2 & 31.3 & 60.4 & 4.2 \\
\hline M & 34 & 0 & 14.7 & 64.7 & 20.6 & 3.0 & 34 & 5.9 & 20.6 & 35.3 & 23.5 & 14.7 & 3.2 & 30 & 0 & 3.3 & 33.3 & 60.0 & 3.3 \\
\hline \multicolumn{20}{|c|}{ Perform proctoscopy (function no. 32) } \\
\hline ANP & 65 & 73.8 & 6.2 & 15.4 & 4.6 & 1.2 & 64 & 79.7 & 9.4 & 10.9 & 0 & 0 & 1.1 & 62 & 12.9 & 0 & 4.8 & 45.2 & 37.1 \\
\hline WHCNP & 55 & 92.7 & 3.6 & 1.8 & 1.9 & 1.0 & 53 & 98.1 & 1.9 & 0 & 0 & 0 & 1.0 & 49 & 12.5 & 0 & 6.3 & 54.2 & 27.1 \\
\hline FNP & 51 & 80.4 & 3.9 & 9.8 & 5.9 & 1.1 & 51 & $B 4.3$ & 9.8 & 5.9 & 0 & 0 & 1.1 & 51 & 25.5 & 0 & 2.0 & 39.2 & 33.3 \\
\hline PMHNP & 51 & 98.0 & 2.0 & 0 & 0 & 1.0 & 48 & 100.0 & 0 & 0 & 0 & 0 & 1.0 & 44 & 15.9 & 0 & 0 & 75.0 & 9.1 \\
\hline PNP & 49 & 100.0 & 0 & 0 & 0 & 1.0 & 49 & 100.0 & 0 & 0 & 0 & 0 & 1.0 & 49 & 22.4 & 0 & 6.1 & 55.1 & 16.3 \\
\hline NM & 34 & 100.0 & 0 & 0 & 0 & 1.0 & 32 & 100.0 & 0 & 0 & 0 & 0 & 1.0 & 33 & 15.2 & 3.0 & 3.0 & 66.7 & 12.1 \\
\hline
\end{tabular}


TABLE VII (CONTINUED)

\begin{tabular}{|c|c|c|c|c|c|c|c|c|c|c|c|c|c|c|c|c|c|c|c|}
\hline \multicolumn{2}{|c|}{ Spectalty } & \multicolumn{5}{|c|}{ Level of Competence ${ }^{a}$} & \multicolumn{7}{|c|}{ Frequency of Use ${ }^{b}$} & \multicolumn{6}{|c|}{ Place In NP Preparationc } \\
\hline Area & $\mathbf{n}$ & (a) & (b) & (c) & (d) & $\overline{\text { Med }}$ & $n$ & (a) & (b) & (c) & (d) & (e) & Med & $n$ & (a) & (b) & (c) & (d) & (e) \\
\hline \multicolumn{20}{|c|}{ Perform sigmodoscopy (function no. 34) } \\
\hline ANP & 64 & 92.2 & 4.7 & 3.1 & 0 & 1.0 & 61 & 98.4 & 1.6 & 0 & 0 & 0 & 1.0 & 60 & 30.0 & 0 & 3.3 & 30.0 & 36.7 \\
\hline WHCNP & 54 & 100.0 & 0 & 0 & 0 & 1.0 & 53 & 98.1 & $\mathbf{0}$ & 1.9 & 0 & 0 & 1.0 & 48 & 20.8 & 0 & 2.1 & 60.4 & 16.7 \\
\hline FNP & 51 & 90.2 & 2.0 & 3.9 & 3.9 & 1.1 & 51 & 94.1 & 3.9 & 2.0 & 0 & 0 & 1.0 & 50 & 32.0 & 0 & 2.0 & 32.0 & 34.0 \\
\hline PMHNP & 51 & 100.0 & 0 & 0 & $\mathbf{0}$ & 1.0 & 46 & 100.0 & 0 & 0 & 0 & 0 & 1.0 & 43 & 16.3 & 0 & 0 & 67.4 & 16.3 \\
\hline PNP & 46 & 93.5 & 0 & 2.2 & 4.3 & 1.0 & 47 & 91.5 & 2.1 & 4.3 & 2.1 & 0 & 1.0 & 49 & 26.5 & 0 & 6.1 & 46.9 & 20.4 \\
\hline NM & 34 & 100.0 & 0 & 0 & 0 & 1.0 & 32 & 100.0 & 0 & 0 & 0 & 0 & 1.0 & 33 & 18.2 & 3.0 & 3.0 & 63.6 & 12.1 \\
\hline \multicolumn{20}{|c|}{ Defending what you consider a patient's rights when this conflicts with an institutional or agency policy (function no. 6 ) } \\
\hline ANP & 65 & 1.5 & 7.7 & 53.8 & 36.9 & 3.3 & 65 & 9.2 & 33.8 & 40.0 & 12.3 & 4.6 & 2.7 & 63 & 3.2 & 12.7 & 54.0 & 23.8 & 6.3 \\
\hline WHCNP & 55 & 0 & 7.3 & 52.7 & 40.0 & 3.3 & 55 & 12.7 & 49.1 & 30.9 & 0 & 7.3 & 2.3 & 47 & 0 & 29.8 & 34.0 & 25.5 & 10.6 \\
\hline FNP & 50 & 2.0 & 14.0 & 42.0 & 42.0 & 3.3 & 51 & 17.6 & 41.2 & 23.5 & 13.7 & 3.9 & 2.3 & 49 & 0 & 12.2 & 46.9 & 32.7 & 8.2 \\
\hline PMHNP & 52 & 3.8 & 7.7 & 36.5 & 51.9 & 3.5 & 51 & 13.7 & 27.5 & 37.3 & 9.8 & 11.8 & 2.7 & 52 & 0 & 11.5 & 46.2 & 42.3 & 0 \\
\hline PNP & 49 & 4.1 & 12.2 & 42.9 & 40.8 & 3.3 & 49 & 18.4 & 49.0 & 20.4 & 12.2 & 0 & 2.1 & 47 & 0 & 12.8 & 72.3 & 3.5 & 6.4 \\
\hline$N$ & 34 & 2.9 & 8.8 & 38.2 & 50.0 & 3.5 & 34 & 5.9 & 35.3 & 35.3 & 17.6 & 5.9 & 2.8 & 29 & 0 & 17.2 & 41.4 & 34.5 & 6.9 \\
\hline
\end{tabular}


TABLE VII (CONTINUED)

\begin{tabular}{|c|c|c|c|c|c|c|c|c|c|c|c|c|c|c|c|c|c|c|c|}
\hline \multirow{2}{*}{$\begin{array}{l}\text { Specialt } \\
\text { Area }\end{array}$} & \multicolumn{6}{|c|}{ Level of Competence ${ }^{a}$} & \multicolumn{7}{|c|}{ Frequency of Use $\mathrm{b}^{\mathrm{b}}$} & \multicolumn{6}{|c|}{ Place in NP Preparationc } \\
\hline & n & (a) & (b) & (c) & (d) & Med & $\bar{n}$ & (a) & (b) & (c) & (d) & $(\mathrm{e})$ & $\overline{\text { Med }}$ & $\bar{n}$ & (a) & (b) & (c) & (d) & (e) \\
\hline \multicolumn{20}{|c|}{ Serving as a catalyst for } \\
\hline ANP & 63 & 1.6 & 17.5 & 42.9 & 33.1 & 3.2 & 63 & 7.9 & 22.2 & 29.6 & 27.0 & 14.3 & 3.2 & 61 & 0 & 8.2 & 49.2 & 34.4 & 8.2 \\
\hline WHCNP & 56 & 0 & 10.7 & 51.8 & 37.5 & 3.3 & 56 & 1.8 & 21.4 & 39.3 & 23.2 & 14.3 & 3.2 & 47 & 0 & 14.9 & 39.3 & 29.8 & 17.0 \\
\hline FN & 51 & 3.9 & 15.7 & 52.9 & 27.5 & 3.1 & 49 & B.2 & 20.4 & 24.5 & 32.7 & 14.3 & 3.4 & 49 & 2.0 & 12.2 & 38.8 & 42.9 & 4.1 \\
\hline PMHNP & 51 & 0 & 13.7 & 39.2 & 47.1 & 3.4 & 50 & 4.0 & 16.0 & 34.0 & 24.0 & 22.0 & 3.4 & 51 & 0 & 2.0 & 29.4 & 66.7 & 2.0 \\
\hline PNP & 50 & 2.0 & 28.0 & 54.0 & 16.0 & 2.9 & 49 & 4.1 & 22.4 & 46.9 & 16.3 & 10.2 & 3.0 & 45 & 0 & 4.4 & 53.3 & 37.8 & 4.4 \\
\hline M & 34 & 2.9 & 14.7 & 61.8 & 20.6 & 3.0 & 34 & 5.9 & 29.4 & 29.4 & 20.6 & 14.7 & 3.0 & 28 & 0 & 17.9 & 53.6 & 25.0 & 3.6 \\
\hline
\end{tabular}

Note:

Med $=$ Median

bFrequency of Use

ANP $=$ Adult nurse Practitioners

(a) Never-little or no need to use the function

(b) Rarely-monthly

(c) Occasionally-a few times a month

HACNP = Women's Health Care Nurse Practitioners

FNP = Family Nurse Practitioners

(d) Frequently-several times weekly or every day

PMHN = Psych1atric Mental Health Nurse Pract1tioners

PNP = Pedlatric Nurse Practitioners

N = Nurse Midwife

(e) All the time-several times every day

aLevel of Competence

(a) Do not feel competent at this time

(b) Feel sllghtly competent

(c) Feel moderately competent

cplace in NP Preparation

(a) Should NOT be included in NP Preparation

(b) Assoclate programs

(c) Baccalaureate programs

(d) Graduate degree programs

(e) Continuing education includes courses, seminars, conferences, etc. 
in percentages. A percent is the number of people within a specialty who selected a particular response category (the number in a cell) divided by the total number of respondents to that specialty times 100. Where applicable, the median for each specialty is shown. Where descriptors or numbers are part of a series, the values may be separated and will appear in the same sequence as in the series.

Table VIII shows the results of the chi-square testing of the Health Promotion and Maintenance functions within the "Level of Competency" category. The statistical hypothesis for independence was rejected for nine of the 11 functions; a significant difference was not found for function 5 ("Defending what you consider a patient's rights when this conflicts with an institutional or agency policy"); no comparison was possible for function 34 . In considering "Frequency of Use" for these functions, the statistical hypothesis for independence was rejected for seven of the 11 functions; the statistical hypothesis was not rejected for function 6 ("Defending a patient's rights...") and function 5 ("Serving as a catalyst for needed heaith care changes"); comparisons were not possible for functions 32 and 34 . For "Place in NP preparation," the statistical hypothesis for independence was rejected for seven of the 11 functions; it was not rejected for function 33 ("Perform joint inspection"), function 17 ("Palpating uterus for fetus position"), function 27 ("Distinguishing between normal and abnormal EKG"), and function 20 ("Dialating Pupils"). 
TABLE VIII

RESULTS OF CHI-SQUARE TESTS ON RESPONSES* TO HEALTH PROMOTION AND MAINTENANCE FUNCTIONS

\begin{tabular}{|c|c|c|c|c|c|c|c|c|c|c|c|c|}
\hline \multirow[b]{2}{*}{ Functions } & \multicolumn{4}{|c|}{ Level of Competence } & \multicolumn{4}{|c|}{ Frequency of Use } & \multicolumn{4}{|c|}{ Place In NP Preparation } \\
\hline & $\underline{x}^{2}$ & df & $\mathbf{p}$ & Note & $\underline{x}^{2}$ & $d f$ & p & Note & $\underline{x}^{2}$ & $d f$ & p & Note \\
\hline $\begin{array}{l}\text { 24. Perform general physical } \\
\text { examination in absence }\end{array}$ & & & & combines & & & & comblnes & & & & excludes \\
\hline of physiclan & 222.56 & 10 & .0000 & (a) \& (b) & 228.79 & 15 & .0001 & (b) \& (c) & 20.09 & 5 & .0012 & $(a)(b)(e)$ \\
\hline 33. Perform folnt & & & & & & & & combines & & & & excludes \\
\hline Inspection & 161.40 & 15 & .0000 & & 144.63 & 15 & .0000 & (d) \& (e) & 4.70 & 5 & .4539 & $(a)(b)(e)$ \\
\hline 15. Providing routine & & & & & & & & comblnes (a) & & & & excludes \\
\hline prenatal care & 227.70 & 15 & .0000 & & 201.91 & 10 & .0000 & $\&(b) ;(c) \&(d)$ & 19.32 & 5 & .0017 & $(a)(b)(e)$ \\
\hline \multirow{2}{*}{ 17. Palpating uterus for } & & & & & & & & combines (a) & & & & excludes \\
\hline & 271.09 & 15 & .0000 & & 202.09 & 10 & .0000 & $\&(b) ;(c) \&(d)$ & 5.04 & 5 & .4106 & $(a)(b)(e)$ \\
\hline \multirow{3}{*}{$\begin{array}{l}\text { 27. Distinguish between } \\
\text { normal and abnormal EKG }\end{array}$} & & & & & & & & combines & & & & excludes \\
\hline & 107.42 & 15 & .0000 & & 133.29 & 10 & .0000 & $(c)(d)(e)$ & 11.43 & 10 & .3245 & $(a) \&(b)$ \\
\hline & & & & & & & & combines & & & & excludes \\
\hline \multirow[t]{2}{*}{ 20. Dillating pupils } & 57.31 & 15 & .0000 & & 21.11 & 5 & .0009 & $(b)(c)(d)(e)$ & 12.11 & 10 & .2777 & (d) \& (e) \\
\hline & & & & & & & & & & & & excludes \\
\hline $\begin{array}{l}\text { 16. Examining ears with } \\
\text { otoscope }\end{array}$ & 253.41 & 15 & .0000 & & 244.59 & 20 & .0000 & & 14.22 & 5 & .0143 & $(a)(b)(e)$ \\
\hline 32. Perform protoscopy & 35.78 & 5 & .0000 & $\begin{array}{l}\text { comblnes } \\
\text { (b) (c) (d) }\end{array}$ & & & & $\begin{array}{l}\text { no inter- } \\
\text { preptation } \\
\text { is possible }\end{array}$ & 19.90 & 5 & .0013 & $\begin{array}{l}\text { excludes } \\
\text { (a) (b) (c) }\end{array}$ \\
\hline
\end{tabular}


TABLE VIII (CONTINUED)

\begin{tabular}{|c|c|c|c|c|c|c|c|c|c|c|c|c|}
\hline \multirow[b]{2}{*}{ Functions } & \multicolumn{4}{|c|}{ Level of Competence } & \multicolumn{4}{|c|}{ Frequency of Use } & \multicolumn{4}{|c|}{ Place in NP Preparation } \\
\hline & $\underline{x}^{2}$ & $\underline{d f}$ & $\mathbf{p}$ & Note & $\underline{x}^{2}$ & df & p & Note & $\underline{x}^{2}$ & $\underline{\mathrm{df}}$ & $\underline{\mathbf{p}}$ & Note \\
\hline 34. Perform sigmoidscopy & & & & $\begin{array}{l}\text { no inter- } \\
\text { pretation } \\
\text { is possible }\end{array}$ & & & & $\begin{array}{l}\text { no inter- } \\
\text { pretation } \\
\text { is possible }\end{array}$ & 22.28 & 5 & .0005 & $\begin{array}{l}\text { excludes } \\
\text { (a) (b)(c) }\end{array}$ \\
\hline $\begin{array}{l}\text { 6. Defending what you } \\
\text { consider a patient's } \\
\text { rights when this } \\
\text { conflicts with an } \\
\text { institutional or } \\
\text { agency pollcy }\end{array}$ & 3.17 & 10 & .6119 & $\begin{array}{l}\text { combines } \\
\text { (a) \& (b) }\end{array}$ & 19.43 & 15 & .1948 & $\begin{array}{l}\text { comblines } \\
\text { (d) \& (e) }\end{array}$ & 26.31 & 10 & .0028 & $\begin{array}{l}\text { excludes } \\
\text { (a) \& (e) }\end{array}$ \\
\hline $\begin{array}{l}\text { 5. Serving as a catalyst } \\
\text { for needed health } \\
\text { care changes }\end{array}$ & 19.75 & 10 & .0317 & $\begin{array}{l}\text { combines } \\
\text { (a) \& (b) }\end{array}$ & 12.86 & 15 & .6129 & $\begin{array}{l}\text { combines } \\
\text { (a) \& (b) }\end{array}$ & 13.46 & 5 & .0194 & $\begin{array}{l}\text { excludes } \\
\text { (a) (b) (e) }\end{array}$ \\
\hline
\end{tabular}

*The responses were defined in Table VI 
For function 24 ("Perform general physical examination in absence of a physician"), the statistical hypotheses were rejected for all three categories: "Level of Competence" (with " $a$ " and "b" combined, chi-square $=222.6 ; \mathrm{df}=10 ; \underline{p}<.0000)$; "Frequency of Use" ( $w i$ th "b" and "c" combined, chi-square = 228.8; $\underline{d f}=15 ; \underline{p}=.0001$ ); and "Place in NP Preparation" (contrasting " $c$ " and "d" only, chisquare $=20.1 ; \underline{d f}=5 ; \underline{p}<.0012)$. Thus for each category, a relationship between the levels of the category and the specialties was found. In contrast with the other specialties, the PMHNPs expressed a lower level of competence in and less frequent use of this function (medians $=1.4$ and 1.1 ); the next lowest medians were 3.8 and 4.4). They also placed this function with greater frequency (91\%) in graduate programs. Baccalureate programs were chosen second most often for the major emphasis of this function. The lowest selection of graduate programs was by the WHCNPS (57\%).

For function 33 ("Perform joint inspection"), the statistical hypothesis for independence was not rejected for "Place in NP Preparation"; the majority within each specialty placed this function in graduate programs. The statistical hypothesis was rejected for each of the other two categories: "Level of Competence" (chi-square $=161.4 ; \underline{d f}=15 ; \underline{p}<.0000$ ) and "Frequency of Use" (with "d" and "e" combined to meet the minimum expected frequency criterion, chisquare $=144.6 ; \underline{d f}=15 ; \underline{p}(.0000)$. Therefore, significant relationships between specialty groups and the categories of "Level of Competence" and "Frequency of Use" were found. In contrast with the other specialties, the PMHNPS, WHCNPS, and NMs expressed a lower 
level of competence (medians $=1.1,1.2$ ) and frequency of use (medians $=1.0,1.1,1.0)$. The greatest felt competency (median 3.2) and frequency of use (median $=3.3$ ) was expressed by the FNPS. For function 15 ("Providing routine prenatal care"), the statistical hypotheses were rejected for all three categories: "Level of Competence" (chi-square $=227.7 ; \underline{d f}=15 ; \underline{p}<.0000)$; "Frequency of Use" (contrasting " $a$ " and "b" and "c" with " $d$ " and with "e," chi-square $=201.9 ; \underline{d f}=10 ; \underline{p}<.0000)$; and "Place in NP Preparation" (contrasting " $c$ " and "d," chi-square $=19.3$, $\underline{\mathrm{df}}=5, \underline{\mathrm{p}}$ $<.0017)$. Thus, for each category a relationship between the leve1 of the category and the specialties was found. In contrast with the other specialties, the PMHNPS, PNPS, and ANPS, expressed a lower level of competence (medians $=1.2,1.4,1.4$ ) and less frequent use (medians $=1.0,1.0,1.1$ ) of this function. The greatest felt competence (median $=4.0$ ) and frequency of use (median $=4.9$ ) were expressed by the NMs. With about the same "Level of Competence" but with less frequent use were the WHCNPs (medians $=3.8$ and 3.1 ). With the exception of the NMS and WHCNPS, the use of this function by all specialty groups was moderate or low. With respect to "Place in NP Preparation," at least $80 \%$ of the NMs and FNPs placed this function in graduate degree programs. The PMHNPs tended to divide their assignment between baccalaureate (39\%) and graduate degree (41\%) programs. For each of the other groups, a majority of the respondents placed this function in graduate programs.

For function 17 ("Palpating uterus for fetal position"), the statistical hypothesis for independence was not rejected for "Place 
in NP Preparation;" all specialties tended toward even choices between baccalareate and graduate programs, with a tendency for the groups to select graduate programs more frequently. The statistical hypothesis was rejected for "Level of Competence" (chi-square $=271.1 ; \underline{d f}=15 ; \underline{p}<.0000$ ) and "Frequency of Use" (combining "a" with "b" and "c" with "d" to contrast with "e," chi-square = 202.1; $\underline{d f}=10 ; p<.0000)$. Therefore, significant relationships between specialty groups and the response categories of "Level of Competence" and "Frequency of Use" were found. In contrast with other specialty groups, the ANPS, PMHNPS, and PNPS expressed less competence (medians $=1.2,1.1$, and 1.1 ) and less frequent use (medians $=1.1,1.0$, and 1.0). The NMS expressed the greatest felt competence (median $=4.0$ ) and frequency of use (median $=4.8$ ).

For function 27 ("Dinstinguish between normal and abnormal EKG"), the statistical hypothesis for independence was not rejected for "Place in NP Preparation." The statistical hypotheses were rejected for the other categories: "Level of Competence" (chisquare $=107.4 ; \underline{d f}=15 ; \underline{p}<.0000$ ) and "Frequency of Use" (with the last three response categories combined, chi-square $=133.3$; df $=10 ; \mathrm{p}<.0000)$. Therefore significant relationships were found between the specialty groups and the response categories of "Level of Competence" and "Frequency of Use.", Although relatively low for a11 groups, the ANPs and FNPS expressed the greatest felt competency (medians = 2.8 and 2.6) and "Frequency of Use" (medians = 2.7 and 1.9). 
For function 20 ("Dilating pupils"), the statistical nypothesis for independence was not rejected for "Place in NP Preparation." The statistical hypotheses were rejected for "Level of Competence" (chi-square $=57.3 ; \underline{d f}=15 ; \underline{p}<.0000$ ) and "Frequency of Use" (contrasting response category "a" with the other categories, chi-square $=21.1 ; \underline{d f}=5 ; \underline{p}<.0008)$. Therefore, significant relationships were found between the specialty groups and the response categories of "Level of Competenc.y" and "Frequency of Use." All groups perceived themselves as relatively low in competence and frequency of use; however, the ANPS and FNPS expressed greater feel ings of competence (medians $=2.0$ and 2.3 ) and usage (medians $=1.2$ ) than the other groups.

For function 16 ("Examining ears with otoscope"), the statistical hypotheses of independence were rejected for all three categories: "Level of Competence" (chi-square $=253.4 ; \underline{d f}=15 ; \underline{p}$ $<.0000)$; "Frequency of Use" (chi-square $=244.6 ; \underline{d f}=20 ; \underline{p}<.0000$ ); and "Place in NP Preparation" (contrasting "c" and "d," chi-square $=14.22 ; \underline{d f}=5 ; \underline{p}(.0143)$. Therefore, significant relationships were found between the specialty groups and the three categories of the function. In contrast with the other specialties, the PMHNPS expressed the lowest felt competence (median $=1.4$ ) and frequency of use (media $=1.1$ ); they also placed a greater emphasis on assigning preparation to baccalaureate programs (59\%). The FNPs, PNPs and ANPs expressed the greatest feeling of competence (medians $=4.0$, 4.0, and 3.7) and frequency of use (medians $=4.8,4.8$, and 4.0); the PNPS, NMS, and FNPS chose graduate degree programs more often 
than any of the other specialties. The ANPs tended toward similar selections of baccalaureate and graduate programs. Preference for baccalaureate programs was expressed by the WHCNPS and the PMHNPS.

For function 32 ("Perform proctoscopy"), all specialty groups expressed little or no use of this function; no statistical comparison was performed because of low expected frequencies in all response categories except "a." The statistical hypotheses of independence were rejected for "Level of Competency" (contrasting "a" with the other categories, chi-square - 35.8; $d f=5 ; \underline{p}<.0000$ ) and "Place in NP Preparation" (contrasting "d" and "e," chi-square $=19.90 ; \underline{d f}=5 ; p<.0013)$. Thus, relationships were found between specialties and the categories of "level of Competence" and "Place in NP Preparation." Although all specialty groups expressed low competence, the medians for the ANPS and FNPs were slightly greater than the medians for the other groups (1.2 and 1.1), versus 1.0 for all other groups). The PMHNPS and NMs chose graduate programs more than any other response category (75\% and 68\%). While more NPs in all the specialties preferred graduate programs, many ANPS and FNPS chose continuing education (37\% and $33 \%)$. The majority in each of the other groups assigned graduate degree programs to provide greatest emphasis of this function.

The function 34 ("Perform sigmoidoscopy"), all groups expressed low competence and infrequent usage; the expected frequencies in both categories were too low for all response categories except "a" to permit a statistical test. The statistical hypothesis of independence for "Place in NP Preparation" was rejected (contrasting "d" 
and "e," chi-square $=22.3 ; \underline{d f}=5 ; \underline{p}<.0005)$. The PNiHNPs, NMs, and WHCNPS placed the greatest emphasis on graduate degree programs $(67 \%, 64 \%$ and $60 \%)$. Althoug tending toward similar choices of graduate degree programs and continuing education, the ANPS and FNPS expressed a preference for the latter (37\% and 34\%). With a range between $16 \%$ (PMHNPs) and 32\% (FNPS), many respondents in each group said that this function does not belong in NP preparation.

For function 6 ("Defending what you consider a patient's rights when this conflicts with an institutional or agency policy"), the statistical hypothesis was NOT rejected for "Level of Competence" and "Frequency of Use." The statistical hypothesis for independence was rejected for "Place in NP Preparation" (excluding response categories " $a$ " and "e," chi-square $=26.8 ; \underline{d f}=10 ; \underline{p}$ $<.0028)$. A majority of the PNPS $(72 \%)$ and ANPs $(54 \%)$ chose baccalaureate programs; this was the most frquently chosen category for all groups. However, an apreciable number of PMHNPs (42\%), NMS (35\%), and FNPs (33\%) al so chose graduate degree programs. At least $11 \%$ of each group chose associate programs, with $30 \%$ of the WHCNPS so choosing.

For function 5 ("Serving as a catalyst for needed health care changes"), the statistical hypothesis for independence was not rejected for "Frequency of Use." The statistical hypothesis for independence was rejected for "Level of Competence" (with "a" and "b" combined, chi-square $=19.8 ; \underline{d f}=10 ; p<.0317)$ and "Place in NP Preparation" (contrasting response categories "c" and "d," chisquare $=13.5 ; \underline{\mathrm{df}}=5 ; \underline{\mathrm{p}}<.0194)$. Thus a relationship between 
specialties and response categories was found for both "Level of Competence" and "Place in NP Preparation." The greatest felt competence was expressed by the PMHNPS (median $=3.4$ ); the PNPS expressed the least competence (median $=2.9$ ). A majority of the PNPs $(53 \%)$ and NMs (54\%) preferred baccalaureate programs, whereas a majority of the PMHNPS preferred graduate degree programs (67\%). The other groups tended toward similar choices of baccalaureate and graduate degree programs; with the exception of the PMHNPS and the FNPS, a slight preference was expressed for baccalaureate programs for major emphasis of this function.

\section{Management of Health Care}

The results of the analyses of the Management of Health Care functions are presented in this section for the total sample and for the six specialty groups.

Total Sample. Table IX shows that for this category in "Level of Competence," a majority (82\%) of the NPs felt "Very competent" in "Using judgment and initiative making health care decisions" (function 3). Also most (74\%) nurse practitioners felt "Very competent" to "Evaluate and prescribe medications in your specialty" (function 37). As a group most of the nurse practitioners judged themselves to be "Very competent" or "Moderately competent" in eight of the fifteen functions in this category: functions 7 (94\%), 40 (88\%), 11 $(95 \%), 3(99 \%), 9(91 \%), 13(81 \%), 37(93 \%)$, and $29(87 \%)$. A majority of NPS did not feel competent to "Set fracture" (function 35 -- 92\%), to "Aspirate joint fluid from knee" (function 
TABLE IX

PERCENTACE OF RESPONSES BY MANAGEMENT OF HEALTH CARE FUNCTIONS

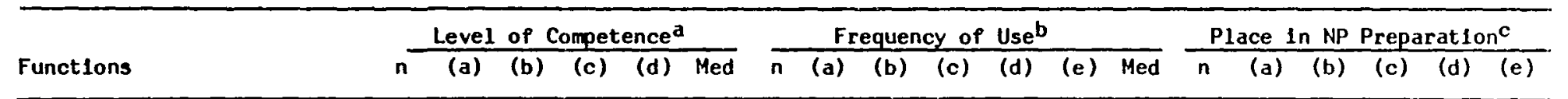

7. Using a problem-solving process to plan, provide, and evaluate the primary care for a client and $\begin{array}{lllllllllllllllllllllll}\text { their entire family } & 351 & 0.9 & 5.1 & 26.2 & 67.8 & 3.8 & 345 & 4.6 & 10.4 & 14.2 & 25.5 & 45.2 & 4.3 & 330 & 0.3 & 15.5 & 48.5 & 33.3 & 2.4\end{array}$

40. Ordering and/or perform$\begin{array}{lllllllllllllllllllllll}\text { Ing diagnostlc tests } & 355 & 3.1 & 9.3 & 32.1 & 55.4 & 3.6 & 352 & 6.8 & 7.7 & 17.6 & 25.9 & 42.0 & 4.2 & 341 & 0.6 & 3.8 & 18.5 & 71.3 & 5.9\end{array}$

30. Manage abnormal pain from distension

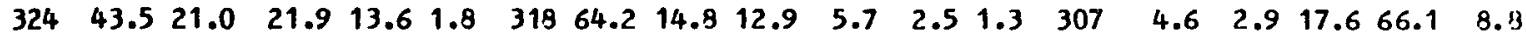

11. Providing primary care to patients and $\begin{array}{lllllllllllllllllllll}\text { fanilles } & 346 & 1.7 & 3.8 & 24.3 & 70.2 & 3.8 & 344 & 6.4 & 4.9 & 8.1 & 16.0 & 64.5 & 4.7 & 327 & 0 & 6.4 & 23.9 & 66.4 & 3.4\end{array}$

26. Diagnose and treat acute $\begin{array}{lllllllllllllllllllll}\text { ot1tis media } & 355 & 22.0 & 11.3 & 22.3 & 44.5 & 3.3 & 351 & 38.7 & 16.5 & 15.1 & 11.4 & 18.2 & 2.2 & 342 & 0.6 & 1.8 & 12.0 & 79.9 & 6.7\end{array}$

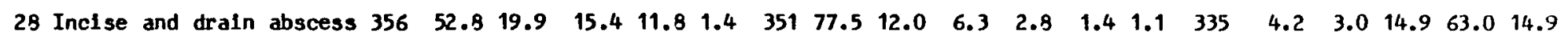

14. Taping ankle, wrist or

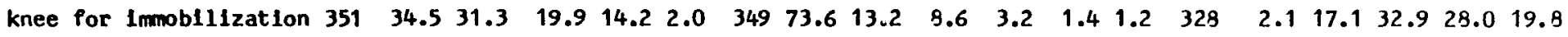

31. Aspirate foint fluid from

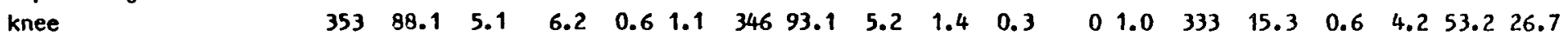

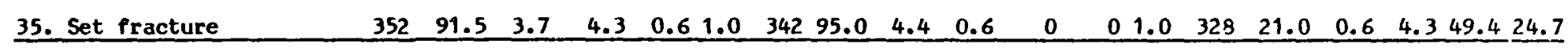


TABLE IX (CONTINUED)




31 -- 88\%), to "Make delivery following uncomplicated pregnancy" (function 25 - 71\%), or to "incise and drain abscess" (function 28 -- 53\%). They judged themselves to have slight or lacking competence in six: functions $28(73 \%), 30(65 \%), 31(93 \%), 35$ $(95 \%), 25(82 \%)$, and $14(66 \%)$.

Function 3 ("Using judgment and initiative making health care decisions") was the most frequently used of these functions by the NPs; $81 \%$ reported using it "Several times each day," and an additional 16\% reported using it "Several times each week." Another frequently performed function (11, "Providing primary care to patients and families") was reported to be used "Several times a day" by $65 \%$ of the respondents to that function in that column; an additional $16 \%$ indicated frequent usage ("Several times a week"). A1 so $63 \%$ reported using "Several times each day" function 37 ("Evaluate and prescribe medications in your specialty"); frequent weekly use was reported by an additional 17\%. As a group most of the nurse practitioners reporied using six functions at least "Several times each week": numbers 7 (72\%), 40 (68\%), 11 (81\%), 3 $(97 \%), 37(79 \%)$, and $29(66 \%)$.

The functions used least often ("Never-little") were: function 35 ("Set fracture"), function 31 ("Aspirate joint fluid from knee"), function 25 ("Make delivery following uncomplicated pregnancy"), function 28 ("Incise and drain abscess"), function 14 ("Taping ankle, wrist, or knee for immobilization"), and function 30 ("Manage abnormal pain from distension") as indicated by $95 \%, 93 \%$, $88 \%, 78 \%, 74 \%$, and $64 \%$ of the respondents. Eight functions were 
used no more than once each month: functions 35 (99\%), 25 (91\%), 31 $(98 \%), 28(90 \%), 14(87 \%), 30(79 \%), 26(55 \%)$, and $13(54 \%)$.

The functions in which the NPS considered themselves to be more competent (functions 3,11 , and 37 ) were the most frequently used. The functions they identified as least competent to use (functions $28,31,35$, and 25) were least often used.

In considering the "Place in NP Preparation" in which these functions belong a majority of the respondents placed nine of the functions in graduate degree programs: "Ordering and/or performing diagnostic tests" (function 40 -- 71\%); "Manage abnomal pain from distenion (function 30 - 66\%); "Providing primary care to patients and families" (function 11 -- 66\%); "Diagnose and treat acute otitis media" (function 26 -- 79\%); "Incise and drain abscess" (function 28 -- 63\%); "Aspirate joint flud from knee" (function 31 -- 53\%); "Evaluate and prescribe medications in your specialty" (function 37 -- 79\%); "Initiate drug therapy" (function 29 -- 81\%), and "Make delivery following uncomplicated pregnancy" (function 25 - $81 \%$ ). Except for functions 28, 31, and 37, which were assigned to continuing education by most or an equal number of the remaining respondents, the second most used category for the above functions was baccalaureate programs. Three additional functions were assigned to graduate degree programs more often than to any other program: "Set fracture" (function 35 -- 49\%); "Evaluating the health care provided by physicians" (function 9 -- 49\%); and, "(Managing patient with chronic disorders according to standing orders" (function 13 -43\%). However, nearly as many (37\%) assigned baccalaureate programs 
to emphasize function 13. The respondents assigned three functions more often to baccalaureate programs: "Using a problem-solving process..." (function 7 -- 49\%); "Taping ankle, wrist, or knee for immobilization" (function 14 -- 33\%); and, "Using judgment and initiative making health care decisions" (function $3--49 \%$ ). For these three functions, graduate degree programs were the second most frequently chosen.

Thus, all of the 15 functions in the category of Management of Health Care were recommended by the NPs to receive major emphasis in the baccalaureate or graduate nurse programs. No function was selected for omission by a majority of the NPs. However, the most recominendedations (21\% and $15 \%)$ for omission were received by functions 35 and 31 ("Set fracture" and "Aspirate joint fluid from knee"). The fewest recommendations (0) for omission were received by function 11 ("Providing primary care to patients and families").

Some NPs chose associate nurse programs to provide major emphasis in the development of competencies associated with the management of health care. The functions $14,7,3$, and 13 were assigned by at least $13 \%$ of the NPs to receive major emphasis in associate nurse programs. Each function in the category was chosen by some NPs to be emphasized in the associate and continuing education programs.

The functions $28,14,31$, and 35 were chosen by at least $15 \%$ of the NPS to receive major emphasis in continuing education programs. Also these functions were noted as rarely used by most 
NPS. The same functions received "not competent" indicators from more than $35 \%$ of the NPs.

Percentage of Responses by Specialty Areas to Management of Health Care Functions. In Table $X$, the responses by NPS in six specialties to the 15 functions in this category are presented with respect to three dimensions or columns: "Level of Competence," "Frequency of Use," and "Place in NP Preparation." Choices are presented as percentages by a specialty. Where applicable, the median for each specialty is shown. Details from the tables may be included to clarify statistical procedures.

Table XI reports the results of the chi-square testing of the Management of Health Care functions. For the "Level of Competence" category, the statistical hypothesis for independence was rejected for 12 or the 15 functions; significant difference were not found for function 7 ("Using a problem-solving process...") and function 11 ("Providing primary care to patients and families"); no comparison was possible for function 35 ("Set fracture"). In considering "Frequency of Use" for these functions, the statistical hypothesis for independence was rejected for 12 of the functions; the statistical hypothesis was not rejected for function 3 ("Using judgment and initiative making health care decisions"); comparisons were not possible for functions 31 ("Aspirate joint fluid from knee") and 35 ("Set fracture"). For "Place in NP Preparation," the statistical hypothesis for independence was rejected for eight of the fifteen functions; it was not rejected for function 7 ("Using a problemsolving process..."); function 30 ("Manage abnormal pain from 
TABLE $X$

PERCENTACES of RESPONSES BY SPECIALTY AREAS TO MANAGEMENT OF HEALTH CARE FLNCTIONS

\begin{tabular}{|c|c|c|c|c|c|c|c|c|c|c|c|c|c|c|c|c|c|c|c|}
\hline \multirow{2}{*}{$\begin{array}{l}\text { Speclalty } \\
\text { Area }\end{array}$} & \multicolumn{6}{|c|}{ Level of Competence ${ }^{a}$} & \multicolumn{7}{|c|}{ Frequency of Use } & \multicolumn{6}{|c|}{ Place In NP Preparationc } \\
\hline & n & (a) & (b) & (c) & (d) & Med & $\mathbf{n}$ & (a) & (b) & (c) & (d) & (e) & Med & $n$ & (a) & (b) & (c) & (d) & (e) \\
\hline \multicolumn{20}{|c|}{$\begin{array}{l}\text { Using a problem-solving process to plan, provide, and evaluate the primary } \\
\text { care for a cllent and their entire family (function no. 7) }\end{array}$} \\
\hline ANP & 62 & 0 & 4.8 & 30.6 & 64.5 & 3.7 & 59 & 1.7 & 6.8 & 16.9 & 32.2 & 42.4 & 4.3 & 61 & 0 & 11.5 & 49.2 & 34.4 & 4.9 \\
\hline WHCNP & 54 & 1.9 & 7.4 & 27.8 & 63.0 & 3.7 & 54 & 7.4 & 22.2 & 14.8 & 18.5 & 37.0 & 3.3 & 49 & 0 & 20.4 & 59.2 & 19.4 & 2.0 \\
\hline FNP & 50 & 0 & 2.0 & 26.0 & 72.0 & 3.8 & 50 & 2.0 & 10.0 & 8.0 & 34.0 & 46.0 & 4.4 & 49 & 0 & 16.3 & 39.8 & 42.9 & 2.0 \\
\hline PMHNP & 52 & 0 & 1.9 & 19.2 & 78.8 & 3.9 & 51 & 5.9 & 5.9 & 11.8 & 25.5 & 51.0 & 4.5 & 50 & 0 & 10.0 & 50.0 & 38.0 & 2.0 \\
\hline PNP & 50 & 2.0 & 6.0 & 36.0 & 56.0 & 3.6 & 49 & 4.1 & 12.2 & 12.2 & 36.7 & 34.7 & 4.1 & 49 & 0 & 18.8 & 52.1 & 29.2 & 0 \\
\hline NM & 34 & 0 & 8.8 & 29.4 & 61.8 & 3.7 & 34 & 5.9 & 5.9 & 26.5 & 8.8 & 52.9 & 4.6 & 27 & 3.7 & 11.1 & 48.1 & 37.0 & 0 \\
\hline
\end{tabular}

Ordering and/or performing diagnostic tests (function no. 40)

\begin{tabular}{|c|c|c|c|c|c|c|c|c|c|c|c|c|c|c|c|c|c|c|c|}
\hline ANP & 65 & 0 & 12.3 & 29.2 & 58.5 & 3.6 & 64 & 0 & 9.4 & 10.9 & 29.7 & 50.0 & 4.5 & 62 & 1.6 & 4.9 & 17.7 & 72.6 & 3.2 \\
\hline WHCNP & 54 & $\mathbf{0}$ & 1.9 & 24.1 & 74.1 & 3.8 & 55 & 0 & 5.5 & 14.5 & 27.3 & 52.7 & 4.6 & 47 & 0 & 2.1 & 27.7 & 57.4 & 12.8 \\
\hline FNP & 52 & 3.8 & 1.9 & 36.5 & 57.7 & 3.6 & 52 & 5.8 & 3.8 & 15.4 & 26.9 & 49.1 & 4.4 & 50 & 0 & 4.0 & 14.0 & 80.0 & 2.0 \\
\hline PMHNP & 52 & 13.5 & 25.0 & 34.6 & 26.9 & 2.8 & 51 & 25.5 & 21.6 & 23.5 & 17.6 & 11.8 & 2.6 & 51 & 2.0 & 0 & 7.8 & 89.2 & 2.0 \\
\hline PNP & 50 & 2.0 & 20.0 & 42.0 & 36.0 & 3.2 & 50 & 14.0 & 6.0 & 26.0 & 22.0 & 32.0 & 3.7 & 50 & 0 & 2.0 & 26.0 & 64.0 & 9.0 \\
\hline MM & 34 & 0 & 0 & 29.4 & 70.6 & 3.8 & 32 & 0 & 0 & 28.1 & 25.0 & 46.9 & 4.4 & 33 & 0 & 9.1 & 15.2 & 69.7 & 6.1 \\
\hline
\end{tabular}


TABLE $X$ (CONTINUED)

\begin{tabular}{|c|c|c|c|c|c|c|c|c|c|c|c|c|c|c|c|c|c|c|c|}
\hline \multirow{2}{*}{$\begin{array}{l}\text { Specialty } \\
\text { Area }\end{array}$} & \multicolumn{6}{|c|}{ Level of Competence ${ }^{a}$} & \multicolumn{7}{|c|}{ Frequency of Use ${ }^{b}$} & \multicolumn{6}{|c|}{ Place in NP Preparation $c$} \\
\hline & $n$ & (a) & (b) & (c) & (d) & Med & $\bar{n}$ & (a) & (b) & (c) & (d) & (e) & $\overline{\text { Med }}$ & $\bar{n}$ & (a) & (b) & (c) & (d) & (e) \\
\hline \multicolumn{20}{|c|}{ Manage abnormal pain from distension (function no. 30 ) } \\
\hline ANP & 58 & 8.6 & 31.0 & 37.9 & 22.4 & 2.8 & 58 & 41.4 & 27.6 & 17.2 & 12.1 & 1.7 & 1.8 & 57 & 3.5 & 1.8 & 19.3 & 70.2 & 5.3 \\
\hline WHCNP. & 51 & 52.9 & 17.6 & 19.6 & 9.8 & 1.4 & 51 & 72.5 & 11.8 & 11.8 & 2.0 & 2.0 & 1.2 & 45 & 6.7 & 2.2 & 20.0 & 60.0 & 11.1 \\
\hline FP & 45 & 15.6 & 22.2 & 35.6 & 26.7 & 2.8 & 44 & 34.1 & 22.7 & 27.3 & 13.6 & 2.3 & 2.2 & 43 & 2.3 & 2.3 & 16.3 & 69.8 & 9.3 \\
\hline PMHNP & 51 & B0.4 & 17.6 & 2.0 & 0 & 1.1 & 49 & 98.0 & 0 & 0 & 2.0 & 0 & 1.0 & 45 & 4.4 & 0 & 11.1 & 77.8 & 6.7 \\
\hline P'PP & 44 & 63.6 & 27.3 & 6.8 & 2.3 & 1.3 & 44 & 89.6 & 4.5 & 6.8 & 0 & 0 & 1.1 & 43 & 7.0 & 0 & 23.3 & 60.5 & 9.3 \\
\hline NH & 32 & 56.3 & 25.0 & 12.5 & 6.3 & 1.4 & 30 & 73.3 & 20.0 & 3.3 & 3.3 & 0 & 1.2 & 32 & 0 & 9.4 & 12.5 & 71.9 & 6.3 \\
\hline \multicolumn{20}{|c|}{ Providing primary care to patients and famllies (function no. 11) } \\
\hline ANP & 63 & 0 & 7.9 & 36.5 & 55.6 & 3.6 & 64 & 6.3 & 4.7 & 6.3 & 23.4 & 59.4 & 4.7 & 61 & 0 & 1.6 & 18.0 & 80.3 & 0 \\
\hline HHCNP & 53 & 1.9 & 3.8 & 24.5 & 69.8 & 3.8 & 53 & 5.7 & 7.5 & 11.3 & 20.8 & 54.7 & 4.6 & 47 & 0 & 6.4 & 40.4 & 48.9 & 4.3 \\
\hline FNP & 50 & 0 & 0 & 20.0 & 80.0 & 3.9 & 49 & 4.1 & 2.0 & 4.1 & 12.2 & 77.6 & 4.9 & 49 & 0 & 6.3 & 16.7 & 72.9 & 4.2 \\
\hline FMHNP & 51 & 3.9 & 7.9 & 15.7 & 72.5 & 3.8 & 51 & 9.8 & 9.8 & 17.6 & 15.7 & 47.1 & 4.3 & 49 & 0 & 8.2 & 26.5 & 63.3 & 2.0 \\
\hline PNP & 49 & 2.1 & 2.1 & 27.1 & 69.8 & 3.8 & 48 & 4.2 & 4.2 & 2.1 & 14.6 & 75.0 & 4.8 & 48 & 0 & 4.2 & 29.2 & 60.4 & 6.3 \\
\hline NM & 33 & 6.1 & 3.0 & 18.2 & 72.7 & 3.8 & 33 & 9.1 & 3.0 & 3.0 & 12.1 & 72.7 & 4.8 & 30 & 0 & 10.0 & 10.0 & 80.0 & 0 \\
\hline
\end{tabular}


TABLE $\times$ (CONTINUED)

\begin{tabular}{|c|c|c|c|c|c|c|c|c|c|c|c|c|c|c|c|c|c|c|c|}
\hline \multirow{2}{*}{$\begin{array}{l}\text { Speclalt } \\
\text { Area }\end{array}$} & \multirow{2}{*}{ n } & \multicolumn{5}{|c|}{ Level of Competence ${ }^{a}$} & \multicolumn{7}{|c|}{ Frequency of Use $\mathrm{b}^{\mathrm{b}}$} & \multicolumn{6}{|c|}{ Place in NP Preparation $c$} \\
\hline & & (a) & (b) & (c) & (d) & Med & $\bar{n}$ & (a) & (b) & (c) & (d) & (e) & $\overline{\text { Med }}$ & $\bar{n}$ & (a) & (b) & (c) & (d) & (e) \\
\hline \multicolumn{20}{|c|}{ Dlagnose and treat acute ot ltis medla (function no. 26) } \\
\hline ANP & 65 & 1.5 & 19.5 & 29.2 & 50.8 & 3.5 & 64 & 21.9 & 23.4 & 26.6 & 20.3 & 7.8 & 2.7 & 63 & 1.6 & 0 & 4.8 & 84.1 & 9.5 \\
\hline MHCNP & 54 & 40.7 & 14.8 & 27.8 & 16.7 & 2.1 & 55 & 63.6 & 18.2 & 10.9 & 5.5 & 1.8 & 1.3 & 50 & 0 & 0 & 26.0 & 62.0 & 12.0 \\
\hline FNP & 52 & 3.8 & 0 & 17.3 & 78.8 & 3.9 & 52 & 13.5 & 7.7 & 17.3 & 23.1 & 33.5 & 4.0 & 51 & 0 & 2.0 & 13.7 & 32.4 & 2.0 \\
\hline PMHNP & 51 & 80.4 & 15.7 & 2.0 & 2.0 & 1.1 & 50 & 100.0 & 0 & 0 & 0 & 0 & 1.0 & 46 & 2.2 & 0 & 0 & 97.8 & 0 \\
\hline PNP & 50 & 0 & 0 & 14.0 & 86.0 & 3.9 & 50 & 12.0 & 4.0 & 14.0 & 12.0 & 58.0 & 4.6 & 50 & 0 & 2.0 & 22.0 & 72.0 & 4.0 \\
\hline$N$ & 34 & 26.5 & 23.5 & 44.1 & 5.9 & 2.5 & 32 & 43.8 & 37.5 & 18.8 & 0 & 0 & 1.7 & 33 & 0 & 3.0 & 12.1 & 81.8 & 3.0 \\
\hline \multicolumn{20}{|c|}{ Incise and drain abscess (function no, 28) } \\
\hline ANP & 65 & 44.6 & 19.5 & 19.5 & 18.5 & 1.8 & 64 & 70.3 & 9.4 & 12.5 & 6.3 & 1.6 & 1.2 & 60 & 3.3 & 1.7 & 13.3 & 56.7 & 25.0 \\
\hline WHCNP & 56 & 58.9 & 23.2 & 10.7 & 7.1 & 1.3 & 56 & 89.3 & 7.1 & 1.8 & 1.8 & 0 & 1.1 & 50 & 2.0 & 6.0 & 20.0 & 59.0 & 14.0 \\
\hline FNP & 52 & 17.3 & 28.8 & 29.8 & 25.0 & 2.6 & 52 & 46.2 & 26.9 & 15.4 & 7.7 & 3.5 & 1.6 & 51 & 3.9 & 2.0 & 11.8 & 68.6 & 13.7 \\
\hline PMHNP & 51 & 86.3 & 7.8 & 5.9 & 0 & 1.1 & 50 & 100.0 & 0 & 0 & 0 & 0 & 1.0 & 46 & 8.7 & 0 & 17.4 & 69.6 & 4.3 \\
\hline PNP & 50 & 62.0 & 24.0 & 12.0 & 2.0 & 1.3 & 50 & 86.0 & 12.0 & 2.0 & 0 & 0 & 1.1 & 49 & 6.1 & 2.0 & 16.3 & 57.1 & 19.4 \\
\hline$N$ & 34 & 64.7 & 20.6 & 11.8 & 2.9 & 1.3 & 32 & 90.6 & 9.4 & 0 & 0 & 0 & 1.1 & 33 & 0 & 6.1 & 15.2 & 72.7 & 6.1 \\
\hline
\end{tabular}


TABLE $X$ (CONTINUED)

\begin{tabular}{|c|c|c|c|c|c|c|c|c|c|c|c|c|c|c|c|c|c|c|c|}
\hline \multirow{2}{*}{$\begin{array}{l}\text { Speclalty } \\
\text { Area }\end{array}$} & \multicolumn{6}{|c|}{ Level of Competence ${ }^{a}$} & \multicolumn{7}{|c|}{ Frequency of Use ${ }^{b}$} & \multicolumn{6}{|c|}{ Place in NP Preparation ${ }^{c}$} \\
\hline & $n$ & (a) & (b) & (c) & (d) & Med & $n$ & (a) & (b) & (c) & (d) & (e) & Med & $n$ & (a) & (b) & (c) & (d) & (e) \\
\hline \multicolumn{20}{|c|}{ Taping ankle, } \\
\hline ANP & 63 & 17.5 & 42.9 & 20.6 & 19.0 & 2.3 & 63 & 63.5 & 12.7 & 15.9 & 6.3 & 1.6 & 1.3 & 58 & 3.4 & 6.9 & 31.0 & 34.5 & 24.1 \\
\hline WHCNP & 53 & 52.8 & 32.1 & 13.2 & 1.9 & 1.4 & 54 & 96.3 & 1.9 & 1.9 & 0 & 0 & 1.0 & 48 & 2.1 & 25.0 & 20.8 & 33.3 & 18.8 \\
\hline FNP & 51 & 13.7 & 35.3 & 25.5 & 25.5 & 2.5 & 51 & 43.1 & 29.4 & 19.6 & 7.8 & 0 & 1.7 & 49 & 2.0 & 12.2 & 32.7 & 19.4 & 34.7 \\
\hline PMHAP & 51 & 54.9 & 27.5 & 7.8 & 9.8 & 1.4 & 50 & 94.0 & 4.0 & 2.0 & 0 & 0 & 1.0 & 49 & 2.1 & 27.1 & 43.8 & 19.8 & 3.3 \\
\hline PNP & 50 & 26.0 & 36.0 & 22.0 & 16.0 & 2.2 & 49 & 75.5 & 18.4 & 4.1 & 2.0 & 0 & 1.2 & 49 & 0 & 12.2 & 38.8 & 22.4 & 26.5 \\
\hline 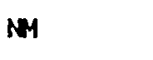 & 34 & 70.6 & 14.7 & 11.8 & 2.9 & 1.2 & 34 & 97.1 & 2.9 & 0 & 0 & 0 & 1.0 & 31 & 3.2 & 22.6 & 35.5 & 35.5 & 3.2 \\
\hline \multicolumn{20}{|c|}{ Asplrate folnt fluid from knee (function no. 31) } \\
\hline ANP & 65 & 83.1 & 6.2 & 10.8 & 0 & 1.1 & 64 & 90.6 & 6.3 & 3.1 & 0 & 0 & 1.1 & 63 & 15.9 & 0 & 4.8 & 41.3 & 33.1 \\
\hline WHCKP & 55 & 98.2 & 1.8 & 0 & 0 & 1.0 & 54 & 100.0 & 0 & 0 & 0 & 0 & 1.0 & 49 & 10.4 & 0 & 8.3 & 64.6 & 16.7 \\
\hline FNP & 52 & 65.4 & 13.5 & 21.2 & 0 & 1.3 & 52 & 79.8 & .17 .3 & 3.8 & 0 & 0 & 1.1 & 51 & 17.6 & 2.0 & 2.0 & 35.3 & 43.1 \\
\hline PMHNP & 51 & 98.0 & 2.0 & 0 & 0 & 1.0 & 49 & 99.0 & 0 & 0 & 2.0 & 0 & 1.0 & 45 & 20.0 & 0 & 0 & 68.9 & 11.1 \\
\hline PNP & 48 & 100.0 & 0 & 0 & 0 & 1.0 & 49 & 100.0 & 0 & 0 & 0 & 0 & 1.0 & 49 & 22.9 & 0 & 6.3 & 52.1 & 19.8 \\
\hline N4 & 34 & 100.0 & 0 & 0 & 0 & 1.0 & 32 & 100.0 & 0 & 0 & 0 & 0 & 1.0 & 32 & 9.4 & 3.1 & 3.1 & 69.8 & 15.6 \\
\hline
\end{tabular}


TABLE $\times$ (CONTINUED)

\begin{tabular}{|c|c|c|c|c|c|c|c|c|c|c|c|c|c|c|c|c|c|c|c|}
\hline \multirow{2}{*}{$\begin{array}{l}\text { Speclalty } \\
\text { Area }\end{array}$} & \multicolumn{6}{|c|}{ Level of Competence ${ }^{a}$} & \multicolumn{7}{|c|}{ Frequency of Use ${ }^{b}$} & \multicolumn{6}{|c|}{ Place In NP Preparationc } \\
\hline & $n$ & (a) & (b) & (c) & (d) & Med & $\bar{n}$ & (a) & (b) & (c) & (d) & (e) & Med & n & (a) & (b) & (c) & (d) & (e) \\
\hline \multicolumn{20}{|c|}{ Set fracture (function no. 35 ) } \\
\hline ANP & 65 & 39.2 & 1.5 & 9.2 & 0 & 1.1 & 64. & 95.3 & 4.7 & 0 & $\mathbf{0}$ & 0 & 1.0 & 60 & 21.7 & 0 & 6.7 & 33.3 & 38.3 \\
\hline WHCAP & 55 & 100.0 & $\mathbf{0}$ & 0 & 0 & 1.0 & 54 & 99.1 & 1.9 & 0 & 0 & 0 & 1.0 & 47 & 17.0 & 0 & 2.1 & 61.7 & 19.1 \\
\hline FNP & 52 & 78.8 & 11.5 & 5.8 & 3.8 & 1.1 & 52 & 90.4 & 9.6 & 0 & 0 & 0 & 1.1 & 51 & 19.6 & 0 & 2.0 & 43.1 & 35.3 \\
\hline PMHNP & 51 & 99.0 & 2.0 & 0 & 0 & 1.0 & 46 & 100.0 & 0 & 0 & 0 & 0 & 1.0 & 43 & 30.2 & 0 & 2.3 & 55.9 & 11.6 \\
\hline PNP & 48 & 93.8 & 2.1 & 4.2 & 0 & 1.0 & 49 & 97.9 & 2.1 & 0 & 0 & 0 & 1.0 & 49 & 22.4 & 0 & 9.2 & 51.0 & 18.4 \\
\hline MM & 34 & 100.0 & 0 & 0 & 0 & 1.0 & 32 & 96.9 & 3.1 & 0 & 0 & 0 & 1.0 & 32 & 15.6 & 3.1 & 3.1 & 68.8 & 9.4 \\
\hline \multicolumn{20}{|c|}{ Using fudgment and initiative making health care decislons (function no. 3) } \\
\hline ANP & 64 & 0 & 1.6 & 26.6 & 71.9 & 3.8 & 64 & 0 & 0 & 4.7 & 14.1 & 89.3 & 4.9 & 59 & 0 & 13.6 & 47.5 & 33.9 & 5.1 \\
\hline WHCNP & 54 & 0 & 9.3 & 89.9 & 1.9 & 4.0 & 52 & 0 & 0 & 1.9 & 9.6 & 88.5 & 4.9 & 50 & 0 & 24.0 & 52.0 & 20.0 & 4.0 \\
\hline FNP & 51 & 0 & 0 & 13.7 & 96.3 & 3.9 & 51 & 0 & 0 & 0 & 13.7 & 86.3 & 4.9 & 50 & 0 & 14.0 & 34.0 & 48.0 & 4.0 \\
\hline PMHNP & 52 & 0 & 0 & 17.3 & 82.7 & 3.9 & 51 & 0 & 3.9 & 0 & 25.5 & 70.6 & 4.8 & 51 & 0 & 5.9 & 60.8 & 33.3 & 0 \\
\hline PNP & 50 & 0 & 0 & 32.0 & 69.0 & 3.9 & 50 & 0 & 0 & 6.0 & 14.0 & 80.0 & 4.9 & 49 & 2.0 & 14.3 & 55.1 & 24.5 & 4.1 \\
\hline NM & 33 & 0 & 0 & 6.1 & 93.9 & 3.9 & 33 & 0 & 0 & 0 & 15.2 & 84.8 & 4.9 & 29 & 0 & 17.2 & 49.3 & 34.5 & 0 \\
\hline
\end{tabular}


TABLE $\times$ (CONTINUED $)$

\begin{tabular}{|c|c|c|c|c|c|c|c|c|c|c|c|c|c|c|c|c|c|c|c|}
\hline \multirow{2}{*}{$\begin{array}{l}\text { Specialt } \\
\text { Area }\end{array}$} & \multirow{2}{*}{$n$} & \multicolumn{5}{|c|}{ Level of Competence ${ }^{a}$} & \multicolumn{7}{|c|}{ Frequency of Use ${ }^{b}$} & \multicolumn{6}{|c|}{ Place In NP Preparationc } \\
\hline & & (a) & (b) & (c) & (d) & $\overline{\text { Med }}$ & $\bar{n}$ & (a) & (b) & (c) & (d) & $(e)$ & $\overline{\text { Med }}$ & $\bar{n}$ & (a) & (b) & (c) & (d) & (e) \\
\hline \multicolumn{20}{|c|}{ Evaluating the health care provided by physicians (function no. 9) } \\
\hline ANP & 65 & 1.5 & 9.2 & 49.2 & 40.0 & 3.3 & 64 & 7.8 & 12.5 & 21.9 & 35.9 & 21.9 & 3.7 & 62 & 11.3 & 1.6 & 22.6 & 58.1 & 6.5 \\
\hline WHCNP & 55 & 0 & 3.6 & 50.9 & 45.5 & 3.4 & 54 & 9.3 & 24.1 & 33.3 & 24.1 & 9.3 & 3.0 & 45 & 4.4 & 15.6 & 37.8 & 37.8 & 4.4 \\
\hline FNP & 51 & 0 & 5.9 & 59.8 & 35.3 & 3.2 & 51 & 2.0 & 11.8 & 29.4 & 39.2 & 17.6 & 3.7 & 51 & 3.9 & 9.8 & 21.6 & 56.9 & 7.8 \\
\hline PMHNP & 52 & 3.8 & 7.7 & 38.5 & 50.0 & 3.5 & 51 & 7.8 & 19.6 & 43.1 & 17.6 & 11.8 & 3.0 & 51 & 3.9 & 2.0 & 21.6 & 68.6 & 3.9 \\
\hline $\mathbf{P N P}$ & 48 & 4.2 & 12.5 & 64.6 & 19.9 & 3.0 & 49 & 14.3 & 22.4 & 39.9 & 18.4 & 6.1 & 2.8 & 47 & 8.5 & 6.4 & 44.7 & 29.9 & 10.6 \\
\hline MM & 34 & 0 & 2.9 & 50.0 & 47.1 & 3.4 & 34 & 11.9 & 11.8 & 38.2 & 23.5 & 14.7 & 3.2 & 30 & 6.7 & 13.3 & 36.7 & 36.7 & 6.7 \\
\hline \multicolumn{20}{|c|}{ Managing pa } \\
\hline ANP & 61 & 0 & 3.3 & 27.9 & 68.9 & 3.8 & 61 & 23.0 & 11.5 & 18.0 & 27.9 & 19.7 & 3.4 & 60 & 3.3 & 10.0 & 35.0 & 45.0 & 6.7 \\
\hline WHCNP & 53 & 11.3 & 15.1 & 34.0 & 39.6 & 3.2 & 52 & 50.0 & 23.1 & 13.5 & 3.8 & 9.6 & 1.5 & 46 & 0 & 19.6 & 32.6 & 43.5 & 4.3 \\
\hline FNP & 51 & 0 & 7.8 & 19.6 & 72.5 & 3.8 & 51 & 11.8 & 21.6 & 19.6 & 15.7 & 31.4 & 3.4 & 50 & 0 & 12.0 & 36.0 & 48.0 & 4.0 \\
\hline PMHFP & 48 & 8.3 & 6.3 & 22.9 & 62.5 & 3.7 & 47 & 44.7 & 17.0 & 21.3 & 9.5 & 8.5 & 1.8 & 46 & 2.2 & 13.0 & 60.9 & 19.6 & 4.3 \\
\hline PNP & 49 & 8.2 & 12.2 & 40.8 & 39.8 & 3.2 & 49 & 44.9 & 20.4 & 16.3 & 8.2 & 10.2 & 1.7 & 47 & 0 & 3.5 & 42.6 & 39.3 & 10.6 \\
\hline NM & 34 & 38.2 & 20.6 & 23.5 & 17.6 & 2.1 & 34 & 64.7 & 11.8 & 17.6 & 2.9 & 2.9 & 1.3 & 32 & 0 & 12.5 & 18.8 & 62.5 & 6.3 \\
\hline
\end{tabular}


TABLE $X$ (CONTINUED)

\begin{tabular}{|c|c|c|c|c|c|c|c|c|c|c|c|c|c|c|c|c|c|c|c|}
\hline \multirow{2}{*}{$\begin{array}{l}\text { Specialty } \\
\text { Area }\end{array}$} & \multicolumn{6}{|c|}{ Level of Competence ${ }^{a}$} & \multicolumn{7}{|c|}{ Frequency of Use ${ }^{b}$} & \multicolumn{6}{|c|}{ Place in IP Preparationc } \\
\hline & $n$ & (a) & (b) & (c) & (d) & Med & $n$ & (a) & (b) & (c) & (d) & (e) & $\overline{\text { Med }}$ & $\bar{n}$ & (a) & (b) & (c) & (d) & (e) \\
\hline \multicolumn{20}{|c|}{ Evaluate and prescribe medlcations in your specialty (function no. 37) } \\
\hline ANP & 65 & 1.5 & 7.7 & 20.0 & 70.8 & 3.8 & 65 & 4.6 & 3.1 & 13.8 & 9.2 & 69.2 & 4.8 & 61 & 1.6 & 0 & 4.9 & 88.5 & 4.9 \\
\hline MHCNP & 55 & 1.8 & 0 & 3.6 & 94.5 & 3.9 & 55 & 0 & $\mathbf{0}$ & 3.6 & 10.9 & 85.5 & 4.9 & 48 & $\mathbf{0}$ & 0 & 20.3 & 66.7 & 12.5 \\
\hline FNP & 51 & 0 & 2.0 & 15.7 & 82.4 & 3.9 & 52 & 0 & 1.9 & 9.6 & 19.2 & 69.2 & 4.8 & 52 & 0 & 1.9 & 5.8 & 84.6 & 7.7 \\
\hline PMHNP & 52 & 13.5 & 9.6 & 21.2 & 55.8 & 3.6 & 51 & 41.2 & 5.9 & 3.9 & 11.8 & 37.3 & 3.3 & 51 & 2.0 & 0 & 0 & 98.2 & 9.8 \\
\hline PNP & 47 & 2.1 & 4.3 & 36.2 & 57.4 & 3.6 & 48 & 9.3 & 4.2 & 20.8 & 12.5 & 54.2 & 4.6 & 48 & 0 & 2.1 & 16.7 & 70.8 & 10.4 \\
\hline NM & 34 & 0 & 5.9 & 20.6 & 73.5 & 3.8 & 33 & 3.0 & 3.0 & 9.1 & 27.3 & 57.6 & 4.6 & 32 & 0 & 3.1 & 9.4 & 94.4 & 3.1 \\
\hline \multicolumn{20}{|c|}{ Initiate drug therapy (function no. 29) } \\
\hline ANP & 65 & 0 & 6.2 & 38.5 & 55.4 & 3.6 & 65 & 3.1 & 10.8 & 21.5 & 19.5 & 46.2 & 4.3 & 60 & 1.7 & 0 & 1.7 & 93.3 & 3.3 \\
\hline WHCNP & 56 & 3.6 & 0 & 23.2 & 73.2 & 3.8 & 56 & 3.6 & 3.6 & 7.1 & 21.4 & 64.3 & 4.7 & 50 & 0 & 0 & 22.0 & 66.0 & 12.0 \\
\hline FNP & 52 & 1.9 & 5.8 & 23.1 & 69.2 & 3.8 & 52 & 3.8 & 3.8 & 13.5 & 19.2 & 59.6 & 4.7 & 52 & 0 & 1.9 & 7.7 & 94.5 & 1.8 \\
\hline PMHNP & 52 & 28.3 & 13.5 & 29.3 & 25.8 & 2.8 & 51 & 52.9 & 5.9 & 13.7 & 13.7 & 13.7 & 1.4 & 48 & 4.2 & 0 & 0 & 97.5 & 8. 3 \\
\hline PNP & 48 & 8.3 & 4.2 & 35.4 & 52.1 & 3.5 & 47 & 14.9 & 9.5 & 14.9 & 10.6 & 51.1 & 4.5 & 48 & 0 & 2.1 & 14.6 & 75.0 & 8.3 \\
\hline NM & 33 & 0 & 12.1 & 42.4 & 45.5 & 3.4 & 32 & 9.4 & 9.4 & 15.8 & 31.3 & 31.3 & 3.9 & 33 & 0 & 3.0 & 9.1 & 87.9 & 0 \\
\hline
\end{tabular}


TABLE $\times($ CONTINUED $)$

\begin{tabular}{|c|c|c|c|c|c|c|c|c|c|c|c|c|c|c|c|c|c|c|c|}
\hline \multirow{2}{*}{$\begin{array}{l}\text { Specialty } \\
\text { Area }\end{array}$} & \multirow{2}{*}{$n$} & \multicolumn{5}{|c|}{ Level of Competence ${ }^{a}$} & \multicolumn{7}{|c|}{ Frequency of Use ${ }^{\mathbf{b}}$} & \multicolumn{6}{|c|}{ Place in NP Preparation ${ }^{c}$} \\
\hline & & (a) & (b) & (c) & (d) & Med & $\bar{n}$ & (a) & (b) & (c) & (d) & (e) & $\overline{\text { Med }}$ & $n$ & (a) & (b) & (c) & (d) & (e) \\
\hline \multicolumn{20}{|c|}{ Make dellvery } \\
\hline ANP & 63 & 85.7 & 9.5 & 4.8 & 0 & 1.1 & 63 & 99.4 & 1.6 & 0 & 0 & $\mathbf{0}$ & 1.0 & 60 & 6.7 & 0 & 6.7 & 91.7 & 5.0 \\
\hline WHCNP & 56 & 76.8 & 16.1 & 5.4 & 1.8 & 1.2 & 55 & 96.4 & 0 & 1.8 & 1.8 & 0 & 1.0 & 51 & 2.0 & 0 & 11.8 & 79.4 & 7.8 \\
\hline FNP & 52 & 63.5 & 23.1 & 5.8 & 7.7 & 1.3 & 51 & 90.2 & 5.9 & 3.9 & 0 & 0 & 1.1 & 51 & 9.8 & 2.0 & 3.9 & 76.5 & 7.8 \\
\hline PMHNP & 50 & 86.0 & 10.0 & 4.0 & 0 & 1.1 & 49 & 100.0 & 0 & 0 & 0 & 0 & 1.0 & 45 & 4.4 & 0 & 6.7 & 83.9 & 0 \\
\hline PNP & 49 & 98.0 & 2.0 & 0 & 0 & 1.0 & 49 & 100.0 & 0 & 0 & 0 & 0 & 1.0 & 49 & 0 & 2.0 & 12.2 & 79.6 & 6.1 \\
\hline$N M$ & 34 & 0 & 0 & 5.9 & 94.1 & 3.9 & 31 & 22.6 & 0 & 3.2 & 19.4 & 54.8 & 4.6 & 32 & 0 & 3.1 & 6.3 & 87.5 & 3.1 \\
\hline
\end{tabular}

Note:

Med $=$ Median

bF requency of Use

ANP = Adult Nurse Practitloners

WHCNP = Women's Health Care Nurse Practitioners

FNP = Family Nurse Practitloners

PMHNP = Psychiatric Mental Health Nurse Practitloners

PNP = Pediatric Nurse Practitioners

NM = Nurse MIdwife
(a) Never-little or no need to use the function
(b) Rarely-monthly
(c) Occasionally-a few times a month
(d) Frequently-several times weekly or every day
(e) All the time-several times every day

aLevel of Competence

Cplace in NP Preparation

(a) Should NOT be included in NP Preparation

(b) Assoclate programs

(a) Do not feel competent at this time

(c) Baccalaureate programs

(b) Feel slightly competent

(c) Feel moderately competent

(d) Graduate degree programs

(e) Continuing education includes courses, seminars, conferences, etc. 
TABLE XI

RESULTS OF CHI-SQUARE TESTS ON RESPONSES* TO MANACEMENT OF HEALTH CARE FUNCTIONS

\begin{tabular}{|c|c|c|c|c|c|c|c|c|c|c|c|c|}
\hline \multirow[b]{2}{*}{ Functions } & \multicolumn{4}{|c|}{ Level of Competence } & \multicolumn{4}{|c|}{ Frequency of Use } & \multicolumn{4}{|c|}{ Place In NP Preparation } \\
\hline & $\underline{x^{2}}$ & df & $\mathbf{p}$ & Note & $\underline{x^{2}}$ & df & p & I:ote & $\underline{x^{2}}$ & $d f$ & $\mathrm{p}$ & Note \\
\hline $\begin{array}{l}\text { 7. Using a problem-solving } \\
\text { process to plan, provide, } \\
\text { and evaluate the primary } \\
\text { care for a client and } \\
\text { their entire Pamily }\end{array}$ & 7.43 & 5 & .1903 & $\begin{array}{l}\text { combines } \\
(\mathrm{a})(\mathrm{b})(\mathrm{c})\end{array}$ & 27.45 & 15 & .0253 & $\begin{array}{l}\text { combines } \\
\text { (a) \& (b) }\end{array}$ & 10.50 & 10 & .3978 & $\begin{array}{l}\text { excludes } \\
\text { (a) \& (e) }\end{array}$ \\
\hline $\begin{array}{l}\text { 40. Ordering and/or perform- } \\
\text { ing diagnostic tests }\end{array}$ & 57.15 & 10 & .0000 & $\begin{array}{l}\text { combines } \\
\text { (a) \& (b) }\end{array}$ & 68.13 & 15 & .0000 & $\begin{array}{l}\text { combines } \\
\text { (a) \& (b) }\end{array}$ & 11.27 & 5 & .0463 & $\begin{array}{l}\text { excludes } \\
\text { (a)(b)(e) }\end{array}$ \\
\hline $\begin{array}{l}\text { 30. Manage abnormal pain } \\
\text { from distension }\end{array}$ & 100.70 & 15 & .0000 & & 75.56 & 10 & .0000 & $\begin{array}{l}\text { comblnes } \\
\text { (c) (d) (e) }\end{array}$ & 3.84 & 5 & .5725 & $\begin{array}{l}\text { excludes } \\
\text { (a)(b)(e) }\end{array}$ \\
\hline $\begin{array}{l}\text { 11. Providing primary care } \\
\text { to patients and } \\
\text { familles }\end{array}$ & 8.70 & 5 & .1216 & $\begin{array}{l}\text { comblnes } \\
(a)(b)(c)\end{array}$ & 22.92 & 10 & .0110 & $\begin{array}{l}\text { combines } \\
(a)(b)(c)\end{array}$ & 15.39 & 5 & .0008 & $\begin{array}{l}\text { excludes } \\
\text { (a) (b)(e) }\end{array}$ \\
\hline $\begin{array}{l}\text { 26. Dlagnose and treat acute } \\
\text { otitls medla }\end{array}$ & $\begin{array}{l}\text { e } \\
226.35\end{array}$ & 15 & .0000 & & 221.77 & 20 & .0000 & & 23.16 & 5 & .0003 & $\begin{array}{l}\text { excludes } \\
\text { (a)(b)(e) }\end{array}$ \\
\hline $\begin{array}{l}28 \text { Inclse and drain } \\
\text { abscess }\end{array}$ & 69.45 & 15 & .0000 & & 58.22 & 5 & .0000 & $\begin{array}{l}\text { combines } \\
(a)(c)(d)(e)\end{array}$ & 13.20 & 10 & .2129 & $\begin{array}{l}\text { excludes } \\
\text { (a) \& (e) }\end{array}$ \\
\hline $\begin{array}{l}\text { 14. Taping ankle, wrist or } \\
\text { knee for Immobilization }\end{array}$ & 63.05 & 15 & .0000 & & 73.30 & 10 & .0000 & $\begin{array}{l}\text { combines } \\
\text { (c)(d)(e) }\end{array}$ & 34.28 & 15 & .0031 & excludes (a) \\
\hline $\begin{array}{l}\text { 31. Aspirate foint fluid } \\
\text { from knee }\end{array}$ & 54.53 & 5 & .0000 & $\begin{array}{l}\text { no (d) } \\
\text { combines } \\
\text { (c) \& (b) }\end{array}$ & & & & $\begin{array}{l}\text { no Inter- } \\
\text { pretation } \\
\text { is possible }\end{array}$ & 25.99 & 5 & .0001 & $\begin{array}{l}\text { exc ludes } \\
\text { (a)(b)(c) }\end{array}$ \\
\hline
\end{tabular}


TABLE XI (CONTINUED)

\begin{tabular}{|c|c|c|c|c|c|c|c|c|c|c|c|c|}
\hline \multirow[b]{2}{*}{ Functions } & \multicolumn{4}{|c|}{ Level of Competence } & \multicolumn{4}{|c|}{ Frequency of Use } & \multicolumn{4}{|c|}{ Place in NP Preparation } \\
\hline & $\underline{x^{2}}$ & $\underline{\text { df }}$ & $\mathrm{p}$ & Note & $\underline{x^{2}}$ & $\underline{d f}$ & $\mathbf{p}$ & Note & $\underline{x^{2}}$ & df & $\mathrm{p}$ & Note \\
\hline 35. Set Practure & & & & $\begin{array}{l}\text { no inter- } \\
\text { pretation } \\
\text { is possible }\end{array}$ & & & & $\begin{array}{l}\text { no inter- } \\
\text { pretation } \\
\text { is possible }\end{array}$ & 24.76 & 10 & .0058 & $\begin{array}{l}\text { excludes } \\
\text { (b) \& (c) }\end{array}$ \\
\hline $\begin{array}{l}\text { 3. Using fudgment and inf- } \\
\text { tlat I ve making health } \\
\text { care decisions }\end{array}$ & 17.05 & 5 & .0044 & $\begin{array}{l}\text { no (a) } \\
\text { adds (b) to } \\
\text { (c) }\end{array}$ & 6.85 & 5 & .2322 & $\begin{array}{l}\text { combines } \\
\text { (a) (b)(c) } \\
\text { (d) }\end{array}$ & 17.04 & 10 & .0735 & $\begin{array}{l}\text { excludes } \\
\text { (a) (b) (e) }\end{array}$ \\
\hline $\begin{array}{l}9 \text { Evaluating the health } \\
\text { care provided by } \\
\text { physiclans }\end{array}$ & 13.08 & 5 & .0227 & $\begin{array}{l}\text { combines } \\
(a)(b)(c)\end{array}$ & 26.77 & 15 & .0307 & $\begin{array}{l}\text { combines } \\
\text { (a) \& (b) }\end{array}$ & 18.56 & 5 & .0023 & $\begin{array}{l}\text { excludes } \\
(\mathrm{a})(\mathrm{b})(\mathrm{e})\end{array}$ \\
\hline $\begin{array}{l}\text { 13. Managling patient with } \\
\text { chronic di sorders } \\
\text { according to standing } \\
\text { orders }\end{array}$ & 65.87 & 10 & .0000 & $\begin{array}{l}\text { comblnes } \\
\text { (a) \& (b) }\end{array}$ & 63.10 & 20 & .0000 & & 21.97 & 10 & .0153 & $\begin{array}{l}\text { excludes } \\
\text { (a) \& (e) }\end{array}$ \\
\hline $\begin{array}{l}\text { 37. Evaluate and prescribe } \\
\text { mediations in your } \\
\text { specialty }\end{array}$ & 25.77 & 5 & .0000 & $\begin{array}{l}\text { combines } \\
(\mathrm{a})(\mathrm{b})(\mathrm{c})\end{array}$ & 91.07 & 15 & .0000 & $\begin{array}{l}\text { combines } \\
\text { (a) \& (b) }\end{array}$ & & & & $\begin{array}{l}\text { no inter- } \\
\text { pretation } \\
\text { is possible }\end{array}$ \\
\hline 29. Int1ate drug therapy & 56.78 & 10 & .0000 & $\begin{array}{l}\text { combines } \\
\text { (a) \& (b) }\end{array}$ & 75.37 & 15 & .0000 & $\begin{array}{l}\text { combines } \\
\text { (a) \& (b) }\end{array}$ & & & & $\begin{array}{l}\text { no inter- } \\
\text { pretation } \\
\text { is possitle }\end{array}$ \\
\hline $\begin{array}{l}\text { 25. Make delivery following } \\
\text { uncomplicated pregnancy }\end{array}$ & 213.58 & 10 & .0000 & $\begin{array}{l}\text { combines } \\
\text { (c) \& (d) } 1\end{array}$ & 164.04 & 5 & .0000 & $\begin{array}{l}\text { comblines } \\
(b)(c)(d(e)\end{array}$ & & & & $\begin{array}{l}\text { no inter- } \\
\text { pretation } \\
\text { is possible }\end{array}$ \\
\hline
\end{tabular}


distension"); function 28 ("Incise and drain abscess"), and function 3 ("Using judgment and initiative making health care decisions"). Comparisons were not possible for functions 37 ("Evaluate and prescribe medications in your specialty"), 29 ("Initiate drug therapy"), and 25 ("Make delivery following uncomplicate pregnancy").

For function 7 ("Using a problem-solving process..."), the statistical hypothesis was not rejected for "Level of Competence" and "Place in NP Preparation"; the majority within each specialty feit very competent in this function, and, except for the FNPs who expressed a slight preference for graduate preparation, baccalaureate degree programs were chosen more frequently. The statistical hypothesis was rejected for "Frequency of Use," with "a" and "b" combined, chi-square $=27.5, \underline{\mathrm{df}}=15 ; \underline{\mathrm{p}}<.0253$. Thus for "Frequency of Use" of this function, a relationship was found with the speciatties. For each of the specialties, the median was at least 3.8, with the PMHNPS (Median $=4.5$ ) and NMs (median $=4.6$ ) expressing the highest usage and the WHCNPS (median $=3.8$ ) and the PNPS (median = 4.1) the lowest usage.

For function 40 ("Ordering and/or performing diagnostic tests"), the statistical hypotheses were rejected for all three categories: "Level of Competence" (with "a" and "b" combined, chisquare $=57.2, \underline{d f}=10 ; p<.0000$ ); "Frequency of Use" (with "a" and "b" combined, chi-square $=68.1$, df 15; $\mathrm{p}<.0000)$; and, "P1 ace in NP preparation" (contrasting " $c$ " and " $d$ " only, chi-square $=11.3$, df $=5 ; \mathrm{p}<.0463)$. Thus for each category, a relationship between the levels of the category and the specialties was found. In contrast 
with the other specialties, the PMHNPs expressed a lower level of competency and frequency of use (medians $=2.8$ and 2.6, respectively). With the exception of this group and the PNPS (with medians $=3.2$ and 3.7, , , the medians for "Level of Competency" and "Frequency of Use" for all specialties were at least 3.6 and 4.4. Although all specialties placed this function most often in graduate programs, the PMHNPs chose this category the most (88\%) and the WHCNPS chose it the least (57\%).

For function 30 ("Manage abnormal pain from distension"), the statistical hypothesis was not rejected for "Place in NP Preparation." The statistical hypotheses were rejected for the other two categories: "Level of competence" (chi-square $=100.7$, df $=15 ; p$ $<.0000$ ) and "Frequency of Use" (Combining "c," "d," and "e," chisquare $=75.6, \underline{d f}=10 ; \underline{p}<.0000)$. Therefore, significant relationships were found between the specialty groups and the response categories of "Level of Competence" and "Frequency of Use." Although comparatively low for all groups, the ANPS and FNPs expressed the most competence (median $=2.8$, each) and frequency of use (medians $=1.8$ and 2.2 ).

For function 11 ("Providing primary care to patients and families"), the statistical hypothesis for independence was not rejected for "Level of Competence"; the majority in each specialty reported themselves to have been "Very competent" in the performance of the function. The statistical hypotheses were rejected for each of the other two categories: "Frequency of Use" (with the first three response categories combined, chi-square $=22.9$, df $=10 ; \underline{p}$ 
$<.0110$ ) and "Place in NP Preparation" (contrasting " $c$ " and "d," chi-square $=15.4$, df $=5 ; \underline{p}<.0088)$. Thus for each of the two categories, a relationship was found between the specialties and the levels of the category. Although all specialties reported relatively high levels of use, the FNPs had the highest (median 4.9) and the PMHNPS the lowest (median $=4.3$ ). With respect to "Place in NP Preparation," at least $80 \%$ of the NMs and the ANPs assigned this function to graduate degree programs. The WHCNPS divided their assignment similarly between baccalaureate (40\%) and graduate (49\%) degree programs. The majority of the NPs in the other specialties assigned this function in graduate programs (60-70\%).

For function 26 ("Diagnose and treat acute otitis media"), the statistical hypotheses were rejected for all three categories: "Leve1 of Competence" (chi-square $=226.4$, df $=15 ; \underline{p}<.0000)$; "Frequency of Use " (chi-square $=221.8, \underline{d f}=20 ; \underline{p}<.0000)$; and, "Place in NP Preparation" (contrasting " $c$ " and "d," chi-square $=23.2$, df $=5 ; p<, 0003)$. Thus, for each category, a relationship was found between the specialties and the levels of the category. In contrast to the other specialties, the PMHNPs expressed a lower level of competence (median $=1.1$; the next lowest median was 2.1) and less frequent use of this function (median $=1.0$ ). The specialties expressing the greatest competency were the PNPS, FNPS, and ANPS (with medians of $3.9,3.9$, and 3.5 ); they all expressed the greatest usage (with medians $=4.6,4.0$, and 2.7). The PMHNPs (with the lowest expressed competence and usage) placed the function with greater frequency (78\%) in graduate programs. The lowest assignment 
to graduate programs was $62 \%$ by the WHCNPS. For the remaining four specialties, the range was $72 \%-84 \%)$.

For function 28 ("Incise and drain abscess"), the statistical hypothesis was not rejected for "Place in NP Preparation." The majority within each specialty placed this function in graduate programs. The statistical hypothesis was rejected for each of the other two categories: "Level of competence (chi-square $=69.5$, df $=15 ; \mathrm{p}<.0000$ ) and "Frequency of Use" (combining the last four response categories, chi-square $=58.2$, $\underline{d f}=5 ;(.0000)$. Therefore, significant relationships were found between specialty groups and the categories of "Level of Competence" and "Frequency of Use." The ANPs and the FNPs expressed the most competence (medians $=1.8$ and 2.6) and use (medians $=1.2$ and 1.6 ) of this function. In general the felt competence and utilization were low.

For function 14 ("Taping ankle, wrist, or knee for immobilization"), the statistical hypotheses were rejected for all three categories: "Level of Competence" (chi-square $=63.1, \underline{d f}=15 ; \underline{p}$ $<.0000$ ); "Frequency of Use" (combining the last three response categories, chi-square $=73.3, \underline{\mathrm{df}}=10 ; \underline{\mathrm{p}}(.0000)$; and, "Place in NP Preparation" (excluding "a," chi-square $=34.3$, $\underline{\mathrm{df}}=15 ; \underline{\mathrm{p}}<.0031$ ). Therefore, for each category, a relationship was found between its response categories and the specialties. In comparison with the other specialties, NMs, PMHNPs, and WHCNPS felt less competent (inedians $=1.2,1.4$, and 1.4) and used this function rarely (medians $=1.0$, each). Among choices which were generally low-moderate, the most competence and use was expressed by FNPs (medians $=2.5$ and 
1.7). With respect to "Place in NP Preparation," more of the FNPS (35\%) chose continuing education, but more of the PMHNPS and PNPS preferred baccalaureate degree programs (44\% and 39\%). Graduate degree programs were chosen more than any other response category by the ANPS (35\%) and the WHCNPS (33\%). The NMs chose evenly between baccalaureate and graduate programs, with $36 \%$ in each.

For function 31 ("Aspirate joint fluid from knee"), at least $79 \%$ of the NPs in the specialty groups expressed little or no use; no statistical comparison was performed because of low expected frequencies in all response categories except "a." The statistical hypotheses of independence were rejected for "Level of Competency" (contrasting " $c$ " and "b" with " $a$," chi-square $=54.5$, df $=5 ; \underline{p}$ $<.0000$ ) and PIace in NP Preparation" (contrasting "d" and "e," chisquare $=26.0, \underline{d f}=5 ; \underline{p}(.0001)$. Thus, relationships were found between specialties and the response categories of "Level of Competence" and "Place in NP Preparation." Though all specialties reported low competency, the medians for the FNPS and the ANPs were slightly greater than the medians for the other groups (1.3 and 1.1 , versus 1.0 for all other groups). The PMHNPs and the NMs chose graduate programs more often than any other response category $69 \%$ each). Except for $43 \%$ of the FNPS and $38 \%$ of the ANPs who chose continuing education, the majority of the NPS in the other specialties preferred graduate degree programs to provide the greatest emphasis of this function.

For function 35 ("Set fracture"), all groups expressed low competence and infrequent usage; the expected frequencies in both 
categories were too low for all response categories except "a" to permit a statistical test. The statistical hypothesis of independence for "Place in NP Preparation" was rejected (contasting "a" with "d" and with "e," chi-square $=24.8$, df $=10 ; \underline{p}<.0058)$. The NMS and WHCNPS, chose graduate degree programs to emphasize this function (69\% and 62\%), more than did any other specialty. Although the FNPS and the ANPs tended to split between graduate programs and continuing education, the ANPs expressed a preference for the latter $(38 \%)$, and more of the FNPs chose the former (43\%). With a range between 16\% (NMs) and 30\% (PMHNPs), many respondents in each group indicated that this function does not belong in NP preparation.

For function 3 ("Using judgment and initiative making health care decisions"), the statistical hypothesis was not rejected for "Frequency of Use" and "Place in NP Preparation." The statistical hypothesis was rejected for "Level of Competence" (with "b" and "c" combined to contrast with "d," chi-square $=17.1, \underline{d f}=5 ; \underline{p}$ $<.0044)$. Thus a relationship was found between specialties and response categories for "Level of Competence." Although the greatest competence was expressed by WHCNPS, FNPs, PMHNPs, and NMS (medians $=4.0,3.9,3.9$, and 3.9), the ANPs and PNPS were very close (medians $=3.8$, each) and the lowest. Except for the WHCNPs, a majority of the specialty groups felt "Very competent" in the performance of this function.

For function 9 ("Evaluating health care provided by physicians"), the statistical hypotheses for independence were rejected for all three categories: "Level of Competence" (combining "a," 
"b," and "c," chi-square $=13.1, \underline{d f}=5 ; \underline{p}<.0227)$; "Frequency of Use" (combining "a" and "b," chi-square = 26.8, $d f=15 ; \underline{p}<.0307$ ); and, "Place in NP Preparation" (contrasting " $c$ " and "d," chi-square $=18.6 \mathrm{df}=5 ; \underline{p}(.0023)$. Therefore, significant relationships were found between the specialty groups and the three categories of the function. The PMHNPS expressed the greatest competence (median =3.5). The PNPS reported the lowest competence and use (medians $=3.0$ and 2.8). The ANPS and FNPS indicated the greatest use (medians $=3.7$ ) of this function. The majority of ANPs $(58 \%)$, FNPS (57\%), and PMHNPS (69\%) chose graduate degree prograns. The other specialty groups tended to choose similarly between baccalaureate and graduate degree programs (WHCNP, 38\% - 38\%; PNPS, $45 \%-30 \%$; and NMs $37 \%-37 \%)$.

For function 13 ("Managing patient with chronic disorders according to standing orders"), the statistical hypotheses for independence were rejected for all three categories: "Level of Competence" (combining "a" and "b," chi-square $=65.9$, df $=10 ; \underline{p}$ <.0000); "Frequency of Use" (chi-square $=63.1$, df $=20 ; \underline{p}<.0000)$; and, "Place in NP Preparation" (excluding "a" and "e," chi-square $=22.0, \underline{d f}=10 ; p<.0153)$. Therefore, in each category a relationship was found between the specialties and the dimensions of the category. In contrast to the other specialties, the NMs expressed a lower level of competency and of usage (medians $=2.1,1.3$ ). The greatest competence and use were reported by the ANPs and the FNPS (medians $=3.8$ and 3.4 for each specialty). The PMHNPs and PNPS selected baccalaureate programs oftener than any other category $161 \%$ 
and $43 \%$ ); more of the NPS in the other specialties preferred graduate degree programs to emphasize this function (NMS 63\%, FNPS $48 \%$, WHCNPS $44 \%$, and ANPS $45 \%$ ).

For function 37 ("Evaluate and prescribe medications in your specialty"), all specialty groups expressed great unanimity in choosing graduate degree programs. No statistical comparison was performed because of low expected frequencies in all response categories except "d." The statistical hypotheses of independence were rejected for "Level of Competence" (combining the first three response categories, chi-square $=28.8$, $\underline{d f}=5 ; \underline{p}<.0000)$ and "Frequency of Use" (combining "a" and "b," chi-square = 91.1, $\underline{\text { df }}=15$; $\underline{p}<.0000)$. Thus, relationships were found between "Level of Competence" and "Frequency of Use." Although all the specialty groups expressed great competence in the performance of this function, the medians for the PMHNPS (3.6) and PNPs (3.6) were slightly lower than those of all the other groups (medians $=3.8$ or 3.9 ). With the PMHNPS reporting the least usage (median $=3.3$ ) and the most use indicated by the WHCNPs (median $=4.9$ ), the function was reported to be used "Several times every day" by the majority of the NPs in five of the six specialties.

For function 29 ("Initiate drug therapy"), all specialty groups agreed in their preference for major emphasis in graduate degree programs; no statistical comparison was performed because of low expected frequencies in all response categories except "d." The statistical hypotheses for independence were rejected for "Level of Competency" (combining "a" and "b," chi-square $=56.8, \underline{d f}=10 ; \underline{p}$ 
$<.0000$ ) and for "Frequency of Use" (combining "a" and "b,"

chi-square $=75.4, \underline{d f}=15 ; \underline{p}<.0000)$. Therefore, relationship were found between specialty groups and the categories of "Level of Competence" and "Frequency of Use." In contrast with the other groups, the PMHNPs expressed a lower level of comeptency (median $=2.8$, versus 3.4 for the next lowest group) and less frequent use (median $=1.4$, versus 3.9 for the next lowest group). In the other four groups, "Very competent" and "Several times every day" were chosen more often than any other in these two response categories for this function.

For function 25 ("Make delivery following uncomplicated pregnanc $y^{\prime \prime)}$, major emphasis was assigned to graduate degree programs by all specialty groups. No statistical comparison was performed because of low expected frequencies in all response categories except "d." The statistical hypotheses for independence were rejected for "Level of Competence" (combining "c" and "d," chi-square $=213.9$, $\underline{\mathrm{df}}=10 ; \underline{p}<.0000$ ) and for "Frequency of Use" (combining the last four response categories, chi-square $=164.1$, $\underline{d f}=5 ; \underline{p}$ $<.0000)$. Thus, relationships were found between specialties and the categories of "Level of Competence" and "Frequency of Use." With the exception of the NMs who reported the greatest competency and usage (medians $=3.9$ and 4.6 ), the groups expressed low competency and usage (median ranges $=1.0-1.3$ and $1.0-1.1$ ) 
Treatment in Collaboration

The results of the analysis of the Treatment in Collaboration functions are presented in this section for the total sample and for the six specialty groups.

Total Sample. Table XII shows that for this category in "Level of Competency," a majority (80\%) of the NPs felt "Very competent" while "Functioning as a collaborator with a physician" (function 8). Also most nurse practitioners (70\%) felt "Very competent" to "Perform physical examination with physician confirming heart and lung findings" (function 21). As a group, most of the nurse practitioners judged themselves to be "Very competent" or "Moderately competent" in all of the four functions in this category: Functions $8(99 \%), 21(85 \%), 4(97 \%)$, and $2(92 \%)$.

Function 21 ("Perform physical examination with physician...") was the most frequently used of these functions by the NPS, with $40 \%$ reporting using it "Several times every day"; (19\% more said they used it "Several times each week"). However, this function was reported also as being unused or little used by $25 \%$, the largest percent in the unused column of any function in the category. Two functions were performed frequently by a majority of the respondents: function 8 ("Functioning as a collaborator with a physician:), which $37 \%$ of the NPs said they used "Several times every day," and, an additional 37\% reported using "Several times each week"; function 4 ("Reducing the fragmentation and bringing continuity..." was performed by the respondents "Several times every day" and "Several times each week" at the rates of $36 \%$ and $34 \%$. The 
TABLE XII

PERCENTACE OF RESPONSES BY TREATMENT IN COLLABORATION FUNCTIONS

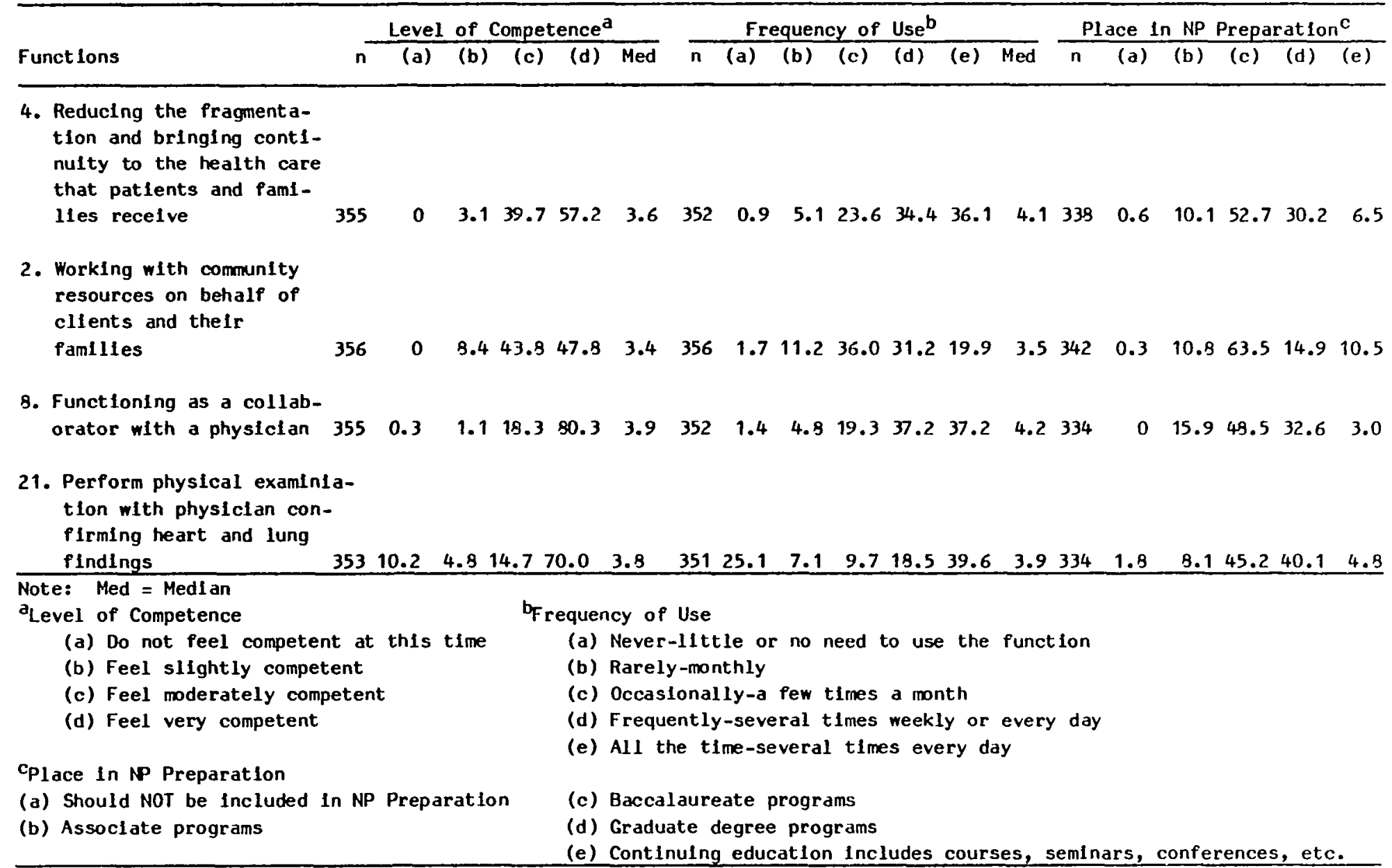


least used function (21, "Working with community resources....")

reportedly was used "A few times a month" by $36 \%$ of the respondents; an additional $51 \%$ of the NPs said they used it "Several times week $1 y$ " and "Several times a day."

The functions ( 8 and 4 ) which the NPs considered themselves to be more competent to perform were the functions most frequently used. The function (2) in which they identified a moderate competence was less used; (most respondents chose once a month). For function 21, the distribution was curvilinear for competence and frequency of usage, with more at the high end than at the low end for both.

In considering the "Place in NP Preparation in which these functions belong, a majority of the respondents assigned two of the functions in baccalaureate programs: "Working with community resources..." (function 2 -- 64\%) and "Reducing the fragmentation and bringing continuity..." (function 4 -- 53\%). More respondents to the other two functions also chose baccalaureate programs oftener than any other category: "Functioning as a collaborator with a physician (function 8 - 49\%) and "Perform physical examination with physician" (function 21 -- 45\%), for which an almost equal number of respondents $(40 \%)$ chose graduate programs. For all four functions, graduate degree programs were the second most often chosen for emphasis.

Therefore, all of the four functions in the category of Treatment in collaboration were recommended by the NPs to receive major emphasis in the baccalaureate or graduate nurse programs. No 
function was selected for omission from their preparation by a majority of the NPS. The fewest recommendations (0) for omission were received by function 8 ("Functioning as a collaborator with a physician"); the highest was 1.8\% for number 21 .

Although all of the functions in the category were chosen for associate degree nursing (ADN) programs by many of the respondents (range: $8 \%$-- 16\%), function 8 ("Functioning as a collaborator with a physician") was preferred for ADN by $16 \%$ of its respondents.

Each function was chosen by some NPS to be emphasized in continuing education programs. Function 2 ("Working with community resources...") was chosen by $11 \%$ of the NPS to receive major emphasis in continuing education.

Percentage of Responses by Specialty Areas to Treatment in Collaboration Functions. In Table XIII, are presented the responses by NPS in six specialties to the four functions in this category with respect to three response categories or columns: "Level of Competence," "Frequency of Use," and "Place in NP Preparation." Responses are discussed as percentages of choices by a specialty within the categories (columns) of each dimension. Where applicable, the median is shown for each specialty.

Table XIV presents the results of the chi-square testing of the Treatment in Collaboration functions. Within the "Level of Competence" category, the statistical hypothesis for independence was rejected for two of the four functions; a significant difference was not found for function 4 ("Reducing the fragmentation and bringing continuity...") and function 8 ("Functioning as a collaborator 


\section{TABLE XIII}

PERCENTACE OF RESPONSES BY SPECIALTY AREAS TO TREATMENT IN COLLABORATION FUNCTIONS

\begin{tabular}{|c|c|c|c|c|c|c|c|c|c|c|c|c|c|c|c|c|c|c|c|}
\hline \multirow{2}{*}{$\begin{array}{l}\text { Specilalty } \\
\text { Area }\end{array}$} & \multicolumn{6}{|c|}{ Level of Competence ${ }^{a}$} & \multicolumn{7}{|c|}{ Frequency of Use ${ }^{b}$} & \multicolumn{6}{|c|}{ Place in NP Preparation $c$} \\
\hline & $n$ & (a) & (b) & (c) & (d) & Med & $\bar{n}$ & (a) & (b) & (c) & (d) & (e) & Med & $\bar{n}$ & (a) & (b) & (c) & (d) & $(\mathrm{e})$ \\
\hline Reducing & g the & fra & nent at & Ion ar & d brin & ging & cont & Inulty & to the & health & care & at pat & ents & ind $f$ & $\mathrm{amll}$ & rece & e $(f u$ & tion $n$ & $0.4)$ \\
\hline ANP & 65 & $\mathbf{0}$ & 4.6 & 41.5 & 53.8 & 3.6 & 65 & 1.5 & 3.1 & 19.5 & 30.9 & 46.2 & 4.4 & 63 & 0 & 4.8 & 44.4 & 44.4 & 6.3 \\
\hline WHCNP & 54 & 0 & 1.9 & 37.0 & 61.1 & 3.7 & 53 & 0 & 3.8 & 26.4 & 35.8 & 34.0 & 4.1 & 50 & 0 & 24.0 & 49.0 & 16.0 & 12.0 \\
\hline FNP & 52 & 0 & 0 & 48.1 & 51.9 & 3.5 & 52 & 0 & 5.8 & 19.2 & 44.2 & 30.8 & 4.1 & 50 & 2.0 & 9.0 & 52.0 & 30.0 & 3.0 \\
\hline PMHNP & 52 & 0 & 3.8 & 40.4 & 55.8 & 3.6 & 52 & 3.8 & 5.8 & 34.6 & 28.8 & 26.9 & 3.7 & 52 & 0 & 1.9 & 65.4 & 32.7 & 0 \\
\hline PNP & 50 & 0 & 4.0 & 42.0 & 54.0 & 3.6 & 50 & 0 & 10.0 & 22.0 & 40.0 & 28.0 & 3.9 & 49 & 2.0 & 8.2 & 61.2 & 16.3 & 12.2 \\
\hline NN & 34 & 0 & 2.9 & 35.3 & 61.8 & 3.7 & 34 & 0 & 5.9 & 14.7 & 26.5 & 52.9 & 4.6 & 30 & 0 & 13.3 & 46.7 & 40.0 & 0 \\
\hline
\end{tabular}

Working with community resources on behalf of cllents and thelr familles (function no. 2)

\begin{tabular}{|c|c|c|c|c|c|c|c|c|c|c|c|c|c|c|c|c|c|c|c|}
\hline ANP & 65 & 0 & 12.3 & 52.3 & 35.4 & 3.2 & 65 & 1.5 & 16.9 & 41.5 & 23.1 & 16.9 & 3.3 & 64 & 0 & 7.8 & 62.5 & 15.6 & 14.1 \\
\hline HHCNP & 54 & 0 & 3.7 & 42.6 & 53.7 & 3.6 & 55 & 1.8 & 10.9 & 36.4 & 36.4 & 14.5 & 3.5 & 52 & 0 & 21.2 & 57.7 & 11.5 & 9.6 \\
\hline FNP & 52 & 0 & 7.7 & 55.8 & 36.5 & 3.3 & 52 & 1.9 & 3.8 & 42.3 & 34.6 & 17.3 & 3.6 & 51 & 2.0 & 7.8 & 60.8 & 19.6 & 9.9 \\
\hline PMHNP & 52 & 0 & 1.9 & 25.0 & 73.1 & 3.8 & 52 & 1.9 & 13.5 & 26.9 & 21.2 & 36.5 & 3.9 & 52 & 0 & 3.8 & 57.7 & 36.5 & 1.9 \\
\hline PNP & 50 & 0 & 6.0 & 46.0 & 48.0 & 3.5 & 50 & 0 & 8.0 & 20.0 & 50.0 & 22.0 & 3.9 & 47 & 0 & 3.5 & 72.3 & 19.1 & 0 \\
\hline$M$ & 34 & 0 & 3.9 & 59.3 & 32.4 & 3.2 & 34 & 2.9 & 11.8 & 35.3 & 38.2 & 11.8 & 3.5 & 32 & 0 & 12.5 & 69.8 & 9.4 & 9.4 \\
\hline
\end{tabular}


TABLE XIII (CONTINUED)

\begin{tabular}{|c|c|c|c|c|c|c|c|c|c|c|c|c|c|c|c|c|c|c|c|}
\hline \multicolumn{2}{|c|}{ Specialty } & \multicolumn{5}{|c|}{ Level of Competence ${ }^{a}$} & \multicolumn{7}{|c|}{ Frequency of Use ${ }^{b}$} & \multicolumn{6}{|c|}{ Place in NP Preparationc } \\
\hline Area & $n$ & (a) & (b) & (c) & (d) & Med & $n$ & (a) & (b) & (c) & (d) & (e) & Med & $\bar{n}$ & (a) & (b) & (c) & (d) & (e) \\
\hline \multicolumn{20}{|c|}{ Functioning } \\
\hline ANP & 65 & 0 & 1.5 & 26.2 & 72.3 & 3.8 & 64 & 0 & 4.7 & 19.8 & 29.7 & 46.9 & 4.4 & 62 & 0 & 3.1 & 48.4 & 37.1 & 6.5 \\
\hline WHCNP & 55 & 0 & 0 & 16.4 & 83.6 & 3.9 & 55 & 0 & 5.5 & 27.3 & 50.9 & 16.4 & 3.8 & 49 & $\mathbf{0}$ & 26.5 & 55.1 & 16.3 & 2.0 \\
\hline FNP & 51 & 0 & 0 & 23.5 & 76.5 & 3.8 & 51 & 2.0 & 2.0 & 15.7 & 35.3 & 45.1 & 4.4 & 50 & 0 & 14.0 & 36.0 & 48.0 & 2.0 \\
\hline PMHNP & 51 & 0 & 2.0 & 11.8 & 86.3 & 3.9 & 51 & 0 & 3.9 & 31.4 & 35.3 & 29.4 & 3.9 & 50 & 0 & 10.0 & 52.0 & 36.0 & 2.0 \\
\hline PNP & 50 & 2.0 & 4.0 & 22.0 & 72.0 & 3.8 & 50 & 6.0 & 8.0 & 14.0 & 26.0 & 46.0 & 4.3 & 48 & 0 & 18.8 & 66.7 & 14.6 & 0 \\
\hline NM & 34 & 0 & 0 & 11.8 & 88.2 & 3.9 & 33 & 0 & 6.1 & 18.2 & 39.4 & 36.4 & 4.2 & $2 B$ & 0 & 14.3 & 42.9 & 39.3 & 3.6 \\
\hline \multicolumn{20}{|c|}{ Ferform physical examination with physiclan confirming heart and lung findings (function no. 21) } \\
\hline ANP & 64 & 0 & 1.6 & 17.2 & 81.3 & 3.9 & 64 & 10.9 & 10.9 & 9.4 & 25.0 & 43.8 & 4.3 & 63 & 1.6 & 9.5 & 52.4 & 36.5 & 0 \\
\hline WHCNP & 54 & 3.7 & 5.6 & 14.8 & 76.0 & 3.8 & 54 & 16.7 & 11.1 & 5.6 & 14.8 & 51.9 & 4.5 & 45 & 2.2 & 15.6 & 48.9 & 26.7 & 6.7 \\
\hline $\mathbf{F N P}$ & 51 & 0 & 2.0 & 5.9 & 92.2 & 3.9 & 51 & 19.6 & 3.9 & 7.8 & 19.6 & 49.0 & 4.5 & 50 & 4.0 & 2.0 & 39.0 & 46.0 & 10.0 \\
\hline PMHNP & 51 & 54.9 & 19.6 & 19.6 & 5.9 & 1.4 & 50 & 89.0 & 4.0 & 6.0 & 2.0 & 0 & 1.1 & 48 & 2.1 & 3.3 & 43.8 & 43.8 & 2.1 \\
\hline PNP & 50 & 4.0 & 0 & 16.0 & $\mathbf{3 0 . 0}$ & 3.9 & 50 & 14.0 & 6.0 & 12.0 & 20.0 & 48.0 & 4.4 & 49 & 0 & 4.1 & 46.9 & 46.9 & 2.0 \\
\hline NM & 34 & 2.9 & 2.9 & 14.7 & 79.4 & 3.9 & 34 & 11.8 & 3.8 & 3.8 & 17.6 & 52.9 & 4.6 & 31 & 3.2 & 6.5 & 51.6 & 38.7 & 0 \\
\hline
\end{tabular}


TABLE XIII (CONTINUED)

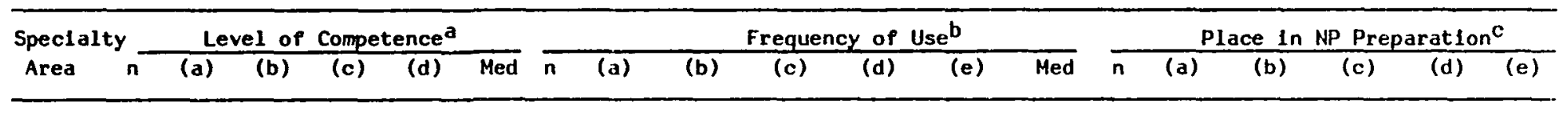

Note:

Med $=$ Medlan

ANP = Adult Nurse Practitioners

WHCNP $=$ Women's Health Care Nurse Practitloners

FNP = Famlly Nurse Practitioners

PMHNP = Psychlatric Mental Health Nurse Practitloners

PNP = Pedlatric Nurse Practitioners

NM = Nurse Midwife

a Level of Competence

(a) Do not feel competent at this time

(b) Feel slightly competent

(c) Feel moderately competent

(d) Feel very competent

brequency of Use

(a) Never-little or no need to use the function

(b) Rarely-monthly

(c) Occasionally-a few times a month

(d) Frequently-several times meekly or every day

(e) All the time-several times every day

CPlace in NP Preparation

(a) Should NOT be included in NP Preparation

(b) Assoclate programs

(c) Baccalaureate programs

(d) Graduate degree programs

(e) Continuing education Includes courses, seminars conferences, etc. 
TABLE XIV

RESULTS OF CHI-SQUARE IESTS ON RESPONSES* TO TREATMENT IN COLLABORATION FUNCTIONS

\begin{tabular}{|c|c|c|c|c|c|c|c|c|c|c|c|c|}
\hline \multirow[b]{2}{*}{ Functions } & \multicolumn{4}{|c|}{ Level of Competence } & \multicolumn{4}{|c|}{ Frequency of Use } & \multicolumn{4}{|c|}{ Place in NP Preparation } \\
\hline & $\underline{x^{2}}$ & $\underline{d f}$ & p & Note & $\underline{x^{2}}$ & df & $\mathbf{p}$ & Note & $\underline{x^{2}}$ & $\underline{d f}$ & $\mathrm{p}$ & Note \\
\hline $\begin{array}{l}\text { 7. Reducing the fragmenta- } \\
\text { tion and bringing consti } \\
\text { nulty to the health care } \\
\text { that patients and fami- } \\
\text { recelve }\end{array}$ & 1.59 & 5 & .9029 & $\begin{array}{l}\text { combines (b) } \\
\&(c) ; \text { no (a) }\end{array}$ & 16.52 & 10 & .0858 & $\begin{array}{l}\text { combines } \\
(a)(b)(c)\end{array}$ & 11.45 & 5 & .0432 & $\begin{array}{l}\text { excludes } \\
(\mathrm{a})(\mathrm{b})(\mathrm{e})\end{array}$ \\
\hline $\begin{array}{l}\text { 2. Working with community } \\
\text { resources on behalf of } \\
\text { clients and their } \\
\text { familles }\end{array}$ & 23.93 & 5 & .0002 & $\begin{array}{l}\text { combines (b) } \\
\&(c) ; \text { no (a) }\end{array}$ & 29.46 & 15 & .0140 & $\begin{array}{l}\text { comblnes } \\
\text { (a) \& (b) }\end{array}$ & 41.10 & 15 & .0003 & $\begin{array}{l}\text { excludes } \\
\text { (a) }\end{array}$ \\
\hline $\begin{array}{l}\text { 3. Functioning as a collab- } \\
\text { orator with a physician }\end{array}$ & 7.54 & 5 & .1837 & $\begin{array}{l}\text { combines } \\
(a)(b)(c)\end{array}$ & 19.86 & 10 & .0307 & $\begin{array}{l}\text { combines } \\
(\mathrm{a})(\mathrm{b})(\mathrm{c})\end{array}$ & 26.13 & 10 & .0036 & $\begin{array}{l}\text { excludes } \\
\text { (a) \& (e) }\end{array}$ \\
\hline $\begin{array}{l}\text { 21. Perform physlcal examin } \\
\text { tion with physician con } \\
\text { firming heart and lung } \\
\text { findings }\end{array}$ & 171.35 & 10 & .0000 & $\begin{array}{l}\text { comblnes } \\
\text { (a) \& (b) } 1\end{array}$ & 122.47 & 15 & .0000 & $\begin{array}{l}\text { combines } \\
\text { (b) \& (c) }\end{array}$ & 4.09 & 5 & .5361 & $\begin{array}{l}\text { excludes } \\
\text { (a)(b) (e }\end{array}$ \\
\hline
\end{tabular}

* Responses defined in Table XIII 
with a physician"). In considering "Frequency of Use" for these functions, the statistical hypothesis for independence was rejected for three of the four functions; the statistical hypothesis was not rejected for number 4 ("Reducing the fraginentation and oringing contininuity..."). For "Place in NP Preparation, the statistical hypothesis for independence was rejected for three of the four functions; it was not rejected for function 21 ("Perform physical examination with physician...").

For function 4 ("Reducing the fragmentation and bringing continuity..."), the statistical hypothesis was not rejected for "Level of Competence" and "Frequency of Use." The statistical hypothesis for independence was rejected for "Place in NP Preparation" (excluding " $a, "$ "b," and "e," chi-square = 11.5, df $=5 ; \underline{p}<.0432$ ). Thus a significant relationship was found between the specialty groups and "Place in NP preparation" for major emphasis of this function. A majority of the PMHNPS (65\%), PNPS (61\%), and FNPS (52\%) chose baccal aureate programs, which was the most frequently chosen response category for all groups. However, the ANPs split (44\%) between each of the baccalaureate and graduate degree programs. At least $2 \%$ of each group chose associate nursing programs, with $24 \%$ of the WHCNPS and $13 \%$ of the NMs so doing.

For function 2 ("Working with community resources on behalf of clients and their families"), the statistical hypotheses for independence were rejected for all three columns: "Level of Competence" (combining " $b$ " and " $c$ " -- "a" was not chosen, chi-square = 23.9, df $=5 ; p<.0002)$; "Frequency of Use" (combining " $a$ " and " $b$," chi- 
square $=29.5$, $\underline{\text { df }}=15 ; \underline{p}<.0140) ;$ and, "Place in NP Preparation" (exciuding : $a, "$ chi-square $=41.1$, df $=15 ; \underline{p}<.0003$ ). Therefore, in each column, a relationship was found with specialty groups. With a narrow range in medians for all the groups in "Level of Competence" and "Frequency of Use" (medians: 3.2-3.8 and 3.3-3.9), 73\% of the PMHNPs expressed themselves as "Very Competent" and reported the greatest usage ( $37 \%$ said they used this function "Several times every day"). They al so chose graduate degree programs more (37\%) than did any other group for major emphasis of this function. However, the majority in each group preferred baccalaureate programs. The ANPs and the NMs expressed the lowest competence (medians $=3.2$ ) and he lowest usage (medians = 3.3 and 3.5; the ANPs also placed this function in continuing education more than any other specialty (14\%).

For function 8 ("Functioning as a collaborator with a physician"), the statistical hypothesis was not rejected for "Level of Competence." All of the groups said they were "Very competent" in this function (medians ranged from 3.8 - 3.9). The statistical hypotheses for independence were rejected for "Frequency of Use" (combining "a," "b," and "c," chi-square = 19.9, df = 10; p <.0307) and for "Place in NP Preparation" (excluding "a" and "e," chi-square $=26.1, \underline{d f}=10 ; p<.0036)$. Thus, a relationship was found between specialties and response categories for both "Frequency of Use" and "Place in NP Preparation." In all the specialties, the majority of NPs reported using the function "Several times every day" and "Several times a week" (median range $=3.8-4.4$ ). ANPS, PNPS, and 
FNPS chose "Several times a day" more often than did the other groups $(47 \%, 46 \%$, and $45 \%)$. A majority of the PNPS, the WHCNPS, and the PMHNPS $(67 \%, 55 \%$, and $52 \%$ ) chose baccalaureate programs for th is function. Except for the FNPS who tended to choose similarly between baccalaureate $(36 \%)$ and graduate $(48 \%)$, the groups chose baccalaureate programs more often than any other response category to emphasize this function. At least $8 \%$ of each group chose associate programs, with $27 \%$ of the WHCNPs so choosing.

For function 21 ("Perform physical examination with physician...") the statistical hypothesis for independence was not rejected for "Place in NP Preparation." The statistical hypothesis was rejected for each of the other two response categories: "Level of Competence" (combining " $a$ " and "b," chi-square = 171.4, $\underline{d f}=10$; $p<.0000$ ) and "Frequency of Use" (combining "b" and "c," chi-square $=122.5, \underline{d f}=15 ; \underline{p}(.0000)$. Therefore, significant relationships were found between specialty groups and the categories of "Level of Competence" and "Frequency of Use." Except for PMHNPs whose medians were 1.4 and 1.1 for "Level of Competence" and "Frequency of Use," the majority of NPS in each group reportedly felt "Very competent" and said they used the function "Several times every day" or "Several times every week"; (excluding the PMHNPs, the medians ranged from 3.8-3.9 and from 4.3-4.6 for the two categories). Prevention of Illness and Disability

The results of the analyses of the Prevention of Illness function are presented in this section for the total sample and for the six specialty groups. 
Total Sample. Table XV shows that for this category in "Level of Competence," a majority (78\%) of NPs felt "Very competent" in "Assuring the rights of patients to be actively involved in their own health care" (function 10). As a group the nurse practitioners most frquently judged themselves as having little or no competence in four of the five functions in this category: 12 (59\%), 22 (73\%), $23(73 \%)$, and $19(51 \%)$.

Function 10 ("Assuring the rights of patients to be actively involved in their own health care") was the most frequently used of these functions by the NPs; 53\% reported using it "Several times every day," and an additional 30\% said they used it "Several times each week." On the other hand, they reported "Never-little" usage of the other functions in this category: function 12 ("Prescribing diabetic diets"), function 22 ("Regulate medication dosage for diabetics"), function 23 ("Adjust medication for patient for benign essential hypertension"), and function 19 ("Changing Foley catheter in male patients") as indicated by $60 \%, 72 \%, 64 \%$, and $86 \%$.

The function which the NPs considered themselves to be more competent to perform (function 10) was the one most frequentiy used. The functions they identified as least competent to use (12, 22, 23, and 19) were least frequently used.

In considering the "Place in NP Preparation" to which to assign these functions, a majority of the respondents assigned functions 22 ("Regulate medication dosage for diabetics") and 23 ("Adjust medication for patient with benign essential hypertension") to graduate programs; baccalaureate programs were chosen by most of the 
TABLE XV

PERCENTACE OF RESPONSES BY PREVENTION OF ILLNESS AND DISABILITY FUNCTIONS

\begin{tabular}{|c|c|c|c|c|c|c|c|c|c|c|c|c|c|c|c|c|c|c|c|c|}
\hline \multirow{2}{*}{\multicolumn{2}{|c|}{ Functions }} & \multicolumn{6}{|c|}{ Level of Competence ${ }^{a}$} & \multicolumn{7}{|c|}{ Frequency of Use ${ }^{b}$} & \multicolumn{6}{|c|}{ Place in NP Preparationc } \\
\hline & & $n$ & (a) & (b) & (c) & (d) & Med & $n$ & (a) & (b) & (c) & (d) & (e) & Med & $n$ & (a) & (b) & (c) & (d) & (e) \\
\hline 10. & $\begin{array}{l}\text { Assuring the rights of } \\
\text { patients to be actively } \\
\text { involved in their own } \\
\text { health care }\end{array}$ & 355 & 0.3 & 1.4 & 20.0 & 78.3 & 3.9 & 351 & 0.9 & 2.8 & 13.1 & 30.2 & 53.0 & 4.6 & 333 & 0.3 & 25.8 & 56.5 & 15.0 & 2.4 \\
\hline 12. & $\begin{array}{l}\text { Prescribing diabetic } \\
\text { diets }\end{array}$ & 353 & 30.3 & 28.3 & 26.6 & 14.7 & 2.2 & 349 & 59.9 & 19.3 & 13.5 & 6.3 & 2.0 & 1.3 & 329 & 1.2 & 7.5 & 37.7 & 41.3 & 12.2 \\
\hline 22. & $\begin{array}{l}\text { Regulate medication } \\
\text { dosage for dfabetics }\end{array}$ & 353 & 54.7 & 19.7 & 14.7 & 11.9 & 1.4 & 352 & 72.4 & 8.0 & 10.2 & 6.5 & 2.8 & 1.2 & 334 & 1.8 & 3.6 & 16.8 & 67.7 & 10.2 \\
\hline 23. & $\begin{array}{l}\text { Adfust medlcation for } \\
\text { patient with benign ess } \\
\text { tial hypertension }\end{array}$ & 356 & 50.6 & 12.4 & 19.9 & 17.1 & 1.5 & 351 & 63.8 & 7.7 & 12.3 & 10.8 & 5.4 & 1.3 & 341 & 1.8 & 1.5 & 9.7 & 78.0 & 9.1 \\
\hline 19. & $\begin{array}{l}\text { Changing Foley catheter } \\
\text { In male patients }\end{array}$ & 354 & 34.7 & 16.7 & 20.6 & 29.0 & 2.4 & 352 & 86.4 & 9.9 & 2.8 & 1.7 & 0.3 & 1.1 & 328 & 1.2 & 43.6 & 46.6 & 6.4 & 2.1 \\
\hline
\end{tabular}

Note: Med $=$ Medlan

aLevel of Competence

(a) Do not feel competent at this time

(b) Feel slightly competent

(c) Feel moderately competent

(d) Feel very competent

CPlace In NP Preparation

(a) Should NOT be included in NP Preparation

(b) Associate programs
bFrequency of Use
(a) Never-little or no need to use the function
(b) Rarely -monthly
(c) Occasionally-a few times a month
(d) Frequently-several times weekly or every day
(e) All the time-several times every day

(c) Baccalaureate programs

(d) Graduate degree programs

(e) Continuing education includes courses, seminars, conferences, etc. 
NPs for "Assuring the rights of patients to be actively involved in their own health care" (function 10). The NPs tended to divide their choices between graduate (41\%) and baccalaureate (38\%) programs for function 12 ("Prescribing diabetic diets") and between baccalaureate (47\%) and associate (44\%) programs for function 19 ("Changing Foley catheters in male patients"). Associate degree nurse programs were the second most frequently chosen for major emphasis of function 10 ("Assuring the rights of patients to be actively involved in their own health care").

Therefore, all of the five functions in the category of prevention of illness were recommended by most NPs to receive major emphasis in baccalaureate or graduate nurse programs. No function was selected for omission by more than a few NPs. Function 12 ("Prescribing diabetic diets") and function 22 ("Regulate medication dosage for diabetics") received the most recommendations for onission $(2 \%$ each). The fewest recommendations $(0.3 \%)$ for omission were received by function 10 ("Assuring the rights of patients to be actively involved in their own health care").

An appreciable number of NPS chose associate programs to provide major emphasis in the development of two of the competencies in the prevention of illness category. Function 10 ("Assuring the rights of patients to be actively involved in their own health care") and function 19 ("Changing Foley catheters in male patients") were chosen by the NPs to be emphasized in associate programs (26\% and $44 \%$ ). Each function in the category was chosen by at least $2 \%$ of the NPS to be emphasized in continuing education programs. 
Functions 12 and 22 were assigned by at least $10 \%$ of the NPS to receive major emphasis in continuing education programs. Also these functions were noted as rarely used by most NPs. The same functions received not competent indicators from more than $30 \%$ of the NPs.

Precentage of Responses by Specialty Areas to Prevention of Illness and Disability Functions. In Table XVI, the responses by NPs in six specialties to the five functions in this category are presented with respect to three dimensions or response categories: "Level of Competence," "Frequency of Use," and "Place in NP Preparation." Responses are discussed as percentages of choices. Where applicable the median for each specialty is shown.

Table XVII shows the results of the chi-square testing of the prevention of illness functions. Within the "Level of Competence" column, the statistical hypothesis for independence was rejected for four of the five functions; a significant difference was not found for function 10 ("Assuring the rights of patients to be actively involved in their own health care"). In considering "Frequency of Use" for these functions, the statistical hypothesis for independence was rejected for four of the five functions; the statistical hypothesis was not rejected for function 10 ("Assuring the rights of patients to be actively involved in their own health care"). For "Place in NP Preparation," the statistical hypothesis for independence was rejected for function 22 ("Regulate medication dosage for diabetics"); it was not rejected for three of the five functions, 
TABLE XVI

PERCENTACE OF RESPONSES BY SPECIALTY AREAS TO PREVENTION OF ILLNESS FUNCTIONS

\begin{tabular}{|c|c|c|c|c|c|c|c|c|c|c|c|c|c|c|c|c|c|c|c|}
\hline \multirow{2}{*}{$\begin{array}{l}\text { Speclalty } \\
\text { Area }\end{array}$} & \multicolumn{6}{|c|}{ Level of Competence ${ }^{a}$} & \multicolumn{7}{|c|}{ Frequency of Use ${ }^{b}$} & \multicolumn{6}{|c|}{ Place in NP Preparationc } \\
\hline & $n$ & (a) & (b) & (c) & (d) & Med & $\bar{n}$ & (a) & (b) & (c) & (d) & (e) & Med & $\bar{n}$ & (a) & (b) & (c) & (d) & (e) \\
\hline & & Assuri & ng the & right & $s$ of $p$ & atien & ts & o be a & tively & Involv & $d$ in $t$ & elr ow & heal & h ca & re (f & ctton & 10. 10) & & \\
\hline ANP & 65 & 0 & 1.5 & 21.5 & 76.9 & 3.9 & 63 & 0 & 0 & 12.7 & 30.2 & 57.1 & 4.6 & 61 & 1.6 & 18.0 & 60.7 & 18.0 & 1.6 \\
\hline WHCNP & 54 & 0 & 0 & 16.7 & 83.3 & 3.9 & 54 & 0 & 1.9 & 5.6 & 33.3 & 59.3 & 4.7 & 47 & 0 & 36.2 & 46.8 & 14.9 & 2.1 \\
\hline FNP & 51 & 0 & 3.9 & 25.5 & 70.6 & 3.9 & 51 & 0 & 5.9 & 5.9 & 35.3 & 52.9 & 4.6 & 50 & 0 & 24.0 & 52.0 & 22.0 & 2.0 \\
\hline PMHNP & 52 & 0 & 1.9 & 21.2 & 76.9 & 3.9 & 51 & 0 & 5.9 & 23.5 & 33.3 & 37.3 & 4.1 & 51 & 0 & 17.6 & 66.7 & 13.7 & 2.0 \\
\hline PNP & 50 & 0 & 2.0 & 20.0 & 78.0 & 3.9 & 50 & 2.0 & 2.0 & 19.0 & 30.0 & 48.0 & 4.4 & 49 & 0 & 24.5 & 63.3 & 9.2 & 4.1 \\
\hline NM & 34 & 0 & 0 & 5.8 & 91.2 & 3.9 & 34 & 0 & 0 & 14.7 & 20.6 & 64.7 & 4.7 & 29 & 0 & 31.0 & 51.7 & 17.2 & 0 \\
\hline \multicolumn{20}{|c|}{ Prescribing diabetic diets (function no. 12) } \\
\hline ANP & 64 & 6.3 & 26.6 & 39.1 & 28.1 & 2.9 & 65 & 32.3 & 20.0 & 32.3 & 9.2 & 6.2 & 2.4 & 61 & $\mathbf{0}$ & 6.6 & 44.3 & 37.7 & 11.5 \\
\hline HHCNP & 55 & 38.2 & 36.4 & 16.4 & 9.1 & 1.8 & 55 & 76.4 & 18.2 & 3.6 & 1.8 & 0 & 1.2 & 49 & 0 & 8. 3 & 39.6 & 39.6 & 12.5 \\
\hline FNP & 51 & 7.8 & 17.6 & 47.1 & 27.5 & 3.0 & 49 & 32.7 & 32.7 & 14.3 & 16.3 & 4.1 & 2.0 & 49 & 2.0 & 6.1 & 32.7 & 44.9 & 14.3 \\
\hline PMHNP & 51 & 60.8 & 29.4 & 9.8 & 0 & 1.3 & 49 & 95.9 & 2.0 & 2.0 & 0 & 0 & 1.0 & 49 & 2.1 & 10.4 & 27.1 & 50.0 & 10.4 \\
\hline PNP & 50 & 46.0 & 36.0 & 14.0 & 4.0 & 1.6 & 50 & 78.0 & 20.0 & 0 & 2.0 & 0 & 1.1 & 49 & 2.0 & 4.1 & 42.9 & 34.7 & 16.3 \\
\hline NM & 34 & 44.1 & 26.5 & 23.5 & 5.9 & 1.7 & 34 & 67.6 & 17.6 & 14.7 & 0 & 0 & 1.2 & 31 & 3.2 & 9.7 & 29.0 & 51.6 & 6.5 \\
\hline
\end{tabular}


TABLE XVI (CONTINUED)

\begin{tabular}{|c|c|c|c|c|c|c|c|c|c|c|c|c|c|c|c|c|c|c|c|}
\hline \multicolumn{2}{|c|}{ Speclalty } & \multicolumn{5}{|c|}{ Level of Competence ${ }^{a}$} & \multicolumn{7}{|c|}{ Frequency of Use ${ }^{b}$} & \multicolumn{6}{|c|}{ Place in NP Preparatlonc } \\
\hline Area & n & (a) & (b) & (c) & (d) & Med & n & (a) & (b) & (c) & (d) & (e) & Med & $n$ & (a) & (b) & (c) & (d) & (e) \\
\hline \multicolumn{20}{|c|}{ Regulate medication dosage for diabetics (function no. 22) } \\
\hline ANP & 65 & 16.9 & 29.2 & 21.5 & 32.3 & 2.7 & 65 & 40.0 & 16.9 & 20.0 & 13.8 & 9.2 & 2.1 & 62 & 0 & 1.6 & 11.3 & 75.8 & 11.3 \\
\hline WHCNP & 55 & 72.7 & 12.7 & 10.9 & 3.6 & 1.2 & 55 & 92.7 & 3.6 & 3.6 & $\mathbf{0}$ & 0 & 1.0 & 47 & 2.1 & 4.3 & 25.5 & 55.3 & 12.8 \\
\hline FNP & 51 & 21.6 & 37.3 & 27.5 & 13.7 & 2.3 & 51 & 47.1 & 13.7 & 19.6 & 15.7 & 3.9 & 1.7 & 50 & 2.0 & 2.0 & 8.0 & 76.0 & 12.0 \\
\hline PMHNP & 51 & 36.3 & 5.9 & 7.8 & 0 & 1.1 & 50 & 94.0 & 6.0 & 0 & 0 & 0 & 1.0 & 49 & 2.1 & 2.1 & 19.9 & 75.0 & 2.1 \\
\hline PNP & 49 & 75.5 & 14.3 & 9.2 & 2.0 & 1.2 & 50 & 92.0 & 6.0 & $\mathbf{0}$ & 2.0 & $\mathbf{0}$ & 1.0 & 49 & 0 & 2.0 & 30.6 & 57.1 & 10.2 \\
\hline MM & 34 & 83.2 & 9.8 & 0 & 2.9 & 1.1 & 34 & 97.1 & 0 & 2.9 & 0 & 0 & 1.0 & 31 & 6.5 & 6.5 & 6.5 & 71.0 & 9.7 \\
\hline \multicolumn{20}{|c|}{ Adfust medication fo } \\
\hline ANP & 65 & 9.2 & 9.2 & 40.0 & 41.5 & 3.3 & 65 & 20.0 & 10.8 & 27.7 & 30.8 & 10.8 & 3.2 & 63 & 1.6 & 0 & 4.9 & 77.9 & 15.9 \\
\hline WHCNP & 56 & 75.0 & 14.3 & 10.7 & 0 & 1.2 & 56 & 94.6 & 1.8 & 3.6 & 0 & 0 & 1.0 & 51 & 0 & 0 & 15.7 & 70.6 & 13.7 \\
\hline FNP & 52 & 5.8 & 15.4 & 46.2 & 32.7 & 3.1 & 52 & 21.2 & 21.2 & 23.1 & 23.1 & 11.5 & 2.8 & 52 & 0 & 0 & 7.7 & 34.6 & 7.7 \\
\hline PMHNP & 51 & 80.4 & 11.8 & 5.9 & 2.0 & 1.1 & 49 & 89.8 & 10.2 & 0 & 0 & 0 & 1.1 & 45 & 2.2 & 0 & 4.4 & 93.3 & 0 \\
\hline PNP & 50 & 90.0 & 10.0 & 0 & 0 & 1.1 & 49 & 99.0 & 2.0 & 0 & 0 & 0 & 1.0 & 50 & 2.0 & 2.0 & 20.0 & 72.0 & 4.0 \\
\hline NM & 34 & 91.2 & 5.9 & 2.9 & 0 & 1.0 & 33 & 100.0 & 0 & 0 & 0 & 0 & 1.0 & 32 & 3.1 & 6.3 & 3.1 & 81.3 & 6.3 \\
\hline
\end{tabular}


TABLE XVI (CONTINUED)

\begin{tabular}{|c|c|c|c|c|c|c|c|c|c|c|c|c|c|c|c|c|c|c|c|}
\hline \multirow{2}{*}{$\begin{array}{l}\text { Speclalty } \\
\text { Area }\end{array}$} & \multicolumn{6}{|c|}{ Level of Competence ${ }^{a}$} & \multicolumn{7}{|c|}{ Frequency of Use ${ }^{b}$} & \multicolumn{6}{|c|}{ Place in NP Preparation $c$} \\
\hline & $n$ & (a) & (b) & (c) & (d) & Med & $\bar{n}$ & (a) & (b) & (c) & (d) & (e) & $\overline{\text { Med }}$ & $\bar{n}$ & (a) & (b) & (c) & (d) & (e) \\
\hline \multicolumn{20}{|c|}{ Changing foley catheters in male patients (function no. 19) } \\
\hline ANP & 65 & 4.6 & 13.8 & 24.6 & 56.9 & 3.6 & 65 & 75.4 & 16.9 & 4.6 & 3.1 & 0 & 1.2 & 62 & 0 & 41.9 & 50.0 & 6.5 & 1.6 \\
\hline WHCNP & 55 & 38.2 & 18.2 & 25.5 & 18.2 & 2.1 & 55 & 96.4 & 3.6 & 0 & 0 & 0 & 1.0 & 46 & 2.2 & 39.1 & 45.7 & 3.7 & 4.3 \\
\hline FNP & 51 & 13.7 & 9.9 & 25.5 & 51.0 & 3.5 & 51 & 72.5 & 19.6 & 7.8 & 0 & 0 & 1.2 & 50 & 0 & 50.0 & 42.0 & 4.0 & 4.0 \\
\hline PMHNP & 51 & 51.0 & 17.6 & 21.6 & 9.8 & 1.5 & 50 & 99.0 & 0 & 0 & 2.0 & 0 & 1.0 & 48 & 4.2 & 41.7 & 47.9 & 6.3 & 0 \\
\hline PNP & 50 & 50.0 & 20.0 & 20.0 & 10.0 & 1.5 & 50 & 96.0 & 0 & 2.0 & 2.0 & 0 & 1.0 & 46 & 0 & 34.8 & 54.3 & 8.7 & 2.2 \\
\hline MM & 34 & 70.6 & 20.6 & 5.9 & 2.9 & 1.2 & 34 & 97.1 & 2.9 & 0 & 0 & 0 & 1.0 & 31 & 0 & 45.2 & 48.4 & 6.5 & 0 \\
\hline
\end{tabular}

Note:

Med $=$ Medi an

ANP $=$ Adult Nurse Practitioners

WHCNP $=$ Women's Health Care Nurse Practitloners

FNP = Famlly Nurse Practitloners

PMHNP = Psychlatric Mental Health Nurse Practitioners

PNP $=$ Pedlatric Nurse Practitioners

NM = Nurse Midwife

bFrequency of Use

(a) Never-little or no need to use the function

(b) Rarely-monthly

(c) Occasionally-a few times a month

(d) Frequently-several times weekly or every day

(e) All the time-several times every day

aLevel of Competence

(a) Do not feel competent at this time

Cplace in NP Preparation

(b) Feel slightly competent

(c) Feel moderately competent

(d) Feel very competent

(a) Should NOT be Included In NP Preparation

(b) Associate programs

(c) Baccalaureate programs

(d) Graduate degree programs

(e) Continuing education includes courses, seminars, conferences, etc. 
TABLE XVII

RESULTS OF CHI-SQUARE TESTING ON RESPONSES* TO PREVENTION OF ILLNESS AND DISABILITY FUNCTIONS

\begin{tabular}{|c|c|c|c|c|c|c|c|c|c|c|c|c|}
\hline \multirow[b]{2}{*}{ Functions } & \multicolumn{4}{|c|}{ Level of Competence } & \multicolumn{4}{|c|}{ Frequency of Use } & \multicolumn{4}{|c|}{ Place in NP Preparation } \\
\hline & $\underline{x^{2}}$ & df & $\mathrm{p}$ & Note & $\underline{x^{2}}$ & df & $\mathrm{p}$ & Note & $x^{2}$ & df & $\mathrm{P}$ & Note \\
\hline $\begin{array}{l}\text { 10. Assuring the rights of } \\
\text { patlents to be actively } \\
\text { Involved in their own } \\
\text { health care }\end{array}$ & 6.10 & 5 & .2969 & $\begin{array}{l}\text { combines (b } \\
\&(c) ; \text { no (a) }\end{array}$ & 16.10 & 10 & .0970 & $\begin{array}{r}\text { combines } \\
(\mathrm{a})(\mathrm{b})(\mathrm{c})\end{array}$ & 11.07 & 10 & .3521 & $\begin{array}{l}\text { excludes } \\
\text { (a) \& (e) }\end{array}$ \\
\hline $\begin{array}{l}\text { 12. Prescribing diabetic } \\
\text { diets }\end{array}$ & 98.57 & 15 & .0000 & & 96.28 & 10 & .0000 & $\begin{array}{l}\text { comblnes } \\
(c)(d)(e\end{array}$ & 7.67 & 10 & .6621 & $\begin{array}{l}\text { excludes } \\
\text { (a) \& (b) }\end{array}$ \\
\hline $\begin{array}{l}\text { 22. Regulate medication } \\
\text { dosage for diabetics }\end{array}$ & 129.49 & 15 & .0000 & & 78.92 & 5 & .0000 & $\begin{array}{l}\text { combines (a)\& } \\
(b) ;(c) \&(d) \& \\
(e)\end{array}$ & 15.79 & 5 & .0075 & $\begin{array}{l}\text { excludes } \\
\text { (a)(b)(e) }\end{array}$ \\
\hline $\begin{array}{l}\text { 23. Adfust medication for } \\
\text { patlent with benign } \\
\text { essential hypertension }\end{array}$ & 204.53 & 15 & .0000 & & 154.07 & 10 & .0000 & $\begin{array}{l}\text { combines (a) } \\
\text { (b) \& (d) (e) }\end{array}$ & & & & $\begin{array}{l}\text { No } x^{2} \text { pos- } \\
\text { slble }\end{array}$ \\
\hline $\begin{array}{l}\text { 19. Changing Foley catheter } \\
\text { in male patients }\end{array}$ & 102.42 & 15 & .0000 & & 35.87 & 5 & .0000 & $\begin{array}{l}\text { combines (b) } \\
\text { (c)(d);no (e) }\end{array}$ & 2.11 & 5 & .8333 & $\begin{array}{l}\text { excludes } \\
(a)(d)(e)\end{array}$ \\
\hline
\end{tabular}

*Responses defined in Table XVI 
and comparisons were not possible for function 23 ("Adjust medication for patient with benign essential hypertension").

For function 10 ("Assuring the rights of patients to be actively involved in their own health care"), the statistical hypotheses for independence were not rejected for all three categories: "Level of Competence," "Frequency of Use," and "Place in NP Preparation." The majority of NPs in each specialty reportedly felt "Very competent" in the performance of this function (range of medians: 3.8 to 3.9 ) and used it "Several times every day" or "Several times every week" (range of medians: 4.1 to 4.7 ). The most preference for "Place in NP preparation" was expressed for baccalaureate programs, with a range from $47 \%$ for WHCNPs to $67 \%$ for PMHNPS .

For function 12 ("Prescribing diabetic diets"), the statistical hypothesis for independence was not rejected for "Place in NP Preparation"; the majority within each specialty placed this function in either baccal aureate or graduate programs. The statistical hypothesis was rejected for each of the other two categories: "Leve1 of Competence" (chi-square $=98.6$, df $=15 ; \underline{p}<.0000$ ) and "Frequency of Use" (combining "c," "d," and "e," chi-square = 96.3, $\underline{d f}=10 ; p<.0000)$. Therefore, significant relationships were found between the specialties and the categories of "Level of Competence" and "Frequency of Use." The majority of the specialty groups reported minimal competency and usage in the performance of this function (medians: WHCNPS 1.8, 1.2; PMHNPS 1.3, 1.0; PNPS 1.6, 1.1; and NMs $1.7,1.2)$. However, $28 \%$ of the ANPs and $28 \%$ of the FNPs 
felt "Very competent" in performing this function; the rate of utilization was somewhat greater for the ANPS and the FNPS than for the other specialties (medians $=2.4$ and 2.0 )

For function 22 ("Regulate medication dosage for diabetics), the statistical hypotheses were rejected for all three categories: "Level of Competence" (chi-square $=129.5$, df $=15 ; \underline{p}<.0000)$; "Frequency of Use" (contrasting "a" and "b" with "c," "d," and "e," chisquare $=78.9$, $\underline{d f}=5 ; \underline{p}(.0000)$; and "Place in NP Preparation" (contrasting "c" and "d" on $1 \mathrm{y}$, chi-square $=15.8$, $\underline{\mathrm{df}}=5 ; \underline{p}$ $<.0075)$. Thus for each category, a relationship was found between the level of the category and the specialties. In contrast with the other two specialties, the PMHNPS, NMS, PNPS, and WHCNPS expressed a lower level of competency (medians $=1.1,1.1,1.2,1.2$ ) and less frequent usage (medians: 1.0, each). A greater level of competency and use was reported by the ANPs (2.7 and 2.1). With about the same expressed "Level of Competence" (median - 2.3) but with less use (median $=1.7$ ) were the FNPS. The use of the function by the majority in all groups was low to slight. With respect to "Place in NP Preparation," 55\% of the WHCNPS and $57 \%$ of the PNPs chose graduate degree programs for major emphasis of this function; an even greater percentage (at least $71 \%$ ) of the remaining specialties chose the same place of emphasis.

For function 23 ("Adjust medication for patient with benign essential hypertension"), no statistical comparison was possible in the category "Place in NP Preparation." At least $71 \%$ of the NPs in each specialty assigned the major emphasis of this function to 
graduate degree programs. The statistical hypotheses of independence were rejected for "Level of Competence" (chi-square $=204.5$, $\underline{d f}=15 ; p<.000$ ) and "Frequency of Use" (combining "b," "c," and "d," chi-square - 35.9, df - 5; $\underline{p}<.0000)$. Thus, relationships were found between specialties and the categories of "Level of Competence" and "Frequency of Use." Four of the specialty groups expressed low competency (medians no greater than 1.1); the medians for the ANPS and the FNPS were greater than the medians for the other groups (3.3 and 3.1). While all specialties reported slight usage of this function, the ANPS and the FNPs used the function somewhat more than the other groups (medians: 3.2 and 2.8 , versus 1.0 or 1.1 for each of the other groups).

For function 19 (Changing Foley catheters in male patients"), the statistical hypothesis for independence was not rejected for "Place in NP Preparation." For all groups, the choices tended toward similarity between graduate and baccalaureate programs. The statistical hypothesis was rejected for "Level of competence" (chisquare $=102.4$, df $=15 ; p<.0000)$ and "Frequency of Use" (contrasting "a" with combined "b," " $c$," and "d," chi-square = 35.9, $d f=5 ; p<.0000)$. Therefore, a relationship was found between specialties and response categories for both "Leve1 of Competence" and "Frequency of Use." The majority of the ANPs and the FNPs reported greater competence than the other specialties (medians: 3.6 and 3.5, versus 2.1 for the next highest specialty -- WHCNPS). In contrast to the expressed competency and noting the slight elevation of the ANPS and FNPS, the reported usage was very low for 
all specialties (medians: ANP and FNP 1.2, versus 1.0 for all other groups).

Guidance and Counseling

The results of the analyses of the guidance and counseling functions are presented in this section for the total sample and for the six specialty groups.

Total Sample. Table XVIII shows that for this category in "Level of Competence," a majority of NPs (81\%) felt "Very competent" in "Teaching and counseling patients and families," (function 1). Also most nurse practitioners (64\%) felt "Very competent" to "Follow up on patients and families referred to another agency or provider for care" (function 39). As a group most of the nurse practitioners judged themselves to be "Very competent" and "Moderately competent" in four of the five functions in this category: functions $1(100 \%), 38(55 \%), 18(60 \%)$, and $39(94 \%)$. They felt less competent as a group to perform "Management of the patient with chronic mental/emotional disorder" (function 36); $45 \%$ indicated slight and no competence in this function.

Function 1 "Teaching and counseling patients and their families") was the most frequently used of these functions by the NPs; $71 \%$ reported using it "Several times each day" and an additional 23\% said they used it "Several times each week." Another function (39, "Follow up on patients and families referred to another agency or provider for care") was used "Several times every day" and "Several times each week" by $43 \%$ of the NPs. 
TABLE XVIII

PERCENTAGE OF RESPONSES BY GUIDANCE AND COUNSEIING FUNCTIONS



Note: Med $=$ Median

Level of Competence

(a) Do not feel competent at this time

(b) Feel slightly competent

(c) Feel moderately competent

(d) Feel very competent

b Frequency of Use
(a) Never-little or no need to use the function
(b) Rarely-monthly
(c) Occasionally-a few times a month
(d) Frequently-several times weekly or every day
(e) All the time-several times every day

Cplace In NP Preparation

(a) Should NOT be Included in NP Preparation

(b) Assoclate programs

(c) Baccalaureate programs

(d) Graduate degree programs

(e) Continuing education includes courses, seminars, conferences, etc. 
The function used least of ten ("Never-1ittle") was 36 ("Management of the patient with chronic mental/emotionai disorder") as indicated by $53 \%$ of the respondents. Other functions used rarely or slightly by the NPs in general were 38 ("Use psychiatric assessment tools...") and 18 ("Counseling patients with minor psychoneuroses") as indicated by $56 \%$ and $49 \%$ of the NP respondents.

The function which the NPS considered themselves to be more competent to perform ( 1 and 39) were the functions most frequently used. The functions they identified as less competent to use (38, 18 , and 36) were less often used.

In considering the "P1ace in NP Preparation" in which these fucntions belong a majority of the respondents placed two of the functions in graduate programs: "Counseling patients with minor psychoneuroses" (function 18 -- 52\%) and "Management of the patient with chronic mental/emotional disorder" (function 36 - 79\%). Except for function 38 ("Use psychiatric assessment tools...") whose respondents tended to choose about evenly between baccalaureate (37\%) and graduate programs (49\%), the majority of the respondents placed the remaining two functions in baccalaureate programs; function 1 ("Teaching and counseling") and function 39 ("Follow up on patients...") were so placed by $59 \%$ and $52 \%$ of the NPs.

Thus, all of the five functions in the category of Guidance and Counseling were recommended by the NPs to receive major emphasis in the baccalaureate or graduate nurse programs. None of the functions were selected for omission by more than $3 \%$ of the respondents. The most recomendations (3\%) for omission were received by 
function 36 ("Management of patient with chronic mental/emotional disorder"). The fewest (0) recommendations for omission were received by function 1 ("Teaching and counseling patients and their families"), but each of the remaining functions (38, 18, and 39) received only $0.3 \%$ recommendations for omission.

Some NPS chose associate programs to provide major emphasis in the development of competencies associated with guidance and counseling. Functions 1 ("Teaching and counseling...") and 39 ("Follow up on patients...") were chosen by $15 \%$ and $11 \%$ of the NPs to be emphasized in associate programs. Each function in the category was chosen by at least 3\% of the NPs to be emphasized in associate and continuing education programs.

Although the distribution of choices for continuing education programs was very similar among the functions, the less frequently used functions $(38,18$, and 36$)$ received somewhat more choices for continuing education $(8 \%, 7 \%$, and $7 \%$ ) than did the other functions: $1(6 \%)$ and $39(5 \%)$.

Percentage of Responses by Specialty Areas to Guidance and Counseling Functions. In Table XIX the responses by NPS in six specialties to the five functions in this category are presented with respect to three dimensions or columns: "Level of Competence," "Frequency of Use," and "Place in NP Preparation." Responses are discussed as percentages of choices. Where applicable, the median for each specialty is shown.

In Table $X X$, the results are shown of the chi-square testing of the guidance and counseling functions. Within the "Level of Competence" column, the statistical hypothesis for independence was 
TABLE XIX

PERCENTACE OF RESPONSES BY SPECIALT AREAS TO GUIDANCE AND COUNSEIING FUNCTIONS

\begin{tabular}{|c|c|c|c|c|c|c|c|c|c|c|c|c|c|c|c|c|c|c|c|}
\hline \multirow{2}{*}{$\begin{array}{l}\text { Special } \\
\text { Area }\end{array}$} & \multirow{2}{*}{ n } & \multicolumn{5}{|c|}{ Level of Competence ${ }^{a}$} & \multicolumn{7}{|c|}{ Frequency of Use ${ }^{b}$} & \multicolumn{6}{|c|}{ Place in NP Preparationc } \\
\hline & & (a) & (b) & (c) & (d) & Med & $n$ & (a) & (b) & (c) & (d) & (e) & Med & $n$ & (a) & (b) & (c) & (d) & (e) \\
\hline \multicolumn{20}{|c|}{ Teaching counseling patients and their famllles (function no. 1) } \\
\hline ANP & 65 & 0 & 0 & 25.0 & 75.4 & 3.8 & 65 & 0 & 0 & 4.6 & 16.9 & 78.5 & 4.9 & 61 & 0 & 13.1 & 60.7 & 19.0 & 8.2 \\
\hline WHCNP & 56 & 0 & 0 & 10.7 & 89.3 & 3.9 & 56 & o & 0 & 1.8 & 16.1 & 82.1 & 4.9 & 53 & 0 & 26.4 & 59.5 & 7.5 & 7.5 \\
\hline FNP & 52 & 0 & 0 & 26.9 & 73.1 & 3.8 & 51 & 0 & 2.0 & 7.8 & 13.7 & 76.5 & 4.8 & 49 & 0 & 10.2 & 63.3 & 22.4 & 4.1 \\
\hline PMHNP & 52 & 0 & 0 & 17.3 & 82.7 & 3.9 & 52 & 0 & 1.9 & 15.4 & 38.5 & 44.2 & 4.4 & 51 & 0 & 3.9 & 52.9 & 43.1 & 0 \\
\hline PNP & 50 & 0 & 0 & 22.0 & 78.0 & 3.9 & 50 & 0 & 4.0 & 0 & 18.0 & 78.0 & 4.9 & 50 & 0 & 12.0 & 58.0 & 20.0 & 10.0 \\
\hline NM & 34 & 0 & 0 & 11.8 & 85.2 & 3.9 & 34 & 0 & 0 & 2.9 & 26.5 & 70.6 & 4.8 & 31 & 0 & 16.1 & 54.8 & 19.4 & 9.7 \\
\hline
\end{tabular}

Use psychlatric assessment tools (e.g., sulcide, mental status, etc.) (function no. 38)

\begin{tabular}{lrrrrrrrrrrrrrrrrrrrrrr}
\hline ANP & 65 & 10.8 & 33.8 & 32.3 & 23.1 & 2.7 & 65 & 19.5 & 40.0 & 21.5 & 12.3 & 7.7 & 2.3 & 61 & 0 & 3.3 & 42.6 & 47.5 & 6.6 \\
WHCNP & 55 & 23.6 & 30.9 & 34.5 & 10.9 & 2.4 & 55 & 29.1 & 43.6 & 21.8 & 3.6 & 1.9 & 2.0 & 46 & 0 & 15.2 & 34.8 & 43.5 & 6.5 \\
FNP & 51 & 2.0 & 33.3 & 45.1 & 19.6 & 2.8 & 51 & 15.7 & 37.3 & 33.3 & 7.8 & 5.9 & 2.4 & 50 & 0 & 4.0 & 34.0 & 56.0 & 6.0 \\
PMHNP & 52 & 1.9 & 0 & 11.5 & 56.5 & 3.9 & 51 & 5.9 & 3.9 & 9.8 & 23.5 & 56.9 & 4.6 & 50 & 0 & 0 & 32.0 & 63.0 & 0 \\
PNP & 49 & 30.6 & 40.8 & 24.5 & 4.1 & 2.0 & 49 & 55.1 & 24.5 & 16.3 & 2.0 & 2.0 & 1.4 & 49 & 0 & 0 & 39.8 & 46.9 & 14.3 \\
NM & 34 & 41.2 & 47.1 & 11.8 & 0 & 1.7 & 32 & 75.0 & 13.8 & 6.3 & 0 & 0 & 1.2 & 32 & 3.1 & 9.4 & 37.5 & 43.8 & 6.3 \\
\hline
\end{tabular}


TABLE XIX (CONTINUED)

\begin{tabular}{|c|c|c|c|c|c|c|c|c|c|c|c|c|c|c|c|c|c|c|c|}
\hline \multirow{2}{*}{$\begin{array}{l}\text { Specialty } \\
\text { Area }\end{array}$} & \multirow{2}{*}{$\mathrm{n}$} & \multicolumn{5}{|c|}{ Level of Competence ${ }^{a}$} & \multicolumn{7}{|c|}{ Frequency of Use $\mathrm{b}^{\mathrm{b}}$} & \multicolumn{6}{|c|}{ Place In NP Preparationc } \\
\hline & & (a) & (b) & (c) & (d) & Med & $\bar{n}$ & (a) & (b) & (c) & (d) & (e) & $\overline{\text { Med }}$ & $n$ & (a) & (b) & (c) & (d) & (e) \\
\hline \multicolumn{20}{|c|}{ Counseling patients with minor psychoneuroses (function no. 18) } \\
\hline ANP & 64 & 10.9 & 29.7 & 37.5 & 21.9 & 2.7 & 64 & 15.6 & 26.6 & 25.0 & 15.6 & 17.2 & 2.3 & 61 & 0 & 1.6 & 41.0 & 55.7 & 1.6 \\
\hline WHCNP & 55 & 23.6 & 21.8 & 43.6 & 10.9 & 2.6 & 55 & 30.9 & 32.7 & 25.5 & 9.1 & 1.8 & 2.1 & 47 & 0 & 8.5 & 44.7 & 42.6 & 4.3 \\
\hline FNP & 51 & 7.8 & 23.5 & 37.3 & 31.4 & 3.0 & 51 & 21.6 & 13.7 & 31.4 & 27.5 & 5.9 & 3.0 & 50 & 0 & 2.0 & 34.0 & 54.0 & 10.0 \\
\hline PMHNP & 52 & 0 & 0 & 15.4 & 84.6 & 3.9 & 52 & 3.8 & 11.5 & 15.4 & 17.3 & 51.9 & 4.5 & 52 & 0 & 0 & 32.7 & 63.5 & 3.8 \\
\hline PAP & 50 & 42.0 & 36.0 & 18.0 & 4.0 & 1.7 & 50 & 58.0 & 24.0 & 16.0 & 2.0 & 0 & 1.4 & 48 & 2.1 & 2.1 & 33.3 & 51.2 & 10.4 \\
\hline$N$ & 34 & 29.4 & 41.2 & 26.5 & 2.9 & 2.0 & 34 & 32.4 & 38.2 & 23.5 & 2.9 & 2.9 & 2.0 & 30 & 0 & 10.0 & 30.0 & 53.3 & 6.7 \\
\hline \multicolumn{20}{|c|}{ Management } \\
\hline ANP & 65 & 29.2 & 33.8 & 20.0 & 16.9 & 2.1 & 65 & 40.0 & 29.2 & 3.1 & 15.4 & 12.3 & 1.8 & 62 & 1.6 & 3.2 & 8.1 & 80.6 & 6.5 \\
\hline WHCNP & 55 & 69.1 & 18.2 & 10.9 & 1.8 & 1.2 & 54 & 79.6 & 7.4 & 11.1 & 1.9 & 0 & 1.1 & 47 & 0 & 2.1 & 4.3 & 85.1 & 8.5 \\
\hline FNP & 51 & 29.4 & 33.3 & 31.4 & 5.9 & 2.1 & 52 & 40.4 & 25.0 & 17.3 & 11.5 & 5.8 & 1.9 & 51 & 9.8 & 2.0 & 5.9 & 74.5 & 7.8 \\
\hline PMHNP & 52 & 3.8 & 7.7 & 3.8 & 84.6 & 3.9 & 48 & B. 3 & 2.1 & 10.4 & 22.9 & 56.3 & 4.6 & 51 & 0 & 2.0 & 3.9 & 94.1 & 0 \\
\hline PNP & 48 & 66.7 & 20.8 & 12.5 & 0 & 1.3 & 49 & 77.1 & 12.5 & 5.3 & 2.1 & 0 & 1.1 & 49 & 4.1 & 2.0 & 18.4 & 65.3 & 10.2 \\
\hline$M M$ & 34 & 82.4 & 14.7 & 2.9 & 0 & 1.1 & 31 & 96.8 & 3.2 & 0 & 0 & 0 & 1.0 & 32 & 0 & 3.1 & 6.3 & 84.4 & 6.3 \\
\hline
\end{tabular}


TABLE XIX (CONTINUED)

\begin{tabular}{|c|c|c|c|c|c|c|c|c|c|c|c|c|c|c|c|c|c|c|}
\hline \multirow{2}{*}{$\begin{array}{l}\text { Specialty } \\
\text { Area }\end{array}$} & \multicolumn{5}{|c|}{ Level of Competence $^{a}$} & \multicolumn{7}{|c|}{ Frequency of Use $\mathrm{U}^{\mathbf{b}}$} & \multicolumn{6}{|c|}{ Place In NP Preparation ${ }^{c}$} \\
\hline & (a) & (b) & (c) & (d) & Med & $\bar{n}$ & (a) & (b) & (c) & (d) & (e) & Hed & $\bar{n}$ & (a) & (b) & (c) & (d) & (e) \\
\hline \multicolumn{19}{|c|}{ Follow-up on patients and } \\
\hline ANP & $65 \quad 3.1$ & 6.2 & 46.2 & 44.6 & 3.4 & 64 & 7.8 & 26.6 & 34.4 & 20.3 & 10.9 & 3.0 & 63 & $\mathbf{0}$ & 7.9 & 44.4 & 38.1 & 9.5 \\
\hline WHСNP & 55 & 3.6 & 23.6 & 72.7 & 3.8 & 55 & 5.5 & 16.4 & 30.9 & 36.4 & 10.9 & 3.4 & 47 & 0 & 19.1 & 55.3 & 21.3 & 4.3 \\
\hline FNP & 51 & 3.9 & 31.4 & 64.7 & 3.7 & 52 & 5.8 & 7.7 & 48.1 & 19.2 & 19.2 & 3.3 & 49 & 0 & 8.2 & 46.9 & 40.8 & 4.1 \\
\hline PMHNP & 52 & 0 & 21.2 & 79.8 & 3.9 & 50 & 3.0 & 10.0 & 36.0 & 24.0 & 22.0 & 3.4 & 52 & 0 & 1.9 & 50.0 & 45.1 & 0 \\
\hline PNP & 50 & 8.0 & 24.0 & 68.0 & 3.8 & 50 & 4.0 & 12.0 & 28.0 & 32.0 & 24.0 & 3.7 & 50 & 0 & 8.0 & 62.0 & 20.0 & 10.0 \\
\hline M & 34 & 11.8 & 35.3 & 52.9 & 3.6 & 32 & 6.3 & 46.9 & 15.6 & 12.5 & 18.8 & 2.4 & 30 & 0 & 16.7 & 53.3 & 30.0 & $\underline{0}$ \\
\hline \multicolumn{8}{|c|}{$\begin{array}{l}\text { Note: Med = Medlan } \\
\text { ANP = Adult Nurse Practitloners } \\
\text { WHCNP = Women's Health Care Nurse Practitioners } \\
\text { FNP = Family Nurse Practitioners } \\
\text { PMHNP = Psychlatrlc Mental Health Nurse Practitioners } \\
\text { PNP = Pediatric Nurse Practitloners } \\
\text { NH = Nurse Midwlfe }\end{array}$} & \multicolumn{9}{|c|}{$\begin{array}{l}\text { brequency of Use } \\
\text { (a) Never-little or no need to use the function } \\
\text { (b) Rarely-monthly } \\
\text { (c) Occasionally-a few times a month } \\
\text { (d) Frequently-several times weekly or every day } \\
\text { (e) All the time-several times every day }\end{array}$} & & \\
\hline $\begin{array}{l}\text { aLevel of } \\
\text { (a) Do not } \\
\text { (b) Feel } \\
\text { (c) Feel } \\
\text { (d) Feel }\end{array}$ & $\begin{array}{l}\text { Compete } \\
\text { ot feel } \\
\text { slightl } \\
\text { moderat } \\
\text { very co }\end{array}$ & $\begin{array}{l}\text { ce } \\
\text { ompete } \\
\text { compe } \\
\text { ly com } \\
\text { petent }\end{array}$ & $\begin{array}{l}\text { nt at } t \\
\text { tent } \\
\text { petent }\end{array}$ & Is $t$ & & & & $\begin{array}{l}\text { CPlac } \\
\text { (a) } \\
\text { (b) } \\
\text { (c) } \\
\text { (d) } \\
\text { (e) }\end{array}$ & $\begin{array}{l}\text { in } N \\
\text { Should } \\
\text { Associ } \\
\text { Baccal } \\
\text { Gradua } \\
\text { Contin } \\
\text { confe }\end{array}$ & $\begin{array}{l}\text { Prepa } \\
\text { NOT be } \\
\text { te pro } \\
\text { ureate } \\
\text { e degr } \\
\text { ing ed } \\
\text { ences, }\end{array}$ & $\begin{array}{l}\text { ation } \\
\text { Includ } \\
\text { rans } \\
\text { orogra } \\
\text { prog } \\
\text { cation } \\
\text { te. }\end{array}$ & $\begin{array}{l}\text { s } \\
\text { ams } \\
\text { Inclu }\end{array}$ & $\mathbf{P} \mathbf{P r}$ & par & semir & & & \\
\hline
\end{tabular}


TABLE $X X$

RESULTS of CHI-SQUARE TESTING ON RESPONSES* TO GUIDANCE AND COUNSEL ING FUNCTIONS

\begin{tabular}{|c|c|c|c|c|c|c|c|c|c|c|c|c|c|}
\hline \multirow{2}{*}{\multicolumn{2}{|c|}{ Functlons }} & \multicolumn{4}{|c|}{ Level of Competence } & \multicolumn{4}{|c|}{ Frequency of Use } & \multicolumn{4}{|c|}{ Place in NP Preparation } \\
\hline & & $\underline{x^{2}}$ & df & $\mathrm{p}$ & Note & $x^{2}$ & df & p & $\overline{\text { Note }}$ & $x^{2}$ & df & $\mathrm{p}$ & Note \\
\hline 1. & $\begin{array}{l}\text { Teaching and counseling } \\
\text { patients and their } \\
\text { famllies }\end{array}$ & 7.34 & 5 & .1966 & $\begin{array}{l}\text { combines } \\
(a)(b)(c)\end{array}$ & 25.57 & 5 & .0001 & $\begin{array}{l}\text { comblnes (b) } \\
\text { (c)\&(d);no } \\
\text { (a) }\end{array}$ & 26.26 & 10 & .0034 & $\begin{array}{l}\text { excludes } \\
\text { (a) \& (e) }\end{array}$ \\
\hline 39. & $\begin{array}{l}\text { Use psychlatric assessn } \\
\text { tools (e.g., sulclde, } \\
\text { mental status, etc.) }\end{array}$ & $\begin{array}{l}\text { ment } \\
169.71\end{array}$ & 15 & .0000 & & 194.05 & 20 & .0000 & & 3.46 & 55 & .6292 & \\
\hline 19. & $\begin{array}{l}\text { Counseling patients wit } \\
\text { minor psychoneuroses }\end{array}$ & $\begin{array}{l}\text { th } \\
152.16\end{array}$ & 15 & .0000 & & 137.00 & 20 & .0000 & & 3.23 & 5 & .6646 & $\begin{array}{l}\text { excludes } \\
\text { (a) (b) (e) }\end{array}$ \\
\hline 36. 1 & $\begin{array}{l}\text { Management of the patie } \\
\text { with chronic mental/emo } \\
\text { tional disorder }\end{array}$ & $\begin{array}{l}\text { ent } \\
226.04\end{array}$ & 15 & .0000 & & 174.80 & 15 & .0000 & $\begin{array}{l}\text { combines } \\
\text { (c) \& (d) }\end{array}$ & $\begin{array}{l}\text { No } i \\
\text { is } p\end{array}$ & inter & $\begin{array}{l}\text { pretatic } \\
\text { ble }\end{array}$ & \\
\hline 39. & $\begin{array}{l}\text { Follow up on patients } \\
\text { and famllles referred } t \\
\text { another agency or pro- } \\
\text { vider for care }\end{array}$ & to 19.41 & 5 & .0016 & $\begin{array}{l}\text { combines } \\
(a)(b)(c)\end{array}$ & 42.81 & 20 & .0022 & & 9.90 & 5 & .0782 & $\begin{array}{l}\text { excludes } \\
\text { (a)(d)(e) }\end{array}$ \\
\hline
\end{tabular}

*Responses defined In Table XIX 
rejected for four of the five functions a significant difference was not found for function 1 ("Teaching and counseling..."). In considering "Frequency of Use" for these functions, the statistical hypothesis for independence was rejected for all of the five functions. For "Place in NP Preparation," the statistical hypothesis for independence was rejected for one of the five functions; it was not rejected for function 38 ("Use psychiatric assessment tools..."), function 18 ("Counseling patients with minor psychoneuroses"), and for function 39 ("Follow up on patients and families..."); and comparisons were not possible for function 36 . For function 1 ("Teaching and counseling patients and their families"), the statistical hypothesis for independence was not rejected for "Level of Competence." At least $73 \%$ of the NPs in each of the specialties reported themselves "Very competent" in the performance of this function. The statistical hypothesis was rejected for "Frequency of Use" (no "a"; combining "b," "c," and " $d$ " to contrast with "e," chi-square $=25.6$, $\underline{d f}=5 ; \underline{p}<.0001$ ) and for "Place in NP Preparation" (excluding "a" and "e," chi-square $=26.3$, df $=10 ; p<.0034)$. Thus, a relationship was found between specialties and responses categories for both "Frequency of use" and "Place in NP Preparation." Though all specialties reported frequent usage, the most frequent use was reported by the WHCNPS, ANPS, and PNPS: medians $=4.9$ each. The PMHNPs expressed the least use for this function (median: 4.4). A majority of the NPs in each specialty chose baccal aureate programs to emphasize this function, with $63 \%$ of the FNPS and $53 \%$ of the PMHNPS so choosing. Except for the WHCNPS 
(of whoin $26 \%$ preferred assocate programs), the other specialties made graduate degree programs the second choice. Associate degree programs were chosen least often by the PMHNPS (4\%).

For function 38 ("Use psychiatric assessment tools, e.g., suicide, mental status, etc."), the statistical hypothesis for independence was not rejected for "Place in NP Preparation"; baccalaureate and graduate programs were chosen by the majority of the specialty groups to emphasize this function. The statistical hypothesis was rejected for each of the other two categories: "Level of Competence" (chi-square $=169.7, \underline{\mathrm{df}}=15 ; \mathrm{p}<.0000)$ and "Frequency of Use" (chi-square $=194.1, \underline{d f}=20 ; \underline{p}<.0000)$. Therefore, significant relationships were found between specialty groups and "Level of Competence" and "Frequency of Use." In contrast with the other specialties, the PMHNPs expressed the greatest and the NMs the least competence in the performance of this function (medians: 3.9 and 1.7). "Frequency of Use" followed a pattern similar to "Level of Competence" for this function; medians: 4.6 (PMHNPs) and 1.2 (NMs).

For function 18 ("Counseling patients with minor psychoneuroses"), the statistical hypothesis for independence was not rejected for "Place in NP Preparation"; except for the WHCNPS who chose similarly between baccalaureate and graduate programs, the majority of NPS in each of the other specialties preferred graduate programs. The statistical hypothesis was rejected for the other two columns: "Level of Competence" (chi-square $=152.2$, df $=15 ; \underline{p}$ $<.0000$ ) and "Frequency of Use" (chi-square $=137$, df $=20: \underline{p}$ $<.0000)$. Thus, significant relationships were found between 
specialty groups and response categories of "Level of "ompetence" and "Frequency of Use." In contrast with other speciaity groups, the PNPS and NMs expressed less competence (medians: 1.7 and 2.0) and less frequent use (medians: 1.4 and 2.0). The PMHNPs expressed the greatest competency (median: 3.9) and usage (median: 4.5).

For function 36 ("Management of the patient with chronic mental/emotional disorder), the expected frequencies in "Place in NP Preparation" were too low for all response categories except " $d$ " to permit a statistical test. At least $65 \%$ of the respondents in each specialty chose graduate programs to emphasize this function. For the other two columns, the statistical test for independence was rejected: "Level of Competence" (chi-square $=226$, $\underline{d f}=15 ; \underline{p}$ $<.0000$ ) and "Frequency of Use" (combining " $c$ " and "d," chi-square $=174.8, \underline{\mathrm{df}}=15 ; \underline{\mathrm{p}}(.0000)$. Therefore, significant relationships were found between specialty groups and the response categories of "Level of Competence" and "Frequency of Use." In contrast with other specialty groups, the NMS, WHCNPS, and PNPS expressed less competence (medians: 1.1, 1.2, and 1.3) and less frequent use (medians: 1.0, 1.1, and 1.1). The PMHNPs reported the greatest competence and frequency of use (medians: 3.9 and 4.6).

For function 39 ("Follow up on patients and families referred to another agency or provider for care"), the statistical hypothesis for independence was not rejected for "Place in NP Preparation." The majority of the NPs in the specialty groups chose baccalaureate and graduate programs to emphasize this function. The statistical hypotheses were rejected for the other categories: "Level of 
Competence" (combining "a," "b," and "c," chi-square = 19.4, df $=5$; $\underline{p}<.0016$ ) and "Frequency of Use" and "Frequency of Use" (chi-square $=42.8, \underline{d f}=20 ; \underline{p}<.0022)$. Thus, significant relationships were found between the specialty groups and the response categories of "Level of Competence" and "Frequency of Use." Although relatively high for all groups, the PMHNPS, PNPS, and WHCNPS expressed the greatest competency (medians: 3.9, 3.8, and 3.8) and "Frequency of Use" (medians: 3.4, 3.7, and 3.4).

\section{POLICY-MAKING FUNCTIONS}

Analyses of the responses to the health care and administrative policy-making activities of the NPs are presented in this section for the total sample and by specialties.

\section{Health Care Policy-makers}

Table XXI presents the responses made by the NPs in general and in the specialty areas to functions associated with admnistration of health care in the practice setting. For the total sample, the greatest number of respondents perceived health care policymaking as a joint activity of MDs and NPs (32\%) or thse two in cooperation with one or more other professionals (41\%). With the exception of the PMHNPS, the most frequent decision-making participants with respect to health care policies were the NP and the

physician (31\% or greater of respondents). The PMHNPs reported another person participated with the NP and the Physician in making policy for the administration of health care in the practice setting (31\%). The majority of the respondents within each specialty 
TABLE XXI

FREQUENCIES AND PERCENTACES OF RESPONSES: HEALTH CARE POLICY-MAKERS IN PRACTICE SETTING

\begin{tabular}{|c|c|c|c|c|c|c|c|c|c|c|c|c|c|c|}
\hline \multirow[b]{2}{*}{ Decislons Made By } & \multicolumn{2}{|c|}{$\begin{array}{c}\text { ALL NPS } \\
(358)\end{array}$} & \multicolumn{2}{|c|}{$\begin{array}{l}\text { ANPs } \\
(65) \\
\end{array}$} & \multicolumn{2}{|c|}{$\begin{array}{c}\text { HHCNPS } \\
(56)\end{array}$} & \multicolumn{2}{|c|}{$\begin{array}{l}\text { FNPs } \\
(53) \\
\end{array}$} & \multicolumn{2}{|c|}{$\begin{array}{c}\text { PNANPS } \\
\text { (52) }\end{array}$} & \multicolumn{2}{|c|}{$\begin{array}{l}\text { PNPs } \\
(50) \\
\end{array}$} & \multicolumn{2}{|c|}{$\begin{array}{l}\text { NMs } \\
(34) \\
\end{array}$} \\
\hline & $n$ & $\%$ & $n$ & $\%$ & $n$ & $\%$ & $n$ & $\bar{x}$ & $\bar{n}$ & $\overline{8}$ & $\bar{n}$ & $\bar{x}$ & $n$ & $\bar{x}$ \\
\hline$M D$ and $N$ & 113 & 31.9 & 20 & 31.3 & 22 & 39.3 & 22 & 42.3 & 5 & 9.6 & 16 & 32.7 & 16 & 47.1 \\
\hline MD, NP and Other & 49 & 13.6 & 9 & 14.1 & 7 & 12.5 & 5 & 9.6 & 16 & 30.8 & 5 & 10.2 & 3 & 8.8 \\
\hline$M D, N P$ and $R N$ & 47 & 13.3 & 5 & 7.8 & $\mathbf{8}$ & 14.3 & 7 & 13.5 & 6 & 11.5 & 6 & 12.2 & 8 & 23.5 \\
\hline MD, NP, RN and Other & 33 & 9.3 & 7 & 10.9 & 0 & 0 & 9 & 17.3 & 4 & 7.7 & 3 & 6.1 & 3 & 9.8 \\
\hline NP & 33 & 9.3 & 7 & 10.9 & 3 & 5.4 & 1 & 1.9 & 11 & 21.2 & 4 & 82 & 3 & 8.8 \\
\hline MD & 19 & 5.4 & 3 & 4.7 & 6 & 10.4 & 0 & $\mathbf{0}$ & 1 & 1.9 & 4 & 8.2 & 1 & 2.9 \\
\hline$M D$ and $A N$ & 13 & 3.7 & 3 & 4.7 & 3 & 5.4 & 1 & 1.9 & 3 & 5.8 & 0 & 0 & 0 & 0 \\
\hline$M D$ and other & 8 & 2.3 & 1 & 1.6 & 0 & 0 & 2 & 3.8 & 2 & 3.8 & 2 & 4.1 & 0 & 0 \\
\hline$M D, N P$ and $P A$ & 7 & 2.0 & 2 & 3.1 & 3 & 5.4 & 2 & 3.5 & 0 & 0 & 0 & 0 & 0 & 0 \\
\hline MD, NP, PA, FN and Other & 5 & 1.4 & 1 & 1.6 & 0 & 0 & 0 & 0 & 0 & 0 & 1 & 2.0 & 0 & 0 \\
\hline NP and RN & 5 & 1.4 & 0 & 0 & 1 & 1.8 & 1 & 1.9 & 0 & 0 & 2 & 4.1 & 0 & 0 \\
\hline NP and other & 4 & 1.1 & 1 & 1.6 & 0 & 0 & 0 & 0 & 3 & 5.8 & 0 & 0 & 0 & 0 \\
\hline
\end{tabular}


TABLE XXI (CONTINUED)

\begin{tabular}{|c|c|c|c|c|c|c|c|c|c|c|c|c|c|c|}
\hline \multirow[b]{2}{*}{ Decisions Made By } & \multicolumn{2}{|c|}{$\begin{array}{c}\text { ALL NS } \\
(358) \\
\end{array}$} & \multicolumn{2}{|c|}{$\begin{array}{l}\text { ANPs } \\
(65) \\
\end{array}$} & \multicolumn{2}{|c|}{$\begin{array}{c}\text { WHCNPs } \\
(56) \\
\end{array}$} & \multicolumn{2}{|c|}{$\begin{array}{l}\text { FNPS } \\
(53)\end{array}$} & \multicolumn{2}{|c|}{$\begin{array}{c}\text { PMHNS } \\
(52) \\
\end{array}$} & \multicolumn{2}{|c|}{$\begin{array}{l}\text { PNPs } \\
(50) \\
\end{array}$} & \multicolumn{2}{|c|}{$\begin{array}{l}\mathrm{NMs} \\
(34)\end{array}$} \\
\hline & $\bar{n}$ & $\%$ & $\mathbf{n}$ & $\bar{x}$ & $n$ & $\%$ & $n$ & $\bar{x}$ & $n$ & $\varnothing$ & $n$ & $\mathscr{x}$ & $n$ & 9 \\
\hline$M D, N P, P A$ and $R N$ & 4 & 1.1 & 2 & 3.1 & 0 & 0 & 1 & 1.9 & 0 & 0 & 0 & 0 & 0 & 0 \\
\hline NP, RN and Other & 3 & 0.8 & $\mathbf{0}$ & 0 & 1 & 1.3 & 1 & 1.9 & 0 & 0 & 1 & 2.0 & 0 & 0 \\
\hline $\mathbf{R N}$ & 3 & 0.8 & $\mathbf{0}$ & $\mathbf{0}$ & 0 & 0 & 0 & 0 & $\mathbf{0}$ & 0 & 3 & 6.1 & 0 & 0 \\
\hline other & 3 & 0.8 & $\mathbf{0}$ & $\mathbf{0}$ & 1 & 1.8 & 0 & $\mathbf{0}$ & 1 & 1.9 & 0 & 0 & 0 & 0 \\
\hline MD, NP PA and Other & 2 & 0.6 & 2 & 3.1 & 0 & 0 & $\mathbf{0}$ & 0 & 0 & 0 & 0 & 0 & 0 & 0 \\
\hline RN and Other & 2 & 0.6 & $\mathbf{0}$ & $\mathbf{0}$ & 1 & 1.8 & 0 & 0 & 0 & 0 & 1 & 2.0 & 0 & 0 \\
\hline $\mathrm{MD}, \mathrm{PA}$ and $\mathrm{RN}$ & 1 & 0.3 & 1 & 1.6 & 0 & 0 & 0 & 0 & 0 & 0 & 0 & 0 & 0 & 0 \\
\hline MD, PN and Other & 1 & 0.3 & 0 & 0 & 0 & 0 & 0 & 0 & 0 & 0 & 1 & 2.0 & 0 & 0 \\
\hline
\end{tabular}

Note: $M D=$ Physiclan

NP = Nurse Practitioner

PA $=$ Physiclan's Assistant

RN = Registered Nurse 
perceived the decision-making process to be a joint action of the MD and NP or these two in conjunction with one or more other professionals, (ranging from 60\% for PMHNPs to $88 \%$ for FNPS and NMS). Nevertheless, $21 \%$ of the PMHNPS and $11 \%$ of the ANPs said the decision rested with the NP; of the WHCNPS, 10\% selected the MD as the decision-maker.

\section{Administrative Policy-makers}

Table XXII shows that $54 \%$ of the NPs in general perceived the administrative decision-making to rest jointly with the NPs and MDs (16\%) or these two in combination with others (38\%). About $18 \%$ of the NPs in general assigned decision-making to the NP and RN, together, singley, or with some other professional other than an MD. Approximatey $14 \%$ viewed decision-making as the responsibility of the MD, alone or with others (not NPs). For the specialty groups, $43 \%$ of the PNPS and 46\% of the WHCNPS and PMHNPs perceived the function to be the joint responsibility of the MD and the NP, or in conjunction with others. At least $56 \%$ of the respondents in the other specialty groups agreed with a similar assignment of the function. MDs were observed to make the administrative decisions by $13 \%$ of the WHCNPs and $12 \%$ of the NMs. However, $15 \%$ of the PMHNPs assigned decision-making for administrative policy to the NP, and an additional 15\% assigned the function to the NP and another person. More variety existed in the making of admnistrative policy than in the making of health care policy. 
TABLE XXII

FREQUENCIES AND PERCENTACE OF RESPONSES: ADMINISTRATIVE POLICY-MAKERS IN THE PRACTICE SETTING

\begin{tabular}{|c|c|c|c|c|c|c|c|c|c|c|c|c|c|c|}
\hline \multirow[b]{2}{*}{ Decislons Made By } & \multicolumn{2}{|c|}{$\begin{array}{c}\text { ALL NPS } \\
(358) \\
\end{array}$} & \multicolumn{2}{|c|}{$\begin{array}{l}\text { ANPs } \\
(65) \\
\end{array}$} & \multicolumn{2}{|c|}{$\begin{array}{c}\text { WHCNPS } \\
(56)\end{array}$} & \multicolumn{2}{|c|}{$\begin{array}{l}\text { FNPs } \\
(53) \\
\end{array}$} & \multicolumn{2}{|c|}{$\begin{array}{c}\text { PMHPS } \\
(52) \\
\end{array}$} & \multicolumn{2}{|c|}{$\begin{array}{l}\text { PNPs } \\
(50) \\
\end{array}$} & \multicolumn{2}{|c|}{$\begin{array}{l}\text { NMs } \\
(34)\end{array}$} \\
\hline & $n$ & $x$ & $n$ & 8 & $n$ & \% & $n$ & $\overline{8}$ & $n$ & $\bar{x}$ & $\bar{n}$ & $\bar{x}$ & $n$ & $\bar{x}$ \\
\hline$M D$ and $N P$ & 53 & 16.4 & 12 & 18.8 & 11 & 19.6 & 12 & 23.1 & 4 & 7.7 & 3 & 8.2 & 5 & 14.7 \\
\hline MD, NP and Other & 52 & 14.7 & 10 & 15.6 & 7 & 12.5 & 7 & 13.5 & 12 & 23.1 & 7 & 14.3 & 6 & 17.6 \\
\hline$M D, N$ and $R N$ & 40 & 11.3 & 4 & 6.3 & 4 & 7.1 & 3 & 5.8 & 6 & 11.5 & 6 & 12.2 & 7 & 20.6 \\
\hline MD, ND, RN and Other & 31 & 8.8 & 7 & 10.9 & 3 & 5.4 & 7 & 13.5 & 2 & 3.9 & 4 & 8.2 & 2 & 5.9 \\
\hline MD & 30 & 8.5 & 6 & 9.4 & 7 & 12.5 & 3 & 5.8 & 3 & 5.8 & 4 & 9.2 & 4 & 11.8 \\
\hline other & 26 & 7.3 & 3 & 4.7 & 5 & 8.9 & 5 & 9.6 & 4 & 7.7 & 4 & 9.2 & 0 & 0 \\
\hline NP & 25 & 7.1 & 4 & 6.3 & 4 & 7.1 & 3 & 5.8 & 8 & 15.4 & 1 & 2.0 & 3 & 3.9 \\
\hline MD and other & 20 & 5.6 & 4 & 6.3 & 4 & 7.1 & 1 & 1.9 & 3 & 5.8 & 4 & 9.2 & 2 & 5.9 \\
\hline NP and other & 18 & 5.1 & 3 & 4.7 & 1 & 1.8 & 2 & 3.8 & 8 & 15.4 & 2 & 4.1 & 1 & 2.9 \\
\hline MD and RN & 15 & 4.2 & 4 & 6.3 & 4 & 7.1 & 2 & 3.8 & 2 & 3.8 & 3 & 6.1 & 0 & 0 \\
\hline MD, RN and Other & 7 & 2.0 & 1 & 1.6 & $\mathbf{0}$ & $\mathbf{0}$ & 0 & 0 & 0 & 0 & 3 & 6.1 & 2 & 5.9 \\
\hline $\mathrm{MD}, \mathrm{NP}, \mathrm{PA}$ and $\mathrm{RN}$ & 6 & 1.7 & 3 & 4.7 & $\mathbf{0}$ & 0 & 1 & 1.9 & 0 & 0 & 0 & 0 & 1 & 2.9 \\
\hline$N P$ and $R N$ & 6 & 1.7 & 1 & 1.6 & 2 & 3.6 & 1 & 1.9 & 0 & 0 & 1 & 2.0 & 1 & 2.9 \\
\hline
\end{tabular}


TABLE XXII (CONIINUED)

\begin{tabular}{|c|c|c|c|c|c|c|c|c|c|c|c|c|c|c|}
\hline \multirow[b]{2}{*}{ Declsions Made By } & \multicolumn{2}{|c|}{$\begin{array}{c}\text { ALL NPS } \\
(358) \\
\end{array}$} & \multicolumn{2}{|c|}{$\begin{array}{l}\text { ANPs } \\
(65) \\
\end{array}$} & \multicolumn{2}{|c|}{$\begin{array}{c}\text { WHCNPs } \\
(56)\end{array}$} & \multicolumn{2}{|c|}{$\begin{array}{l}\text { FNPs } \\
(53)\end{array}$} & \multicolumn{2}{|c|}{$\begin{array}{c}\text { PMHNPs } \\
(52) \\
\end{array}$} & \multicolumn{2}{|c|}{$\begin{array}{l}\text { PNPs } \\
(50)\end{array}$} & \multicolumn{2}{|c|}{$\begin{array}{l}\text { NMs } \\
(34)\end{array}$} \\
\hline & $\bar{n}$ & $\bar{x}$ & $\bar{n}$ & $\bar{x}$ & $\bar{n}$ & 8 & $n$ & $\bar{x}$ & $\bar{n}$ & $\overline{8}$ & $\bar{n}$ & $\bar{\phi}$ & $n$ & $\%$ \\
\hline RN and Other & 6 & 1.7 & 2 & 3.1 & 1 & 1.8 & 0 & 0 & 0 & 0 & 2 & 4.1 & 0 & 0 \\
\hline NP, $P N$ and Other & 4 & 1.1 & 0 & $\mathbf{0}$ & 1 & 1.8 & 1 & 1.9 & 0 & 0 & 1 & 2.0 & 0 & 0 \\
\hline RN & 3 & 0.8 & 0 & 0 & 1 & 1.8 & 0 & $\mathbf{0}$ & 0 & 0 & $\mathbf{0}$ & 0 & 2 & 4.1 \\
\hline$M D, N P, P A, R N$ and other & 2 & 0.6 & 0 & 0 & 0 & 0 & 0 & $\mathbf{0}$ & 0 & 0 & 0 & 0 & 0 & 0 \\
\hline MD, NP, PA & 2 & 0.6 & 0 & 0 & 0 & $\mathbf{0}$ & 1 & 1.9 & $\mathbf{0}$ & 0 & 0 & 0 & 0 & 0 \\
\hline MD, NP, PA and Other & 1 & 0.3 & 0 & 0 & 1 & 1.8 & 1 & 1.9 & 0 & 0 & 0 & 0 & 0 & 0 \\
\hline$M D$ and $P A$ & 1 & 0.3 & 0 & 0 & 0 & 0 & 1 & 1.9 & 0 & 0 & 0 & $\mathbf{0}$ & 0 & 0 \\
\hline$P A$ and other & 1 & 0.3 & 0 & 0 & 0 & 0 & 1 & 1.9 & 0 & 0 & 0 & 0 & 0 & 0 \\
\hline
\end{tabular}

Note: MD $=$ Physlcian

NP = Nurse Practltioner

$P A=$ Physician's Assistant

RN = Reglstered Nurse 


\section{PUBLIC RELATIONS FUNCTIONS}

Appendix $C$ contains ranked and summarized content analyses of the responses by the NPs in general to open-ended questions about interpersonal relationships with patients, other disciplines, the community, and with legislators.

To the question "How do you interpret the function of nurse practitioner? (a) to your patients, (b) to other disciplines, (c) to the community, [and] (d) to legislators," respondents answered in their own words. In Appendix C, answers are content-analyzed and ranked in descending order. For three of the four parts, some respondents answered "Same as above," and the investigator analyzed the answer for the relevant part as though the same words had been written again. To assess a possible effect of "Same as above," 41 questionnaires were analyzed for frequency of "Same as above." Table XXXII shows that the answer occurred once in $13(32 \%)$ of the sample (see Appendix C).

The words below and in Appendix $C$ are quotations and compilations of the original responses. Individual responses have been grouped together and are discussed by reference to the first in a cluster of words which represent concepts and activities.

\section{To Patients}

Table XXVIII shows that "Expert Specialist" appeared the greatest number of times (688) of any concept in the Table (see Appendix C). Supportive activities included "Primary care provider (231)," "Experienced, knowledgeable (183)," "Assessment (93)," 
"Consultation, integrated plan, nursing diagnosis, and

availabil[ity] (181)." The NPS made nearly as many references

(555) to the idea of "Care/Health Education," where "Resource

Professional" occurred most often (269) among the supportive

concepts and activities, which also included

"Preventive (109)," "Education (86)," "Psychosocial (79)." and

"Physical, Financial (12)."

To Other Disciplines

Table XXIX in Appendix C presents the interpretations of the NPS in general to other disciplines. "Collaborator" was identified in 397 responses; the greatest number (230) of supportive activities were found with extended nursing role" and included "Diagnosis," "Problem-solve," "Referrals," "Liaison," and "Health," each of which appeared a similar number of times $(38,38,34,30$, and 29$)$. "Counseling," "Advocacy," and "Resource" occurred somewhat less often (20, 20, and 18). "Research" was named least often (3). To "Educate/Explain Credentials" occurred less often (59\%) than "Collaborator," and contained fewer supportive categories ("Compare/ contrast" most common -- 105; "Academic" approximatley 50\% as common, with "Alternative," and "Complement" less common -- 29 and 25 -- while "Competitive/threatening" and "Cost" least commonly used, at 15 and 7 instances). "Same [interpretation as to patients]" appeared in 96 responses. 


\section{Io the Community}

Table $X X X$ in Appendix $C$ presents classifications of the behaviors the total sample of NPs said they used to interpret their function to the community. The largest classification (255) "Advocate Di sease Prevention" contains nearly equal supportive activities ("Change Agent"--113 and "Wellness and Growth Promotion" -96); another activity, "Assessment," appeared in 46 instances. The concept "Mid-Level Care Provider" occurred 61\% as often, and "Scope of Practice" has the most frequently mentioned supportive activities (71); "Supportive care" (46) and "Liaison" (32) appeared in a similar number of comments, while "Research" was the least identified activity in the category.

"Same as Above" occurred in 140 instances. The interpretation of the NP function to the community resembled the one given to patients and/or to other disciplines.

"Provider for the Underserved" was found in 34 interpretations; "Cost containment" and "Care for the underserved" represented supportive concepts or activities with approximately equal frequency (18 and 16 , respectively).

\section{To Legislators}

Table XXXI in Appendix C presents classifications of behaviors reported by the NPs in general to interpret their function to legislators. Of the classifications, "Testify as Expert" appeared the most (192), and "Avoid" occurred the least often (1); the 
remaining categories ("Same as Above" and "Encourage Votes") included 86 and 32, respectively, of the interpretations.

In summary, the supportive activities included the following: (a) encourage votes, provide contacts support special interest groups, and inform/advise legislators about the role and impact of NPs; (b) write research-based descriptions of need for services in the constituency of the legislator; (c) testify as an expert about NP qualifications; (d) emphasize proactive, holistic, health promotion and maintenance and recognition of early signs of illness; (e) describe accessibility to underserved/medically needy, low income clients in rural/urban schools, nursing homes, correctional institutions, and indigents in various settings in the community; (f) underline the economic and professional benefits to the consumer of multiple health care roles; and (g) focus on the cost advantages of health promotion, disease prevention, and the lower rates of morbidity and mortality where outcomes are equal or higher and at lower cost than those of physicians. NPs are less expensive than MDs to educate, license, and insure. NPs are at a lower liability rate due to the practice of referral of higher risk cases to physicians. NPs free physicians for more technical care. 
CHAPTER $V$

SUMMARY, CONCLUSIONS, RECOMMENDATIONS

Each nurse practitioner (NP) participant in Oregon donated up to 142 responses to the findings of this study. The findings are summarized in the first section. In the second section, conclusions are identified. The last section contains recommendations for future investigations.

\section{SUMMARY}

This section reiterates the purpose of the study, reviews the population studied, and summarizes the principal findings. Mailed questionnaires were used to collect data from all NPS who were certified in Oregon in January, 1986.

Purpose of the Study

The study was designed as an exploratory survey of nurse practitioners (NPs) in Oregon in general and by specialty with regard to three aspects of certain functions used in the practice setting. Two purposes were stated: 
1. To determine the perceptions of the Oregon-certified NP with respect to their (a) frequency of performance, (b) competence in performance, (c) preparation for each function: and,

2. To compare the perceptions of NPs in various specialties with respect to each of the above.

Populations Studied

One of 574 questionnaires was mailed to each NP certified in Oregon and living in any of the 50 states during the Winter of 1986. Of the 388 or $68 \%$ of the NPS who responded, 2 were too late to be counted and 28 were not then in active practice in Oregon. Except for references to practice settings, the demographic characteristics include usable responses from 386 NPs. The responses to certain functions came from 358 certified NPs in Oregon practice settings between January and April, 1986. The data were analyzed with summary statistics and the Chi-square test for independence.

\section{Selected Characteristics and Attitudes}

The NPs who responsed to this study represented a wide range of demographic characteristics. The greatest number of respondents were between 36 and 45 years of age (46\%) had practiced less than 10 years as an NP in Oregon (82\%), had practiced as an RN less than 10 years $(60 \%)$, and reported themselves to be very satisfied with the autonomy (60\%) and responsibilities (53\%) of their primarily 
ambulatory (49\%) and non-hospital community practice settings

(31\%). Very few (3\%) NPs were in hospital units/wards.

Basic nursing education was obtained by the majority (more than $60 \%$ ) in a baccalaureate program. The highest level of education achieved by most respondents $(57 \%)$ was the master's degree. The doctorate degree had been awarded to 14 NPS, four of whom majored in nursing.

The sequence of NP preparation preferred by $80 \%$ of the participants was a baccalaureate followed by a master's degree which qualifies for NP certification in a specialty area. Most of the respondents were products of master's degree NP programs (52\%) most of which they used (52\%) and found to be adequate or very adequate for the responsibilities of the practice setting (66\%). The 1 argest number $(46 \%)$ of NPS perform the major part of their professional activities in a large city. Nearly half (49\%) of the NPs served persons whose income was estimated to be low or very low.

\section{Nurse Practitioner Functions}

The functions selected for this study were arranged into categories derived from the Oregon Board of Nursing Administrative Rules (1980). The categories are:

1. Health Promotion and Maintenance,

2. Management of Health Care,

3. Treatment in Collaboration,

4. Prevention of Illness and Disability, and

5. Guidance and Counseling 
The results of the analyses of these functions are suminarized in five tables (corresponding to the aforementioned categories); the general nature of these tables is discussed first, followed in order by the presentation of the tables. In each category, functions are ranked in descending order of usage by the NPs in general. The function at the top of the list was said to be most used by the greatest number of 358 respondents. The function at the bottom of the list was reportedly used the least by the participants in general.

As a way of comparing the responses by the NPs in six specialty areas to the functions in a category, an asterisk is used to show a significant relationship between the specialty groups and three dimensions of the function: "Competency," Usage," and "Program." If the relationship existed between "Level of Competency" of a function and NP specialty area, the asterisk appears in the appropriate space in the column labeled "Competency"; medians of the speciality groups are aligned with the function where "I" indicates the least and "4" indicates the most self-perceived competence. If the relationship existed between specialty groups and "Frequency of Use" of a function, the asterisk appears in the indicated space in the column entitled "Usage," and the numbers "1" through "5" represent the medians of the specialties. To indicate a relationship between "Place in NP Preparation" and specialty groups, the asterisk is in the column entitled "Program." The letters "a," "B," "C," and "G" aligned with the function show the preferences 
expressed by the respondents for the location of major emphasis of the function.

Health Promotion and Maintenance Functions. Table XXIII presents the functions in this category and shows that the NPs in general expressed competence in five functions, with moderate usage of three of these. In most instances the perceived competency level of a function tends to coincide with the frequency of its use. When analyzed on a percentage basis, "Health Promotion and Maintenance" functions are arranged with those at the top the ones which the NPs in general used the most frequently. At the bottom are the least used functions in the category. (For the various specialties, please note that the chi-square test compared the distributions of response-categories, not medians.) 
TABLE XXIII

RANK ORDER BY SPECIALTY RESPONSES TO HEALTH PROMOTION

AND MAINTENANCE FUNCTIONS: COMPETENCE, USAGE, AND PREFERRED PROGRAM FOR PREPARATION

\begin{tabular}{|c|c|c|c|c|}
\hline Inctions & $\frac{\text { Competence }}{A W F \underline{P} P}$ & & $\frac{\text { Usage }}{A W F \underline{P} P S}$ & $\frac{\text { Program }}{A W F \perp P N S}$ \\
\hline $\begin{array}{l}n \text { in } \\
\text { sician }\end{array}$ & 44414 & & $455155 \star$ & $G G G G G G$ * \\
\hline$h$ & 43414 & & 435153 * & $G B G B G G$ * \\
\hline E Crianges & 33333 & & 333333 & $B B G G B B$ * \\
\hline $\begin{array}{l}\text { sider a patient's right } \\
\text { when this conflicts wit } \\
\text { an institutional or } \\
\text { agency policy }\end{array}$ & 33343 & & 322323 & B B B B B B * \\
\hline & 31313 & $\star$ & 313121 * & $G G G G G G$ \\
\hline 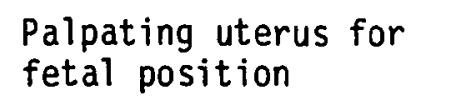 & 14311 & $4 \star$ & 132115 * & $B G G B G G$ \\
\hline $\begin{array}{l}\text { Provide routine } \\
\text { prenatal care }\end{array}$ & 14311 & * & 133115 * & $G G G G G G$ * \\
\hline and abnormal EKG & 31311 & * & 312111 * & $B B G \stackrel{B}{G} B G$ \\
\hline Dialating pupils & 21211 & & 111111 * & $G G G G G G$ \\
\hline Perform proctoscopy & 11111 & $1 *$ & 1111110 & $G G G G G G$ * \\
\hline Perform sigmoidoscopy & 11111 & 10 & 1111110 & $C G \subset G G G$ * \\
\hline \multicolumn{5}{|c|}{$\begin{array}{ll}A=\text { Adult NPs } & a=\text { Associate Degree Nursing } \\
W=\text { Women's Health Care NPS } & B=\text { Baccalaureate Nursing } \\
F=\text { Family NPS } & C=\text { Continuing Education } \\
P=\text { Psychiatric/Mental Health NPS } & G=\text { Graduate Degree Nursing } \\
P=\text { Pediatrics NPs } & S=\text { Significance } \\
N=\text { Nurse Midwives } & \star \text { S Significant chi-square Test } \\
& (\alpha=\text {.05) } \\
& 0=\text { No Interpretation Possible }\end{array}$} \\
\hline
\end{tabular}


For all but three of these functions, the greatest number of NPS preferred "Graduate degree programs" for major emphasis. The responses of the NPS in six specialty areas were examined with a chi-square test for independence. A relationship was found between NP specialty area and "Level of Competence" in 9, "Frequency of Use" in 7, and "Place in NP Preparation in 7 of the 11 functions included with "Health Promotion and Maintenance." In this category, differences did exist between NPS in the specialty areas in some aspects of some of the functions. With respect to 10 of the 11 functions in this category, the greatest number of NPs in specialty areas were in agreement about wanting major emphasis to occur in higher education. Management of Health Care Functions. In Table XXIV, the functions are ranked according to their usage by the NPS, in general who expressed at least moderate competence in nine functions, with at least moderate usage of 7 of them. For most of the functions in the "Health Care Management" category, the perceived competency was similar to usage. When analyzed on a percentage basis, "Health Care Management" functions used most often are at the top of the list. At the bottom of the list are the functions in this category used least frequently by the NPs as a whole. The medians are provided to indicate differences in self-reported competence and usage among the various specialties. Significant chi-square testing of the distributions of the response-categories (not the medians) is shown by an asterisk where appropriate. 
TABLE XXIV

RANK ORDER BY SPECIALTY RESPONSES TO MANAGEMENT OF HEALTH CARE FUNCTIONS: COMPETENCE, USAGE, AND PREFERRED PROGRAM

FOR PREPARATION

\begin{tabular}{|c|c|c|c|}
\hline Functions & $\frac{\text { Competence }}{A W F P N S}$ & $\frac{\text { Usage }}{A W F \underline{P} P N}$ & $\frac{\text { Program }}{A W F P N S}$ \\
\hline $\begin{array}{l}\text { Using judgmen } \\
\text { initiative ma } \\
\text { health care d }\end{array}$ & $444444 \star$ & 555555 & $B B G B B B$ \\
\hline $\begin{array}{l}\text { Providing primary } \\
\text { care to patients } \\
\text { and families }\end{array}$ & 444444 & 555455 & $G G G G G G$ * \\
\hline $\begin{array}{l}\text { Evaluate and prescribe } \\
\text { medications in your } \\
\text { specialty }\end{array}$ & 444444 * & 555355 * & $G G G G G G 0$ \\
\hline $\begin{array}{l}\text { Using a problem-solving } \\
\text { process to plan, provid } \\
\text { and evaluate the primar } \\
\text { care for the client and } \\
\text { their family }\end{array}$ & $\begin{array}{l}\text { le, } \\
444444\end{array}$ & 444545 * & $B B G B B B$ \\
\hline Initiate drug therapy & 444343 * & 455154 * & $G G G G G G 0$ \\
\hline $\begin{array}{l}\text { Ordering and/or perform } \\
\text { ing diagnostic tests }\end{array}$ & $444334 *$ & $554344 \%$ & $G G G G G G:$ \\
\hline $\begin{array}{l}\text { Evaluate the health } \\
\text { care provided by } \\
\text { physicians }\end{array}$ & 333433 * & 434333 * & $G \stackrel{B}{G} G G B \stackrel{B}{G}$ * \\
\hline $\begin{array}{l}\text { Managing patient with } \\
\text { chronic disorders accor } \\
\text { ing to standing orders }\end{array}$ & 434432 * & 323221 * & $G G G B B G$ * \\
\hline $\begin{array}{l}\text { Diagnose and treat } \\
\text { acute otitis media }\end{array}$ & 424143 * & 314152 * & $G G G G G G *$ \\
\hline $\begin{array}{l}\text { Mange abnormal pain } \\
\text { from distension }\end{array}$ & 313111 * & 212111 * & $G G G G G G$ \\
\hline
\end{tabular}


TABLE XXIV

(CONT INUED)

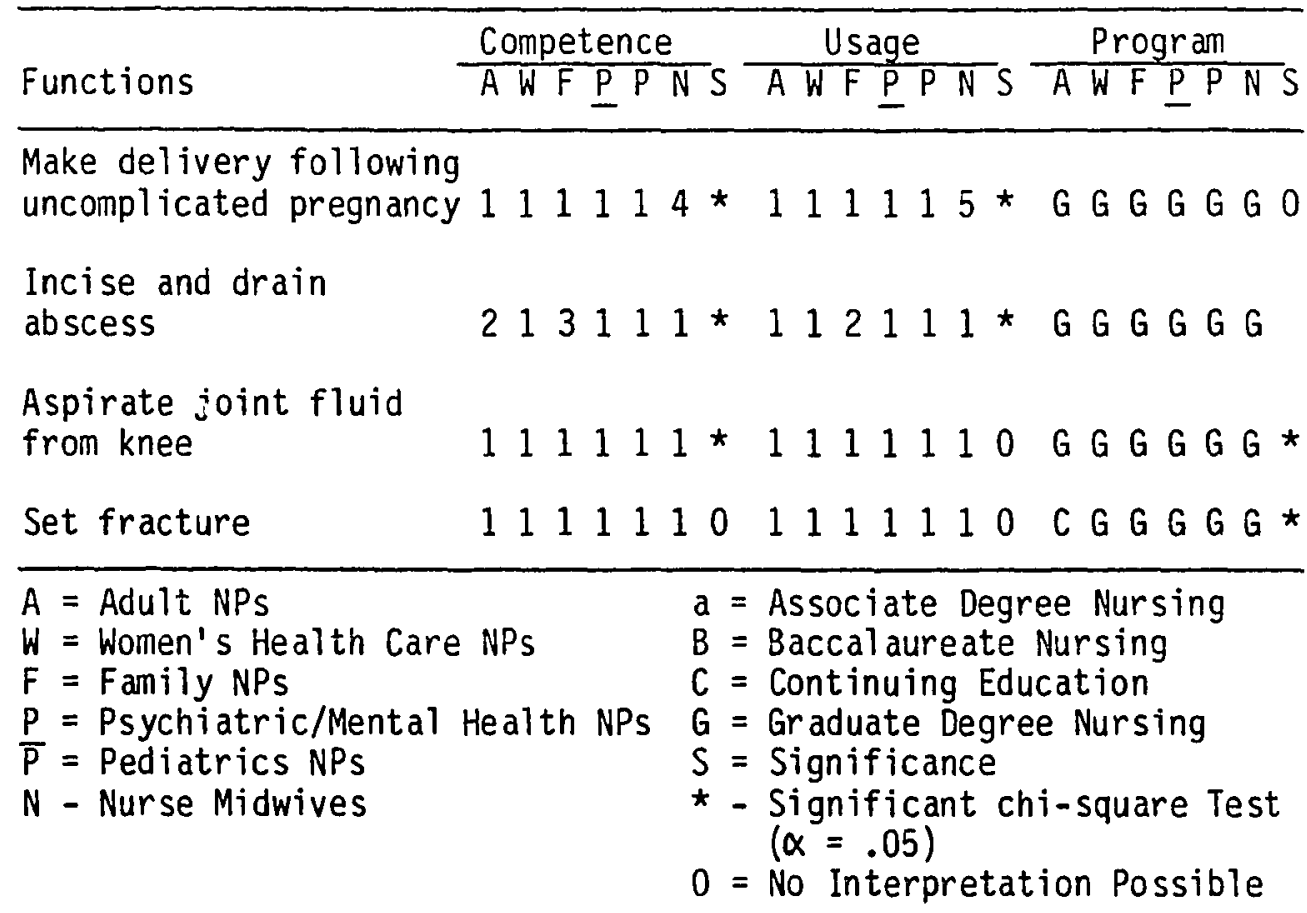

Graduate degree nursing programs were preferred by the greatest number of the NPs for major emphasis of 12 of the 15 functions in the category. The responses of the NPs in six specialty areas were examined with a chi-square for independence. A relationship was found between NP specialty area and "Level of Competency" in 12, "Frequency of Use" in 11, and "Place in NP Preparation" in 8 of the 15 functions included with "Health Care Management." In this category, differences existed between NPs in the specialty arei's in some aspects of some of the functions. With respect to 14 of the 15 functions in the category, the greatest number of NPs in six specialties agreed that major emphasis should occur in higher 
education; for nine of the functions, the majority of the NPS in each specialty selected graduate education.

Treatment in Collaboration Functions. Table XXV presents a rank-ordering based upon the percentage of usage reported by the NPs in general, who expressed at least moderate competence and usage of these functions. In most of the functions in the "Treatment in Collaboration" category, the perceived competency generally was associated with the reported usage. At the top are the functions used most often, and at the bottom are those used least frequently. (Please note that the chi-square test compared the distributions of response-categories (not medians) for the various specialties.) 
TABLE XXV

RANK ORDER BY SPECIALTY FOR TREATMENT IN COLLABORATION FUNCTIONS: COMPETENCE, USAGE, AND PREFERRED PROGRAM FOR PREPARATION

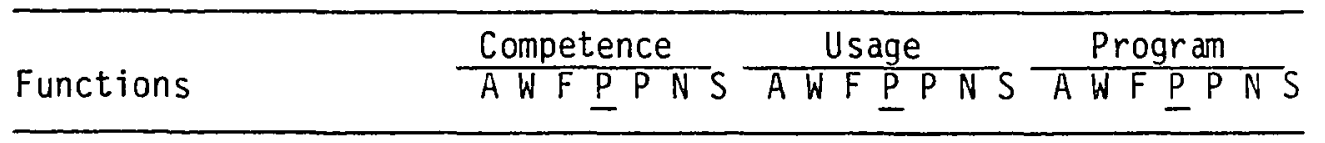

Functioning as a

collaborator with a physician $444444 \quad 444444$ * B B G B B B *

Reducing the fragmentation and bringing continuity to the health care that patients and families receive $444444 \quad 444445 \quad$ G B B B B B * Perform physical examination with physician confirming heart and lung findings

Working with community resources on behaif of clients and their families 343443 * 344444 * B B B B B B *

$A=$ Adult NPs

$W=$ Women's Health Care NPs

$F=$ Family NPs

$a=$ Associate Degree Nursing

$B=$ Baccalaureate Nursing

$\quad C=$ Continuing Education

$\underline{P}=$ Psychiatric/Mental Health NPS

$\bar{P}=$ Pediatrics NPs

N - Nurse Midwives

$G=$ Graduate Degree Nursing

$S=$ Significance

* - Significant chi-square Test $(\alpha=.05)$

$0=$ No Interpretation Possible

For all four of these functions, the greatest number of NPS preferred baccalaureate nursing programs to provide major emphasis. The responses of the NPS is six specialties were examined with a chi-square for independence. A relationship was found between the specialties and "Level of Competence" in two, "Frequency of Use" in three, and "Place in NP Preparation" in three of the four functions 
in the "Treatment in Collaboration" category. Differences were found between NPS in the specialties and some response-categories of some of the functions. With respect to all four of the functions in this category, the greatest number of NPS in six specialties agreed that major emphasis should occur in higher education, with a tendency to prefer undergraduate programs.

Prevention of Illness and Disability Functions. In Table $X X V I$, the functions in this category are ranked according to percentages of response-categories for "Frequency of Use" by NPS in general. For only one of the functions in the category did the NPS (total sample) express at least moderate competence and usage. The perceived competency generally coincided with usage of the functions in the "Prevention of Il Iness and Disability" category. The function at the top was used most often, and the function at the bottom was used least frequently. (Please note that the chi-square test compared the distibutions of response-categories (not medians) of the various specialties.) 
TABLE XXVI

RANK ORDER BY SPECIALTY FOR PREVENTION OF ILLNESS AND DISABILITY FUNCTIONS: COMPETENCE, USAGE, AND PREFERRED

PROGRAM FOR PREPARATION

\begin{tabular}{|c|c|c|c|}
\hline Functions & $\frac{\text { Competence }}{A W F \underline{P}}$ & & 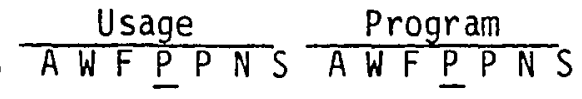 \\
\hline \multicolumn{4}{|l|}{$\begin{array}{l}\text { Assuring the rights of } \\
\text { patients to be actively } \\
\text { involved in their own } \\
\text { health care }\end{array}$} \\
\hline $\begin{array}{l}\text { Prescribing diabetic } \\
\text { diets }\end{array}$ & 32312 & 2 & $212111 * B G G G B G$ \\
\hline \multicolumn{4}{|l|}{$\begin{array}{l}\text { Adjust medication for } \\
\text { patient with benign } \\
\text { essential hypertension }\end{array}$} \\
\hline $\begin{array}{l}\text { Regulate medication } \\
\text { dose for diabetics }\end{array}$ & 31211 & 1 & 212111 * $G G G G G G$ * \\
\hline $\begin{array}{l}\text { Changing Foley cathet } \\
\text { in male patients }\end{array}$ & 4342 & & $=111111$ * B B a B B B * \\
\hline $\begin{array}{l}A=\text { Adult NPs } \\
W=\text { Women's Health Care } \\
F=\text { Family NPs } \\
P=\text { Psychiatric/inental } \\
\bar{P}=\text { Pediatrics NPS } \\
N=\text { Nurse Midwives }\end{array}$ & $\begin{array}{l}\text { NPS } \\
\text { Health NPS }\end{array}$ & $\begin{array}{l}\text { D } \\
\text { G } \\
\text { S }\end{array}$ & $\begin{aligned}= & \text { Associate Degree Nursing } \\
= & \text { Baccalaureate Nursing } \\
= & \text { Continuing Education } \\
= & \text { Graduate Degree Nursing } \\
= & \text { Significance } \\
- & \text { Significant chi-square Test } \\
& (\alpha=.05) \\
= & \text { No Interpretation Possible }\end{aligned}$ \\
\hline
\end{tabular}

With the exception of "Assuring the rights of patients...", the NPS as a whole expressed little competence and infrequent usage of these functions. For two of these functions, "Graduate Degree Programs" were preferred for major emphasis. The chi-square test for independence was used to examine the responses of the NPs in six specialties. A relationship was found between NP specialties and "Level of Competency" in four, "Frequency of Use" in four, and 
"Place in NP Preparation" in two of the five functions included in the "Prevention of Illness and Disability" category. Differences did exist between NPS in the specialty areas in some aspects of some of the functions. With respect to four out of the five functions in this category, the greatest number of NPs in six specialties agreed with wanting the major emphasis to occur in higher education.

Guidance and Counseling Functions. Table XXVII presents the functions in this category in rank-order according to the frequency of usage by NPS in general. For only one function did they express slight or no/competence; however, usage of the functions was relatively infrequent. In most instances, the perceived competency of a function was associated with the frequency of its usage. At the top of the list is the function used most often; at the bottom is the function used least often in this category. (Please note that the chi-square test compared the distributions of responsecategories, not medians, of the various specialties.) 
TABLE XXVII

RANK ORDER BY SPECIALTY FOR GUIDANCE AND COUNSELING FUNCTIONS: COMPETENCY, USAGE, AND PREFERRED PROGRAM FOR PREPARATION

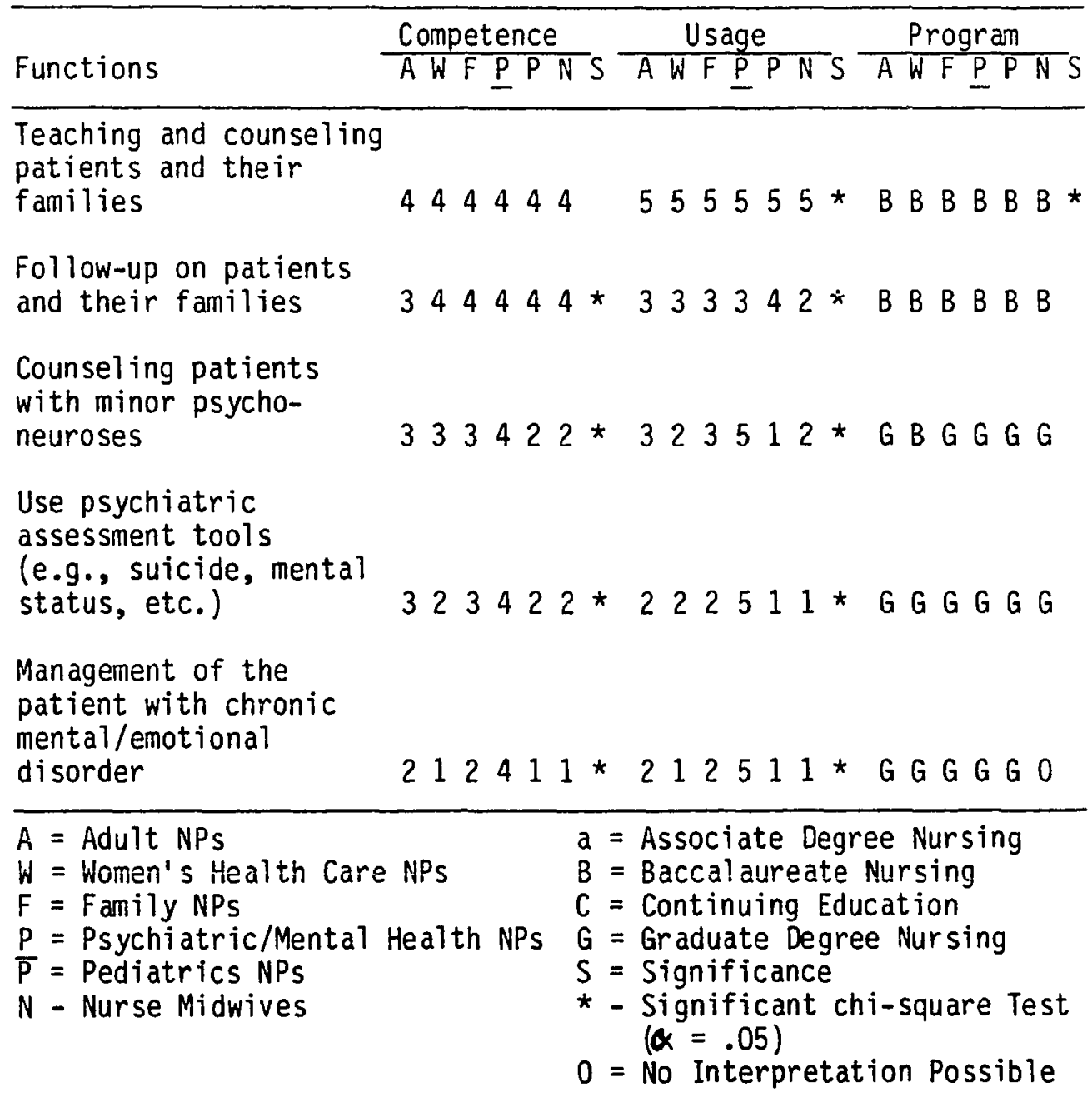

For three of the five functions, the greatest number of NPs preferred "Graduate degree programs" for major emphasis. In six specialty areas, the responses of the NPs were examined with a chisquare test of independence. A relationship was found between specialties and "Level of Competence" in four, "Frequency of Use" in five, and "Place in NP Preparation" in one of the five functions in 
the "Guidance and Counseling" category. Differences were found between NPS in specialties in some aspects of some of the functions. Similarities of competency and usage existed among the NPs more frequently in functions that are broad in scope and application. With respect to all of the five functions in this category, the greatest number of NPS in specialty areas were in agreement about wanting major emphasis to occur in higher education.

\section{CONCLUSIONS}

In this section, findings are identified and implications are made for education and for the field. Limitations of the study are noted.

Findings with Implications for Education and the Field

1. Most of the consumers of health care provided by NPs in Oregon live in urban areas. Approximately half of the NPs in Oregon serve consumers at a low or very low economic level. The greatest number of NPs practice in community or home health agencies.

With respect to population served, the findings support those of Warren (1979) in her study of NPs in Arkansas. Neither the Arkansas NPs in 1979 nor the Oregon NPs in 1986 have "moved in, in substantial numbers to fill the existing gaps in rural areas and towns... where health care providers are decidedly needed" (Warren, 1979, p. 345). The urban practice settings of the Oregon NPs may be associated with other findings. In Oregon, most NPs work in 
ambulatory or community health settings. One may speculate about a connection between the urban poor, their location in the large cities, and their consumption of NP services provided through community health settings. Many community health settings are publicly funded and may be underutilized outside of a high-density catchment area.

Another possibility may be associated with the tendency of NPs to practice in collaboration with other health care professionals. Qualified colleagues may not be as available for referral and consultation in rural as in urban areas.

Some private and pubiic health institutions may have developed alternative health care delivery systems for small towns and rural areas. In recent years Oregon has been financially handicapped in its attempts to discover and to implement new -- or existing -- methods of health care delivery.

Although Warren (1979) found most of the NP respondents in Arkansas to be working in "regular in-hospital units" (p. 348), very few $(3.4 \%)$ of the Oregon respondents were employed on the wards of hospitals.

2. Functions in which NPs in general consider usage and competence to be relatively high are needed in the preparatory programs of all NPs in Oregon.

The top two functions from each of the categories in this study are listed in order of their analysis and discussion as follows: (a) "Perform general physical examination in absence of physician"; (b) "Examining ears with otoscope"; (c) "Using judgment and initiative 
making health care decisions"; (d) "Providing primary care to patients and families"; (e) "Functioning as a collaborator with a physician"; (f) "Reducing the fragmentation and bringing continuity to the health care that patients and families receive"; (g) "Assuring the rights of patients to be actively involved in their own health care"; (h) "Prescribing diabetic diets"; (i) "Teaching and counseling patients and their families"; and ( $j$ ) "Follow-up on patients and families referred to another agency or provider for care." For the location in their preparation of the major emphasis of these 10 , the NPS as a whole preferred baccalaureate nurse programs for $60 \%$ and graduate degree nurse programs for $40 \%$ of the functions. Graduate degree preparation was chosen more often for major emphasis of functions which require advanced and specialized knowledge.

3. Higher education is the preference of NPs in Oregon for major emphasis of the functions which comprise NP practice. Master's level preparation is typical of NP practice in Oregon. The preferred sequence of NP preparation is baccalaureate with a nursing major, followed by a master's program which qualified for NP certification in Oregon.

In contrast to the respondents in Warren's (1979) and Ward's (1975) studies, most of the respondents to this study had received NP preparation in a master's degree program. The Oregon NPs' preference for the master's probably results from the increasingly 
stringent requirements for certification set by the Board of Nursing.

4. A core or basic program benefits most NPs if it includes the functions most used by the greatest number of NPS. The baccalaureate nursing preparation was selected for the core or basic knowledge for functions similar to those which Ward (1975) described as "activities which nurses traditionally performed" ( $p$. 155). For example, "Teaching and counseling patients and their families" could be required at the baccalaureate level as part of curricula in educational principles and methods.

A graduate core could include programs in policy-making and public relations. Since Oregon NPs participated in the majority of the policy-making in their practice settings, preparation in the principles and methods of administrative and health care decisionmaking could be useful to most NPs. Despite a finding in this study that MDs and NPS in general make the majority of policy decisions in administration and health care, NPs may not be required to include policy-making courses in their preparation.

Another preparatory core program suitable at the graduate level would focus on public relations. Respondents in this study provided explicit and extensive detail about their functions with respect to public relations. They described what they did and said to interpret their function with consumers, other disciplines, the community, and legislators. Most NPs would use the sophisticated knowledge and skills obtained from courses in public relations accredited at the graduate level. 
5. For the 40 selected functions in this study, NPs in different specialty areas vary in perceived competency and usage. The assignment of preparation for some functions is consistent for all NPS; the assignment of preparation for other functions varies among the specialty areas. Most NPs in Oregon assigned graduate degree programs in nursing to place major emphasis on $60 \%$ of the functions. Contrary to Ward's (1975) findings about FNPs nationally, fewer of the Oregon NPs chose continuing education ("special programs," in Ward, 1975, p. 163) for development of competency in the performance of any of the 40 functions. Baccaluareate degree programs were picked by the greatest number of NPS for the development of 16 functions. The preference of the NPS for most function emphasis to be at the graduate degree level supports the Longintudinal Study of Nurse Practitioners (1980). "The trend suggests that master's graduates will constitute a growing proportion of all nurse practitioners in the coming years" (USDHEW, p. 10).

Ward (1975) found FNPS who were products of master's programs preferred them for skill development, and nurse educators wanted to teach FNP skills at the master's level (p. 164). Perhaps the quality and depth of graduate degree preparation is valued. In 1979, Warren wrote of NPs in Arkansas, "Graduates of the master's degree program are the [best] prepared NPs in this study" (p. 399). She went on to describe some of the problems associated with matriculation in master's degree programs. 
Among the problems were (a) the loss of income and (b) absence from responsibilities at home during the fulfillment of degree requirements. Some observers have feared the loss from nursing of the professional identity of the NP who may seem insufficiently separated and differentiated from physicians. Educators are challenged to prepare nurse practitioners to meet the reponsibilities of technological expansion in the practice setting without abandonment by the NP of either home or practice responsibilities.

6. For the functions in which NPs generally feel less competent and under-utilized, reduced emphasis or deletions from NP preparation is desirable.

The following functions were the lowest in self-perceived competence and usage, again in order of aforementioned discussion: "Perform proctoscopy"; "Perform sigmoidoscopy"; "Aspirate joint fluid from knee"; "Set fracture"; "Working with community resources on behalf of clients and families"; "Perform physical examination with physician confirming heart and lung findings"; "Regulate medication dosage for diabetics"; "Adjust medication for patient with benign essential hypertension"; "Use psychiatric assessment tools (e.g., suicide, mental status, etc.)"; and "Management of the patient with chronic mental/emotional disorder." (A function which appears in both listings in this section may represent an example of biomodality in the frequency distribution.)

Some NP preparatory programs may delete or reduce the emphasis of some functions. The PMHNP may never "Perform proctoscopy," and the function need not be emphasized during a psychiatric/mental 
health program. Core programming at the undergraduate and graduate levels of initia? NP preparation could release preparatory time in the specialties for functions unique to them.

For $80 \%$ of the less commonly used functions, the NPS as a whole chose "Graduate degree" nursing programs to provide major emphasis. More than in the previous list, the effects of specialization are evident. Specialization uses a narrower, deeper, and rarer knowledge base than does the traditional or basic-nursing type of functions.

7. Some functions are suitable for major emphasis in continuing education programs.

Since most NPS prefer graduate degree preparation, functions which require a high level of specialized technique and expertise would be useful to NPS as needed in continuing nursing education accredited at the graduate level. Functions usually performed by one specialty (e.g., "Management of the patient with chronic mental/ emotional disorder") may never by used by a PNP, unless the PNP needs to work with a clientele of mentally/emotionally disturbed children. Then, the PNP may seek additional high-level expertise focused on certain functions typically found in another specialty. Based upon a perceived need, graduate-level preparation may be made accessible to NPs, applicable to the practice-setting, and in flexible academic units to fit the time and economic constraints of professionally active NPs.

Accessible and relevant undergraduate, graduate, and postgraduate preparation applicable to the demands of an expanding 
technology can maintain the professional competence of all NPs in Oregon practice-settings.

\section{Limitations}

Some limitations originate from the method of the study; others occurred for different reasons. The findings in this study are based upon a mailed questionnaire. Sine the return rate of mailed questionnaires usually is less than $100 \%$, the missing information from nonrespondents may to some extent affect the findings.

The items used in the instrumenation are not identified in a constellation of potential items. The items were adapted from earlier studies in other states in America. The unequal distribution of the items among the categories of NP practice in Oregon may reflect circumstances of NP practice which are peculiar to those states or to the time period when the items were developed. Therefore generalizations are impossible beyond the items selected for this instrument.

This study was designed to examine what nurse practitioners in Oregon think about their preparation for some of their functions. The results provide the basis for comparisons with or egoncertified nurse practitioner function and preparation. Since research was conducted with the nurse practitioners of one state (Oregon), with the state's own distinctive character and possibly uncommon character, generalizations can be made only within limits of the population. 
The various practice-settings, geographical, and socioeconomic environments may have affected the responses of the participants in ways that can not be identified.

\section{RECOMMENDATIONS}

Prior to this study, little information was available with respect to the actual practice activities of NPs. More knowledge about what NPs do that is unique to them would aid the nursing profession to identify more specifically the parameters which separate its advanced practitioners from other health care professionals. As nurses in advanced practice become more articulate about their abilities in collaboration with colleagues, the patient may gain the complementary integration of multi-disciplinary health care.

For 40 functions, the respondents were explicit about their preference for higher education as the place for NP preparation. otner investigators have discovered a similar preference, and they have identified some of the difficulties which have hindered the acquisition of higher education. Research is needed to explore ways to link more effectively the current methods of NP preparation with the tasks, functions, and activities used in the practice setting. Further research is needed to help nurse educators make relevant programs available to NPs in the practice setting. Making nigher education accessible to a maximum number of practicing NPs involves the exploration and development of individualized planning and scheduling. 
Instrumentation is needed to assist nurse educators in the development of NP preparation, professional education, and descriptions of competencies essential to practice in the specialities. Comparisons need to be made about general versus individual preparation. For a certain function, continuing education may be more useful than pre-service preparation.

Another fertile field for exploration centers around the role of education in NP practice. Although patient education is part of accepted practice throughout the nursing profession, and teaching was identified as a greatly used function in this study, little is written about a systematic approach to educational strategies and methods in NP preparation. Studies are needed to assess the need for connections between NP and educational preparation in Oregon, and where a need for such a connection exists to devise ways to meet it.

As the function of the nurse practitioner in Oregon continues to evolve, the topics of manpower needs, trends, and other socioeconomic issues need to be addressed. Important research of the future may investigate the effects of nurse practitioner preparation and practice with regard to forecasts/projections of changes in the function of nurse practitioners in relation to the numbers, function and practice of other health care professionals, the growth of health-maintenance organizations, and the cost-effectiveness of various health care providers. 
As the functions of nurse practitioners increase, a study of state statutes and standards which apply to the expanded practice of nursing in Oregon could facilitate orderly and substantive change.

An examination of the views of the health care consumer toward the functions performed by the nurse practitioner could give new dimensions to the preparation and practice of nurse practitioners in Oregon. 


\section{REFERENCES}

Anderson, E. H. (1974). The political context and process of health legislation. In M. Leininger (Ed.), Heath Care Dimensions (pp. 107-114). Philadelphia, PA: F. A. Davis Co.

American Nurses' Association. (1982). How to apply to become a certified nurse. Kansas City, Mo: Author.

Arkansas MDs charged with attempts to restrain NPs. (1981). American Journal of Nursing, 5, 908, 934.

Banton, M. (1965). Roles: An introduction to the study of social relations. New York: Basic Books.

Biddle, B. J. (1979). Role theory: Expectations, identities, and behaviors. New York: Academic Press.

Bliss, A., \& Cohen, E. (1977). Issues and conclusions: The next to the last word? In A. B1 iss \& E. Cohen (Eds.), The new health professionals (pp. 375-381). Germantown, MD: Aspen Systems, Inc.

Bliss, A. (1979). Critical issues confronting nurse practitioners. In H. A. Sultz \& J. A. Sullivan (Eds.), Nurse practitioners: USA (pp. 205-214). Lexington, MA: D. C. Heath.

California state board clarified position on RN prescribing of medications. (1980). American Journal of Nursing, $6,950$.

Cargill, L. (1985, January 8). Nurse's job treads middle ground. The Oregonian, p. NM 7.

Chen, S., Barkauskas, V. H., Ohl son, V. M., \& Chen, E. H. (1982). Health problems encountered by nurse practitioners \& physicians. Nursing Research, 31(3), 163-169.

Cohen, E. D. (1974). An evaluation of policy related research of new and expanded roles of health workers. New Haven, CT: Office of Regional Activities and Continuing Education, Yale University School of Medicine.

Colorado State Board of Nursing. (1982). Colorado nursing practice act. Denver, CO: Author. 
Division on Psychiatric and Mental Health Nursing. (1976). Practice guidelines for the council of advanced practitioners in psychiatric and mental health nursing (pp. 1-6). Kansas City, Bo: American Nurses Association.

Drice, A. D. (1978). The distribution of functions of nurse practitioners according to level of educational preparation and extent of health care experience in four types of organized practice setting. Dissertation Abstracts International, 39, 07B, $3241-B$. (University Microfilms No. 7901353)

Flynn, B. C. (1975). Study documents reactions to nurses in expanded roles. Hospitals: Journal or American Hospital Association, $49(21), 81-83$. (From Nurse Practitioners and the Expanded Role of the Nurse: A Bibliography, 1979, U.S. Dept. HEW NO. (HRA) 79-20, HRP 0500601)

Hall, V. C. (1977). Summary of statutory provisions governing legal scope of nursing practice in the various state. In $A$. Bliss \& E. Cohen (Eds.), The new health professionals. Germantown, MD: Aspen Systems, Inc.

Hanson, E. T. (1973). Nurse practitioners in ambulatory psychiatric care. Nursing Clinics of North America, 8, 313-323. (From Nurse Practitioners and the Expanded Role of the Nurse: A B ibliography, 1979, U.S. Dept. HEW No. (HRA) 79-20, HRP 0500601)

Holmes, G., Livingston, G., \& Mills, E. (1976). Contribution of a nurse clinician to office practice productivity: Comparison of two solo primary care practices. Health Sciences Research, 11(1), 21-33. (From Nurse Practitioners and the Expanded RoTe of the Nurse: A Bibliography, 1979, U.S. Dept. HEW No. (HRA) 79-20, HRP 0500601)

Hopkins, K. D., \& Glass, G. V. (1978). Basic statistics for the behavioral sciences. Englewood $\mathrm{Cl}$ iffs, NJ: Prentice-Hall.

Hul1, C. H. \& Nie, N. H. (1981). SPSS update 7-9: Statistical package for the social services. New York: McGraw-Hill.

Kahn, L., \& Wirth, P. (1975). Modification of pediatrician activity following addition of the pediatric nurse practitioner to the ambulatory care setting: A time and motion study. Pediatrics, 55, 700-708. (From Nurse Practitioners and the Expanded RoTe of the Nurse: A Bibliography, 1979, U.S. Dept. HEW NO. (HRA) 79-20, HRP 0500601) 
Katz, F. E. (1369). Nurse. In A. Etoni (Ed.), The semi-professions and their organizations (pp. 54-81). New York: Free Press.

Keller, N. (1975). Private nursing practice: Some facilitators and barriers in health care. In M. Leininger (Ed.), Health Care Dimensions (p. 43). Philadelphia: F. A. Davis.

Kerlinger, F. N. (1973). Foundations of behavioral research (2nd ed.). New York: Holt, Rinehart, \& Winston.

Kotulak, R. (1985, January 4). New forces threathen 'good life' of doctors. The Oregonian, p. A2.

Lawrence, R. S., De Friese, G. H., Putnam, S. M., Pickard, C. G., Cyr, B. A., \& Whiteside, S. W. (1977). Physician receptivity to nurse practitioners: A study of the correlates of the delegation of clinical responsibility. Medical Care, 15(4), 298-311.

Leitch, C. J., \& Sullivan, M. E. (1977). State by state report: The legal accommodation of nurses practicing expanded roles. Nurse Practitioner, $2(8), 19-22,30$. (From Nurse Practitioners and the Expanded Role of the Nurse: A Bibliography, 1979, U.S. Dept. HEW No. (HRA) 79-20, HRP 0500601)

Lewis, C. E., \& Cheyovich, T. K. (1976). Who is a nurse practitioner: Processes of care and patients' and physicians' perceptions. Medical Care, 14, 365-371. (From Nurse Practitioners and the Expanded Role of the Nurse: A Bibliography, 1979, U.S. Dept. HEW No. (HRA) 79-20, HRP 0500601)

Lewis, H. L. (1978). Nurse practitioners in prevention and health education. Hospital Progress, 1, 80-83. (From Nurse Practitioners and the Expanded RoTe of the Nurse: A Bibliogrpahy, 1979, U.S. Dept. HEW No. (HRA) 79-20, HRP 0500601)

Linn, L. S. (1976). Patient acceptance of the family nurse practitioners. Medical Care, 14, 357-364. (From Nurse Practitioners and the Expanded Role of the Nurse: A Bibliography, 1979, U.S. Dept. HEW NO. (HRA) 79-20, HRP 0500601)

McCormack, J. J. (1975). Current public policy and medical care evaluation. In M. Leininger (Ed.) Health Care Dimensions (pp. 47-57). Philadelphia, PA: F. A. Davis. 
Merenstein, J. H., Harvey, W., \& Barker, K. H. (1974). Use of nurse practitioners in a general practice. Medical Care, 12 , 455-452. (From Nurse Practitioners and the Expanded RoTe of the Nurse: A B ibliography, 1979, U.S. Dept. HEW No. (HRA) 79-20, HRP 0500601)

NP prescribing privileges attacked in Oregon. (1981). American Journal of Nursing, 4, 653.

National Technical Information Service. (1976). Nurse practitioners in Rhode Island (NTIS No. HRP-0010325). (From Nurse Practitioners and the Expanded role of the Nurse: A Bibliography, 1979, U.S. Dept. HEW No. (HRA) 79-20, HRP 0500601)

Nebraska legislature says NP roles must be set by 1 aw, not regulations. (1981). American Journal of Nursing, $8,1446$.

New practice act in Colorado expands definition of nursing. (1980). American Journal of Nursing, $7,1261$.

New state board regulations in Washington okay RNs prescribing without protocols. (1980). American Journal of Nursing, 12, $2125,2136,2152$.

Nie, N. H., Hul1, C. H., Jenkins, J. G., Steinbrenner, K., \& Bent, D. H. (1975). SPSS: Statistical package for the social sciences (2nd ed.). New York: McGraw-Hill.

Nurse Practitioner Special Interest Group. (1982, July). Legislative report, p. 2. Portland, OR: Author.

Nurse Practitioner Special Interest Group. (1984, September). Minutes, pp. 1-6. Portland, OR: Author.

Nurse Practitioner Special Interest Group. (1984, November). Newsletter, pp. 1-8. Portland, OR: Author.

Oregon Nurses Association. (1986). Memorandum, pp. 5-7. Portland, OR: Author.

Oregon revised statutes. Chapters $677.010 \& .060 \& .070 \& .085$, $678.010 \& .375 \& .390 \& .040$.

Oregon State Board of Nursing. (1980). Application requirements for initial certification as a nurse practitioner in a speciality area. Oregon administrative rules, Ch. 851, Div. 20, 30. 
Oregon State Board of Nursing. (1980). Oregon administrative rules, Chaps. 847-50-005, 851-20-300\&-310, 851-30-001\&-003 $\&-170 \&-248$.

Oregon State Board of Nursing. (1983). Letter of notification. Portland: Author.

Patterson, P. K., \& Skinner, P. K. (1971). Group health coop. of Puget Sound, Seattle, WA: Physician response to delegation of well child care. Northwest Medicine, (2), 92-96. (From Nurse Practitioners and the Expanded Role of the Nurse: A Bibliography, 1979, U.S. Dept. HEW No. (HRA) 79-20, HRP 0500601)

Pellegrino, E. D. (1977). Foreword. In A. Bliss \& E. Cohen (Eds.), The new health professionals (p. xv). New York: Free Press.

Popiel, E. S. (1973). Nurse practitioner: A new program in continuing education. Journal of Nursing Education, 12(29), 3136.

Record, J. C., \& Greenlick, M. R. (1975). New health professionals and the physician role: An hypothesis from Kaiser experience. Public Health Reports, 90, 241-246. (From Nurse Practitioners and the Expanded Role of the Nurse: A Bibliography, 1979, U.S. Dept. HEW No. (HRA) 79-20, HRP 0500601)

Redman, B. K. (1980). The process of patient teaching in nursing (4th ed.). St. Louis, Mo: Mosby.

Reed, D. E., \& Rogelmann, K. J. (1971). Acceptability of an expanded nurse role to nurses and physicians. Medical Care, 9 , 372-377. (From Nurse Practitioners and the Expanded Rote of the Nurse: A B ibliography, 1979, U.S. Dept. HEW No. (HRA) 79-20, HRP 0500601)

Rules and regulations to list professional nurses who meet qualifications as advanced practitioners. (1982). Excerpted for personal mailing by Linda Fleming, Educational Consultant, Colorado State Board of Nursing, 1-3.

Schleining, M. (1980). A survey of physicians' attitudes toward the concept of the nurse practitioner. Unpublished master's thesis, Oregon Health Sciences University, School of Nursing: Portland, OR.

Slome, C., Daly, M., Meglen, M., Thiede, H., \& Wetherbee, H. (1976). Effectiveness of certified nurse midwives: A prospective evaluation study. American Journal of Obstetrics and Gynecology, 124, 177-182. (From Nurse Practitioners and the Expanded Role of the Nurse: A BibTiography, 1979, U.S. Dept. HEW No. (HRA) 79-20, HRP 0500601) 
Sullivan, A. (1977, June 11). Way sougint to restore medical aide to vast area. The Oregonian, n.p.

Sullivan, J. A., Kitzman, H. A., \& Dachelet, C. Z. (1979). The NP-MD Team: A descriptive analysis. In H. A. Sultz, 0. M. Henry, \& J. A. Sullivan (Eds.), Nurse practitioners: USA (pp. 163-172). Lexington, MA: D. C. Heath.

Sultz, H. A. (1979). Commentary. In H. A. Sultz \& J. A. Sullivan (Eds.), Nurse practitioners: USA (pp. 215-220). Lexington, MA: D. C. Heath.

Theiss, B. E. (1976). Investigation of perceived role functions and attitudes of the $n$. $p$. role in a primary care clinic. Military Medicine, 141(2), 85-89. (From Nurse Practitioners and the Expanded Role of the Nurse: A B ibliography, 1979, U.S. Dept. HEW No. (HRA) 79-20, HRP 0500601)

Thomas, M. (1982). A joint psychiatric practice. In M. Lynch (Ed.), on your own: Professional growth through independent practice (pp. 193-196). Monterey, CA: Wadsworth Health Sciences.

Thurman, R. L., \& Snowe, R. J. (1976). Nurse practitioner and institutional facilities for the mentally retarded--are they compatible? Journal of Psychiatric Nursing and Mental Health Services, 14(5), 7-10. (From Nurse Practitioners and the Expanded Role of the Nurse: A Bibliography, 1979, U.S. Dept. HEW No. (HRA) 79-20, HRP 0500601)

United States Department of Health, Education and Welfare. (1980). Longitudinal study of nurse practitioners (DHEW Publication No. HRA 80-2). Washington, DC: U.S. Government Printing office.

Utah nurse practitioners conducting pilot project in prescription writing. (1981). American Journal of Nursing, $\underline{8}, 1424-1448$.

WNET (Producer). (1983, September 21). Missouri nurse practitioners. McNeil-Lehrer News Hour. New York: Public Broadcasting Corporation.

Ward, M. J. (1975). A study of family nurse practitioners: Perceived competencies and some of their implications for nursing education. Dissertation Abstracts International, 36, 08B, 3875. (University Microfilms No. 7603964)

Warren, A. M. (1979). Role practice activities of nurses practitioners in Arkansas. Dissertation Abstracts International, 40, 02B, 680. (University Microfilms No. 7916841) 
Washington Department of Licensing. (1982). The law relating to the practice of registered nursing. 01 ympia, WA: Author.

Weiss, S. (1983). Role differentiation between nurse \& physician: Implications for nursing. Nursing Research, 32 (3), 133-139.

Whittington, H. G. (1970, November). Mental health practitioner. Hospitals: Journal of the American Hospital Association, 44, 52-54. (From Nurse Practitioners and the Expanded Role of the Nurse: A B ibliography, 1979, U.S. Dept. HEW No. (HRA) 79-20, HRP 0500601)

Wright, E. (1975). Family nurse clinicians: Physicians' perspective. Nursing Outlook, 24, 771-773. (From Nurse Practitioners and the Expanded Role of the Nurse: A Bibliography, 1979, U.S. Dept. HEN No. (HRA) 79-20, HRP 0500601)

Wright, E. (1976). Registered nurses' opinions on an extended role concept. Nursing Research, 25(2), 112-114. (From Nurse Practitioners and the Expanded RoTe of the Nurse: A B ibTiography, 1979, U.S. Dept. HEW No. (HRA) 79-20, HRP 0500601) 
APPENDIX A 


\section{Oregon State Board of Nursing}

1400 S.W. 5 AVENUE, ROOM 904, PORTLAND, OREGON 97201

July 30,1985

Mary Jean Schindler

5130 SW Dosch Rd.

Portlend, OR 97201

Dear Mary Jean:

I have reviewed the Draft of the materials you sent and also asked Sandra Stone, who is the Assistant Executive Director in Nurisng Education, to look at your questionnaire and make comments.

We both agreed that your questionnaire should yield some interesting results; however, we have some additional questions you may wish to consider adding to your questionnnaire. If you are focusing on implications for nursing education, it would seem important that the nurse practitioner indicate the type of NP program attended, i.e. certificate program, nurse prectitioner program within a baccalaureate program, or master's program. It also might be interesting to know how many years of experience the nurse had between the basic educational program and entrance into a nurse practitioner program. It might also be important to know the sequencing of the nurse practitioner's entire nursing education. Some examples are:

1. ADN or Diploma to Nurse Practitioner Program to BSN;

2. BSN to MS to Nurse Practitioner Program;

3. BSN to Nurse Practitioner Program to Masters in Nursing;

4. BSN to Masters Degree Program in Nursing which has contained within it a Nurse Practitioner Program.

All of the above educational sequencing possibilities (and there may be others) are ones we have encountered while reviewing nurse practitioner initial certification material.

I hope these comments will be of some assistance to you. Thank you for sharing a draft of the overview of your proposed dissertation.

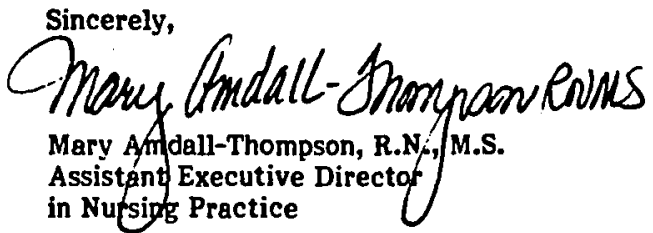

MAT:ba

AN EQUAL OPPORTUNITY EMPLOYER 


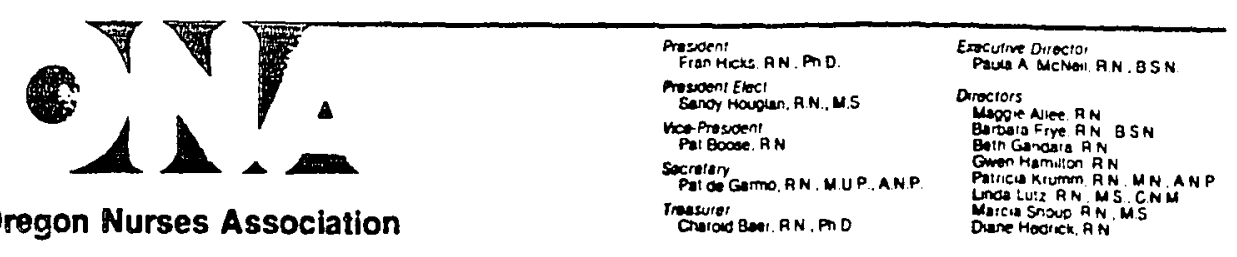

December 5, 1985

Dear Nurse Practitioner,

There are many challenges faced by Nurse Practitioners today --concerns about the legislature and its effect on the Nurse Practice Act, special interest groups, third party payors, changes in standards of certirication and recertification, community politics, increasingly complex client needs, etc. How we meet these challenges is affected by our perception of our function as Nurse Practitioners. These perceptions are being studied by one of our group, Mary Jean Schindler, for her Doctorate in Education.

Her research will be making an important contribution to nursings knowledge base with respect to the preparation and professional growth of Nurse Practitioners. The results of her study should provide valuable and useful information to planners and policy makers, colleagues and consumers at the local, and state levels in oregon. I hope you will participate in her study as a way of demonstrating your continued support of one of our professional colleagues.

sincerely,

Slente 21. Olajzei

Nanette N. Clapper, RNC, MS, ANP

Chairperson

NPSIG 
Dear Fellon: Nurse Fractitione:-

Manv colleaques believe that Jecisions are being made about our orofessional actavities in Dregor from an iriadeouste base ak snowledge. If this is so. then the lack of infarmation mav te related tc a deficit in understandinc what we do. Yulo-esponses to the enclosed inventor would helo to renedi such a knowledge-deficit about some of aur functignz.

All nurse oractitioriers intio are eertified in Grecen are

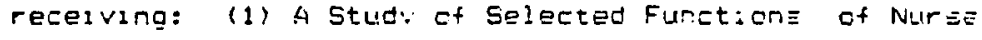
eractitioners in Oreqon. (I) I Letter of Consent. ant: $:$ twc stamped. self-addressec envelgoes. To preserve =onfidentiality, the Letter of Consent 15 tc be -eturret $\pm=$ the investigator iri one ervelope. The Study of selertec Sunctions is to be returned to the inestigetor 17 the gtter envelope. Identification of ar individua? ressondent uil! oE inpossible.

! know how busy vou are. but I would ver'y much agpreciate your taling the time to provide the reauested informatior anc to return it to me in one of the enclosed envelcaes $2 v$ January 15. 198t.

Thank: you again for your =ontribution to this stud 2

Sincerel $\because$.




LETTER OF CONSENT

The purposes of this study have been explained to my satisfaction. I understand that I may withdraw from the study at any time, that all information provided by me on the questionnaire will be held in confidence, and that I will not be identifiable in the findings. I agree to participate in this study by completing the questionnaire and returning it to the investigator in a separate envelope.

Signature

Date

Please checl: (x) if you wish to receive a summary of the findings. 


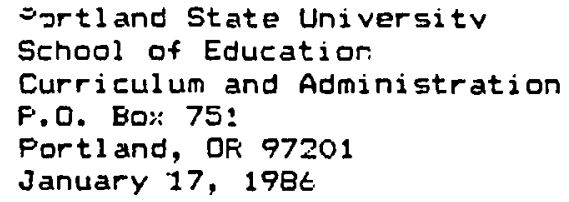

Gecently I mailed you a questionnaire seeking your help in a survey of some functions of nurse practitioners in Oregon. The response so far has been encuuraging. To give the study sufficient statistical significance, it is important that all of us who are certified nurse practitioners have input into the study.

If you have already returned the questionnaire, please consider. this a sincere "Thank you."

If you have not done so, would you please complete and return the questionnaire as soon as possible? Your professional judgment based upen your education and your experience is crucial in determining the extent to which nurse practitioners in Oregon are performing functions for which we were prepared by our educational programs.

I am very grateful for your halp.

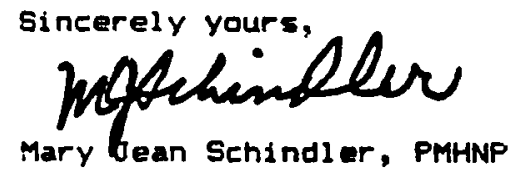


PORTLAND
STATE

UNIVERSITY

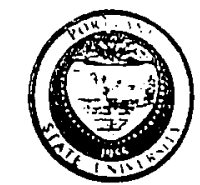

P.O. BOX 75

PORTLAND. ORECON

97207

Fabruarv 14,1986

Clease forgive my persistence in reminding you of the questionnaire you received on nurse practitioner preparation and functions in Dregon. I very much want your input!!

Nurse practitioners are best qualified to say what should be the future direction for our education. Without knowing what you"ve learned from your experience, we may not get a true picture of what NF's do and what should be ineluded in their preparation.

Please send back your questionnaire. Without your input, we may not get a clear picture of every category.

Yours trulis,

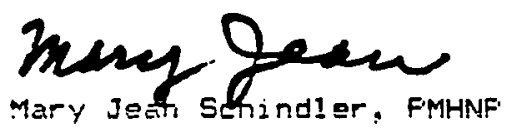



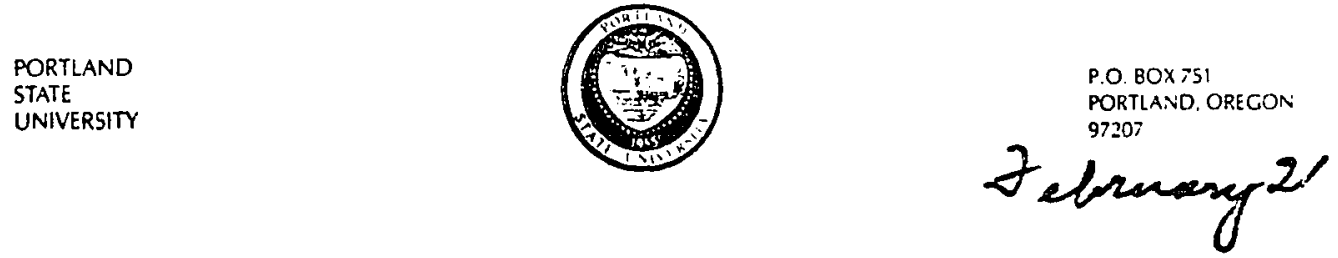

Your questionnaire may have been lost in the mail. If vol have already responded, accept my deep appreciation. complete the attached form and return it in the enclosed envelope.

If you have not returned your questionnaire, please finish and return in separate envelopes as soon as possible the enclosec Juplicate questionnaire and the attached consent form. I look: forward to hearing from you very soor. Sincerely,

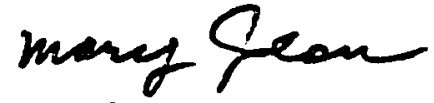

Mary Jean Schindler, FMHNF

\section{LETTEF OF CONSENT}

The purposes of this study have been explained to my satisfaction. I understand that I may withdraw from the study at any time, that all information provided by me on the questionnaire will be held in confidence, and that I will not be identifiable in the findings. I agree to participate in this study by completing the questionnaire and returning it to the investigator in a separate anvelope.

\section{Signature}

Date

Filease check: (x) if you wish to receive a summary of the findings. (Frinted name)

FFrinted adoress to which to send the summarv! 
APPENDIX B 
A STUDY OF SELECTED FUNCTIONS OF NURSE PRACTITTONERS IN

\section{OREGON: IMPLICATIONS FOR PREPARATION}

Part 1: General Information

The following information is needed for interpreting the study data; no other use will be made of the information, which will remain completely confidential. Please complete the following items by circling the appropriate numbers.

1. Age :
a) 25 or under
c) 36 through 45
e) 56 through 65
b) 26 through 35
d) 46 through 55
f) over 65

2. Indicate the type of educational program in which you received your basic nursing education.
a) Diploma
c) Saccalaureate Degree
e) Other (Specify)
b) Associate Degree
d) Master's Degree

3. Please indicate type of your NP program.
a) Certificate
b) BSN
c) Master's

d) Other (please explain)

4. Indicate the highest level of formal education you have completed and the year of graduation. If your major was other than nursing at any level,

please specify. (Circle appropriate number and fill in appropriate space.)

$$
\begin{gathered}
\text { Year of } \\
\text { Grogram Major } \\
\text { Gradion }
\end{gathered}
$$

a) Diploma

b) Associate Degree

c) Baccalaureate Degree

d) Master's Degree

e) Doctorate

If Other than Nursing

5. Please select one sequence of nursing aducation which best prepares the nurse practitioner in your opinion.

a) $A D N$, followed by NP, followed by BS

b) BS, followed by MS, followed by NP

c) BS, followed by us wich includes NP

6. How many years had you been practicing as an RN before you became an NP?

7. Including this year, how many years have you been practicing as an NP in Oregon?

8. How many times a year do you attend workshops, conventions, seminars, or participate in any other type of continuing education in your field of nursing?

a) 0 time

b) 1 time

c) 2 times

e) 4 or more times

9. How adequately do you feel you were prepared by your NP program for the responsibilities encountered in practicing as a nuzse practitioner? $\begin{array}{lll}\text { a) very inadequately } & \text { c) somewhat adequately el very adequately }\end{array}$ b) inadequately d) adequately

10. How much of the knowledge, skills, and attitudes related to NP functions that you learned in your NP program do you feel you actually use in youx practice? (Circle one only)
a) none of thew
b) a few of then
c) nome of them
e) all of them

f) comment:

11. How satisfied are you with your NP rasponsibilities in your practice retting (s)?

a) verg

b) somewhat dissatisied

c) Indifferent

d) somewhat satisfied

e) very satisfied

12. How satisfied are you with the amount of autonomy and independence in the implementation of your NP function in your practice seting (s)?
a) very dissatisfied
c) indifferent
e) very satisfied

b) somewhat dissatisfied

d) somewhat satisfied

NOTE: IF YOU BAVE NOT WORKED AS AN NP SINCE BECOMING CERTIFIED AS AN NP IN OREGON, DO NOT CONPLETE THE REMAINDER OF THE QUESTIONNAIRE, BUT PLEASE RETURN THE OUESTIONNAIRE IN THE ENCLOSED ENVELOPE. 


\section{Part ?: Practice Setting}

13. Circle below the one in which you spend most of your time in NP activities.

In-Hospital Practice

a) patient unit (specify type of unit)

b) emergency room

c) other (specify)

Ambulatory Practice

d) Private (group or solo)

e) prepaid group practice

f) hospital based clinic or cente

g) other (specify)

Non-Hospital Institutional Setting

h) school for mentally or physically handicapped

i) grades 1-12 school system

j) college health program

k) other (specify)
Non-Hospital Community Setting

1) health departrent or home health agency

a) Bchool services or agency

n) other (specify)

\section{School of Nursing}

o) hospital

p) associate degree

q) baccalaureate degree

r) master's degree

s) vocation

\section{Extended Care Facility}

t) nursing home

u) BMO

v) other (specify)

ther Type Setting Not Listed (Bpecify)

14. Of the NP specialties listed below, please circle those in which you are certified.
a) family
b) pediatrics
c) pedilt
e) psychiatry-mental health
1) school heslth
c) geriatrics
f) college health
j) other (specify)
g) midwifery
h) women's health

ALI QUESTIONS PROM THIS POINT ONWARD REFER TO THE PRACTICE SETTING IN ITEM 13

15. What best describes the population and location of your practice setting? $\begin{array}{ll}\text { a) rural }(2,500 \text { or less) } & \text { c) small city }(5,001-25,000)\end{array}$

b) town $(2,501-5,000) \quad$ d) medium-sized city $(25,001-100,000)$

e) large city (over 100,000$)$

16. Which of the following best characterizes the economic level of the majority of patients you see in your practice setting?

a) very low (below $\$ 5,000$ )

b) low $(\$ 5,000-10,999)$

d) medium high $(\$ 17,000-22,999)$

e) high $(\$ 23,000-28,000)$

c) intermediate $(\$ 11,000-16,999)$

f) very high (over $\$ 28,000$ ) 
Part 3: Eunctions

DIRECTIONS: These instructions are applicable to the section on FUNCIIONS which follows immediately.

COLUMN I This colum contains a list of functions which a Nurse Practitioner might perform. Your responses in columns II, III, and IV are to be made in relation to the functions listed in column $I$.

COLUMa II How competent do you judge yourself to be at this time to perform each function listed in colum I? Please circle the one most appropriate response according to the following code:

a Do not feel competent at this time

b Feel slightiy competent

c Feel moderately competent

d reel very competent

COLUna III On the basis of your experience, how often, on the average, do you use the function listed in column I? circle the one most appropriate response according to the following code:

a never-1ittle or no need to use the function

a never-little or no need to use the
b rarely-monthly
c occasionally-a few times a month

d frequently-aeveral times weekly or every day

- all the time-several times every day

CoLjng IV At what level of nurse preparation do you think the development of competency for each function listed in colum I should receive the greatest emphasis? Circle the one most appropriate response according to the following code:

a should NOT be included in nursing education

b Associate programs

c Baccalaureate programs

- Continuing education (includes courses, seminars, conferences, etc)

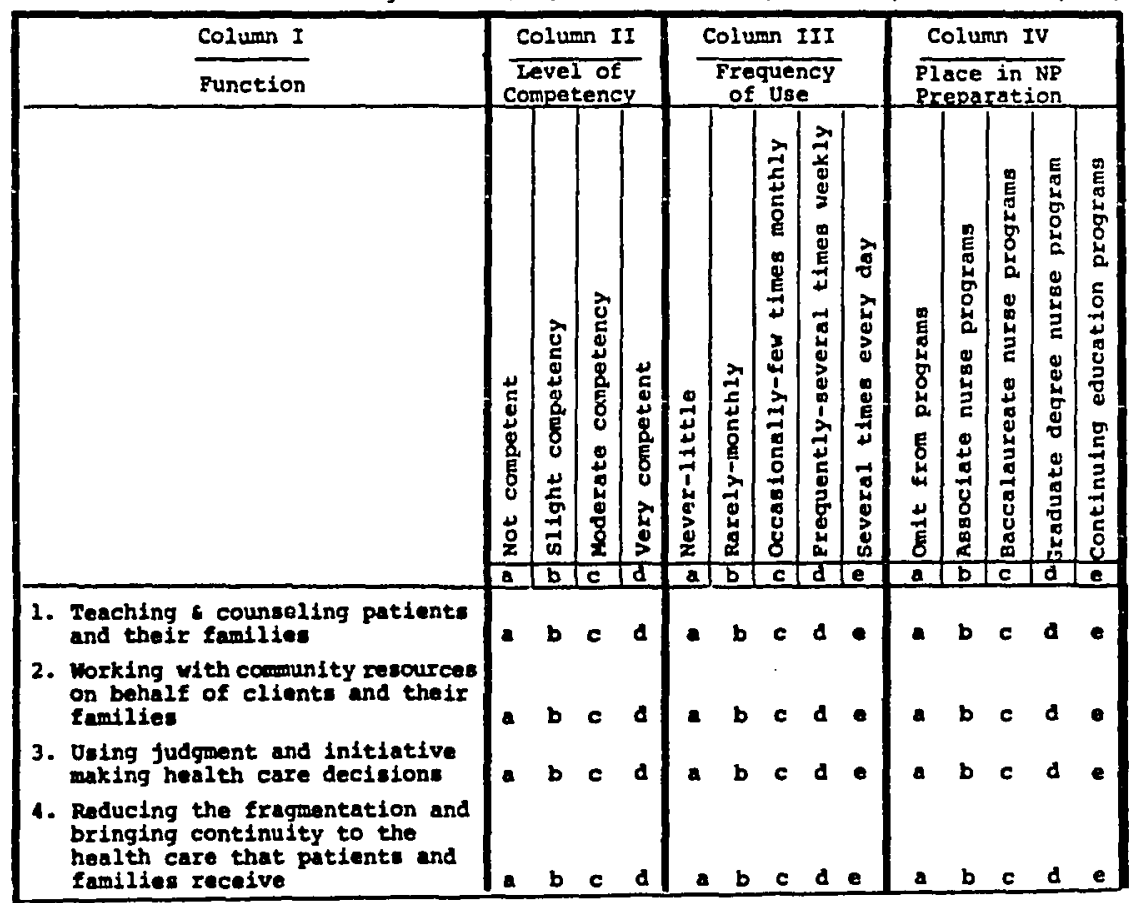




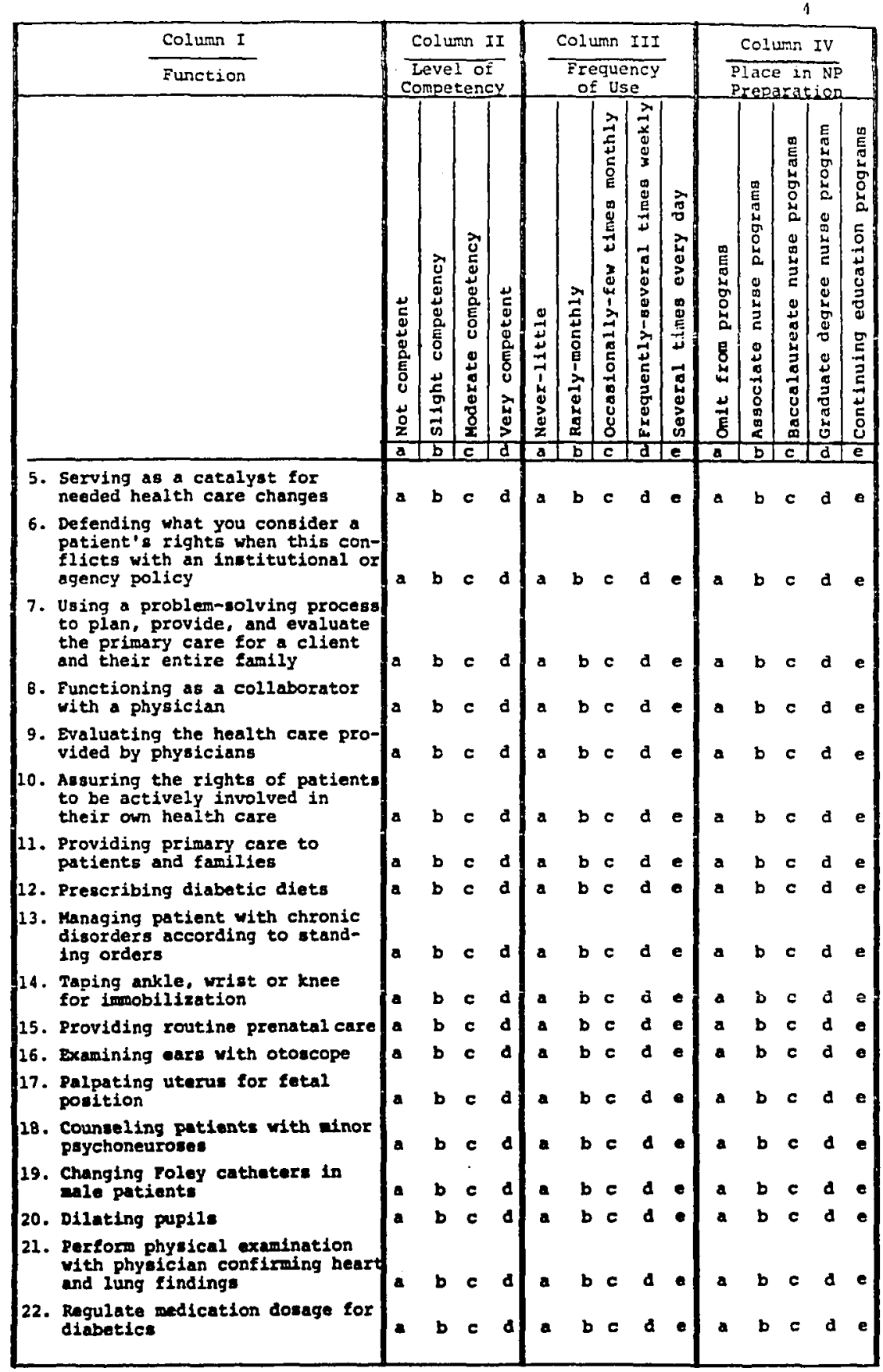




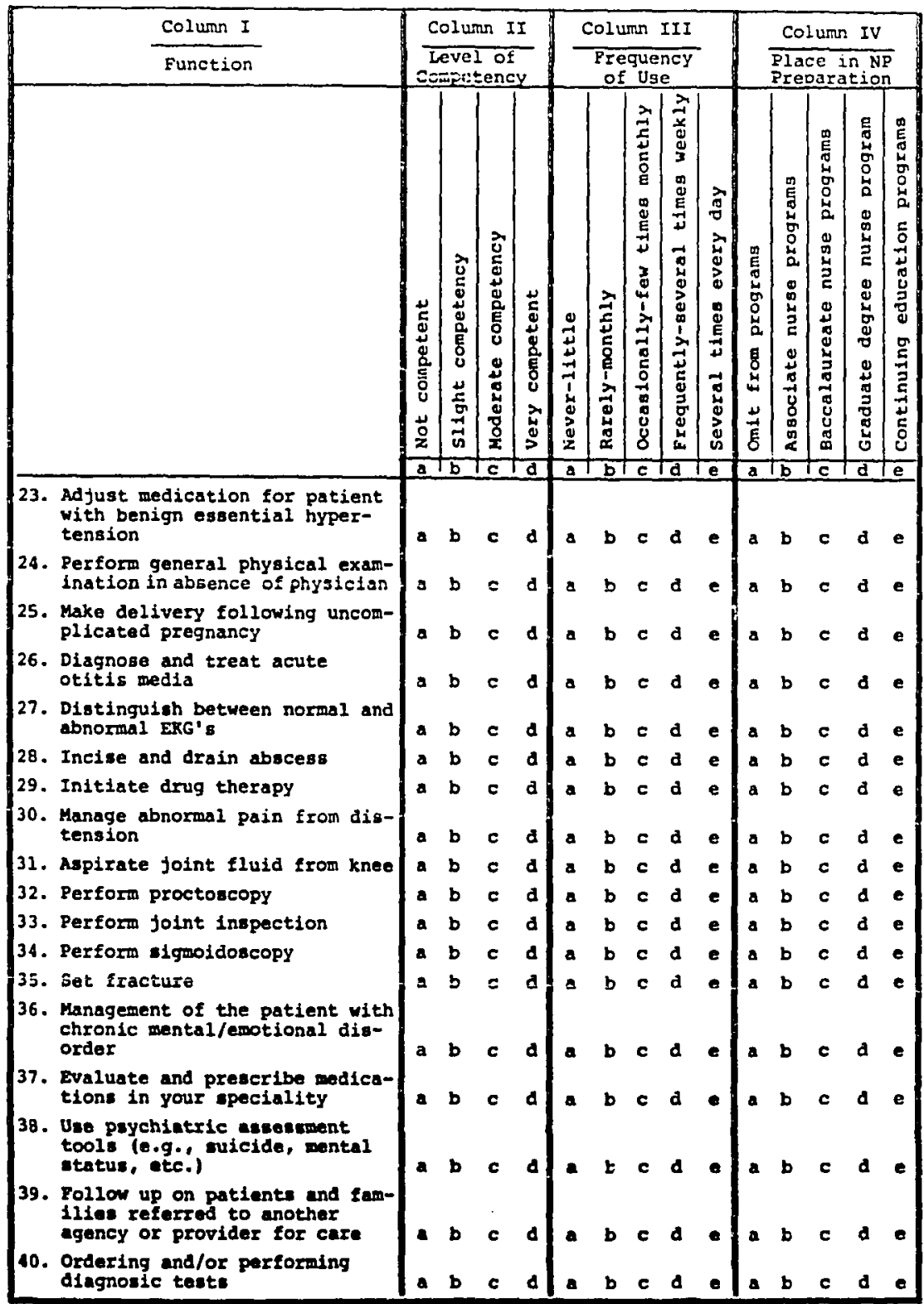


Part 4: Administrative and Public Relations Funetions

Please circle the appropriate answer $(s)$ to the following questions.

1. In your imsediate practice setting, what person(s) participate in health policy-making decislons for care of your patients?

a) physicians

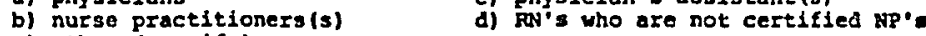

e) other (specify)

2. In your imediate practice setting, what person(s) participate in adrinistrative policy-raking?

a) physicians

c) physiclan's assistant (s)

b) nurse practitioner(s) $\quad$ d) RW's who are not certified NP's

e) other (specify)

PLEASE ANSWER THE FOLIOAING OUESTION IN YOUR OWN WORDS. BE SPECIFIC NND USE BEHAVIORAL TERYS AS MUCH AS POSSIBLE. TURN THE PAGE IF YOU UEED MORE ROOM.

3. How do you interpret the function of the nurae practitioner?

a) to your patients

b) to other disciplines

c) to the community

d) to legislators

Please return the questionnalre in the stamped aelf-addresed envelope to:

Mary Jean Schindler, Rzhns

Portland State Univeraity

School of Education

Curriculum and Mdministration

P.O. BOX 751

Portland, of 97201 


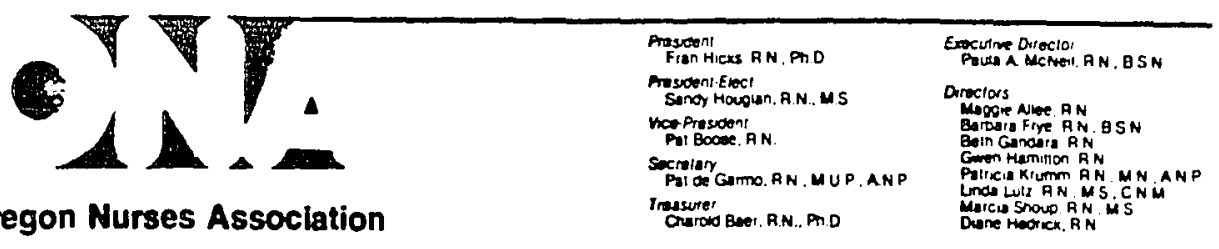

December 5, 1985

Dear Nurse Practitioner.

There are many challenges faced by Nurse Practitioners today --concerns about the legislature and its effect on the wurse Practice Act, special interest groups, third party payors, changes in standards of certification and recertification, community politics, increasingly complex client needs, etc. How we meet these challenges is affected by our perception of our function as Nurse Practitioners. These perceptions are being studied by one of our group, Mary Jean Schindler, for her Doctorate in Education.

Her research will be making an important contribution to nursings knowledge base with respect to the preparation and professional growth of Nurse Practitioners. The results of her study should provide valuable and useful information to planners and policy makers, colleagues and consumers at the local, and state levels in oregon. I hope you vill

participate in her study as a way of demonstrating your continued support of one of our professional colleagues.

sincerely.

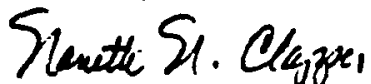

Nanette $\mathrm{N}$. Clapper, RNC, MS, ANP

Chairperson

NPSIG 
APPENDIX C 
TABLE XXVIII

CLASSIFICATIONS OF RESPONSES TO QUESTION 3 A: "HOW DO YOU INTERPRET YOUR FUNCTION TO PATIENTS?"

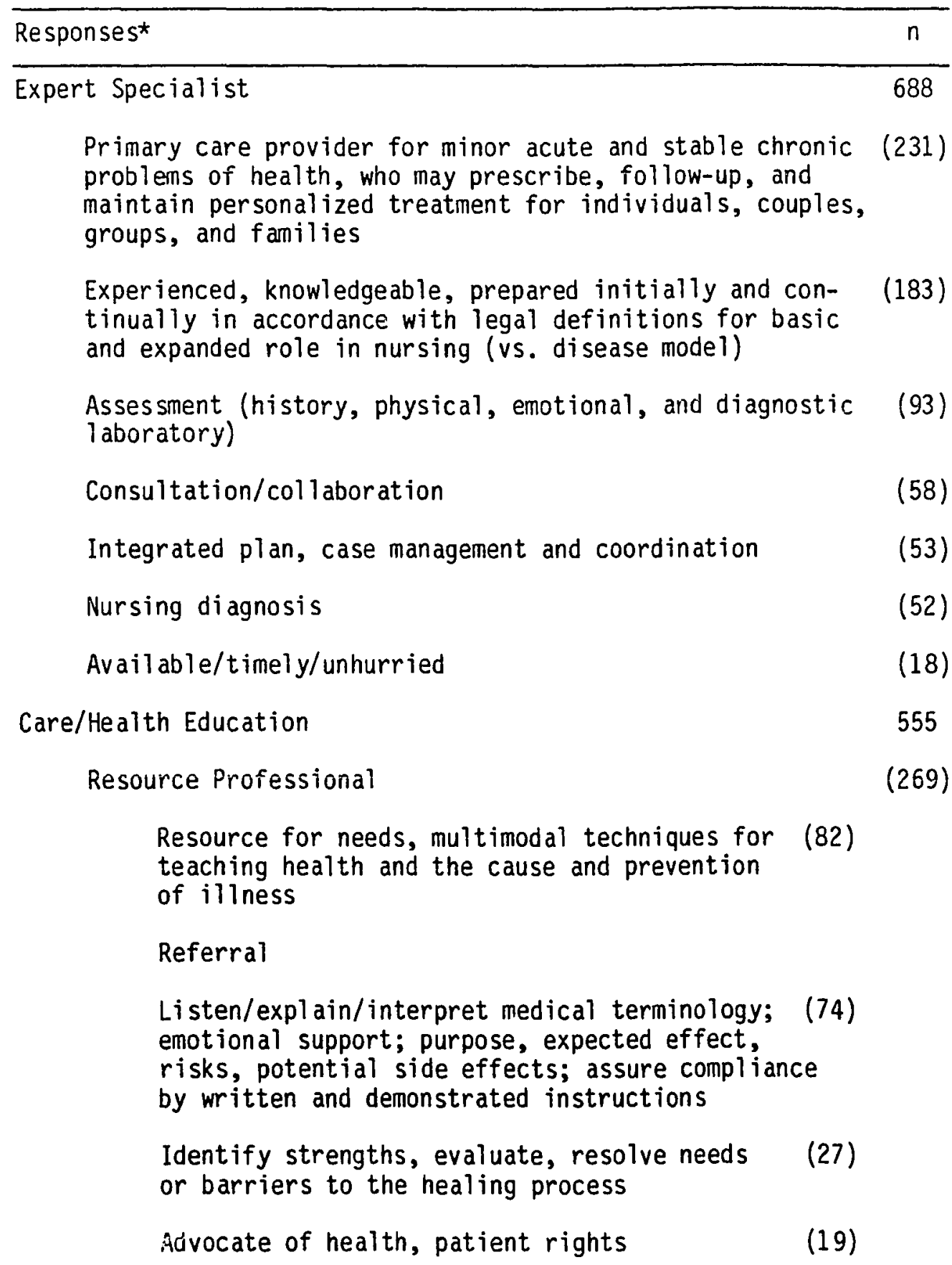


TABLE XXVIII

(CONTINUED)

\begin{tabular}{|c|c|c|}
\hline \multicolumn{2}{|l|}{ Responses* } & \multirow[t]{2}{*}{$\bar{n}$} \\
\hline $\begin{array}{l}\text { Liaison between patient, physician, } \\
\text { community agencies }\end{array}$ & $(18)$ & \\
\hline Joint health-policy making decision process & (3) & \\
\hline Change agent & (2) & \\
\hline $\begin{array}{l}\text { Preventive, prophylaxis, promotion, and monitorin } \\
\text { of wellness }\end{array}$ & & $(109)$ \\
\hline $\begin{array}{l}\text { Education for self care client and family respons } \\
\text { bility/internal locus of control, impact of illne } \\
\text { adaptability normal development, nutrition, exerc } \\
\text { stress management }\end{array}$ & & $(86)$ \\
\hline $\begin{array}{l}\text { Psychosocial, spiritual health, home situation/ma } \\
\text { sexual/life-style changes; mental health counseli } \\
\text { guidance, crisis intervention, short/long term ps } \\
\text { therapy, cognitive, imaging, hypnosis, acceptance } \\
\text { inevitable; primary care and health education for } \\
\text { patient and family }\end{array}$ & $\begin{array}{l}\text { tall } \\
\text { ho- } \\
\text { af } \\
\text { total }\end{array}$ & $(79)$ \\
\hline Physical and emotional environment & & $(10)$ \\
\hline Financial capabilities, reimbursement, 3rd party & & $(2)$ \\
\hline $\begin{array}{l}\text { Extender of health care monies mid level between RN - } \\
\text { (Function and standards identified by professional ass } \\
\text { [NPSIG/ONA, ANA, etc.] via media articles, flyers, car }\end{array}$ & $\begin{array}{l}\text { Diations } \\
\text { s) }\end{array}$ & 14 \\
\hline
\end{tabular}

* Responses are rank ordered according to the major headings; subheadings denote supportive activities or concepts. 
TABLE XXIX

CLASSIFICATIONS OF RESPONSES TO QUESTION 3 B: "HOW DO YOU INTERPRET YOUR FUNCTION TO OTHER DISCIPLINES?"




TABLE XXIX

(CONTINUED)

Responses* n n

Colleague, consultant, team-nember, learn from each other

Interdependent, independent, dependent provider of comprehensive primary care in a nursing speciality

Educate/Explain Credentials

Compare/contrast in written, oral terminology and emphasis appropriate to listeners about the importance, competence, and usefulness of nurse practitioners

Academic, professional, legal qualifications and background, maintenance of competency, knowledge base, current standards of practice, mechanisms for quality assurance

Alternative, new dimension, mid-level care provider; expander; assistant; adjunct; not mini-physician but similar to physician, psychologist, social worker

Complement; support; not threat; accepted, appreciate for skills; time; increased quality of care

Competitive/threatening; second rate; less power; turf battles; resentment; avoid discussion; touchy

Cost containment; available to rural low-income; less costly than physicians; less duplication of services

Same As Above (interpretation as to patients)

* Responses are rank ordered according to the major headings; subheadings denote supportive activities or concepts. 
TABLE $X X X$

CLASSIFICATIONS OF RESPONSES TO QUESTION $3 \mathrm{C}$ : "HOW DO YOU INTERPRET YOUR FUNCTION IN THE COMMUNITY?"

Responses*

Advocate Di sease Prevention n

255

Change Agent

Advocate for prevention minded, identify and solve community health care needs, disease prevention, spokesperson/leader, board member, volunteer screening for schools, participant in cominunity public health projects, resource to schools/community groups for health care materials and agencies, caretaker of community health, change agent, community run--based \& managed

Wellness and Growth Promotion Education about heaith needs, services concerns, prevention, health maintenance, promotion of wellness and growth--even when dying; self-care, answer questions, interpret treatment, teach patients anticipated outcomes and focus of care and service

Mediator Between Wellness and 11 iness Assessment, physical exams, acute care, diagnose, treat, presecribe, and manage medical care, follow-up, facilitate return to community, pregnancy, well baby/child care, crisis intervention groups, explain psychopathology, empathize, mediate between illness and weliness, therapy counseling, holistic, effects of multiple life changes on elderly, emphasize strengths

Mid-Level Care Provider

Scope of Practice Explain, teach, discuss nurse practitioner functions, skills, specialties, education, experience, scope and 1 imitations of practice licensure, authority from legislature; use multimedia in meaningful terms, combat reputation of predecessors--PAs \& MDS--in rural comunity 
TABLE XXX

(CONT INUED)

Responses*

n

Supportive Care

Responsible, accountable option of choice for suppor-

(46)

tive, mid-level health care provider in specialty;

standards of care maintained via continuing education;

accessible, independent, respected educational guide-

lines and body of knowledge with peer support and own

research applicable to the clinical setting

Liaison

Collaboration/consultation, coordination, referral,

follow-up in hospital and community, liaison between

cormunity, agencies, health professionals

Research

Interpret function to community in the same way as to

140

patients and/or to other disciplines

Provider for Underserved

Cost containment (20\% sphysician in office)

Care for the underserved or those with special needs in rural or community health setting

* Responses are rank ordered according to the major headings; subheadings denote supportive activities or concepts. 
TABLE $X X X I$

CLASSIFICATIONS OF RESPONSES TO QUESTION 3 D: "HOW DO YOU INTERPRET YOUR FUNCTION TO LEGISLATORS?"

\section{Responses*}

Testity as Expert

Describe Legislative Impact

Write descriptions of impact of legislation, document need for services in legislator's constituency; testify as expert about NP qualifications, scope of practice, body of knowledge; emphasize proactive, holistic, health promotion and maintenance and recognition of ear?y signs of illness; screening, counseling, fit contraceptives, order and manage medicines

Economic Benefits

Multiple roles in health care; cost advantages of health focus, disease prevention, lower rates of morbidity and mortality; equal or higher outcomes at lower cost than physicians; less expensive than physicians to educate, license, insure; financially feasible; lower risk of liability due to practice of referral of hicher risk cases to physicians; physician extender--free physician for more technical care; facilitate home care; deal with $90 \%$ of health problems brought to physician; decrease costs of tertiary care; third-party payments; adequate and direct pay for services; increase salary

Accessibility Underserved/medically needy; low income clients in rural/urban schools, nursing home, corrective institutions, indigents, various settings in community; independent; autonomous; responsive to health needs and preferences of clients (elderly, women); popular

Education

Self care; increase compliance, decrease illness and complications of illness; breast exam, nutrition, health assessment 
TABLE XXXI

(CONTINUED)

Responses*
Safe Competence
Accountability; increased qual ity of health care;
decreased client and family trauma in illness; increased
quality of service by MD-NP team than by either indi-
vidual provider; need continuing education and peer
review; increase education to increase competence
Same As Above
(Inteipret NP function to legislators in the same way as to
patients, and/or to other disciplines and to the community?)
Encourage Votes
Provide contacts, be an active resource, give money,
inform/advise/educate legislators via research-based descrip.
tions of the nurse practitioner role/impact and persistent
advocacy for health related rights and legislation (money for
mental health assessments in jails); common core required for
all NP preparation (physical assessment); state board of nursing
use NPs to decide scope of practice based on level of competency
and community need; the pressure and money behind physicians;
support politically active special interest groups

Avoid

* Responses are rank ordered according to the major headings; subheadings denote supportive activities or concepts. 
TABLE XXXII

ANALYSIS OF SAMPLE OF "SAME AS ABOVE" RESPONSES TO QUESTION 3:

"HOW DO YOU INTERPRET YOUR FUNCTION TO PATIENTS, OTHER

DISCIPLINES, THE COMMUNITY, AND LEGISLATORS?"

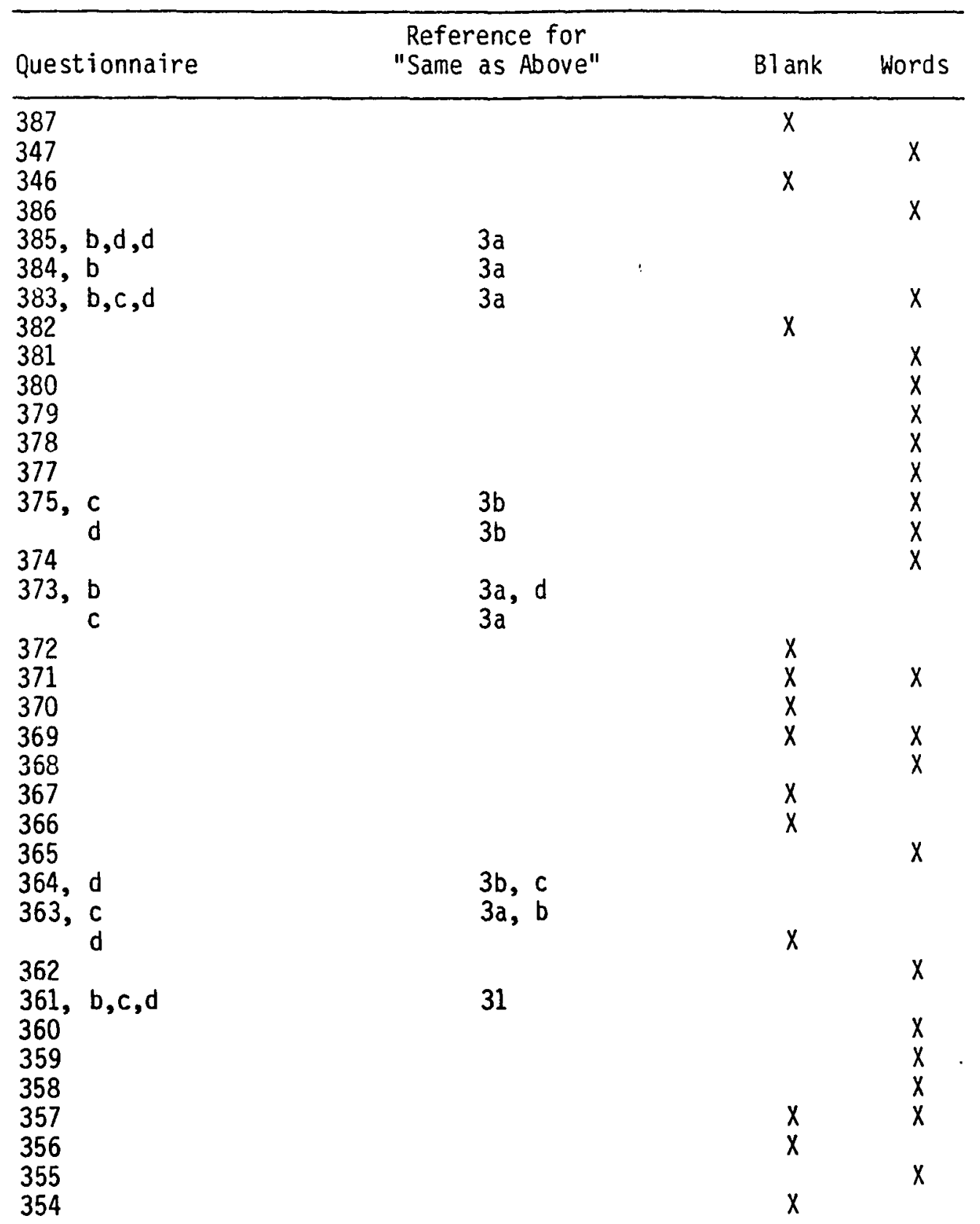


TABLE XXXII

(CONTINUED)

\begin{tabular}{l} 
Questionnaire \\
\hline 353 \\
$352, \mathrm{~b}, \mathrm{c}$ \\
351 \\
350 \\
$349, \mathrm{~b}, \mathrm{c}, \mathrm{d}$ \\
$348, \mathrm{~b}, \mathrm{c}, \mathrm{d}$
\end{tabular}

